Nathália Molleis Miziara

\title{
REGULAÇÃO DO MERCADO DE MEDICAMENTOS: A CMED E A POLÍTICA DE CONTROLE DE PREÇOS
}

\author{
Mestrado em Direito \\ Orientador: Professor Associado Diogo R. Coutinho
}

Universidade de São Paulo

Faculdade de Direito

São Paulo 
Nathália Molleis Miziara

\section{REGULAÇÃO DO MERCADO DE MEDICAMENTOS: A CMED E A POLÍTICA DE CONTROLE DE PREÇOS}

Dissertação apresentada à Faculdade de Direito da Universidade de São Paulo como requisito parcial à obtenção do título de mestre em Direito, sob a orientação do Professor Associado Diogo R. Coutinho.

Área de concentração: Direito Econômico, Financeiro e Tributário.

\section{Universidade de São Paulo}

Faculdade de Direito

São Paulo 
Autorizo a reprodução total ou parcial deste trabalho, por qualquer meio convencional ou eletrônico, para fins de estudo e pesquisa, desde que citada a fonte.

Miziara, Nathalia Molleis

Regulação do mercado de medicamentos: a CMED e a política de controle de preços.

São Paulo, 2013.

$229 \mathrm{f}$.

Dissertação de mestrado. 
MIZIARA, N.M. Regulação do mercado de medicamentos: a CMED e a política de controle de preços. Dissertação apresentada à Faculdade de Direito da Universidade de São Paulo para a obtenção do título de Mestre em Direito.

\section{Banca examinadora}

Prof. Dr. Instituição:

Julgamento: Assinatura:

Prof. Dr. Instituição:

Julgamento: Assinatura:

Prof. Dr. Instituição:

Julgamento: Assinatura: 
Aos meus pais, com amor, admiração e gratidão;

À minha avó Joaquina Galego Molleis que deixa saudades; e Ao Léo. 


\section{Agradecimentos}

Ao Professor Associado Diogo R. Coutinho, pela oportunidade, atenção, apoio e ensinamentos durante o processo de orientação.

À Faculdade de Direito da Universidade de São Paulo, pela oportunidade de realização do Curso de Mestrado em Direito.

À Fundação de Amparo à Pesquisa do Estado de São Paulo, pela concessão da bolsa de mestrado e pelo apoio financeiro para a realização desta pesquisa.

Aos membros do IDEC, principalmente, Dra. Ione Amorim, pelos ensinamentos, apoio e concessão de entrevistas.

A todas as pessoas que se dispuseram a conceder entrevistas para a realização deste trabalho: membros da CMED, da ANVISA, do PROCON-SP e Professora Dra. Basilia Aguirre, da FEA-USP. 


\section{RESUMO}

MIZIARA, N. M. Regulação do mercado de medicamentos: a CMED e a política de controle de preços. 2013. 229 f. Dissertação (Mestrado) - Faculdade de Direito, Universidade de São Paulo, São Paulo, 2013.

Esta dissertação consiste em um estudo de caso sobre a regulação jurídica e econômica do mercado de medicamentos realizada pela Câmara de Regulação do Mercado de Medicamentos (CMED). Esse órgão regulador foi criado pela Lei 10.742/03, com a finalidade de promover a assistência farmacêutica à população, por meio de mecanismos que estimulem a oferta de medicamentos e a competitividade no setor.

A natureza da regulação empreendida pela CMED é eminentemente social e se justifica como forma de impulsionar o acesso a medicamentos no Brasil, no que diz respeito à aquisição de produtos pelos particulares no varejo e às compras públicas. Por meio do emprego de técnicas qualitativas e quantitativas de pesquisa, este trabalho avaliou a efetividade da atividade regulatória da CMED, considerando como efetividade a capacidade dessa política em promover o acesso a medicamentos, tal como preceitua a Lei 10.742/03. Para tanto, foram realizadas entrevistas com especialistas no assunto e membros do órgão regulador, bem como a análise de dados sobre a evolução dos preços dos medicamentos, desde a criação da CMED, em 2003. Em plano adicional, foram estudadas as dificuldades e gargalos de implementação da política de regulação do mercado farmacêutico pela CMED. Uma série de problemas foram constatados, principalmente, no tocante à aplicação do coeficiente de adequação de preços às compras públicas e a mecanismos de transparência, participação e accountability relativos à atividade regulatória.

Por fim, uma vez identificados os problemas, foram aventadas possíveis soluções que passam pela necessidade de modificação da Lei $10.742 / 03$, que traça as diretrizes regulatórias.

Palavras-chave: Regulação. Controle de preços. Acesso a medicamentos. CMED. 


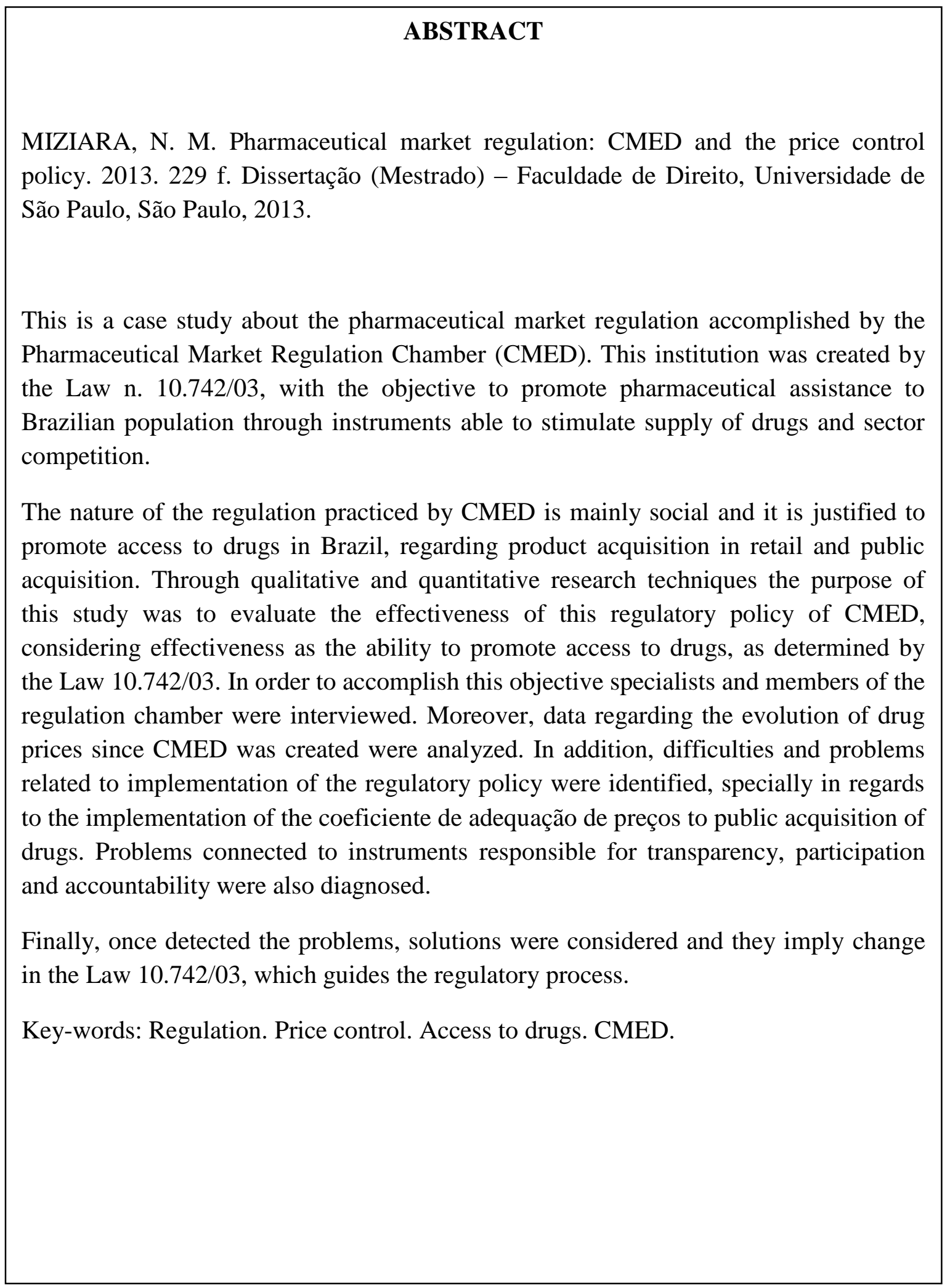




\section{LISTA DE TABELAS}

Tabela 1: População brasileira: perfil $\mathrm{X}$ renda e acesso a medicamentos e a serviços de saúde

Tabela 2: Dados sobre gastos com medicamentos extraídos da pesquisa de orçamentos Familiares (POF) - 2008/2009.....

Tabela 3: Concentração do mercado farmacêutico em diferentes países do mundo. 39

Tabela 4: Ranking das indústrias farmacêuticas no Brasil (2002-2011)..... .47

Tabela 5: Evolução da venda dos medicamentos genéricos e dos medicamentos de referência no início dos anos 2000

Tabela 6: Técnicas de regulação do mercado de medicamentos utilizadas pelos países europeus

Tabela 7: Diferença entre preço médio em SP de medicamento similar versus preço máximo da CMED (em R\$).

Tabela 8: Diferença entre preço médio em SP de medicamento genérico versus preço

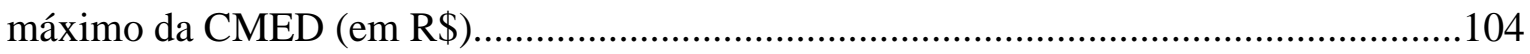

Tabela 9: Variação entre os preços praticados no mercado e o respectivo teto..................104

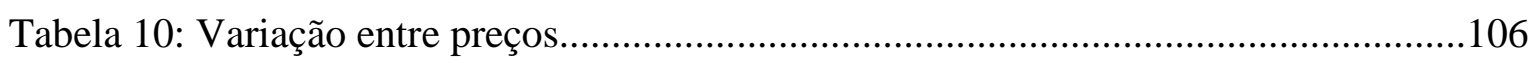

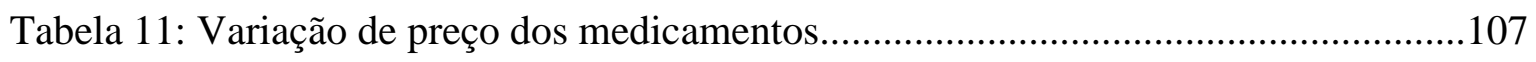

Tabela 12: Medicamentos lançados após 2003...............................................................111

Tabela 13: Pesquisas IDEC realizadas na cidade de São Paulo (publicações: 2009 e 2012).

Tabela 14: Pesquisas PROCON-SP realizadas na cidade de São Paulo (publicações: 2010, 2011 e 2012).

Tabela 15: Medicamentos cujo processo administrativo de registro foi instaurado a partir de 2004. 


\section{LISTA DE GRÁFICOS}

Gráfico 1: Evolução dos gastos com medicamentos por fonte pagadora (2002-

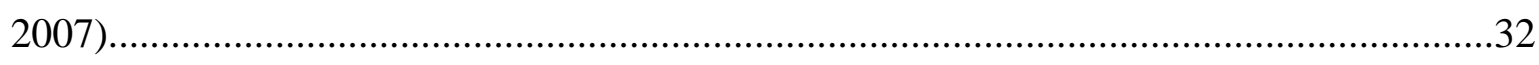

Gráfico 2: Comparação entre a despesa total com saúde e a despesa com assistência farmacêutica (federal, estadual e municipal) entre 2005 e 2008. .36

Gráfico 3: Participação no mercado por categoria medicamentosa (2012 -

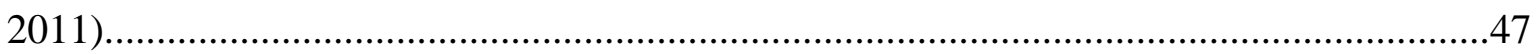




\section{LISTA DE SIGLAS}

ABCFARMA Associação Brasileira do Comércio Farmacêutico

ANVISA Agência Nacional de Vigilância Sanitária

ABCFARMA Associação Brasileira do Comércio Farmacêutico

CAMED Câmara de Medicamentos

CAP Coeficiente de Adequação de Preços

CIP Conselho Interministerial de Preços

CMED Câmara de Regulação do Mercado de Medicamentos

CNS Conselho Nacional de Saúde

COFAP Comissão Federal de Abastecimento e Preços

CONEP Comissão Nacional para Estabilização de Preços

CRMED Coordenação de Registro de Medicamentos da ANVISA

DF Distrito Federal

EUA Estados Unidos da América

FIPE Fundação Instituto de Pesquisas Econômicas

IBGE Instituto Brasileiro de Georgrafia e Estatística

IDEC Instituto de Defesa do Consumidor

Interfarma Associação da Insdústria Farmacêutica de Pesquisa

IPEAD Fundação Instituto de Pesquisas Econômicas, Administrativas e Contábeis de Minas Gerais

MDIC Ministério da Indústria, Desenvolvimento e Comércio Exterior

NUREM Núcleo de Regulação Econômica da ANVISA

OMS Organização Mundial de Saúde

OPAS Organização Pan-Americana da Saúde

PF Preço-Fábrica

PNM Preço Máximo ao Consumidor

PNAF Política Nacional de Assistência Farmacêutica

PNM Política Nacional de Medicamentos

PROCON-SP Fundação de Defesa e de Proteção do Consumidor do Estado de São Paulo RENAME Relação Nacional de Medicamentos Essenciais

SEAE Secretaria de Acompanhamento Econômico

Sindusfarma Sindicato da Indústria de Produtos Farmacêuticos do Estado de São Paulo

SUNAB Superintendência Nacional de Abastecimento

SP São Paulo 


\section{LISTA DE ABREVIATURAS}

Cáps. Cápsula

Comp. Comprimido

Cx. Caixa

Fr. Frasco

Inj. Injetável

Mg Miligrama

Ml mililitro 


\section{SUMÁRIO}

\section{CAPÍTULO 1: INTRODUÇÃO}

1.1. Justificativa para a regulação econômica do mercado farmacêutico............................15

1.2. A regulação do mercado e as políticas de saúde........................................................20

1.3. A criação da Câmara de Regulação do Mercado Farmacêutico (CMED) e o controle de preços.

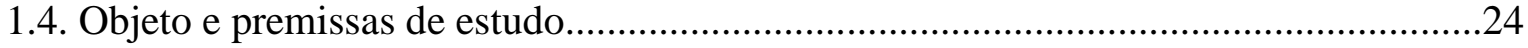

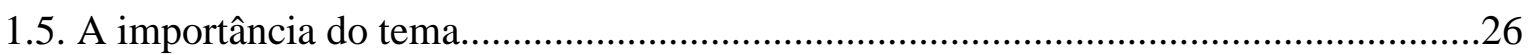

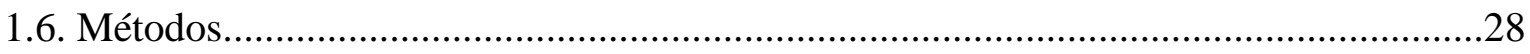

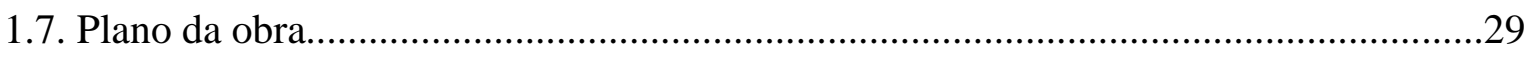

CAPÍtULO 2: O MERCADO FARMACÊUTICO E O ACESSO A

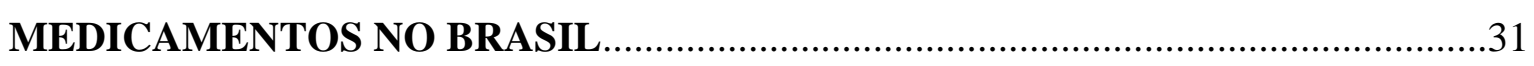

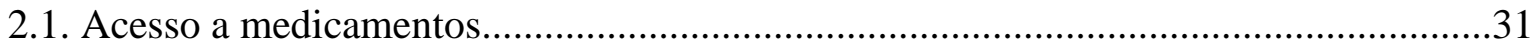

2.2. O mercado farmacêutico e a indústria de medicamentos................................................37

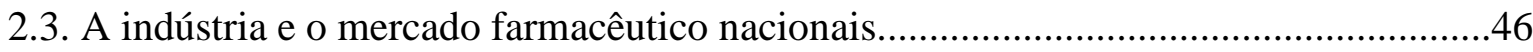

CAPÍtulo 3: A CÂMARA DE REGULAÇÃO DO MERCADO DE

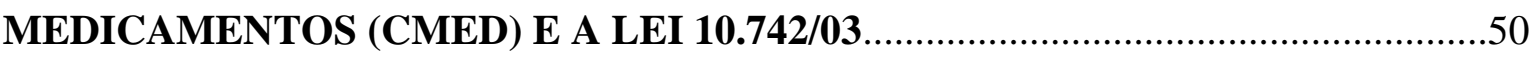

3.1. Breve histórico da regulação econômica e jurídica do mercado farmacêutico brasileiro:

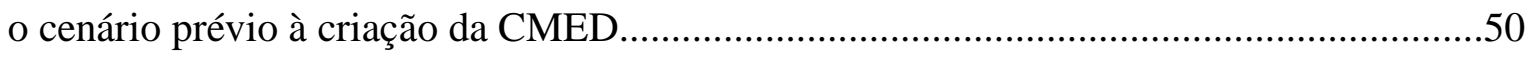

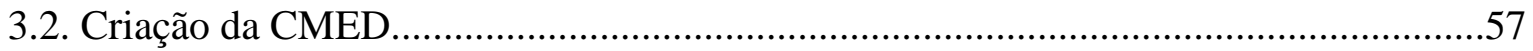

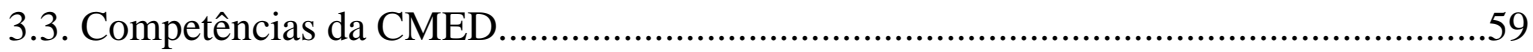

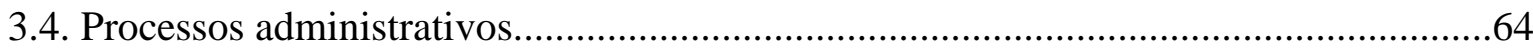

3.5. Estrutura organizacional, composição e funcionamento da CMED..............................65

CAPÍtUlO 4: A POLÍticA DE REGULAÇÃO DOS PREÇOS DOS MEDICAMENTOS

4.1. Breve análise da dimensão jurídica das políticas de saúde de assistência farmacêutica. .69

4.2. A política de regulação econômica dos preços de medicamentos no Brasil..................73

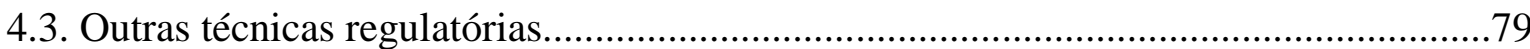

CAPÍtulo 5: A POLÍtica REGULATÓRIA NA PRÁticA: "PRÓS", “CONTRAS" E DISFICULDADES JURÍDICAS DA REGULAÇÃO DO MERCADO DE MEDICAMENTOS NO BRASIL ....................................................

5.1. Controle de preços X mecanismos antitruste.............................................................98 
5.2. Quais são os "prós" e "contras" da política regulatória prevista na Lei $10.742 / 03 ?$ 101

5.2.1. Distorção inicial dos preços dos medicamentos 119

5.2.2. Falta de flexibilidade da Lei $10.742 / 03$ que estabelece as diretrizes regulatórias. 122

5.2.3. Ausência de monitoramento de preços nos pontos de venda. 123

5.2.4. O caso dos medicamentos lançados depois da criação da CMED. 124

5.2.5. O exercício das competências previstas na Lei 10.742/03. 129

5.2.6. O coeficiente de adequação de preços (CAP). 130

5.2.7. Participação, transparência e accountability na regulação da CMED. 134

5.3. Nos moldes em que foi concebida e conforme é praticada, a política de regulação dos preços contribui para a promoção da assistência farmacêutica, isto é, ela é efetiva? 138

5.4. Possíveis soluções 140

CAPÍTULO 6: CONCLUSÃO 143

REFERÊNCIAS. .147

ANEXOS 


\section{INTRODUÇÃO}

\subsection{Justificativa para a regulação econômica do mercado farmacêutico}

Os preços elevados de medicamentos essenciais são um grave problema de saúde pública no Brasil. ${ }^{1}$ Admitindo-se que, na grande maioria dos casos, o uso de medicamentos é a única estratégia terapêutica possível para a recuperação de um paciente, a dificuldade de acesso a esses produtos causada pelos preços altos prejudica significativamente a efetividade do processo de atenção a saúde. ${ }^{2}$

No Brasil, o consumidor responde, hoje, por cerca de $80 \%$ dos gastos totais do país com medicamentos, ou seja, quase 8 em cada 10 compras de medicamentos saem dos bolsos dos pacientes. $^{3}$ Desse modo, os preços dos medicamentos são uma variável importante na determinação do acesso a produtos farmacêuticos pela população.

As camadas mais vulneráveis da sociedade são as mais prejudicadas por esse quadro. ${ }^{4}$ A Pesquisa de Orçamentos Familiares (POF), realizada pelo Instituto Brasileiro de Geografia e Estatística (IBGE), em 2008-2009, comprova que as famílias de baixa renda gastam alto percentual da renda familiar em remédios, em comparação com as famílias pertencentes às classes mais privilegiadas da população. ${ }^{5}$

Sabe-se que os preços desses produtos se encontram em patamares elevados por inúmeras razões, principalmente, de natureza econômica. ${ }^{6}$ As explicações mais comuns para essa situação são apresentadas abaixo.

${ }^{1}$ FOLLADOR, W. Alguns aspectos da variação de preços de medicamentos no Brasil no período de 1980 a 2001. 2001. Dissertação (Mestrado em Ciências Farmacêuticas) - Faculdade de Ciências Farmacêuticas, Universidade de São Paulo, São Paulo, 2001. p.38.

${ }^{2}$ BELTRAME, A. Ampliação do acesso a medicamentos de alto custo: uma análise da política brasileira. 2002. Dissertação (Mestrado em Administração de Saúde) - Instituto de Medicina Social, Universidade do Estado do Rio de Janeiro, Rio de Janeiro, 2002. p.5.

${ }^{3}$ SINDICATO DO COMÉRCIO VAREJISTA DE PRODUTOS FARMACÊUTICOS - SINDIFARMA, Dois gargalos na saúde: financiamento e acesso a medicamentos. São Paulo, 2010. Disponível em: <http://www.sindifarmajp.com.br>. Acesso em: 4 abr. 2011.

${ }^{4}$ MACHADO DOS SANTOS, S.C. Busca na equidade no acesso a medicamentos no Brasil: os desafios impostos pela competição extra-preço. 2001. Dissertação (Mestrado em Saúde Pública) - Escola Nacional de Saúde Pública, Fundação Oswaldo Cruz, Rio de Janeiro, 2001. p.110.

${ }^{5}$ As famílias cuja renda mensal é inferior a $\mathrm{R} \$ 830,00$ gastam $4,2 \%$ dos rendimentos com medicamentos, enquanto as famílias de renda familiar superior a $\mathrm{R} \$ 10.375,00$ gastam $1,9 \%$ dos rendimentos com esses produtos (BRASIL. Instituto Brasileiro de Geografia e Estatística. Pesquisa de Orçamentos Familiares 2008-2009. Disponível em: <www.ibge.com.br>.Acesso em: 16 mar. 2011).

${ }^{6}$ Em estudo realizado por pesquisadores da Universidade de Brasília, foi apurado que os preços de medicamentos essenciais chegam a ser $1.200 \%$ mais caros no Brasil do que na Europa (NÓBREGA, O.T. et al. Retail prices of essencial drugs in Brazil. Revista Panamericana de Salud Publica, Washington D.C., v.22, n.2, p.118-123. 2007. p.120). 
Em primeiro lugar, a indústria farmacêutica se baseia na produção de inovação e, por isso, despende grandes montantes em Pesquisa e Desenvolvimento (P\&D). Tal investimento, segundo alegam os laboratórios farmacêuticos, só pode ser recuperado mediante o repasse desses custos aos preços dos produtos. ${ }^{7}$ É principalmente no período de reserva de mercado, proporcionado graças ao reconhecimento do direito patentário, que os laboratórios recuperam seus investimentos. No intervalo de tempo em que a patente está em vigor, apenas o laboratório inovador está autorizado a produzir e vender o novo medicamento. ${ }^{8} \mathrm{O}$ preço de monopólio fixado em decorrência do direito sobre patentes de medicamentos ocorre em várias partes do mundo, contudo, seus efeitos são mais gravosos nos países subdesenvolvidos, em que o acesso a produtos farmacêuticos é difícil e a renda da população é notadamente menor. ${ }^{9}$

\footnotetext{
${ }^{7}$ Sobre essa questão, vale lembrar que a pressão por inovação baseada em evidências científicas nem sempre é confiável. Há estudos que sustentam que a substituição de medicamentos tradicionais por inovações farmacêuticas apenas contribui para aumentar os custos das drogas e dos tratamentos médicos. Muitas indústrias utilizam a estratégia de introduzir pequenas modificações nas fórmulas medicamentosas, apenas para reintroduzir no mercado os medicamentos já existentes com preços mais elevados. Normalmente, esse artifício é utilizado pouco tempo antes da expiração da patente. (BELTRAME, A. Ampliação do acesso a medicamentos de alto custo: uma análise da política brasileira. 2002. Dissertação (Mestrado em Administração de Saúde) - Instituto de Medicina Social, Universidade do Estado do Rio de Janeiro, Rio de Janeiro, 2002. p.19). A título de ilustração, vale registrar o caso do Laboratório Merck Sharp \& Dohme produtor do Fosamax, medicamento destinado ao tratamento da osteoporose e um dos mais consumidos no Brasil. A empresa perdeu a patente do Fosamax em 2004 e, em 2007, lançou o Fosavance, que supostamente seria mais eficiente no tratamento da osteoporose. Essa farmacêutica fatura milhões com a venda deste novo produto, atualmente, com a patente em vigor, embora sua fórmula seja a mesma do Fosamax, com a diferença de ter a adição de vitamina $\mathrm{D}$. Os médicos não questionam a importância da vitamina $\mathrm{D}$ no tratamento da osteoporose, contudo esta é captada facilmente com a mera exposição solar (Instituto Brasileiro de Defesa ao Consumidor - IDEC. Farmacêutica Fatura milhões com inovação duvidosa na osteoporose. Disponível em: 〈http://www.idec.org.br/consumidorsa/arquivo/mar00/mar0012.htm〉. Acesso em: 13 mai. 2011).

${ }^{8}$ Antes da Rodada do Uruguai do GATT, a maior parte dos países em desenvolvimento não possuía a barreira patentária. Entretanto, após a celebração do Acordo TRIPS, em 1994, tais países foram obrigados por normas de direito internacional a reconhecer as patentes de inovações registradas em seu território. Em cumprimento ao disposto no referido acordo internacional, em 1996, passou a vigorar, no Brasil, a Lei 9.279, que regula os direitos e as obrigações relativos à propriedade industrial. Essa lei instituiu, no âmbito interno, o direito de patente sobre inovações, estabelecendo o prazo de vigência de 20 anos para cada patente (Art. 40, da Lei $n^{\circ}$. 9.279, de 14 de maio de 1996).

${ }^{9}$ Existe um importante debate em torno do papel das patentes no acesso a medicamentos. De um lado, há quem diga que as regras de propriedade intelectual criam monopólio sobre a venda de medicamentos essenciais, impedindo que versões genéricas mais baratas dos remédios de marca sejam comercializadas em países subdesenvolvidos. Por essa razão, milhares de pessoas não possuiriam acesso ao tratamento de saúde adequado nesses países, onde a renda é notadamente menor em comparação com a renda da população de países desenvolvidos (OXFAM. Briefing paper: patents versus patients. Disponível em: 〈http://www.dochas.ie〉. Acesso em 30 jun. 2011). Em oposição, há quem defenda que as regras de propriedade intelectual não interferem no acesso a medicamentos nos países em desenvolvimento, vez que essa questão envolve outros mecanismos de grande complexidade, tais como infraestrutura do setor de saúde pública, preços internacionais, financiamento e tributos (World Intellectual Property Organization - WIPO. Annual Report - 2000. Disponível em: 〈http://www.wipo.int>. Acesso em: 22 jun. 2011). Apesar de reconhecer a relevância desse assunto no que diz respeito ao acesso a medicamentos, o foco deste trabalho recai apenas sobre a regulação dos preços do mercado de farmacêutico no Brasil, não havendo pretensão de adentrar no debate sobre patentes.
} 
Em segundo lugar, nos países subdesenvolvidos, as filiais de laboratórios estrangeiros importam medicamentos e matérias primas do exterior. No Brasil, nos últimos 10 anos, 134 produtos farmacêuticos deixaram de ser fabricados no país e se converteram em produtos de importação. Sabe-se que um remédio importado diretamente da matriz de um laboratório na Europa ou nos EUA paga 35\% de imposto ao ingressar no país. Esse custo, por sua vez, é repassado ao consumidor, contribuindo para o encarecimento do produto. ${ }^{10}$

Em terceiro lugar, o mercado de medicamentos é um setor econômico imperfeito, marcado por falhas de mercado e proteção por patentes. As imperfeições do mercado prejudicam a concorrência e permitem que indesejáveis aumentos de preços ocorram. ${ }^{11}$ Dentre as falhas do mercado de medicamentos, pode-se citar: a) presença de monopólios e oligopólios, b) assimetria de informação, e c) separação das decisões sobre prescrição, consumo e financiamento. ${ }^{12}$

Ademais, em quarto lugar, embora seja notável o progresso em eficiência dos serviços de assistência farmacêutica ${ }^{13}$ prestados pelo Sistema Único de Saúde (SUS), nos últimos anos, foi possível observar a existência de uma desarticulação interna que interfere no processo de aquisição e distribuição de medicamentos. Essa desarticulação diz respeito ao fato de que muitos pacientes não conseguem obter junto ao SUS os remédios de que necessitam, contribuindo para o aumento da demanda de medicamentos no varejo ${ }^{14}$. Tal situação se explica em razão de boa parte dos médicos do setor público não priorizarem a prescrição de medicamentos presentes na Relação Nacional de Medicamentos Essenciais (RENAME) e ainda rejeitarem a indicação de medicamentos genéricos. ${ }^{15}$ Além disso, nem todas as unidades do SUS fornecem os medicamentos arrolados na RENAME. ${ }^{16}$

\footnotetext{
${ }^{10}$ KRIEGER, G.; ALBERTO JÚNIOR, C. Os truques dos importados. São Paulo, 2010. Disponível em: <http://revistaepoca.globo.com/revista/epoca/0,,emi160425-15259>. Acesso em: 13 mai. 2011.

${ }^{11}$ BRASIL. Agência Nacional De Vigilância Sanitária - ANVISA. Regulação econômica do mercado farmacêutico. Disponível em: <http://portal.anvisa.gov.br/wps/wcm/connect/>. Acesso em: 15 mai. 2012.

${ }^{12}$ VENTURI, C.B. et al., Política de Patentes e Direito da Concorrência. In: Política de Patentes em Saúde Humana. SANTINI, M.F.; ARANHA, M.I. (orgs.). São Paulo: Atlas, 2001, p.154-189. p.170-173.

${ }^{13} \mathrm{O}$ art. $1^{\circ}$, inciso III, da Resolução CNS n ${ }^{\circ} 38$, de 6 de maio de 2004, define assistência farmacêutica como: "conjunto de ações voltadas à promoção, proteção e recuperação da saúde, tanto individual como coletivo, tendo o medicamento como insumo essencial e visando o acesso e o seu uso racional" (BRASIL. Conselho Nacional de Saúde. Resolução CNS $n^{\circ}$ 38, de 6 de maio de 2004. Disponível em: <http://portal.saude.gov.br/portal/arquivos/pdf/resol_cns338.pdf>. Acesso em: 8 jun. 2012).

${ }^{14}$ BELTRAME, A. Ampliação do acesso a medicamentos de alto custo: uma análise da política brasileira. 2002. Dissertação (Mestrado em Administração de Saúde) - Instituto de Medicina Social, Universidade do Estado do Rio de Janeiro, Rio de Janeiro, 2002. p.18.

${ }^{15}$ A RENAME é a lista nacional oficial de medicamentos considerados básicos e indispensáveis para tratar um grande número de doenças e problemas de saúde. Essa lista é atualizada periodicamente e serve de modelo para a preparação do rol de medicamentos a serem oferecidos pelo SUS (CONSELHO REGIONAL
} 
No mais, o perfil epidemiológico e demográfico da população brasileira tem-se alterado nos últimos anos. A expectativa de vida dos brasileiros encontra-se em uma crescente, de modo que o envelhecimento da população representa um incremento na demanda por medicamentos de uso contínuo e maior custo. Esse é o caso dos medicamentos utilizados no tratamento de doenças crônico-degenerativas, tais como moléstias cardiovasculares, reumáticas e diabetes. ${ }^{17}$

A dificuldade de acesso a medicamentos pela população, ocasionada dentre outros fatores por aqueles acima mencionados, justifica, assim, a intervenção estatal no mercado de medicamentos, com o propósito de incrementar o acesso à saúde. ${ }^{18}$ Nesse sentido, a

DE MEDICINA DO ESTADO DE SÃO PAULO - CREMESP; CONSELHO REGIONAL DE FARMÁCIA DO ESTADO DE SÃO PAULO - CRF/SP; INSTITUTO DE DEFESA DO CONSUMIDOR - IDEC. Medicamento: um direito essencial. São Paulo, 2008. Disponível em:<http://www.fabry.org.br/doc/publi/arquivo4.pdf>. Acesso em: 4 jan. 2013). No que diz respeito à prescrição de medicamentos genéricos, muitos médicos alegam que, na prática, alguns desses medicamentos não são tão eficientes quanto os medicamentos de referência no tratamento de doenças. Aqui surge a questão relativa ao controle de qualidade dos medicamentos genéricos brasileiros. No entanto, graças a uma intensa campanha de conscientização empreendida pelo Ministério da Saúde junto à população e aos médicos, a utilização dos medicamentos genéricos tem aumentado, de modo que, em 2002, os genéricos já dominavam 6,8\% do mercado farmacêutico nacional. (BELTRAME, A. Ampliação do acesso a medicamentos de alto custo: uma análise da política brasileira. 2002. Dissertação (Mestrado em Administração de Saúde) Instituto de Medicina Social, Universidade do Estado do Rio de Janeiro, Rio de Janeiro, 2002.p.9).

${ }^{16}$ Pesquisa realizada pelo Instituto Brasileiro de Defesa do Consumidor verificou a ausência de 61 produtos da RENAME em 50 unidades de saúde de 11 cidades brasileiras, demonstrando um importante quadro de desabastecimento de medicamentos essenciais (Instituto Brasileiro de Defesa do Consumidor - IDEC. Faltam remédios essenciais no SUS. São Paulo, 2009. Disponível em: 〈http://www.idec.org.br〉. Acesso em: 22 jun. 2011).

${ }^{17}$ PANIZ, V. et al. Acesso a medicamentos de uso contínuo em adultos e idosos nas regiões Sul e Nordeste do Brasil. Cadernos de Saúde Pública, Rio de Janeiro, v.24, n.2, p.267-280, fev. 2008. p.268.

${ }^{18}$ Sabe-se que a dificuldade de acesso a medicamentos não é consequência apenas de fatores econômicos, mas é reflexo, também, de fatores políticos e sociais. A Organização Mundial da Saúde aponta quatro fatores-chave determinantes das condições de acesso a medicamentos em um país: uso racional, preços acessíveis, financiamento sustentável de medicamentos e sistemas de saúde e de fornecimento de medicamentos confiáveis (tradução livre de "rational use", "affordable prices", "sustainable financing for the medicines" e "reliable health and medicine supply systems" de falhas do sistema público de saúde e de políticas de assistência farmacêutica (ORGANIZAÇÃ̃O MUNDIAL DA SAÚDE. The World Medicines Situation. Disponível

em: <http://www.who.int/medicines/areas/policy/world_medicines_situation/en/index.html.>. Acesso em: 27 mar. 2012). Dentre os mencionados fatores, dois (financiamento sustentável e sistemas de saúde e de fornecimento de medicamentos confiáveis) são essencialmente de ordem política e remetem à necessidade de políticas governamentais que incentivem o consumo racional de remédios e melhoras de gestão do Sistema Único de Saúde. Ainda, conforme ressalta Machado dos Santos, influi diretamente sobre a questão do acesso a medicamentos a prescrição e dispensação de medicamentos, conforme será visto adiante. Esse autor ainda destaca a importância das condições da demanda na configuração do problema do acesso a medicamentos, a saber: a situação socioeconômica geral da população e a distribuição de renda (MACHADO DOS SANTOS, C. S. Melhoria na equidade no acesso aos medicamentos no Brasil: os desafios impostos pela competição extra-preço, 2001. Dissertação (Mestrado em Saúde Pública) - Escola Nacional de Saúde Pública, FIOCRUZ, Rio de Janeiro, 2001. p.8-9).

Registra-se que dispensação é o "ato de fornecimento ao consumidor de drogas, medicamentos, insumos farmacêuticos e correlatos, a título remunerado ou não" (BRASIL. Agência Nacional de Vigilância Sanitária. Medicamentos - $\quad$ conceitos técnicos. Disponível em: $<$ http://www.anvisa.gov.br/medicamentos/conceito.htm\#1.15>. Acesso em 20 dez. 2012). Segundo a 
política de regulação econômica do mercado farmacêutico tem, também, como função garantir o acesso a medicamentos pela população a preços razoáveis, corrigindo as falhas de mercado. ${ }^{19}$

A regulação do mercado farmacêutico é bastante antiga e a intervenção estatal na formação dos preços dos medicamentos ocorreu pela primeira vez, no Brasil, em 1808. ${ }^{20}$ $\mathrm{Na}$ história recente do país, a regulação dos preços dos produtos farmacêuticos também existiu. Nas décadas de 1970 e 1980, todos os preços da economia, inclusive os preços dos medicamentos eram controlados pelo Conselho Interministerial de Preços (CIP). ${ }^{21}$ Esse órgão não obteve sucesso em sua missão, pois, apesar do controle, os preços acabaram evoluindo na mesma intensidade dos preços de produtos pertencentes a setores não regulados. $^{22}$ Já na década de 1990 o controle de preços foi intercalado com momentos de liberação total do mercado. Nos intervalos de tempo em que houve a liberação dos preços, a comercialização de medicamentos ocorreu praticamente sem restrições de caráter econômico. ${ }^{23} \mathrm{O}$ resultado dessa experiência foi a "crise de medicamentos no Brasil", ${ }^{24} \mathrm{o}$ que acarretou uma alta sem precedentes dos preços dos produtos farmacêuticos, em função da prática de condutas abusivas por parte dos laboratórios nacionais e internacionais. ${ }^{25}$

Organização Pan-Americana de Saúde: "o procedimento de dispensação deve assegurar que o medicamento de boa qualidade seja entregue ao paciente certo, na dose prescrita, na quantidade adequada; que sejam fornecidas as informações suficientes para o uso correto e que seja embalado de forma a preservar a qualidade do produto (ORGANIZAÇÃO PAN-AMERICANA DE SAÚDE -OPAS. Assistência farmacêutica para gerentes municipais. 2003. Disponível em: <http://www.opas.org.br/medicamentos>. Acesso em: 20 dez. 2012).

${ }^{19}$ BRASIL. Agência Nacional de Vigilância Sanitária - ANVISA. Regulação e defesa do consumidor. Disponível em: <http://www.portal.anvisa.gov.br>. Acesso em: 03 mar. 2011.

${ }^{20}$ Neste ano, o príncipe regente determinou o tabelamento dos preços dos medicamentos, visando proteger os interesses dos cidadãos. (GODOY, M. R.; OLIVEIRA, A. L. R. de; CÂMARA, M. R. G. O controle de preços na indústria farmacêutica no Brasil. Disponível em: <http://www.bnb.gov.br/content/aplicacao/ETENE/Anais/docs/2004-o-controle-pdf>. Acesso em: 04 jun. 2011.

${ }^{21} \mathrm{O}$ CIP utilizava como ferramenta regulatória o controle de preços, diferente das práticas do tabelamento e congelamento de preços, até então comuns no Brasil (CONSIDERA, C. M. Uma breve história da economia política da defesa da concorrência. Disponível em: <http://www.seae.fazenda.gov.br/central_documentos/.../doctrab22.pdf>. Acesso em: 04 jun. 2011.

${ }^{22}$ Ibid.,p.13.

${ }^{23}$ KORNIS, G.; BRAGA, M. H.; ZAIRE, C. E. Os marcos legais das políticas de medicamentos no Brasil contemporâneo (1990-2006). Revista APS, São Paulo, v.11. n.1. p.85-99, jan./mar. 2008. p.91.

${ }^{24}$ GODOY, M. R.; OLIVEIRA, A. L. R. de; CÂMARA, M. R. G. O controle de preços na indústria farmacêutica no Brasil. $\quad$ Disponível em: <http://www.bnb.gov.br/content/aplicacao/ETENE/Anais/docs/2004-o-controle-pdf>. Acesso em: 04 jun. 2011.

${ }^{25}$ BELTRAME, A. Ampliação do acesso a medicamentos de alto custo: uma análise da política brasileira. 2002. Dissertação (Mestrado em Administração de Saúde) - Instituto de Medicina Social, Universidade do Estado do Rio de Janeiro, Rio de Janeiro, 2002. p.17. Este autor ressalta que, no período compreendido entre 1989 e 1999, os preços dos medicamentos subiram 54\% além da inflação. 
Depois das dificuldades enfrentadas na década de 1990, no que concerne à aquisição de medicamentos, o Estado entendeu ser necessário retomar o controle sobre a venda desses produtos, com a finalidade de facilitar o acesso pela população. Desse modo, em 2001, foi criada a Câmara de Medicamentos (CAMED), órgão regulador específico do setor dos medicamentos. Esse órgão foi extinto, em 2003, pela Lei 10.742 e foi substituído pela Câmara de Regulação do Mercado de Medicamentos (CMED), atrelada à estrutura do Ministério do Desenvolvimento, Indústria e Comércio Exterior (MDIC). Como será visto adiante, a CMED possui como atribuição:

[a] adoção, implementação e coordenação de atividades relativas à regulação econômica do mercado de medicamentos, voltados a promover a assistência farmacêutica à população, por meio de mecanismos que estimulem a oferta de medicamentos e a competitividade do setor. ${ }^{26}$

\subsection{A regulação do mercado e as políticas de saúde}

A regulação do mercado farmacêutico praticada pela CMED se insere no contexto maior de proteção da saúde, cuja origem é a Política Nacional de Promoção da Saúde. Essa política se desdobra na Política Nacional de Medicamentos (PNM) e na Política Nacional de Assistência Farmacêutica (PNAF).

A Política Nacional de Promoção da Saúde traça as diretrizes para a elaboração das demais políticas sanitárias. Um de seus objetivos gerais é promover o acesso a bens e serviços essenciais no âmbito da saúde. ${ }^{27}$ Dessa política decorre a Política Nacional de Medicamentos (PNM), aprovada em 1998, com o propósito de "assegurar o acesso da população a medicamentos seguros, eficazes e de qualidade, ao menor custo possível", ${ }^{28}$ Tal política tem como prioridade a assistência farmacêutica. ${ }^{29}$

Em 2004, o Conselho Nacional de Saúde publicou a Resolução CNS n ${ }^{\circ}$ 38. Essa resolução reafirmou a importância da regulação do mercado farmacêutico para a promoção do acesso a medicamentos, estando, por isso, em consonância com a Lei 10.742/03.

\footnotetext{
${ }^{26}$ Art. $5^{\circ}$, da Lei 10.742 , de 6 de outubro de 2003.

${ }^{27}$ BRASIL. Ministério da Saúde. Política Nacional de Promoção da Saúde. Disponível em: <http://portal.saude.gov.br/portal/arquivos/pdf/Politica_nacional_\%20saude_nv.pdf >. Acesso em: 8 jun. 2012.

${ }^{28}$ BRASIL. Ministério da Saúde. Portaria n³.916/MS/GM, de 30 de outubro de 1998. Disponível em: <http://www.anvisa.gov.br/legis/consolidada/portaria_3916_98.pdf >. Acesso em: 8 jun.2012.

${ }^{29}$ Além da assistência farmacêutica, são prioridades da PNM: a revisão permanente da Relação Nacional de Medicamentos Essenciais (RENAME), a promoção do uso racional de medicamentos e a organização das atividades de vigilância sanitária de medicamentos (Ibid.).
} 
Dentro desse contexto, a política de regulação do mercado de medicamentos praticada pela Câmara de Regulação do Mercado de Medicamentos possui um viés notadamente social, uma vez que tem como propósito promover a assistência farmacêutica. ${ }^{30}$ Isso, porque a regulação do mercado de medicamentos, no Brasil, tem como justificativa o objetivo de promover o acesso a medicamentos, enquadrando-se sob a égide do art. 196, da Constituição Federal e das demais políticas de saúde fundamentadas nesse preceito constitucional. ${ }^{31}$ Além disso, a política regulatória assume um viés redistributivo, na medida em que, por meio do controle de preços, procura limitar indiretamente os lucros da indústria em benefício da população, cujo acesso a medicamentos é restrito. Nesse sentido, a regulação do mercado farmacêutico pode ser entendida como um instrumento de implementação de um objetivo de caráter social, além de buscar meramente promover a eficiência e a estabilidade do mercado, corrigindo suas falhas.

\subsection{A criação da Câmara de Regulação do Mercado Farmacêutico (CMED) e} o controle de preços

A CMED, criada pela Lei 10.742, de 6 de outubro de 2003, tem como objetivos regular economicamente o mercado farmacêutico, promovendo a assistência farmacêutica à população, por meio de mecanismos que estimulem a oferta de medicamentos e a competitividade do setor. ${ }^{32}$ A intervenção exercida pela CMED no mercado de medicamentos se dá por direção e indução. Na primeira modalidade de ingerência econômica "o Estado exerce pressão sobre a economia, estabelecendo mecanismos e normas de comportamento compulsório para os sujeitos da atividade econômica em sentido estrito". ${ }^{33}$ Já na segunda modalidade, o Estado estimula os agentes econômicos a praticarem determinadas condutas desejáveis, manipulando os instrumentos de intervenção em consonância e na conformidade das leis que regem o funcionamento dos mercados. ${ }^{34}$

Paralelamente ao processo de desestatização, a Câmara de Regulação do Mercado de Medicamentos surgiu no contexto de inserção da regulação na agenda da governança

\footnotetext{
${ }^{30}$ Art. $5^{\circ}$, da Lei ${ }^{\circ} 10.742$, de 6 de outubro de 2003.

${ }^{31}$ Segundo o art. 196, da Constituição Federal, é dever do Estado garantir a saúde, mediante políticas sociais e econômicas que estabeleçam o acesso igualitário a serviços e ações para sua promoção, proteção e recuperação

Admite-se que o acesso a medicamentos é indissociável do direito fundamental à saúde.

${ }^{32}$ Art. $1^{\circ}$, da Lei 10.742 , de 6 de outubro de 2003.

${ }^{33} \mathrm{~A}$ atividade econômica em sentido estrito é aquela que pressupõe a iniciativa privada (GRAU, E. A ordem econômica na Constituição de 1988. 13ª . ed. São Paulo: Malheiros, 2008 p.102).

${ }^{34}$ Ibid., p.147.
} 
pública. No final da década de 1990 e início de 2000, foram criados diversos órgãos reguladores, sendo a grande maioria deles agências reguladoras. ${ }^{35}$ Essas agências são autarquias sob regime especial, portanto, integrantes da administração indireta, vinculadas aos Ministérios e com autonomia financeira. ${ }^{36}$ Embora tenha surgido na mesma conjuntura história e política e também exerça função reguladora, a CMED é muito diferente, do ponto de vista jurídico, das chamadas agências reguladoras independentes. A Câmara de Regulação do Mercado de Medicamentos não tem o status de autarquia (é parte da administração direta), sendo subordinada ao Ministério do Desenvolvimento, Indústria e Comércio Exterior. Em sua estrutura possui como integrantes e responsáveis pelas decisões finais ministros de Estado, que compõem o Conselho Ministerial. ${ }^{37}$ Desse modo, são políticos, em princípio, e não técnicos que dão a palavra final acerca das determinações emanadas da CMED, diferentemente do que ocorre nas agências reguladoras, em que as decisões são tomadas por técnicos teoricamente independentes do cenário político.

Praticamente falando, a regulação econômica exercida pela CMED se consubstancia na prerrogativa de estabelecer critérios para a fixação e ajuste de preços de medicamentos, bem como para a fixação de margens de comercialização de produtos a serem observadas pelos representantes, distribuidores, farmácias e drogarias. ${ }^{38}$ Esse órgão regulador faz, assim, uma distinção entre o controle de preços efetuado em relação aos fabricantes de medicamentos e aquele direcionado aos demais comerciantes. Os primeiros devem observar o teto estabelecido para o "preço-fábrica" (PF). ${ }^{39} \mathrm{Já}$ os segundos, responsáveis pela venda dos medicamentos em varejo, devem observar o "preço máximo

\footnotetext{
${ }^{35}$ SANTOS, L. A. dos. Desafios da governança regulatória no Brasil. Disponível em: <http://www.regulacao.gov.br/publicacoes/artigos/desafio-da-governanca-regulatoria-no-brasil.pdf-1>. Acesso em:15 mai. 2012.

${ }^{36}$ SANTOS, L. op. cit.

${ }^{37}$ Art. $4^{\circ}$, da Resolução CMED no 03, de 29 de julho de 2003. Sobre a composição da CMED vale a pena registrar que, além do Conselho Ministerial, são órgãos dessa câmara reguladora o Comitê TécnicoExecutivo e a Secretaria Executiva. O Comitê Técnico-Executivo é o núcleo executivo colegiado da CMED. Seus membros são: o Secretário de Ciência e Tecnologia e Insumos Estratégicos do Ministério da Saúde, que coordena o comitê; o Secretário Executivo da Casa Civil; o Secretário de Direito Econômico, do Ministério da Justiça; o Secretário de Acompanhamento Econômico, do Ministério da Fazenda; e o Secretário de Desenvolvimento da Produção, do Ministério do Desenvolvimento, Indústria e Comércio Exterior (Art. $9^{\circ}$, da Resolução CMED no 3, de 29 de julho de 2003). Compete, eminentemente, ao Comitê Técnico-Executivo, sugerir diretrizes, critérios e procedimentos relativos à regulação econômica do mercado de medicamentos (Art.10, da Resolução CMED n ${ }^{\circ}$ 3, de 29 de julho de 2003). Por sua vez, a Secretaria Executiva da CMED é exercida pela Agência Nacional de Vigilância Sanitária (Art. 11, da Resolução CMED n ${ }^{\circ}$ 3, de 29 de julho de 2003). Suas principais competências são prestar assistência ao Conselho de Ministros e implementar as deliberações emanadas desse órgão(Art. 12, da Resolução CMED n 3, de 29 de julho de 2003).

${ }^{38}$ Arts. $4^{\circ}$ e $6^{\circ}$, respectivamente, da Lei ${ }^{\circ} 10.742$, de 6 de outubro de 2003.

${ }^{39}$ Nos termos do art $2^{\circ}$, da Resolução CMED n ${ }^{\circ}$, de 25 de fevereiro de 2005, o Preço-Fabricante (PF) é baseado em um índice, um fator produtividade, uma parcela de fator de ajuste de preços relativos intra-setor e outra entre setores.
} 
ao consumidor" (PMC) fixado pela CMED, anualmente. ${ }^{40}$ Há também a determinação do coeficiente de adequação de preços (CAP) que consiste em um desconto obrigatório sobre determinados medicamentos vendidos a entidades públicas. ${ }^{41}$

Segundo a Agência Nacional de Vigilância Sanitária (ANVISA), desde a criação da Câmara de Regulação do Mercado de Medicamentos, os preços de comercialização dos produtos farmacêuticos diminuíram. ${ }^{42}$ No entanto, há quem critique a atuação da CMED, alegando que o teto estabelecido para a comercialização dos medicamentos poderia ser bem menor que o atualmente determinado, pressionando por uma queda ainda maior dos preços desses produtos. ${ }^{43}$

Foi diagnosticado, então, um debate acerca da efetividade da regulação da CMED. Entende-se como efetiva a política regulatória capaz de reduzir os custos dos consumidores nas compras de medicamentos. A ideia é que a regulação seja capaz de pressionar os preços para baixo, evitando aumentos de preços repentinos e discrepantes que sejam prejudiciais aos consumidores.

No que diz respeito à regulação da CMED, o maior problema verificado foi em relação ao reajuste dos preços dos medicamentos vendidos em varejo. Conforme será explicitado neste trabalho, nesse ponto, a política regulatória da CMED não é efetiva, porque é incapaz de influenciar os preços determinados pela indústria farmacêutica, farmácias e drogarias. Na prática, os percentuais de reajustes reais são bem maiores do que aqueles permitidos pelo governo. Isso ocorre, porque, dentre outras razões, anualmente, ao determinar o preço máximo ao consumidor (PMC), que serve como teto para os reajustes de preços formulados pelas farmácias e drogarias, o governo não leva em consideração os preços realmente praticados nos pontos de venda. Essa situação, contudo, não é ilegal, pois os novos preços fixados pelas farmácias e drogarias não ultrapassam o teto de preço fixado pelo órgão regulador (preço máximo ao consumidor). ${ }^{44}$

\footnotetext{
${ }^{40} \mathrm{O}$ valor do PMC é o resultado da divisão do preço-fábrica pelos fatores que qualificam a margem de comercialização. Nas unidades de comércio varejista, os preços dos medicamentos não podem ultrapassar esse valor (Art. $4^{\circ}$ da Resolução CMED n 2, de 19 de março de 2007).

${ }^{41}$ Resolução CMED n ${ }^{\circ}$, de 18 de dezembro de 2006.

${ }^{42}$ BRASIL. Agência Nacional de Vigilância Sanitária - ANVISA. Política vigente para a regulamentação de medicamentos no Brasil. Brasília, 2004. Disponível em: <http://www.portal.anvisa.gov.br/medicamentos/politica/htm>. Acesso em: 03 mar. 2011.

${ }^{43}$ Conforme demonstra pesquisa realizada pelo Instituto de Defesa do Consumidor (IDEC), os preços efetivos de comercialização dos produtos farmacêuticos estão muito abaixo do teto fixado pela CMED (INSTITUTO BRASILEIRO DE DEFESA DO CONSUMIDOR. Remédio pro Bolso. Disponível em: <www.idec.org.br/rev_idec_texto_impressa.asp>. Acesso em 16 mar. 2011.

${ }^{44}$ MEIO cheio ou meio vazio? Revista do IDEC. São Paulo, n.142, p. 22-25, abr. 2010. p. 22.
} 


\subsection{Objeto e premissas do estudo}

Interessa, neste trabalho, realizar uma breve análise da relação entre a regulação do mercado de medicamentos e as políticas de saúde, apenas com o propósito de contextualizar a atuação da CMED no cenário da assistência farmacêutica no Brasil. Essas políticas serão estudadas com base nas categorias de classificação do papel do direito nas políticas públicas, uma vez que o Estado utiliza normas jurídicas e processos administrativos mediados pelo direito para pôr políticas públicas em prática. $\mathrm{O}$ direito é, por isso, um elemento intrínseco e componente central das políticas públicas, sendo possível dizer que a dimensão jurídica de uma política, em boa medida, influi diretamente sobre sua efetividade. ${ }^{45}$ Dito de outra forma, os atributos jurídicos de uma política pública contribuem para a estruturação do funcionamento, regulamentação dos procedimentos e se encarregam de viabilizar a articulação entre atores direta e indiretamente nela envolvidos. Nesse sentido, os papéis assumidos pelo direito, nas políticas em geral, são variados, podendo o direito ser visto, dentre outras formas, como definidor de objetivos, articulador de ferramentas, estruturador de arranjos institucionais e vocalizador de demandas. ${ }^{46}$

Uma vez contextualizada a atuação da Câmara de Regulação do Mercado de Medicamentos no cenário da assistência farmacêutica, surge a questão central desta pesquisa: em que medida a regulação do mercado farmacêutico praticada pela CMED é um instrumento capaz de promover a assistência farmacêutica? Faz-se necessária a ressalva de que o escopo do trabalho não é realizar uma "avaliação de impacto regulatório" 47 , mas apenas apontar indícios de efetividade ou inefetividade da política de regulação dos preços dos medicamentos no Brasil. Para os fins a que esta pesquisa se propõe, a regulação do mercado farmacêutico será considerada efetiva na medida em que servir como instrumento capaz de manter os preços dos medicamentos em patamar acessível aos consumidores, cumprindo, assim, o papel definido pelo direito de promover o acesso a medicamentos. Em contrapartida, será considerada inefetiva quando não conseguir exercer tal função.

\footnotetext{
${ }^{45}$ MEIO cheio ou meio vazio? Revista do IDEC. São Paulo, n.142, p. 22-25, abr. 2010. p. 22.

${ }^{46}$ COUTINHO, D. R. O direito nas políticas públicas. A ser publicado em Eduardo Marques e Carlos Aurélio de Pimenta de Faria (eds.) "Política Pública como Campo Disciplinar", São Paulo, Ed. Unesp, no prelo.

${ }^{47}$ Avaliação de impacto regulatório é o "instrumento formal que permite a explicitação dos problemas regulatórios, das opções disponíveis de política e das consequências das decisões regulatórias, em cada caso concreto, mediante a utilização de dados empíricos" (GAETANI, F.; ALBUQUERQUE, K. Análise de impacto regulatório e melhoria regulatória. In: BRASIL. Agência Nacional de Vigilância Sanitária ANVISA. RAMALHO, P. I. S. (Org.). Regulação e agências reguladoras: governança e análise de impacto regulatório. Brasília: ANVISA, 2009. p. 195.
} 
Os métodos selecionados para desvendar essa questão serão adiante expostos, e consistem, principalmente, na análise de documentos e estudos oriundos de órgãos públicos e privados, tais como pesquisas elaboradas pelo Instituto de Defesa do Consumidor (IDEC) e pela Fundação de Proteção e Defesa do Consumidor (PROCON), acerca dos preços dos medicamentos no Brasil; e na realização de entrevistas com especialistas e interessados no tema.

A partir do quadro anteriormente descrito, o presente trabalho pretende contribuir para a produção de conhecimento científico principalmente na seara da regulação do mercado farmacêutico, respondendo às seguintes questões de pesquisa:

1) Quais são as principais características da regulação do mercado de medicamentos praticada pela CMED? Quais são os "prós" e os "contras" da política regulatória prevista na Lei 10.742/03?

2) Nos moldes em que foi concebida e conforme é praticada, a política de regulação dos preços contribui para a promoção da assistência farmacêutica, isto é, ela é efetiva?

São algumas das hipóteses a serem testadas no trabalho proposto, orientando o alcance dos objetivos de pesquisa supramencionados, as seguintes assertivas:

a) A política de regulação dos preços empreendida pela CMED, principalmente mediante o controle de preços, apresenta "prós" e "contras", bem como dificuldades e problemas de implementação. Essa política revela, possivelmente, mais aspectos positivos do que negativos, no Brasil, onde os custos dos medicamentos são muito elevados e o controle de preços de desses produtos tende a favorecer o consumidor, facilitando o acesso a medicamentos.

b) A regulação da CMED é efetiva, uma vez que é capaz de pressionar os preços dos medicamentos a patamares mais baixos, mitigando o arbítrio da indústria farmacêutica na fixação dos preços dos medicamentos, de modo a favorecer os interesses dos consumidores. No entanto, os preços dos medicamentos se encontram em patamares elevados, em razão do descumprimento das normas regulatórias pelos agentes regulados. De acordo com essa hipótese, os preços praticados no mercado seriam superiores àqueles estabelecidos como teto pela CMED, caracterizando um problema de enforcement da regulação. 


\subsection{A importância do tema}

Pesquisar a regulação dos preços do mercado farmacêutico é relevante, uma vez que o uso desse instrumento de regulação consiste em uma das mais importantes formas de promover o acesso a medicamentos no Brasil. A questão dos preços dos produtos farmacêuticos é particularmente importante no nosso país, em que as famílias gastam uma parte considerável da renda familiar com medicamentos, conforme mencionado anteriormente. ${ }^{48}$

Deve-se notar que embora a maior parte dos países do mundo regule de uma forma ou de outra o mercado de medicamentos, no Brasil, o debate sobre a regulação desse mercado não é pacífico. De um lado, há quem defenda que os males ocasionados pela regulação são maiores que os benefícios, visto que o controle de preços pode provocar desabastecimento, surgimento de mercados negros, menos investimentos em P\&D e comercialização de medicamentos de pior qualidade ${ }^{49}$. De acordo com esse posicionamento, a intervenção do Estado no mercado farmacêutico deveria ocorrer especialmente mediante mecanismos de controle extra-preço, tais como a legislação antitruste, ao lado do controle de preços. ${ }^{50}$ De outro lado, há quem defenda que a regulação direta do mercado, por meio do controle de preços é essencial, vez que facilita o acesso a medicamentos, mantendo os custos dos produtos farmacêuticos em um patamar mais acessível para a maior parte da população. O papel da legislação antitruste seria, portanto, secundário. Na década de 1990, o Brasil já teria tido uma experiência com o uso isolado da legislação antitruste como forma de conter a elevação dos preços dos medicamentos e os resultados foram decepcionantes, como visto anteriormente. ${ }^{51}$ Diante desse quadro, o presente estudo visa contribuir para a elucidação de questões atinentes a esse debate, analisando os "prós" e "contras" da regulação econômica mediante o controle de preços no Brasil, nos moldes concebidos pela Lei 10.742/03.

\footnotetext{
${ }^{48}$ BRASIL. Instituto Brasileiro de Geografia e Estatística - IBGE. Pesquisa de Orçamentos Familiares 2008-2009. Disponível em <http://www.ibge.com.br>. Acesso em: 16 mar. 2011.

${ }^{49}$ BRONFENBRENNER, M. Price control under imperfect competition. The American Economic Review, Pittsburgh, v. 37, n.1, p.193-216. mar. 1947. p.111.

${ }^{50}$ Segundo Barbara Rosenberg, "é fundamental trabalhar com um marco mais amplo, com abrangência e resultados mais perenes e efetivos que o simples controle de preços." (ROSENBERG, B. Patentes de medicamentos e comércio internacional: os parâmetros do TRIPS e do direito concorrencial para a outorga de licenças compulsórias. 2003. 290 p. Tese (Doutorado em Direito) - Faculdade de Direito, Universidade de São Paulo, São Paulo, 2003. p.89).

${ }^{51}$ GODOY, M. R.; OLIVEIRA, A. L. R. de; CÂMARA, M. R. G. O controle de preços na indústria farmacêutica no Brasil. Disponível em: $\langle$ http://www.bnb.gov.br/content/aplicacao/ETENE/Anais/docs/2004-o-controle-pdf $>$. Acesso em: 04 jun. 2011.
} 
Além disso, poucos foram os estudos jurídicos produzidos sobre essa temática. No Brasil, a maior parte das pesquisas sobre regulação do mercado de medicamentos até hoje realizada foi empreendida no âmbito da saúde pública e da economia, prescindindo de uma abordagem sob a perspectiva jurídica. ${ }^{52}$ Ainda, conforme mencionado anteriormente, no Brasil, faltam estudos que busquem relacionar as políticas públicas com o direito. ${ }^{53}$ Há, também, por essa razão, lacunas relativas à compreensão do tema a ser pesquisado (tais como a questão da efetividade da política regulatória), as quais este trabalho busca suprir.

Dentro da temática relativa aos "contras" da regulação por meio do controle de preços, pretende-se abordar também o assunto referente aos "gargalos" e às dificuldades de implementação da referida política regulatória baseada na utilização desse mecanismo jurídico-econômico no Brasil. A intenção é sistematizar os argumentos favoráveis e contrários à utilização da ferramenta regulatória do controle de preços, coletados principalmente mediante entrevistas realizadas com especialistas sobre o tema. O intuito é

\footnotetext{
${ }^{52}$ Foram encontrados os seguintes estudos sobre regulação do mercado de medicamentos brasileiro, em pesquisa referente aos trabalhos produzidos, na maioria, por pesquisadores não pertencentes à área jurídica, nos últimos 10 anos: MALUF, E. O controle de preço de medicamentos. Revista de Direito Sanitário. São Paulo, v.12, n.1, p.67-84. 2011; OLIVEIRA, R. R. Os conceitos de regulação em saúde no Brasil, 2010. Dissertação (Mestrado em Medicina) - Faculdade de Medicina da Universidade de São Paulo, São Paulo, 2010; BIROLI, A.V.R.; GALVÃO, R.G. Controle de preços de remédios. Disponível em: <www.intertemas.unitoledo.br/revista/index.php/ETIC/article/viewFile/.../2120>. Acesso em: 20 fev. 2011; ZOCKUN, M. Controle de preços de medicamentos pela CMED in Revista Trimestral de Direito Público. $51^{a}$ e $52^{a}$ ed. Malheiros: São Paulo, 2009; AMORIM, M. C. S. Regulação dos preços e acesso ao consumo de medicamento no Brasil. In: ANTAS JR., R. M. Os desafios do consumo. Petrópolis: Vozes, 2007. p. 133138; BATISTA, L. B. Regulação econômica do mercado farmacêutico brasileiro. Dissertação (Mestrado em Direito). Universidade Cândido Mendes, Rio de Janeiro, 2005. 128 p.; ROSENBERG, B. Patentes de medicamentos e comércio internacional: os parâmetros do TRIPS e do direito concorrencial para a outorga de licenças compulsórias. 2004. 290 p. Dissertação (Doutorado em Direito) - Faculdade de Direito, Universidade de São Paulo, São Paulo, 2004; ANDRADE, A.; ANDRADE, C. A. P.; UILIAM, F. O. Controle de preços de remédios. Disponível em: 〈http://intertemas.unitoledo.br/revista/index.php/ETIC〉. Acesso em: 20 fev. 2011; CASTRO, J. D. Regulação em saúde: análise de conceitos fundamentais. Sociologias, Porto Alegre, v.4, n.7, p.1122-135, jan/jun. 2002; FIUZA, E.; LISBOA, M.; VIEGAS, M. Política governamental e regulação do mercado de medicamentos. Rio de Janeiro: FGV, 2001; ANDRADE, M.; LISBOA, M. Regulação do setor de saúde no Brasil. Rio de Janeiro: EPE/FGV, 2001; FOLLADOR, W. Alguns aspectos da variação de preços de medicamentos no Brasil no período de 1980 a 2001, 2001. Dissertação (Mestrado em Ciências Farmacêuticas) Faculdade de Ciências Farmacêuticas da Universidade de São Paulo. São Paulo; ROMANO, R.; BERNARDO, P. J. B. Padrões de regulação de preços do mercado de medicamentos: experiência brasileira dos anos 90 e novos arranjos institucionais. In: NEGRI, B.; DI GIOVANNI, G. Brasil: radiografia da saúde. Campinas: UNICAMP, 2001. p. 445-464. ANDRADE, A.; ANDRADE, C. A. P.; UILIAM, F. O. Controle de preços de remédios. Disponível em: <http://intertemas.unitoledo.br/revista/index.php/ETIC>. Acesso em: 20 fev. 2011; Apenas quatro desses estudos analisam de forma relativamente aprofundada a atividade da Câmara de Regulação do Mercado de Medicamentos: AMORIM, M. C. S. Regulação dos preços e acesso ao consumo de medicamento no Brasil. In: ANTAS JR., R. M. Os desafios do consumo. Petrópolis: Vozes, 2007. p. 133-138; FIUZA, E.; LISBOA, M. ; VIEGAS, M. Política governamental e regulação do mercado de medicamentos. Rio de Janeiro: FGV, 2001; e ROMANO, R.; BERNARDO, P. J. B. Padrões de regulação de preços do mercado de medicamentos: experiência brasileira dos anos 90 e novos arranjos institucionais. In: NEGRI, B.; DI GIOVANNI, G. Brasil: radiografia da saúde.Campinas: UNICAMP, 2001. p. 445-464.

${ }^{53}$ COUTINHO, D.R. Linking promises to policies: law and development in an unequal Brazil. The Law and Development Review. Berkeley, v.3, n.2, artigo 2, 2010. p.4.
} 
colaborar para a melhor compreensão de seus possíveis efeitos, quando da análise acerca das ferramentas jurídicas utilizadas para viabilizar a política de assistência farmacêutica.

\subsection{Métodos}

Este trabalho consiste em um estudo de caso sobre a CMED e a política de regulação do mercado de medicamentos praticada por esse órgão. ${ }^{54}$ As técnicas de pesquisa utilizadas para a coleta de dados e informações foram, na maioria, qualitativas: análise bibliográfica, análise documental e realização de entrevistas semipadronizadas.

A coleta de dados foi feita com base em legislação, livros, artigos de revistas científicas jurídicas e econômicas, pesquisas e documentos oriundos de órgãos oficiais e não oficiais. Com o propósito de analisar a evolução dos preços dos medicamentos em períodos posteriores à criação da Câmara de Regulação do Mercado de Medicamentos, foi construído um banco de dados, com preços coletados por pesquisas realizadas pelo Instituto de Defesa do Consumidor e pela Fundação de Proteção e Defesa do Consumidor do Estado de São Paulo. Posteriormente, cruzou-se as informações sobre os preços coletados por essas instituições com o preço máximo ao consumidor correspondente a cada apresentação medicamentosa no respectivo período. Foi possível, portanto, comparar a o comportamento real dos preços com o teto estipulado pela CMED.

Além disso, foram realizadas entrevistas com membros da CMED, do Instituto de Defesa do Consumidor (IDEC) e da Fundação de Proteção e Defesa do Consumidor do Estado de São Paulo (PROCON-SP). A ideia inicial era entrevistar também representantes da indústria farmacêutica, entretanto, foram realizadas várias tentativas frustradas com membros da Associação da Indústria Farmacêutica de Pesquisa (INTERFARMA) e do Sindicato da Indústria de Produtos Farmacêuticos no Estado de São Paulo (SINDUSFARMA), órgãos representativos dos laboratórios farmacêuticos no Brasil, que se recusaram a conceder entrevistas.

\footnotetext{
${ }^{54} \mathrm{O}$ estudo de caso é uma das principais possibilidades oferecidas pela abordagem qualitativa, ao lado da pesquisa documental e do estudo etnográfico (NEVES, J. L. Pesquisa qualitativa: características, usos e possibilidades. Disponível em:<http://www.ead.fea.usp.br/cad-pesq/arquivos/c03-art06.pdf>. Acesso em: 22 fev. 2011). No que diz respeito à metodologia qualitativa de pesquisa, vale a pena registrar o que segue: “[...]Realizando um exame intensivo dos dados, tanto em amplitude quanto em profundidade [diferentemente da metodologia quantitativa que privilegia o exame em amplitude], os métodos qualitativos tratam as unidades sociais investigadas como totalidades que desafiam o pesquisador. Neste caso, a preocupação básica do cientista social é a estreita aproximação dos dados, de fazê-lo falar da forma mais completa possível, abrindo-se à realidade social para melhor apreendê-la e compreendê-la. Se há uma característica que constitui a marca dos métodos qualitativos ela é a flexibilidade, principalmente quanto às técnicas de coleta de dados, incorporando aquelas mais adequadas à observação que está sendo feita"(MARTINS, H. T. S. Metodologia qualitativa de pesquisa. Educação e Pesquisa, São Paulo, v.10, p.289-300, mai./ago. 2004. p.292).
} 
Os questionários foram previamente elaborados por meio da preparação de formulários de entrevista semipadronizados, como parte do esforço de construção do método. Com o propósito de melhor organizar o conteúdo a ser abordado, o formulário foi dividido em blocos temáticos.

A opção pela realização de entrevistas semipadronizadas ${ }^{55}$, em detrimento de entrevistas padronizadas e despadronizadas decorre da vantagem que esse tipo de entrevista apresenta ao agregar aspectos positivos dos dois outros tipos. As entrevistas semipadronizadas permitem o direcionamento do assunto, ao mesmo tempo em que preservam a flexibilidade do entrevistador para adaptar a sua abordagem àquilo que, no momento, lhe parece mais proveitoso para a compreensão do fenômeno pesquisado. ${ }^{56}$

As entrevistas realizadas apresentaram particular utilidade, na medida em que proporcionaram melhor apreensão da regulação do mercado de medicamentos ${ }^{57}$. A aplicação do questionário formulado possibilitou o teste das hipóteses elaboradas, bem como o esclarecimento das demais dúvidas acerca das características jurídicas da política regulatória, da utilização do controle de preços como uma ferramenta jurídica de regulação setorial no âmbito de uma política pública e, em especial, das dificuldades e "gargalos" de implementação dessa política e da existência de mecanismos de participação social e accountability.

Essas entrevistas foram gravadas e as respectivas transcrições constam dos anexos desta dissertação. Ao longo do trabalho também foram realizadas citações dos textos transcritos ou referências.

\subsection{Plano da obra}

Feitas as considerações introdutórias, importa realizar uma breve explanação sobre a estrutura deste trabalho, que se compõe, além do presente capítulo introdutório, de cinco capítulos:

\footnotetext{
${ }^{55}$ Conforme explica Bernard Phillips, “qualquer consideração da situação de entrevista deve levar em conta os diferentes tipos de entrevistas. Estas podem ser classificadas em três grandes grupos: entrevista padronizada, entrevista despadronizada e entrevista semipadronizada. Na entrevista padronizada o entrevistador está preso ao enunciado específico no roteiro de perguntas da entrevista; ele não é livre de adaptar suas perguntas à situação específica, de modificar, de modificar a ordem de tópicos ou de fazer outras perguntas. Na entrevista despadronizada o entrevistador é livre de desenvolver cada situação em quaisquer direções que considere apropriadas para as finalidades imediatas. Na entrevista semipadronizada o entrevistador deve fazer certo número de perguntas principais e específicas, mas pode ser livre de ir além das respostas dadas a essas perguntas.(PHILLIPS, B. S. Pesquisa social: estratégias e táticas. Rio de Janeiro: Agir, 1974. p.165-166).

${ }^{56}$ Ibid., p.165-166.

${ }^{57}$ Referidas entrevistas foram realizadas no período compreendido entre fevereiro e agosto de 2012.
} 
$\mathrm{O}$ segundo capítulo, intitulado "O mercado farmacêutico e o acesso a medicamentos no Brasil", consiste em um estudo sobre as características econômicas do mercado de medicamentos e sobre as razões da dificuldade de acesso a medicamentos por parte da população brasileira. Esse estudo é necessário para contextualizar o processo regulatório e ajuda o leitor a compreender melhor a importância e a necessidade da regulação do setor correspondente ao mercado de medicamentos.

O terceiro capítulo, cujo título é "A Câmara de Regulação do Mercado de Medicamentos (CMED) e a Lei 10.742/03", adentra propriamente no estudo de caso a que se propõe este trabalho, explanando as características da CMED, órgão responsável pela regulação do mercado farmacêutico, bem como as diretrizes regulatórias expressas na Lei $10.742 / 03$.

O quarto capítulo, designado por "A Câmara de Regulação do Mercado de Medicamentos (CMED) e a Lei 10.742/03”, refere-se à política regulatória, tal como ela se encontra delineada na Lei 10.742/03, bem como aos principais aspectos da regulação presentes nas resoluções e comunicados da CMED.

O quinto capítulo, intitula-se “A política regulatória na prática: 'prós', 'contras' e dificuldades jurídicas da regulação do mercado de medicamentos no Brasil”. Esse é o núcleo do trabalho. Nessa parte analisa-se a regulação do mercado de medicamentos na prática, verificando seus aspectos positivos e negativos, sendo os últimos, em sua maioria, gargalos relativos à qualidade da legislação e às dificuldades de implementação da política regulatória.

O sexto capítulo corresponde a uma sistematização das conclusões explicitadas ao longo do trabalho.

Por fim, o presente trabalho é composto pelas referências e anexos, em que constam as transcrições dos áudios das entrevistas realizadas, bem como o banco de dados sobre preços de medicamentos, elaborado para a realização deste estudo. 


\section{O MERCADO FARMACÊUTICO E O ACESSO A MEDICAMENTOS NO BRASIL}

\subsection{Acesso a medicamentos no Brasil}

Apesar dos avanços conquistados pelo Sistema Único de Saúde em mais de 20 anos de existência, é possível afirmar que, em muitos lugares do Brasil, ainda é difícil o acesso às ações e aos serviços de saúde públicos, inclusive ao fornecimento gratuito de medicamentos. ${ }^{58}$ Diante desse quadro, a aquisição de medicamentos em varejo é, na maioria das vezes, a única opção do paciente para seguir o tratamento prescrito pelo médico. Sendo assim, o preço dos medicamentos constitui um fator importante para o acesso a medicamentos pela população, constituindo, muitas vezes, um obstáculo.

A Organização Mundial da Saúde (OMS) considera o preço um dos mais relevantes impedimentos ao acesso a medicamentos. ${ }^{59}$ De fato, o preço é um dos fatores determinantes da assistência farmacêutica, embora não seja o único. Ao lado do preço, a OMS elege outros fatores decisivos: (i) seleção racional de medicamentos; (ii) financiamento sustentável, mediante compras de remédios diretamente dos laboratórios farmacêuticos por parte do governo; e (iii) sistemas de saúde e de fornecimento de medicamentos confiáveis. ${ }^{60}$

Em 2005, a Organização Pan-Americana de Saúde (OPAS) apurou que a disponibilidade de medicamentos essenciais pelo Sistema Único de Saúde é de apenas $74 \% .{ }^{61}$ Essa circunstância faz com que o consumidor brasileiro responda, hoje, por quase $80 \%$ dos gastos totais do país com medicamentos, de sorte que quase oito entre dez

\footnotetext{
${ }^{58}$ INSTITUTO BRASILEIRO DE DEFESA DO CONSUMIDOR - IDEC. Faltam remédios essenciais no SUS. São Paulo, 2009. Disponível em: 〈http://www.idec.org.br〉. Acesso em: 22 jun. 2011.

${ }^{59}$ ORGANIZAÇÃO MUNDIAL DA SAÚDE, Precios de los medicamentos: una nueva forma de medirlos. Disponível em:<http://apps.who.int/medicinedocs/en/d/Js6163s/2.5.html>. Acesso em 27 mar. 2012.

${ }^{60}$ Tradução livre de: "rational selection of medicines", "sustainable financing" e "reliable health and supply systems". Vale registrar que, ainda de acordo com a Organização Mundial da Saúde, a renda e infra-estrutura são fatores atrelados ao acesso a medicamentos, embora não sejam determinantes. Mesmo diante de populações de baixa renda é possível atingir melhoras consideráveis no que diz respeito à assistência farmacêutica (ORGANIZAÇÃO MUNDIAL DA SAÚDE. The World Medicines Situation. Disponível em: $<$ http://www.who.int/medicines/areas/policy/world_medicines_situation/en/index.html.>. Acesso em: 27 mar. 2012).

${ }^{61}$ Os medicamentos essenciais são considerados "produtos básicos e indispensáveis para atender a maioria dos problemas de saúde da população. São selecionados de acordo com sua relevância na saúde pública, evidência sobre a eficácia e a segurança e os estudos comparativos de custo-efetividade Devem estar disponíveis em todo momento, nas quantidades adequadas, nas formas farmacêuticas requeridas e a preços que os indivíduos e a comunidade possam pagar" (ORGANIZAÇÃO PAN-AMERICANA DE SAÚDE OPAS; BRASIL. MINISTÉRIO DA SAÚDE. Avaliação da Assistência Farmacêutica no Brasil: Estrutura, Procssos e Resultados. Brasília: OPAS/OMS, 2005, p.45).
} 
compras de remédios saem dos bolsos dos pacientes. ${ }^{62}$ Sobre a evolução dos gastos com medicamentos no período compreendido entre 2002-2007, a Interfarma disponibilizou o seguinte dados (Gráfico 1):

Gráfico 1. Evolução dos gastos com medicamentos por fonte pagadora (2002-2007)

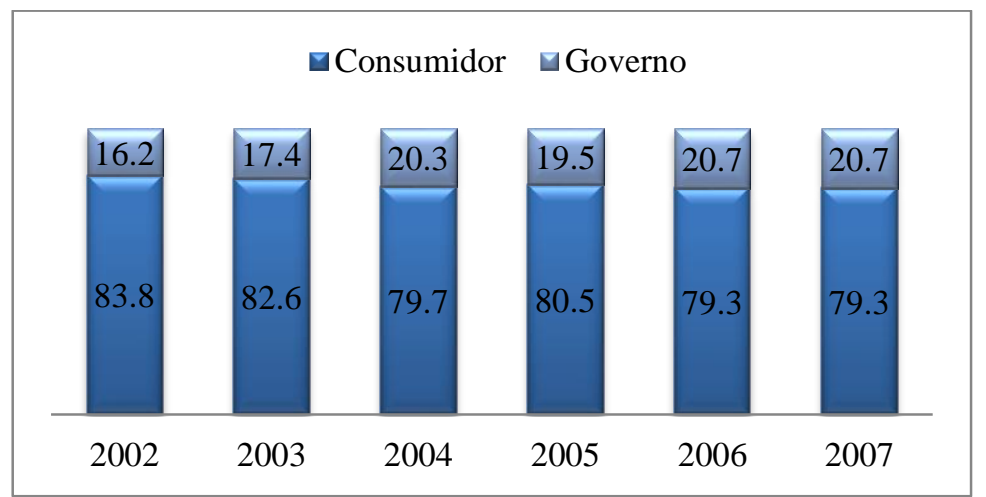

Fonte: Adaptado de INTERFARMA. Evolução dos gastos com medicamentos por fonte pagadora (2002-2007). [2007]. 1 gráfico, color. Disponível em:<http://www.interfarma.org.br/site2/index.php/informacoes-do-setor/indicadores $>$. Acesso em: 27 mar. 2012.

Ademais, existe a agravante conjuntural dos preços dos medicamentos se encontrarem em patamares consideravelmente elevados no Brasil. ${ }^{63}$ Além das falhas de mercado, os fatores que contribuem para os altos preços dos produtos farmacêuticos são (i) os tributos incidentes sobre esses bens que, no Brasil, variam entre 30\% a $45 \%$ do preço praticado em varejo; (ii) o uso de patentes como forma de proteção da propriedade intelectual $^{64}$; (iii) o nível de produção e tecnologia da indústria farmacêutica nacional; (iv) o nível de competição entre os agentes econômicos atuantes no mercado farmacêutico; e (v) a utilização de mecanismos regulatórios ineficazes. ${ }^{65}$

\footnotetext{
${ }^{62}$ Notícia: Dois gargalos na saúde: financiamento e acesso a medicamentos. Publicado em 07/12/2010. Disponível em <http://www.sindifarmajp.com.br/noticias.php?not_id=3190> Acesso em: 01 abr.2011; e GOLDBERG. S. Brasileiro gasta muito na compra de medicamentos. Valor Econômico, Rio de Janeiro, 9 jun.2010, Caderno Especial (F), p.2.

${ }^{63} \mathrm{Cf}$. item1, do Capítulo 1.

${ }^{64} \mathrm{Com}$ base na Lei de Propriedade Industrial, o Instituto Nacional da Propriedade Intelectual (INPI) define patente como um título de propriedade temporária sobre uma invenção ou modelo de utilidade, outorgado pelo Estado aos inventores ou autores ou outras pessoas físicas ou jurídicas detentoras de direitos sobre a criação. Em contrapartida, o inventor se obriga a revelar detalhadamente todo o conteúdo técnico da matéria protegida pela patente"(BRASIL. Instituto Nacional da Propriedade Intelectual -INPI, Guia Prático: Patentes. Disponível em: <http://www.inpi.gov.org> Acesso em 18 jan. 2012) .

${ }^{65}$ ORGANIZAÇÃO MUNDIAL DA SAÚDE. The World Medicines Situation. Disponível em: <http://www.who.int/medicines/areas/policy/world_medicines_situation/en/index.html.>. Acesso em: 27 mar. 2012.
} 
A OMS elaborou recomendações que podem contribuir para a regulação mais eficaz do mercado farmacêutico. Essa organização formulou diferentes diretrizes regulatórias a serem adotadas em relação à demanda pública e à demanda privada de medicamentos.

Em relação à compra de medicamentos pelo setor público, a OMS aconselhou o aumento de recursos destinados à compra de medicamentos, a preferência por gastos com medicamentos genéricos em detrimento dos medicamentos de referência, bem como a priorização de gastos com medicamentos destinados à assistência primária. A Organização Mundial da Saúde ainda sugeriu que para aumentar a disponibilidade de medicamentos os países devem priorizar os medicamentos essenciais, mantendo listas nacionais atualizadas e, no caso de medicamentos sob patentes, estimular a substituição terapêutica, realizar negociações diretas de preços com os fabricantes e utilizar as flexibilidades previstas no TRIPS, tais como a licença compulsória por motivos de saúde pública. Além disso, indicou que os governos dessem preferência para as compras de medicamentos, em conjunto, por instituições públicas, utilizando procedimentos licitatórios. Ademais, a OMS considera ineficiente a regulação de produtos de "origem múltipla", ou seja, de medicamentos que possuam o equivalente genérico. Segundo essa entidade internacional, fixar preço máximo de venda ao público para medicamentos genéricos implica, na verdade, a fixação de um preço mínimo de venda. Isso ocorre porque os produtos genéricos tenderiam a ser vendidos pelo preço máximo permitido ou muito próximo desse preço. A OMS acredita que a regulação de preços de medicamentos genéricos, na verdade, tem o efeito de limitar a concorrência e conduzir à prática de maiores preços. ${ }^{66}$

No que concerne ao setor privado, em que as compras são realizadas pelos consumidores particulares, em varejo, a Organização Mundial da Saúde sugeriu que os governos zelassem pela boa qualidade dos medicamentos genéricos ofertados, exigissem dos médicos a substituição da prescrição de medicamentos de referência pelos equivalentes genéricos, realizassem controle de margens e eliminassem taxas e impostos sobre os medicamentos prescritos. Isso tudo com a finalidade de diminuir os gastos dos consumidores na compra de medicamentos. ${ }^{67}$

Sobre a questão da dificuldade de acesso a medicamentos em razão dos altos preços desses produtos, sabe-se que em circunstâncias em que os preços dos medicamentos são

${ }^{66}$ ORGANIZAÇÃO MUNDIAL DA SAÚDE. Precios de los medicamentos: una nueva forma de medirlos. Disponível em:<http://apps.who.int/medicinedocs/en/d/Js6163s/2.5.html>. Acesso em 27 mar. 2012.

${ }^{67}$ Ibid. 
altos em relação à renda média da população, muitas pessoas podem não ter condições de adquiri-los, tendo de enfrentar o dilema de tratar a saúde ou se endividarem. Na última situação, os dispêndios com medicamentos podem ocasionar o empobrecimento de parcela da população, que passa a ter renda inferior a U\$ 2,00 ao dia (critério de definição de pobreza utilizado pelo Banco Mundial). ${ }^{68}$

No Brasil, o acesso a medicamentos também é marcado pela iniquidade. Conforme evidenciam os dados da tabela abaixo, as famílias de menor renda correspondem à maior parte da população brasileira e são as mais oneradas, visto que possuem maiores dificuldades para adquirir medicamentos (Tabela 1).

Tabela 1. População Brasileira - Perfil X Renda e Acesso a Medicamentos e Serviços de Saúde

\begin{tabular}{llccc}
\hline Classe & Renda per Capta & Distribuição (\%) & $\begin{array}{c}\text { Dificuldade para } \\
\text { Comprar remédios } \\
(\%)\end{array}$ & $\begin{array}{c}\text { Cobertura de } \\
\text { Planos de } \\
\text { SaúdePrivados (\%) }\end{array}$ \\
\hline A & $>5.800$ & 5 & Nenhum & 78 \\
B & $2.325-5.800$ & 14 & $30-40$ & 53 \\
C & $930-2.325$ & 31 & $50-65$ & 29 \\
D & $<930$ & 50 & Acima de 65 & 8 \\
\hline
\end{tabular}

Fonte: Adaptado de IMS HEALTH. 1 tabela, color. Disponível em: <www.imshealth.com>. Acesso em: 14 abr. 2012.

Além disso, os dados coletados pelo IBGE confirmaram que, de fato, no que toca à porcentagem da renda familiar destinada a suprir gastos com medicamentos, as famílias de menor renda são mais oneradas. Conforme se extrai de análise da Pesquisa de Orçamentos Familiares do IBGE (2008-2009), as famílias de menos recursos gastam maior fração da renda familiar com assistência à saúde e com medicamentos (Tabela 2).

\footnotetext{
${ }^{68}$ Foi conduzido estudo empírico que gerou índices de empobrecimento para quatro medicamentos, em 16 países de pequena e média renda, medindo a renda per capita de famílias antes e depois da compra de pelo menos um dos medicamentos selecionados. A constatação dos autores do estudo foi de que $86 \%$ da população dos países analisados seria conduzida à situação de miséria, caso todas adquirissem ao menos um dos medicamentos selecionados. (NIËNS. L. M.; et al. Quantifying the impoverishing effects of purchasing medicines: a cross-country comparison of the affordability of medicines in the developing world. PLoS Med, v.7, n.8, p.1-8, ago. 2010).
} 
Tabela 2. Dados sobre gastos com medicamentos extraídos da Pesquisa de Orçamentos Familiares - POF (2008-2009).

\begin{tabular}{|c|c|c|c|c|c|c|c|c|}
\hline & Total & $\begin{array}{c}\text { Abaixo } \\
\text { de } \\
\text { R } \$ 830\end{array}$ & $\begin{array}{c}\mathrm{R} \$ 830 \\
\mathrm{a} \\
\mathrm{R} \$ 1.245\end{array}$ & $\begin{array}{c}\mathrm{R} \$ 1.245 \\
\mathrm{a} \\
\mathrm{R} \$ 2.490\end{array}$ & $\begin{array}{c}\mathrm{R} \$ 2.490 \\
\mathrm{a} \\
\mathrm{R} \$ 4.150\end{array}$ & $\begin{array}{c}\mathrm{R} \$ 4.150 \\
\mathrm{a} \\
\mathrm{R} \$ 6.225\end{array}$ & $\begin{array}{c}\mathrm{R} \$ 6.225 \\
\mathrm{a} \\
\mathrm{R} \$ 10.375\end{array}$ & $\begin{array}{c}\text { Acima } \\
\text { de } \\
\mathrm{R} \$ \\
10.375\end{array}$ \\
\hline $\begin{array}{l}\text { Porcentagem total de } \\
\text { gastos mensais com } \\
\text { medicamentos - } \\
\text { Assistência à Saúde }\end{array}$ & $48,59 \%$ & $75,9 \%$ & $72,76 \%$ & $61,81 \%$ & $48,80 \%$ & $40,70 \%$ & $31,87 \%$ & $34,46 \%$ \\
\hline $\begin{array}{l}\text { Gastos mensais com } \\
\text { medicamentos (em } \\
\text { Reais) }\end{array}$ & 74,74 & 31,00 & 49,27 & 67,87 & 90,53 & 111,05 & 139,60 & 271,32 \\
\hline $\begin{array}{l}\text { Porcentagem da } \\
\text { renda familiar } \\
\text { destinada à compra } \\
\text { de medicamentos }\end{array}$ & 2,8 & 4,2 & 4,4 & 3,7 & 2,9 & 2,3 & 1,9 & 1,9 \\
\hline
\end{tabular}

Fonte: Elaboração própria, a partir de dados do POF (2008-2009).

Embora o importe gasto com medicamentos aumente conforme a elevação da renda familiar, a demanda por esses produtos tende a ser inelástica e regressiva. ${ }^{69}$ Disso decorre que a variação da renda parece influir mais na decisão de gastar do que propriamente na decisão do montante que se irá gastar. ${ }^{70}$

As informações extraídas do POF (2008-2009) indicam que as participações das despesas com assistência à saúde foram similares nas diferentes faixas de renda familiar. No entanto, a composição desses gastos difere bastante. Para a classe cuja renda familiar é de até $\mathrm{R} \$ 830,00$, os remédios pesam $4,2 \%$, ou seja, correspondem a $75,9 \%$ do dispêndio com saúde; enquanto que a participação do gasto com medicamentos para a classe oposta é de $34,46 \%$.

No entanto, os preços dos medicamentos não são um problema apenas para a população. O poder público também é sobrecarregado em razão do alto custo desses produtos. Portela aponta que, em 1997, os gastos do Sistema Único de Saúde com medicamentos estratégicos ${ }^{71}$ incidiram no patamar de 313,8 milhões de reais, tendo

\footnotetext{
${ }^{69}$ LISBOA, M., FIUZA, E.; VIEGAS, M.; FERRAZ, L. Política governamental e regulação do mercado de medicamentos. Rio de Janeiro: FGV, 2001. p.9.

${ }^{70}$ Ibid.

${ }^{71}$ Medicamentos estratégicos são aqueles utilizados na assistência farmacêutica dos seguintes programas: DST-AIDS, Pneumonia Sanitária (tuberculose), Hanseníase, Controle de Endemias (malária, esquistossomose, tracoma, leishmaniose, meningite, cólera, filariose e outros), Diabetes e Hemofilia
} 
evoluído para alcançar 987,4 milhões de reais, em $2002 .{ }^{72}$ Esse crescimento foi da ordem de $214,6 \%$.

O gráfico abaixo explicita a evolução dos gastos do Ministério da Saúde com medicamentos, incluindo os estratégicos, e a parcela do orçamento da saúde destinada à assistência farmacêutica, no período de 2005 a 2008 (Gráfico 2). Esse padrão de crescimento dos gastos com medicamentos pode ser explicado com base no aumento de demandas judiciais referentes ao fornecimento de remédios de alto custo pelo Estado, dentre outros fatores. ${ }^{73}$

Gráfico 2. Comparação entre a despesa total com saúde e a despesa com assistência farmacêutica (federal, estadual e municipal) entre 2005 e 2008.

Evolução dos gastos do Ministério da Saúde com medicamentos

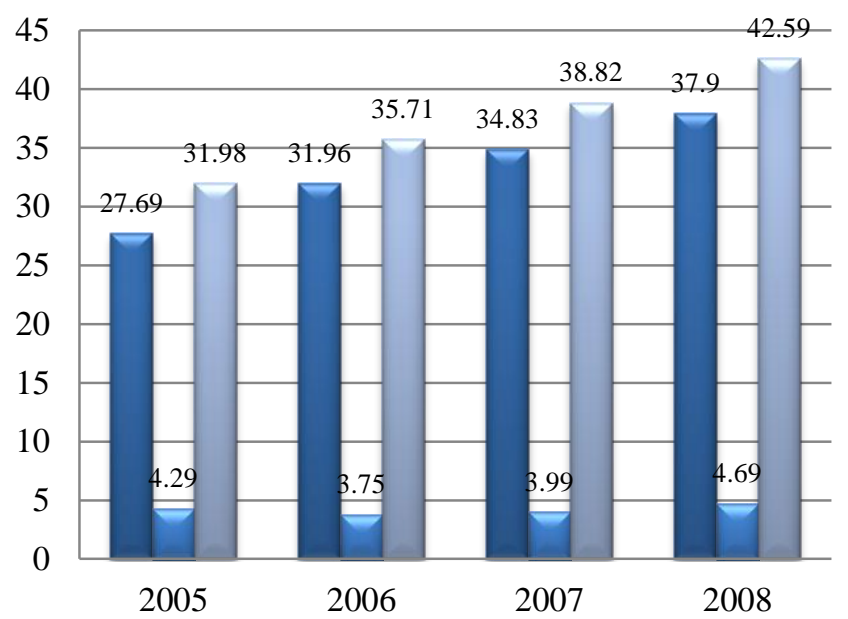

Outras despesas (deflacionadas pelo IPCA - 2008)

๑Despesas Assistência Farmacêutica (deflacionada pelo IPCA - 2008)

Fonte: Adaptado de BRASIL. Instituto de Pesquisa Econômica Aplicada (IPEA). Comparação entre a despesa total com saúde e a despesa com assistência farmacêutica (federal, estadual e municipal) entre 2005 e 2008. [2008]. 1 gráfico, color. Disponível em: <http://www.ipea.gov.br/agencia/images/stories/PDFs/100826_radar09_aprest_samuelcesar.pdf>. Acesso em: 28 mai. 2012.

Como dito anteriormente, para amenizar a difícil situação do acesso a medicamentos no país, em 2003, foi instituída a política de regulação do mercado de medicamentos ${ }^{74}$ centralizada na CMED, órgão regulador responsável por promover a

\footnotetext{
${ }^{72}$ PORTELA, A. S. et al. Políticas públicas de medicamentos: trajetórias e desafios. Revista de Ciências Farmacêuticas Básica e Aplicada, São Paulo, v.31, n.1. p. 9-14, abr. 2010. p.12

${ }^{73}$ FERRAZ, O. L.; VIEIRA, F. S. Direito à saúde, políticas públicas e desigualdades sociais no Brasil: a equidade como princípio fundamental. Paper apresentado na Faculdade de Direito da Universidade de São Paulo, em setembro de 2007.

${ }^{74} \mathrm{O}$ retorno de políticas regulatórias à agenda do governo brasileiro se deveu, principalmente, à "Crise dos Medicamentos”, na década de 1990. Essa crise foi causada, eminentemente, pela ausência de regulação do
} 
assistência farmacêutica. Partindo do pressuposto de que o acesso a medicamentos deve se basear em diferentes frentes de atuação governamental ${ }^{75}$, a política regulatória mediante $o$ controle dos preços visa atuar em uma dessas frentes, facilitando a compra em varejo de medicamentos pela população. Tal política tem o propósito de promover o acesso a medicamentos pela população e será estudada mais adiante, em capítulo específico.

\subsection{O mercado farmacêutico e a indústria de medicamentos}

Antes de adentrar no tema da política regulatória praticada pela CMED, cerne desta dissertação de mestrado, é necessário verificar as principais características do mercado de medicamentos e da indústria farmacêutica, uma vez que determinados traços desses setores da economia provocam e justificam a necessidade de regulação pelo Estado. ${ }^{76}$

Conforme visto anteriormente, no Brasil, os medicamentos têm um alto peso no consumo das famílias, especialmente, das mais pobres. Os reajustes dos preços desses produtos são, normalmente, realizados acima da inflação, quando não controlados pelo governo. Essa situação pode ser explicada por características da indústria farmacêutica e importantes falhas de mercado.

São características do mercado farmacêutico ${ }^{77}$ global e da indústria de medicamentos ${ }^{78}$ :

mercado e pela crise cambial e originou a CPI dos medicamentos que verificou a ausência de regulação como um dos problemas do setor farmacêutico brasileiro.

${ }^{75}$ Semelhante ao que conclui a Organização Mundial da Saúde e deixando de lado apenas a questão do uso e da prescrição racional de medicamentos, Portela et al. explicam que há mais de um fator que interfere na assistência farmacêutica. É dever do Estado atuar sobre todos aqueles fatores que influenciam o acesso a medicamentos. São esses fatores o acesso geográfico, no qual os produtos podem ser obtidos dentro de uma distância razoável; o acesso imediato ou disponibilidade contínua, por meio da qual os medicamentos estão prontamente disponíveis nos postos públicos de saúde; e o acesso econômico ou disponibilidade funcional, em que os serviços e produtos estão disponíveis no mercado de acordo o volume adequados a suprir a demanda e as necessidades de saúde da população, a um preço razoável (ORGANIZAÇÃO MUNDIAL DA SAÚDE - OMS. The world medicines situation. 2004. Disponível em:〈http://www.who.int> Acesso em: 2 jan. 2012; e PORTELA, A. S. et al. Políticas públicas de medicamentos: trajetórias e desafios. Revista de Ciências Farmacêuticas Básica e Aplicada, São Paulo, v.31, n.1. p. 9-14, abr. 2010. p. 12).

${ }^{76} \mathrm{Cf}$. Capítulo 1.

${ }^{77}$ Mercado é o lugar, eventualmente abstrato, "onde as ofertas dos vendedores encontram as procuras dos compradores e estas se ajustam àquelas a dado preço [...] é, pois, uma forma de confrontar oferta e procura a fim de realizar uma troca de serviços, de produtos ou de capitais" (GÉLEDAIN, A.; BRÉMOND, J. Dicionário econômico e social. Lisboa: Livros Horizonte, 1988. p.223). O mercado farmacêutico é, nesse sentido, o locus físico ou abstrato em que se promove a oferta de bens produzidos pela indústria farmacêutica aos seus compradores.

${ }^{78} \mathrm{~A}$ indústria farmacêutica, por sua vez, pode ser definida como o segmento de empresas comerciais dedicadas ao design, ao desenvolvimento e à manufatura de produtos químicos usados em diagnósticos e tratamentos de doenças, incapacidades ou outras disfunções ou na melhora de capacidade (Tradução livre da definição de "pharmaceutical industry" do "Dictionary of Medical Conditions Terminology", qual seja: "Pharmaceutical Industry: that segment of commercial enterprise devoted to the design, development, and 
a) Alto investimento em Pesquisa e Desenvolvimento (P\&D) e produção de inovação.

Nos Estados Unidos, maior produtor mundial de medicamentos, a indústria farmacêutica é a líder em gastos em pesquisa e desenvolvimento. Nos últimos 25 anos, as despesas nessa área aumentaram significativamente: em 1980, a indústria farmacêutica norte-americana investiu 5,5 bilhões de dólares em P\&D, enquanto que, em 2003, esse investimento atingiu o patamar de 39 bilhões. ${ }^{79}$ Os gastos em pesquisa e desenvolvimento para a produção de inovação não seriam tão relevantes se a indústria farmacêutica não utilizasse como instrumento de proteção da propriedade intelectual as patentes. Esse instrumento jurídico de proteção da propriedade intelectual propicia um período de reserva de mercado à empresa inovadora, no qual é possível recuperar o montante investido na concepção de novas tecnologias no setor, incentivando próximos investimentos em inovação. ${ }^{80}$

b) Pulverização econômica como um todo e concentração por classe terapêutica. $^{81}$

A indústria farmacêutica, em geral, não é concentrada. Nesse sentido, explicam Fiúza e Lisboa:

As 20 maiores companhias farmacêuticas mundiais participavam com $52,6 \%$ das vendas globais, em 1996, com a maior delas chegando apenas a 4,4\%. No Brasil, a concentração é maior, mas nem tanto: as 20 maiores empresas do setor detinham, em 1998, 63\% do mercado total, sendo que a maior delas, a Novartis, dominava apenas $6,5 \%$ do mercado. O produto mais vendido, o Cataflam, também da Novartis, detinha apenas 1,5\% do

manufacture of chemical products for use in the diagnosis and treatment of disease, disability, or other dysfunction, or to improve function." Disponível em: $<$ www.medconditions.net $>$ Acesso em: 8 jan.2012.)

${ }^{79}$ ESTADOS UNIDOS DA AMÉRICA. Congresso dos Estados Unidos da América. Research and development in the pharmaceutical industry. Estudo realizado pelo Departamento de Orçamento do Congresso (Congressional Budget Office-CBO), em outubro de 2006. p. 7.

${ }^{80}$ BARROS, Henrique. M. Motivations to patent: the case of pharmaceuticals. REAd, Porto Alegre, v.14, n.3, set./dez.2008. p. 7.

${ }^{81}$ Conforme explica Marislei Nishijima, "as classes terapêuticas se constituem em um agrupamento de medicamentos de acordo com sua atuação anatômica, sua indicação, seu uso terapêutico, sua composição e seu modo de ação, não sendo, todavia, um critério de classificação único e rigidamente fechado. A divisão dos medicamentos, por classe terapêutica, utilizada com mais freqüência é a Anatomical Therapeutic Classification(ATC), (...). No limite, entretanto, o mercado específico de uma classe terapêutica pode ser um determinado medicamento de referência e seus genéricos, que constitui o mercado por princípio ativo." (NISHIJIMA, M. Análise econômica dos medicamentos genéricos no Brasil. 2003. Tese (Doutorado em Economia) - Faculdade de Economia, Administração e Contabilidade. Universidade de São Paulo, São Paulo, 2003. p. 23). 
mercado total. No entanto, essa pulverização é aparente e esconde uma situação de alta concentração do mercado por classe terapêutica ou por patologias. ${ }^{82}$

O índice de concentração do mercado farmacêutico nacional se manteve estável na última década, de tal sorte que os dez maiores laboratórios atuantes no Brasil detiveram domínio sobre 44,2\% do mercado, em 1998, e 44,1\% em 2007. Esses dados não divergiram em grandes proporções do grau de concentração do mercado mundial, em que os 10 maiores laboratórios detinham $48 \%$ do mercado, em 2002, e $45 \%$ em $2007 .{ }^{83}$ Conforme explicita a tabela abaixo, em 2007, o mercado nacional era dividido entre as empresas farmacêuticas da seguinte forma (Tabela 3):

Tabela 3. Concentração do mercado farmacêutico em diferentes países do mundo.

\begin{tabular}{|c|c|c|c|c|c|}
\hline Empresa & $\begin{array}{l}\text { País de } \\
\text { origem }\end{array}$ & $\begin{array}{c}\text { Participação no } \\
\text { mercado }(\%) \\
1998\end{array}$ & Empresa & $\begin{array}{l}\text { País de } \\
\text { origem }\end{array}$ & $\begin{array}{c}\text { Participação no } \\
\text { mercado }(\%) \\
2007\end{array}$ \\
\hline Novartis & Suiça & 6,3 & EMS Sigma Pharma & Brasil & 7,1 \\
\hline Roche & Suiça & 5,5 & Sanofi-Aventis & França & 6,4 \\
\hline $\begin{array}{l}\text { Bristol-Meyers } \\
\text { Squibb }\end{array}$ & EUA & 5,4 & Ache & Brasil & 5,6 \\
\hline $\begin{array}{l}\text { Hoechst Marion } \\
\text { Roussel }\end{array}$ & Alemanha & 5,2 & Medley & Brasil & 5,5 \\
\hline Aché/Prodome & Brasil & 4,7 & Novartis & Suiça & 4,4 \\
\hline Janssen Cilag & Bélgica & 3,7 & Eurofarma & Brasil & 4,4 \\
\hline Boehringer Ing. & Alemanha & 3,7 & Pfizer & EUA & 3,4 \\
\hline Glaxo Wellcome & Reino Unido & 3,5 & $\begin{array}{c}\text { Bayer Schering } \\
\text { Plough }\end{array}$ & Alemanha & 3,2 \\
\hline Schering Plough & Alemanha & 3,2 & Boehringer Ing. & Alemanha & 2,6 \\
\hline Eli Lilly & EUA & 3,0 & Nycomed & Dinamarca & 2,4 \\
\hline Demais empresas & & 55,8 & Demais empresas & & 55,9 \\
\hline
\end{tabular}

Fonte: Adaptado de CALIARI, T.; RUIZ R. Structure and innovation in pharmaceutical industry in Brazil: the impact of generic drugs. Paper apresentado na Academia DRUID - DIME, inverno de 2010. Disponível em:<http://petecounb.files.wordpress.com/2012/05/teste12.pdf>. Acesso em: 12 jan. 2013.

No entanto, existem poucos líderes por mercados particulares ou por classe terapêutica, que tendem a a apresentar estruturas mais concentradas, tais como monopólios

\footnotetext{
${ }^{82}$ LISBOA, M., FIUZA, E.; VIEGAS, M.; FERRAZ, L. Política governamental e regulação do mercado de medicamentos. Rio de Janeiro: FGV, 2001. p. 2.

${ }^{83}$ Adaptado de CALIARI, T.; RUIZ R. Structure and innovation in pharmaceutical industry in Brazil: the impact of generic drugs. Paper apresentado na Academia DRUID - DIME, inverno de 2010. Disponível em:<http://petecounb.files.wordpress.com/2012/05/teste12.pdf>. Acesso em: 12 jan. 2013.
} 
e oligopólios. ${ }^{84}$ Os mercados particulares ou especializados são aqueles relativos aos princípios ativos ou às classes terapêuticas. A título de ilustração, um mercado específico pode ser aquele correspondente a um medicamento de referência e seus equivalentes genéricos, constituindo um mercado especializado por princípio ativo. Nesse sentido, o mercado farmacêutico é um setor oligopolizado ou monopolizado, variando de acordo com o mercado específico analisado.

c) Prevalência da proteção da propriedade industrial sob a forma de patentes.

As patentes de medicamentos surgiram na década de 1940, quando novas técnicas foram desenvolvidas para a purificação e o isolamento da estreptomicina. A partir desse momento, o U.S. Patent Office passou a reconhecer o patenteamento de modificações químicas que criam um novo produto. Desde então, as empresas farmacêuticas inovadoras utilizam patentes para restringir o acesso aos seus produtos e monopolizar temporariamente o mercado. É durante essa fase que a empresa inovadora extrai renda capaz de suprir os gastos anteriormente realizados com a pesquisa e desenvolvimento daquele produto ou de outros que não obtiveram sucesso comercial, praticando preços monopolísticos. ${ }^{85} 86$

Disso se extrai que as patentes desempenham um papel essencial na indústria farmacêutica. Segundo Mansfield, em clássico estudo sobre o assunto, em 1986, 65\% das invenções da indústria farmacêutica não teriam sido lançadas e $60 \%$ não teriam sido desenvolvidas na ausência de proteção por patentes. ${ }^{87}$ Esses dados foram frutos de uma pesquisa empírica baseada na aplicação de questionários a cem empresas aleatoriamente selecionadas dentre doze setores da indústria de transformação nos EUA, inclusive o setor

${ }^{84}$ NISHIJIMA, M. Análise econômica dos medicamentos genéricos no Brasil. 2003. Tese (Doutorado em Economia). Faculdade de Economia, Administração e Contabilidade da Universidade de São Paulo. São Paulo. p. 23 e ROSENBERG, G.; FONSECA, M.G.D; D’ÁVILA L.A. Análise comparativa da concentração industrial e de turnover da indústria farmacêutica no Brasil para os seguimentos de medicamentos de marca e genéricos. Economia e sociedade, Campinas, v.19, n. 1(38), 107-134, abr.2010. p. 130.

${ }^{85}$ CAPANEMA, L. X. de. A indústria farmacêutica brasileira e a atuação do BNDES. BNDES Setorial, Rio de Janeiro, n.23, p.193-216, mar.2006. p. 198.

${ }^{86}$ Registra-se que o ciclo dos produtos farmacêuticos se resume a três fases: (i) fase em que os laboratórios são altamente competitivos no que diz respeito à produção de inovação e investimento em pesquisa e desenvolvimento; (ii) fase de sobrevivência de poucas substâncias de sucesso cujo patenteador goza de um período de monopólio em que sofre a concorrência apenas de medicamentos similares, isto é, compostos diversos, porém, terapeuticamente equivalentes; (iii) por fim, fase correspondente à expiração da patente e ao aumento do grau de competição do mercado, em razão do surgimento de substitutos diretos, isto é, medicamentos genéricos (FIUZA, E.;LISBOA, M. Bens credenciais e poder de mercado: um estudo econométrico da indústria farmacêutica brasileira. Disponível em: <http://www.ipea.gov.br/pub/td/2001/td_0846.pdf>. Acesso em: 22 jul. 2010).

${ }^{87}$ MANSFIELD, E. Patents and innovation: an empyrical study. Management Science, NY, v. 32, n.2, p. 173-181, fev. 1986. p. 175. 
farmacêutico. $\mathrm{O}$ autor pôde concluir que a eficácia desse mecanismo como meio de proteger retornos de inovações industriais no setor farmacêutico é superior à média dos outros setores entre $40 \%$ e $51 \%{ }^{88}$ A razão para isso é o fato de que o objeto da patente é o composto químico ou a própria molécula e não a função que ela desempenha ou o processo pelo qual ela é produzida. Isso evita que o mesmo composto seja produzido por processos químicos diversos e possibilita que compostos muitos semelhantes e com a mesma função obtenham patentes diferentes.$^{89} \mathrm{~A}$ consequência dessa situação é a existência de uma distorção, sendo possível questionar quantas inovações da indústria farmacêutica consistem, realmente, em novo benefício para os consumidores. ${ }^{90}$

d) Risco da atividade

Outro traço característico da indústria farmacêutica consiste em lidar com doenças e com a produção de medicamentos que podem ser (i) ineficazes no tratamento a que se propõem, (ii) caros demais em comparação aos benefícios que proporcionam, e (iii) arriscados, podendo causar outra doença e até a própria morte do paciente. ${ }^{91}$

e) Forma de competição predominante extra-preços

Como se viu, a indústria farmacêutica caracteriza-se pela concentração do mercado no que concerne às classes e subclasses terapêuticas. Nos mercados oligopolizados, verifica-se uma forte tendência à estabilidade e rara flutuação dos preços dos medicamentos. A disputa concorrencial através de preços indica a obstrução dos canais de comunicação entre uma empresa e outra. ${ }^{92}$

\footnotetext{
${ }^{88}$ MANSFIELD, E. Patents and innovation: an empyrical study. Management Science, NY, v. 32, n.2, p. 173-181, fev. 1986. p. 14. Vale lembrar que apesar das patentes serem consideradas instrumentos eficazes na proteção da propriedade intelectual, existe debate acerca da adequação desse mecanismo de proteção da propriedade intelectual no caso dos medicamentos, tendo em vista as consequiências negativas em relação à concretização do direito à saúde, nos países em desenvolvimento. Consoante já mencionado previamente, este estudo não tem a pretensão de adentrar neste debate. (Nesse sentido ver: MAGAJEWSKI, F. L.; CURCIO, A. L. M. C. Direito De Propriedade Industrial: Uma Proposta de Regime Jurídico Especial às Patentes de Medicamentos. Disponível em: <http:// www.conpedi.org.br/anais/36/06_1423.pdf> . Acesso em: 15 mai.2012.)

${ }^{89}$ FIUZA, E.; LISBOA, M. Bens credenciais e poder de mercado: um estudo econométrico da indústria farmacêutica brasileira. Disponível em: <http://www.ipea.gov.br/pub/td/2001/td_0846.pdf.> Acesso em: 22 jul. 2010.

${ }^{90}$ Cf. nota 7, p. 4 .

${ }^{91}$ MACHADO DOS SANTOS, C. S. Melhoria na equidade no acesso aos medicamentos no Brasil: os desafios impostos pela competição extra-preço, 2001. Dissertação (Mestrado em Saúde Pública) - Escola Nacional de Saúde Pública, FIOCRUZ, Rio de Janeiro, 2001. p. 78.

${ }^{92}$ Ibid. p. 78.
} 
A forma predominante de concorrência no mercado farmacêutico é, portanto, extrapreço e se evidencia tanto no caso das empresas produtoras, quanto distribuidoras e drogarias que comercializam os produtos com foco no consumidor final. A concorrência extra-preço presente no mercado farmacêutico consiste na diferenciação dos produtos e na utilização de estratégias de marketing. ${ }^{93}$

A diferenciação dos produtos se baseia principalmente no lançamento de novos medicamentos que, na maioria das vezes, não agregam nenhum benefício terapêutico efetivo. Muitas drogas consideradas novas correspondem ao mesmo princípio ativo presente no mercado, embora com modificações de natureza secundária à molécula básica. ${ }^{94}$

A utilização de estratégias de marketing possui alicerces na consolidação de marcas. Os gastos com marketing são considerados custos fixos para a empresa produtora de medicamentos, uma vez que são necessários em grande quantidade para a divulgação do produto e para organização das vendas. ${ }^{95}$ Em seu estudo intitulado "A verdade sobre os laboratórios farmacêuticos", Marcia Angell revela que a indústria farmacêutica investe mais recursos em marketing do que pesquisa em desenvolvimento. ${ }^{96}$ Sobre o alto gasto do setor farmacêutico com propaganda, vale lembrar que se trata de uma barreira natural, cujo objetivo é criar fidelidade à marca. ${ }^{97}$

f) Empresas líderes de grande porte e atuação globalizada.

As empresas líderes do mercado farmacêutico são de grande porte e atuam no mercado global. Tais empresas se pautam na interdependência entre as estratégias perseguidas por cada grupo nos distintos mercados nacionais e entre os diferentes competidores. $^{98}$

\footnotetext{
${ }^{93}$ MACHADO DOS SANTOS, C. S. Melhoria na equidade no acesso aos medicamentos no Brasil: os desafios impostos pela competição extra-preço, 2001. Dissertação (Mestrado em Saúde Pública) - Escola Nacional de Saúde Pública, FIOCRUZ, Rio de Janeiro, 2001. p.61.

${ }^{94}$ FRENKEL, J. O mercado farmacêutico brasileiro: a sua evolução recente, mercados e preços. In: NEGRI, B; DI GIOVANNI, G. Brasil: radiografia da saúde. Campinas: UNICAMP, 2001. p. 157-174; IMSHEALTH, Country Review: Brazil, 2011. Disponível em:<http://www.imshealth.com>. Acesso em: 2. jan.2012.

${ }^{95}$ MACHADO DOS SANTOS, C. S. op. cit. p. 67.

${ }^{96}$ ANGELL, M. A verdade sobre os laboratórios farmacêuticos. São Paulo: Record, 2007.

${ }^{97}$ NISHIJIMA, M. Análise econômica dos medicamentos genéricos no Brasil. 2003. Tese (Doutorado em Economia). Faculdade de Economia, Administração e Contabilidade da Universidade de São Paulo. São Paulo. p. 20.

${ }^{98}$ VARGAS, M. A. et al. Reestruturação na indústria farmacêutica mundial e seus impactos na dinâmica produtiva e inovativa do setor farmacêutico brasileiro. Disponível em: $\langle$ http://www.fiocruz.br > Acesso em: 12 jan. 2012. p. 11.
} 
O mercado farmacêutico também é, especificamente, incapaz de se regular, em função da presença de falhas de mercado. ${ }^{99}$ Assim, boa parte dos governos assume a tarefa de regulação desse mercado, controlando a venda de medicamentos, inclusive no que diz respeito ao quesito segurança. ${ }^{100}$

São falhas do mercado de medicamentos que justificam a interferência estatal nesse setor: ${ }^{101}$

a) A presença de monopólios e oligopólios

Os monopólios e oligopólios causam elevado grau de discricionariedade por parte de poucas empresas na determinação dos preços dos medicamentos. Conforme mencionado anteriormente, por classe terapêutica, são poucos os laboratórios que administram a produção, sendo comum a concentração do mercado. ${ }^{102}$

Embora já tenha sido abordada a questão da concentração do mercado farmacêutico neste trabalho, é importante ressaltar que os monopólios são normalmente estabelecidos juridicamente, com respaldo no sistema de proteção da propriedade intelectual que inclui os direitos patentários. Sua justificativa é eminentemente concorrencial. Eles impedem o free-riding $^{103}$ e garantem a recuperação do montante investido em pesquisa e desenvolvimento, além de servirem ao estímulo criativo.

\footnotetext{
${ }^{99}$ BRASIL. Agência Nacional de Vigilância Sanitária. Regulação econômica do mercado farmacêutico. Disponível em: <http://www.anvisa.gov.br>. Acesso em: 03 mar. 2011.

${ }^{100} \mathrm{Nem}$ sempre a segurança dos medicamentos foi devidamente controlada pelo poder público. Com o passar do tempo, os governos se viram obrigados exigir que os laboratórios submetessem seus medicamentos novos a testes de segurança, antes de autorizar a comercialização. Por essa razão, durante um período de tempo, o prazo de vigência da patente foi encurtado. Posteriormente, foram concebidas, nos mais variados países, medidas legislativas de extensão do prazo das patentes, aumentando ainda mais o período de monopólio dos laboratórios inovadores (DIMASI, J. A. et al. Cost of innovation in the pharmaceutical industry. Journal of Health Economics, Boston, v.10, n.2, p. 107-142, jul. 1991. p. 235). A apuração dos requisitos de segurança, exigidos para a aprovação de medicamentos, demandam dos laboratórios farmacêuticos a realização de dispendiosos testes, inclusive em seres humanos, o que eleva os custos de desenvolvimento de novos medicamentos. Nos anos 1980, o custo médio de produção de um medicamento variava entre 140 e 280 milhões de dólares. Já nos anos 1990, esse valor atingiu o teto de 350 milhões (FAGAN, P. As gigantes farmacêuticas: prontas para o século XXI? Cambridge: Harvard Business School, 1998. p.431).

${ }^{101}$ VENTURI, C. B. et al. Política de patentes e o direito da concorrência. In: Política de patentes em saúde humana. SANTINI, M. F.; ARANHA, M. I. (orgs.). São Paulo: Atlas, 2001, p.154-189. p. 170.

${ }^{102}$ Ibid., p. 170.

${ }^{103}$ Free-riding consiste na apropriação dos lucros por parte daquele que não investiu em Pesquisa e Desenvolvimento - P\&D. Segundo Calixto Salomão Filho, é o aproveitamento por parte daquele que não investiu na pesquisa dos resultados dela advindos (SALOMÃO FILHO, C. Razoabilidade e legalidade do licenciamento compulsório do ponto de vista concorrencial. In: BASSO, M. et al. Direito da propriedade intelectual e saúde pública: o acesso universal aos medicamentos anti-retrovirais. São Paulo: Instituto de Direito do Comércio Internacional e Desenvolvimento -IDCID, 2007. p.155 )
} 
b) Assimetria de informação

Os mercados de bens e serviços de saúde são marcados pela assimetria de informação causada, eminentemente, pela característica de bens credenciais assumida pelos medicamentos. Os fármacos são bens credenciais, pois sua qualidade jamais poderá ser aferida, a não ser se submetidos à análise de um profissional especializado. ${ }^{104}$ Assim, na maioria das vezes, médicos, farmacêuticos e pacientes dependem das informações prestadas pelos fabricantes dos medicamentos, de modo que pouco sabem sobre a qualidade, segurança, eficácia e preço dos remédios. ${ }^{105}$ Outro fator responsável pela presença de assimetria de informações no mercado de medicamentos é o desconhecimento dos médicos sobre os preços dos genéricos e a existência de reservas quanto à qualidade desse produto em relação ao medicamento de referência. ${ }^{106}$

A assimetria de informação diz respeito, portanto, a dois níveis: (i) a efetividade e segurança do princípio ativo em si e (ii) a efetividade e segurança do medicamento genérico em comparação com o medicamento de referência. Essa falha de mercado poderia ser evitada ou ter seus efeitos atenuados se os dados sobre custo-efetividade dos medicamentos fossem sistematizados e colocados a disposição dos médicos permitindolhes a comparação da eficácia dos remédios entre si. As incertezas sobre a efetividade de um novo medicamento, mesmo que o princípio ativo já seja conhecido, cria um diferencial de qualidade que beneficia a empresa produtora do medicamento de marca. ${ }^{107}$

\footnotetext{
${ }^{104}$ FIUZA, E.; LISBOA, M. Bens credenciais e poder de mercado: um estudo econométrico da indústria farmacêutica brasileira. Disponível em: <http://www.ipea.gov.br/pub/td/2001/td_0846.pdf.> Acesso em: 22 jul. 2010.

${ }^{105} \mathrm{O}$ desconhecimento sobre a qualidade de um bem confere grande importância aos órgãos oficiais de certificação e, diante de sua ausência, ocasiona graves problemas de assimetria de informação. Nessa situação, as marcas pioneiras experimentam considerável vantagem sobre possíveis novos entrantes, configurando uma barreira à entrada, já que uma vez estabelecida determinada marca, os consumidores relutam em substituir seus produtos por outros de qualidade desconhecida.

${ }^{106} \mathrm{~A}$ qualidade de um medicamento desdobra-se nas seguintes dimensões: biodisponibilidade (quanto do princípio ativo é absorvido no fluxo sangüíneo, onde e quanto age terapeuticamente); bioequivalência (dois medicamentos são bioequivalentes se têm a mesma composição química e a mesma biodisponibilidade); e grau de pureza do produto e, portanto, do processo produtivo (FIUZA, E.; LISBOA, M., op. cit.).

${ }^{107} \mathrm{Com}$ relação às informações sobre custo-efetividade de medicamentos, no Sistema Único de Saúde, existe o livro eletrônico "Fundamentos Farmacológicos-Clínicos dos Medicamentos de Uso Corrente". O objetivo do lançamento desse livro foi "equilibrar a informação sobre medicamentos veiculada em propagandas e bulas com revisões de literatura para gerar informação fundamentada em evidências científicas" (ORGANIZAÇÃO MUNDIAL DA SAÚDE -OMS, ORGANIZAÇÃO PAN-AMERICANA DA SAÚDE OPAS, BRASIL - Ministério da Saúde, Avaliação da assistência farmacêutica no Brasil: estrutura, processos e resultados. 2005. Disponível em: <http://www.who.int> Acesso em: 2 jan. 2012). No entanto, esse material não é amplamente divulgado aos médicos do sistema público de saúde e, assim como os cursos de educação continuada de capacitação sobre o uso de medicamentos, sua utilização não é obrigatória. Outro problema identificado no livro é a ausência de informações sobre preços de medicamentos.
} 
c) Separação das decisões sobre prescrição, consumo e financiamento

Os problemas supramencionados não são os únicos que ensejam a assimetria de informação. É importante considerar que quem escolhe o medicamento (o médico) não é a mesma pessoa que o consome (o paciente). Além disso, o pagador pode ser a pessoa do paciente ou outro organismo, tal qual o sistema de saúde público ou o plano de saúde. Isso possibilita que venham à tona interesses contrapostos, como por exemplo, o fato de quem paga querer minimizar os custos, quem consome desejar a melhor qualidade e quem oferta visar o aumento do consumo. Essa dissociação constitui um problema de agência, no qual:

[o] principal (o pagador) quer maximizar a utilidade esperada do paciente, devendo considerar não apenas a probabilidade do estado da natureza em que o paciente goza de boa saúde, mas também os eventuais gastos em tratamento, caso o paciente fique doente. $\mathrm{O}$ agente (o médico), que deveria fazê-lo para o principal, na verdade está preocupado apenas em maximizar a saúde do paciente (ou, pelo menos, minimizar o risco de dano à saúde do paciente e, conseqüentemente, o risco de uma ação judicial), mas não necessariamente se importa com o gasto que ele terá com o remédio ${ }^{108}$

O problema de agência é uma das principais causas dos altos gastos com medicamentos pelas famílias brasileiras.

d) Barreiras à entrada

Há, também, a presença de barreiras à entrada, na maioria das vezes, de caráter institucional, dentre as quais se destacam a economia de escala, os altos investimentos em pesquisa e desenvolvimento, marketing e a fidelidade à marcas. ${ }^{109}{ }^{110}$ Santos considera que as patentes de fármacos e medicamentos, bem como estratégias de comercialização e

\footnotetext{
${ }^{108}$ FIUZA, E.; LISBOA, M. Bens credenciais e poder de mercado: um estudo econométrico da indústria farmacêutica brasileira. Disponível em: <http://www.ipea.gov.br/pub/td/2001/td_0846.pdf.> Acesso em: 22 jul. 2010.

${ }^{109}$ Com base na definição da Lei de Propriedade Industrial, o Instituto Nacional da Propriedade Intelectual INPI - afirma ser a marca "todo sinal distintivo, visualmente perceptível, que identifica e distingue produtos e serviços, bem como certifica a conformidade dos mesmos com determinadas normas os especificações técnicas"(BRASIL. Instituto Nacional da Propriedade Intelectual - INPI, Guia Básico: Marcas. Disponível em: <www.inpi.gov.br> Acesso em: 18 jan. 2012).

${ }^{110}$ NISHIJIMA, M. Análise econômica dos medicamentos genéricos no Brasil. 2003. Tese (Doutorado em Economia) - Faculdade de Economia, Administração e Contabilidade. Universidade de São Paulo, São Paulo, 2003. p.20
} 
fusões e aquisições, também configuram barreiras à entrada de novos competidores no mercado. ${ }^{111}$

\subsection{A indústria e o mercado farmacêutico nacionais}

A indústria farmacêutica brasileira se insere no mesmo contexto, embora possua traços distintivos fundamentais da indústria farmacêutica mundial. No Brasil, o segmento produtor de medicamentos é dependente de indústrias estrangeiras na fabricação de insumos farmoquímicos e na capacidade produtiva de medicamentos ${ }^{112} \mathrm{e}$, por essa razão, a balança comercial relativa a esse setor da economia é deficitária. ${ }^{113}$

A capacidade competitiva da indústria farmacêutica nacional é limitada, principalmente, em razão da dependência de mercado e da utilização de padrões gerenciais inadequados. ${ }^{114}$ Além disso, essa indústria pouco investe em pesquisa e desenvolvimento, de modo que seu dinamismo inovativo está muito aquém da média mundial. ${ }^{115}$ São poucos os pólos farmacêuticos dedicados à produção de tecnologia e aqueles existentes são ligados às universidades públicas que, normalmente, produzem inovações incrementais, deixando de atuar na ponta do desenvolvimento científico e tecnológico. ${ }^{116}$

No início dos anos 2000, a indústria farmacêutica brasileira foi impulsionada pela política dos medicamentos genéricos. Embora sejam de porte reduzido em comparação com os grandes laboratórios multinacionais, muitas dessas empresas figuram como as maiores vendedoras de medicamentos no país. Em 2011, a IMS - Health apurou que dentre os 10 maiores laboratórios farmacêuticos no mercado brasileiro, 4 eram laboratórios de capital nacional: EMS, Aché, Eurofarma e Neoquímica (vide Tabela 4) .

\footnotetext{
${ }^{111}$ MACHADO DOS SANTOS, C. S. Melhoria na equidade no acesso aos medicamentos no Brasil: os desafios impostos pela competição extra-preço, 2001. Dissertação (Mestrado em Saúde Pública) Escola Nacional de Saúde Pública. Rio de Janeiro. p.40.

${ }^{112}$ VARGAS, M. A. et al. Reestruturação na indústria farmacêutica mundial e seus impactos na dinâmica produtiva e inovativa do setor farmacêutico brasileiro. Disponível em:〈http://www.fiocruz.br > Acesso em: 12 jan. 2012.

${ }^{113}$ CAPANEMA, L. X. de. A indústria farmacêutica brasileira e a atuação do BNDES. BNDES Setorial, Rio de Janeiro, n.23, p.193-216, mar.2006. p. 203.

${ }^{114}$ VARGAS, M. A. et al., op. cit.

${ }^{115}$ ALENCAR, R. S. de. Medicamentos no Brasil: uma análise crítica da dinâmica técnica-setorial (19962006). 2007. Dissertação (Mestrado em Desenvolvimento Sustentável) - Centro de Desenvolvimento Sustentável, Universidade de Brasília, Brasília, 2007. p.82.

${ }^{116}$ VARGAS, M. A. et al., op. cit.
} 
Tabela 4. Ranking das Indústrias Farmacêuticas no Brasil (1999-2011) - em dólares

\begin{tabular}{|c|c|c|c|c|c|c|c|c|}
\hline Empresas & 1999 & 2005 & 2006 & 2007 & 2008 & 2009 & 2010 & 2011 \\
\hline SEM Pharma & $29^{\circ}$ & $5^{\circ}$ & $3^{\circ}$ & $1^{\circ}$ & $1^{\circ}$ & $1^{\circ}$ & $1^{\circ}$ & $1^{\circ}$ \\
\hline Medley & 32 & $7^{\circ}$ & $2^{o}$ & $3^{\circ}$ & $3^{\circ}$ & $3^{\circ}$ & $4^{o}$ & $3^{\circ}$ \\
\hline Ache & $3^{\circ}$ & $7^{\circ}$ & $2^{o}$ & $3^{\circ}$ & $3^{\circ}$ & $3^{\circ}$ & $4^{\circ}$ & $3^{\circ}$ \\
\hline Sanofi-Aventis & $1^{\mathrm{o}}$ & $2^{\circ}$ & $1^{\mathrm{o}}$ & $2^{\circ}$ & $2^{\circ}$ & $2^{o}$ & $3^{\circ}$ & $4^{\circ}$ \\
\hline Eurofarma & $28^{\circ}$ & $9^{\circ}$ & $9^{\circ}$ & $8^{\circ}$ & $7^{\circ}$ & $5^{\circ}$ & $5^{\circ}$ & $5^{\circ}$ \\
\hline Novartis & $2^{\circ}$ & $4^{\circ}$ & $6^{\circ}$ & $5^{\circ}$ & $5^{\circ}$ & $6^{\circ}$ & $6^{\circ}$ & $6^{\circ}$ \\
\hline Neo Química & $58^{\circ}$ & $3^{\circ}$ & $36^{\circ}$ & $36^{\circ}$ & $31^{\circ}$ & $20^{\circ}$ & $8^{\circ}$ & $7^{\circ}$ \\
\hline Pfizer & $7^{\circ}$ & $22^{\circ}$ & $4^{\circ}$ & $6^{\circ}$ & $6^{\circ}$ & $7^{\circ}$ & $7^{\circ}$ & $8^{\circ}$ \\
\hline MSD & $15^{\circ}$ & $6^{\circ}$ & $7^{\circ}$ & $7^{\circ}$ & $8^{\circ}$ & $8^{\circ}$ & $9^{\circ}$ & $9^{\circ}$ \\
\hline Astrazeneca Brasil & $19^{\circ}$ & - & $17^{\circ}$ & $14^{\circ}$ & $10^{\circ}$ & $10^{\circ}$ & $10^{\circ}$ & $10^{\circ}$ \\
\hline
\end{tabular}

Fonte: Adaptado de PRÓGENERICOS e IMS HEALTH. Ranking das indústrias farmacêuticas no Brasil. Disponível em: <http://www.progenericos.org.br/index.php/mercado>. Acesso em 12 mai. 2012.

A maior parte da produção desses laboratórios é de medicamentos genéricos (vide Gráfico 3). Ainda em 2001, $26 \%$ das vendas do mercado farmacêutico brasileiro corresponderam a medicamentos genéricos.

Gráfico 3. Participação no mercado por categoria medicamentosa em Valor (\%) do Mercado Total (2002-2011)

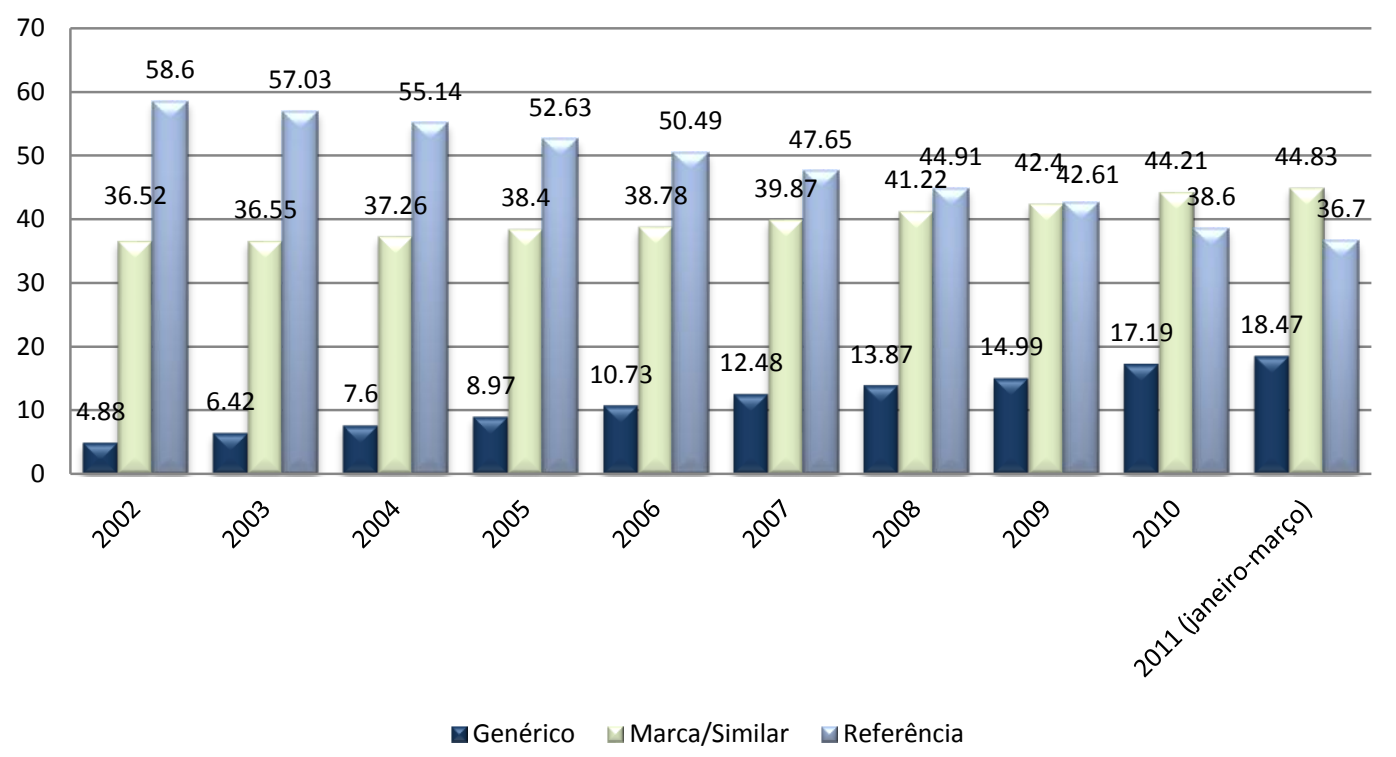

Fonte: Adaptado de PRÓGENERICOS e IMS HEALTH. Um mercado em transformação. Disponível em: <http://www.progenericos.org.br/index.php/mercado>. Acesso em 12 mai. 2012.

Os laboratórios brasileiros, que se baseiam especialmente na produção de medicamentos genéricos, têm se fortalecido por meio de estratégias de fusões e aquisições. Tal artifício também tem sido utilizado nas últimas duas décadas por laboratórios 
multinacionais, inclusive aqueles cuja produção diz respeito primordialmente a medicamentos de referência ${ }^{117}$

Outra característica importante da indústria brasileira é a existência de laboratórios públicos, associados à Rede Brasileira de Produção Pública de Medicamentos. O objetivo dessa rede é coordenar as atividades dos laboratórios oficiais, para suprir as necessidades do Sistema Único de Saúde (SUS), no que se refere à produção e à oferta de medicamentos. ${ }^{118} \mathrm{Em} 2003$, os laboratórios oficiais eram responsáveis por $75 \%$ das unidades de medicamentos dispensadas gratuitamente pelo SUS. ${ }^{119}$

A indústria farmacêutica nacional tem passado por uma série de alterações nos últimos anos. A principal mudança refere-se a investimentos públicos no setor, a fim de impulsionar e incrementar a produção de medicamentos, incentivando a produção em todas as etapas da cadeia.

Em novembro de 2003, o Ministério do Desenvolvimento, Indústria e Comércio Exterior (MDIC) lançou as diretrizes da Política Industrial, Tecnológica e de Comércio Exterior (PITCE). Os objetivos da PITCE eram incentivar setores dinâmicos e intensivos em conhecimento e inovação. Dentre os setores priorizados, estava o setor de fármacos e medicamentos. $^{120}$

Desde então, o Banco Nacional do Desenvolvimento (BNDES) tem colaborado no processo de discussão, elaboração e execução dessa política, destacando-se no papel de fornecedor de crédito diferenciado para a sustentação e implementação da PITCE. Para tanto, foi criado na estrutura organizacional do BNDES o Departamento de Produtos Intermediários Químicos e Farmacêuticos (DFARMA), com a função de fomentar o desenvolvimento de produtos intermediários químicos e farmacêuticos, consistentes em matéria-prima usada na produção de medicamentos. O objetivo principal é incrementar a produção nacional de insumos farmacêuticos, diminuindo as importações que encarecem o preço final dos medicamentos. ${ }^{121}$

\footnotetext{
${ }^{117}$ CAPANEMA, L. X. de. A indústria farmacêutica brasileira e a atuação do BNDES. BNDES Setorial, Rio de Janeiro, n.23, p.193-216, mar. 2006. p. 196.

${ }^{118}$ Portaria $\mathrm{n}^{0}$ 2.438/MS-GM, de 7 de dezembro de 2005, do Ministério da Saúde.

${ }^{119}$ ORGANIZAÇÃO MUNDIAL DA SAÚDE (OMS), ORGANIZAÇÃO PAN-AMERICANA DA SAÚDE (OPAS), BRASIL - Ministério da Saúde. Avaliação da assistência farmacêutica no Brasil: estrutura, processos e resultados. 2005. Disponível em: <http://www.who.int> Acesso em: 2 jan. 2012.

${ }^{120}$ MINISTÉRIO DO DESENVOLVIMENTO, DA INDUSTRIA E DO COMÉRCIO EXTERIOR, et al. Diretrizes da Política Industrial, Tecnológica e de Comércio Exterior. Disponível em: <www.ipea.gov.br/sites/000/2/download/diretrizes_oficial.pdf> Acesso em: 9 dez. 2012.

${ }^{121}$ CAPANEMA, L.X. op. cit., p 206.
} 
Referida atuação do BNDES originou o Programa de Apoio do Desenvolvimento da Cadeia Produtiva Farmacêutica (PROFARMA) que atende aos seguintes objetivos ${ }^{122}$ :

- incentivar o aumento da produção de medicamentos para uso humano e seus insumos no país;

- melhorar os padrões de qualidade dos medicamentos;

- reduzir o déficit comercial da cadeia produtiva;

- estimular a realização de atividades de pesquisa, desenvolvimento e inovação no país;

- fortalecer a posição econômica, financeira, comercial e tecnológica da indústria brasileira.

O PROFARMA lançado pelo BNDES apresentou sinais de sucesso, de modo que, em 2005, já haviam sido investidos $\mathrm{R} \$ 456$ milhões de apoio financeiro na produção farmacêutica brasileira. Posteriormente, esse programa foi reformulado no sentido de destinar apoio também às empresas de médio e pequeno porte, grande maioria das firmas atuantes no setor farmacêutico. Para tanto, foram realizadas modificações nos limites de apoio, garantias e classificações de risco. ${ }^{123}$

Esse programa tem apresentado resultados positivos, sendo responsável pela implementação de projetos de implantação e modernização de parques industriais; por investimentos em fusões e aquisições, fundamentais para o aumento da competitividade das empresas nacionais; e por financiamento de pesquisa e desenvolvimento e inovações incrementais de medicamentos já existentes. A expectativa do BNDES é que o número de operações e o volume de recursos financeiros envolvidos no apoio ao setor farmacêutico brasileiro continue aumentando. Além disso, não previstas revisões periódicas do PROFARMA para estender ainda mais seus benefícios. ${ }^{124}$

\footnotetext{
${ }^{122}$ CAPANEMA, L. X. PALMEIRA FILHO, P.L. PIERONI, J.P. Apoio do BNDES ao complexo industrial da saúde: a experiência do PROFARMA e seus desdobramentos. BNDES Setorial, Rio de Janeiro, n. 27, p. 3-20, mar. 2008. p. 5.

${ }^{123}$ CAPANEMA, L. X. de. A indústria farmacêutica brasileira e a atuação do BNDES. BNDES Setorial, Rio de Janeiro, n.23, p.193-216, mar. 2006. p 212.

${ }^{124}$ Ibid., p 212.
} 


\section{A CÂMARA DE REGULAÇÃO DO MERCADO DE} MEDICAMENTOS (CMED) E A LEI 10.742/03

\subsection{Breve histórico da regulação econômica e jurídica do mercado} farmacêutico brasileiro: o cenário prévio à criação da CMED

A regulação econômica do mercado de medicamentos foi utilizada, pela primeira vez, no Brasil, em 1808. ${ }^{125}$ A regulação dos preços de produtos farmacêuticos também existiu na história recente do país, principalmente na modalidade de tabelamento de preços. A principal justificativa para a utilização desse instrumento jurídico, não só no campo farmacêutico, mas também em outros setores da economia, era o controle da hiperinflação.

Nos anos 50, foi promulgada a Lei $\mathrm{n}^{\circ} 1.522$, de 26 de dezembro de 1951, que tornou crime contra a economia popular o descumprimento de tabelas oficiais de preços de bens e serviços essenciais, incluindo os medicamentos. Também foi criada a Comissão Federal de Abastecimento e Preços (COFAP), encarregada de controlar os valores comerciais desses produtos essenciais. ${ }^{126}$

Posteriormente, em 1962, a COFAP foi substituída pela Superintendência Nacional de Abastecimento (SUNAB), criada pela Lei Delegada $n^{\circ} 5$, que passou a exercer suas atribuições. Tanto a COFAP quanto a SUNAB regulavam os preços dos produtos essenciais, mediante a técnica do tabelamento. ${ }^{127}$ Contudo, apesar da tentativa de regulação dos preços exercida pela SUNAB, a inflação foi responsável pela alta geral dos preços, inclusive dos medicamentos, que alcançaram uma taxa de crescimento de $87 \%$ apenas no ano de $1964 .{ }^{128}$ Por essa razão, em 1967, a forma de regulação dos preços pelo Estado foi alterada, tendo sido atribuída à Comissão Nacional para a Estabilização de Preços (CONEP) o papel de aprovar previamente qualquer aumento de preços por parte da indústria. $^{129}$

\footnotetext{
${ }^{125}$ O Alvará de 5 de novembro de 1808 determinou que os preços dos produtos farmacêuticos fossem fixados pelo governo e, anualmente, por ele revistos, obrigando os boticários a exibirem a tabela de preços ao consumidor e prevendo sanções para o descumprimento do mandamento legal (CONSIDERA, C. M. Uma breve história da economia política da defesa da concorrência. Disponível em: <www.seae.fazenda.gov.br/central_documentos/.../doctrab22.pdf>. Acesso em 4 jun.2011).

${ }^{126}$ A Comissão Federal de Abastecimento e Preços - COFAP foi um órgão criado pela Lei no ${ }^{\circ} .522$, de 26 de dezembro de 1951, subordinado ao então Ministério do Trabalho, Indústria e Comércio, com autonomia administrativa para intervir no domínio econômico e com a finalidade de assegurar a livre distribuição de produtos necessários ao consumo do povo.

${ }^{127}$ Sobre o tabelamento de preços ver: GRAU, E. Tabelamento de preços. Revista de Direito Público, São Paulo, v.21, n.85, p. 100-108, jan/mar. 1988.

${ }^{128}$ CONSIDERA, C. M., op. cit.

${ }^{129}$ Ibid.
} 
No final da década de 60, o governo militar extinguiu a CONEP e criou o Conselho Interministerial de Preços (CIP), ao argumento de ter aquele órgão uma estrutura inadequada para a função que exercia. O Decreto $n^{\circ}$ 63.196, de 29 de agosto de 1968, criou o CIP, órgão responsável pelo controle de quase todos os preços da economia, inclusive dos medicamentos, com exceção dos medicamentos fitoterápicos, homeopáticos e oficinais. O CIP, assim como a CONEP, examinava previamente os preços dos novos produtos e reajustes, mas através de regras detalhadas e complexas que caracterizavam maior intervenção do Estado na economia. O Conselho tinha como atribuição realizar o acompanhamento dos preços e era órgão interministerial, sendo composto pelos Ministros da Fazenda, da Indústria e Comércio; da Agricultura; e do Planejamento e Coordenação Geral. Com o propósito de aparelhar suas competências, o CIP tinha poderes para requisitar informações e esclarecimentos dos agentes econômicos, inclusive, demandando a apresentação prévia de preços programados; restabelecer níveis de preços; determinar a intervenção no domínio econômico e reprimir o abuso do poder econômico. ${ }^{130}$

A lógica da atuação do CIP consistia na ideia de que o preço autorizado deveria ser compatível com um lucro razoável por parte dos agentes econômicos do setor, além de contemplar eventuais custos adicionais. ${ }^{131} \mathrm{O}$ CIP considerava na análise dos preços os efeitos dos produtos e serviços na formação dos custos, a existência de características estruturais mercadológicas que refletissem situações monopolísticas ou oligopolísticas, e a ocorrência de anomalias no comportamento do mercado e dos agentes econômicos que pudessem pertubar os mecanismos de formação de preços no mercado. ${ }^{132}$ Essa comissão verificava o lucro das empresas farmacêuticas através dos balanços dos três útimos anos, concedendo um percentual de aumento a ser aplicado de maneira ponderada pela participação das vendas e limitando o reajuste máximo. ${ }^{133}$ Bastava que o agente econômico demonstrasse ao Conselho um aumento de custos, para que lhe fosse concedido o reajuste dos preços e um aumento do faturamento. A lista de preços das indústrias farmacêuticas dependia da autenticação desse órgão. A consequência dessa política foi que os agentes econômicos deixaram de criar esforços para aumentar a produtividade e a participação no

\footnotetext{
${ }^{130}$ CORREIA DA SILVA, R.A. Regulamentação Econômica da Saúde: Constituição de 1988, CMED, ANVISA, ANS e CADE. São Paulo: LCTE, 2008. p. 147.

${ }^{131}$ Vide arts. $5^{0}$ e $6^{0}$, do Decreto 63.196/1968 (Revogado).

${ }^{132}$ ROMANO, L.A.N. Intervenção e regulação no Brasil: a indústria farmacêutica. São Paulo: FEBRAFARMA, 2005. p. 25.

${ }^{133}$ Ibid., p. 25.
} 
mercado ou, até mesmo, ampliar o mercado específico de atuação. ${ }^{134}$ Eventual melhoria no processo produtivo levaria à queda de custos, obstando a negociação de reajustes de preços junto ao CIP. O CIP exercia a regulação dos preços por meio da técnica do controle e esteve em atividade nas décadas 1970 e 1980. Esse órgão, por sua vez, não obteve sucesso, pois, apesar de controlar os preços por meio da elaboração de índices para cada setor da economia, estes acabaram evoluindo na mesma intensidade dos preços de produtos pertencentes a setores não regulados. ${ }^{135}$ Essa política fracassou de vez, quando o governo permitiu o repasse pleno de custos aos consumidores e a apropriação de ganhos de produtividade pelas empresas, contribuindo para que os preços dos produtos de setores regulados aumentassem nas mesmas proporções que os preços dos produtos de setores não regulados. ${ }^{136} \mathrm{Um}$ dos resultados mais graves dessa política foi a escassez de medicamentos essenciais na década de 80 causado, segundo os próprios fornecedores, por insuficiência da margem de lucro. ${ }^{137}$

Na década de 1990, a tradição de regulação dos preços foi rompida, sendo marcada pela intermitência dessa política econômica. Tal período, no que diz respeito à regulação econômica do mercado de medicamentos, pode ser dividido em 4 momentos: ${ }^{138}$

a) 1990 a 1993: Política de medicamentos do Governo Collor

O CIP foi extinto pela Lei $\mathrm{n}^{0} 8.030$, de 12 de abril de 1990, que instituiu nova sistemática para o reajuste de preços e salários em geral. Nesse período, os preços dos medicamentos oscilaram entre o congelamento e a liberação.

No início do governo Collor, os preços dos medicamentos, assim como os demais preços da economia foram congelados, em razão do descontrole inflacionário. ${ }^{139}$ No entanto, esse período foi marcado pela alternância entre a regulação dos preços e a liberalização. O Decreto $\mathrm{n}^{0}$ 99.244, de 10 de maio de 1990, criou o Departamento de Abastecimento de Preços que veio substituir o CIP. Ficou a cargo desse órgão o acompanhamento do mercado farmacêutico, ao qual competia requisitar, mensalmente,

\footnotetext{
${ }^{134}$ CORREIA DA SILVA, R.A. Regulamentação Econômica da Saúde: Constituição de 1988, CMED, ANVISA, ANS e CADE. São Paulo: LCTE, 2008. p. 148.

${ }^{135}$ CONSIDERA, C. M. Uma breve história da economia política da defesa da concorrência. Disponível em: <www.seae.fazenda.gov.br/central_documentos/.../doctrab22.pdf >. Acesso em 4 jun.2011.

${ }^{136}$ Ibid.

${ }^{137}$ Ibid

${ }^{138}$ GODOY, M. R.; OLIVEIRA, A. L. R. de; CÂMARA, M. R. G. O controle de preços na indústria farmacêutica no Brasil. Disponível em: <www.bnb.gov.br/content/aplicacao/ETENE/Anais/.../2004-ocontrole-.pdf >. Acesso em: 29 mai. 2012.

${ }^{139}$ Vide Portaria MDFP n ${ }^{\circ}$ 106, de 16 de abril de 1990 (Revogada).
} 
informações da indústria farmacêutica. Em agosto de 1990, iniciou-se o processo de liberalização, de sorte que, em outubro desse ano, apenas os preços dos medicamentos de uso contínuo permaneceram congelados. O resultado dessa política foram fortes elevações de preços o que motivou um novo congelamento dos preços em fevereiro de 1991. Nesse período, puderam ser verificados os maiores aumentos dos preços dos remédios, o que deu origem à "crise de medicamentos no Brasill".

Com advento do Plano Collor II, foi instalada a Câmara Setorial da Indústria Farmacêutica, grupo de trabalho que tinha a participação de órgãos do governo e membros da iniciativa privada, cuja finalidade era propor medidas econômicas para o Governo, em relação ao setor farmacêutico. Na prática, essa Câmara teve como objetivo flexibilizar o congelamento dos preços retomado, tendo sido responsável pela autorização de uma série de reajustes de preços no setor. ${ }^{140}$ Em setembro de 1991, reiniciou-se o processo de liberalização gradual dos preços, abrangendo, primeiramente, cem classes terapêuticas. No período de 1992 a 1994, os preços dos medicamentos estiveram completamente liberados, deixando de sofrer qualquer intervenção, direta ou indireta, do governo. ${ }^{141}$

b) 1994 a 1996: Acompanhamento informal dos preços

O Brasil passou a adotar apenas a Lei $n^{\circ} 8.884$, de 11 de junho de 1994, de natureza antitruste, como meio de coibir a elevação dos preços dos medicamentos. As indústrias farmacêuticas foram obrigadas a informar à Secretaria de Acompanhamento Econômico (SEAE), do Ministério da Fazenda, sobre os aumentos dos preços, antes de efetivamente realizá-los. Nesse período, o governo e a Indústria Farmacêutica mantiveram acordo informal segundo o qual, a cada seis meses, foram estabelecidos parâmetros de reajustes para os preços dos medicamentos. ${ }^{142}$

c) 1997 a 1999: Liberalização

No final da década de 1990, o governo instituiu nova sistemática de acompanhamento de preços, por meio da qual os laboratórios eram obrigados apenas a comunicar à Secretaria de Acompanhamento Econômico - SEAE - do Ministério da Fazenda os aumentos de preços de medicamentos sujeitos à prescrição médica.

\footnotetext{
${ }^{140}$ ROMANO, L.A.N. Intervenção e regulação no Brasil: a indústria farmacêutica. São Paulo: FEBRAFARMA, 2005. p. 57.

${ }^{141}$ Ibid., p. 64.

${ }^{142}$ CORREIA DA SILVA, R.A. Regulamentação Econômica da Saúde: Constituição de 1988, CMED, ANVISA, ANS e CADE. São Paulo: LCTE, 2008. p.150.
} 
Em função da crise cambial de 1999, a SEAE admitiu o repasse da variação do câmbio à produção industrial farmacêutica e farmoquímica, de modo que os preços dos medicamentos aumentaram vertigionosamente. Vigorou o acordo entre o governo e a indústria farmacêutica que teve por objetivo repassar o impacto do câmbio sobre os insumos, tendo resultado em aumento médio acumulado dos preços dos medicamentos em $8 \% .{ }^{143}$ Vale lembrar que a indústria farmacêutica atuante no Brasil se baseia na importação de matérias-primas, exercendo atividade nas fases finais da cadeia produtiva, fato que contribuiu para o aumentos dos preços dos medicamentos, em geral. ${ }^{144}$

O resultado prático foi o afastamento da SEAE, de modo que os preços dos medicamentos puderam ser livremente fixados pela indústria farmacêutica. Os altos preços dos medicamentos causaram comoção social, tendo em vista a ampliação dos gastos da população com esses produtos e a limitação ao acesso. Por essa razão, em novembro de 1999, foi instaurada uma Comissão Parlamentar de Inquérito, para investigar a existência de abuso de poder econômico por parte da indústria farmacêutica na determinação dos preços dos medicamentos. Essa Comissão ficou conhecida como CPI dos Medicamentos e, ao seu término, em junho de 2000 , foram identificados graves problemas relacionados à assistência farmacêutica no país, a saber: ${ }^{145}$

(i) Desigualdade de acesso a medicamentos, em função da concentração de renda: a CPI dos medicamentos comprovou um duplo problema, em relação ao acesso e ao uso de medicamentos no país. Existe um pequeno segmento, com grande capacidade de renda, e consumo abusivo e equivocado, ao lado da maioria da população que, por não ter suficiente poder aquisitivo, não satisfaz suas necessidades de saúde;

(ii) $\mathrm{Na}$ época, dentre as 628 empresas farmacêuticas atuantes no mercado nacional, as 10 maiores respondiam por quase $44 \%$ do faturamento total do setor, demonstrando a forte concentração do mercado que fica sujeito à praticas oligopolísticas;

(iii) A produção farmacêutica brasileira consiste, eminentemente, na transformação de princípios ativos em formas acabadas e depende da importação de matérias-primas correspondentes aos princípios ativos;

${ }^{143}$ ROMANO, L.A.N. Intervenção e regulação no Brasil: a indústria farmacêutica. São Paulo: FEBRAFARMA, 2005. p. 57.

${ }^{144}$ CORREIA DA SILVA, R.A. Regulamentação Econômica da Saúde: Constituição de 1988, CMED, ANVISA, ANS e CADE. São Paulo: LCTE, 2008. p.150.

${ }^{145}$ CONSELHO REGIONAL DE MEDICINA DO ESTADO DE SÃO PAULO - CREMESP. CPI dos

Medicamentos.

Disponível

em:<http://www.cremesp.com.br/?siteAcao=PublicacoesConteudoSumario\&id=65>. Acesso em: 28 mar. 2012. 
(iv) A produção nacional de fármacos é cerca de $20 \%$ inferior à demanda, causada pela falta de investimentos no setor e pela ausência de políticas tecnológicas e industriais;

(v) No Brasil, há indícios de formação de cartéis e de abuso de poder econômico por parte das principais empresas do setor. Registra-se, por fim, que o relatório final da CPI culminou na instauração de uma série de processos administrativos no Conselho Administrativo de Defesa Econômica (CADE). ${ }^{146}$

A década de 2000 foi marcada pelo retorno da regulação econômica dos preços à agenda governamental. Em meados de 2000, o governo propôs um acordo aceito pelo setor farmacêutico, com o propósito de estabilizar os preços dos medicamentos. Tal acordo, denominado "Protocolo de Intenções", manteve os preços dos medicamentos vigentes em $1^{\circ}$ de junho até dezembro de 2000. Diante do difícil quadro da assistência farmacêutica no Brasil, em dezembro de 2000, foi editada a Medida Provisória $\mathrm{n}^{\circ} 2.063$, posteriormente, substituída pela Medida Provisória n ${ }^{\circ}$ 2.138-2, de 28 de dezembro de 2000, por sua vez, convertida na Lei Ordinária $n^{\circ} 10.213$, de 27 de março de 2001. Essa lei teve prazo de vigência predeterminado e foi responsável pela criação da Câmara de Medicamentos (CAMED), novo órgão regulador do setor. As formas de regulação utilizadas pela CAMED foram o congelamento ${ }^{147}$ e o modelo de teto de preços, embora sem a aplicação do price cap.

$\mathrm{O}$ art. 12 da referida lei conferiu as seguintes competências regulatórias à CAMED:

d) Julgar os pedidos de reajustes extraordinários de preços;

e) Decidir pela exclusão de grupos ou classes de medicamentos do regime de regulação de que trata a lei;

f) Regulamentar a redução dos preços dos medicamentos que forem objeto de redução de tributos.

A atuação da CAMED ocorreu, inicialmente, mediante o congelamento dos preços. Posteriormente, a regulação dos preços passou a ocorrer mediante a aplicação da Fórmula Paramétrica de Reajuste de Preços - FRP. De acordo com essa fórmula, as empresas farmacêuticas foram classificadas em dois grupos, conforme a diferença entre a Evolução Média de Preços (EMP) e o Índice Paramétrico de Medicamentos (IPM), baseada nos

\footnotetext{
${ }^{146}$ Esses processos, por sua vez, não culminaram em condenação das empresas farmacêuticas, tendo sido arquivados por falta de comprovação de infração contra a ordem econômica ou por entender-se que não houve influência sobre a formação dos preços por parte dos laboratórios representados.

${ }^{147}$ Art. $3^{\circ}$ e art. $7^{\circ}$, da Lei $n^{0} 10.213$, de 27 de março de 2001.
} 
dados obtidos no período de $1^{\text {o }}$ de novembro de 1999 a 31 de outubro de 2001. O primeiro grupo de empresas referiu-se aos laboratórios que tivessem praticado, no período considerado, aumento do preço dos medicamentos igual ou maior que 4,4\%. O segundo grupo agregou as demais empresas, que praticaram aumento inferior a 4,4\%. ${ }^{148}$

As empresas que fossem parte do primeiro grupo não poderiam aumentar seus preços enquanto perdurasse a política de congelamento a elas destinada. Em contrapartida, após janeiro de 2001, as empresas componentes do segundo grupo poderiam aumentar os preços até o limite do Índice Paramétrico de Medicamentos. Tal forma de regulação causou polêmica, vez que as empresas submetidas ao congelamento se sentiram penalizadas por atitudes tomadas anteriormente à vigência da Lei 10.213/01.

Contudo, a questão mais polêmica acerca da regulação empreendida pela CAMED surgiu em relação às apresentações e aos medicamentos vendidos a partir de 2002, que passaram a ter regime jurídico diferenciado para o estabelecimento de seus preços iniciais, em razão da edição da Medida Provisória 2.230/01. A Lei 10.213/01 estabelecia que os preços unitários iniciais das novas apresentações deveriam ser inferiores à média dos preços unitários das apresentações já existentes. Diferentemente do que prescrevia a lei para esses produtos, a MP 2.230/01 veio a permitir que, a partir de 2002, a CAMED determinasse, livremente, os critérios de definição desses preços. Quanto aos preços unitários iniciais dos medicamentos, a Lei 10.213/01 não previa que fossem regulados pela CAMED. Essa possibilidade, por sua vez, surgiu, com a edição da MP 2.230/01, que passou a permitir que a CAMED estabelecesse os critérios de definição de preços unitários iniciais dos novos produtos.

Com o término do governo do Presidente Fernando Henrique Cardoso, a forma de regulação do mercado de medicamentos até então vigente perdeu respaldo e, em 2003, com a edição da MP $\mathrm{n}^{\circ} 123$, de 26 de junho, foi extinta a CAMED, dando lugar à Câmara de Regulação do Mercado de Medicamentos (CMED). Essa câmara absorveu as atribuições da primeira e adquiriu novas competências regulatórias. A principal diferença observada entre as duas câmaras é que a CMED passou a considerar, para a determinação do teto permitido para reajustes dos preços dos medicamentos, a produtividade da indústria e o fator de ajuste relativos de preços intra-setor e entre setores. ${ }^{149}$ A CMED e as características de sua política regulatória serão melhor estudadas no próximo tópico.

\footnotetext{
${ }^{148}$ Art. $5^{\circ}$, art. $6^{\circ}$ e os itens 2.1 e 2.2 do anexo, da Lei ${ }^{0} 10.213$, de 27 de março de 2001.

${ }^{149}$ Art. $4^{\circ}, \S 1^{\circ}$, da Lei $\mathrm{n}^{\circ} 10.742$, de 6 de outubro de 2003 . Vale ressaltar que, neste trabalho, a nomenclatura "controle de preços" não é utilizada como sinônimo de "regulação de preços". Conforme anteriormente
} 


\subsection{Criação da CMED}

A Medida Provisória $n^{0} 123$, de 26 de junho de 2003, e o Decreto $n^{0} 4.766$, da mesma data, instituíram um novo marco regulatório para o mercado de medicamentos, no Brasil. Posteriormente convertida na Lei ${ }^{\circ} 10.742$, de 6 de outubro de 2006, a referida medida provisória foi, na prática, responsável pela criação da Câmara de Regulação do Mercado de Medicamentos (CMED), órgão regulatório do setor farmacêutico.

A CMED substituiu a antiga Câmara de Medicamentos (CAMED) ${ }^{150}$. Também fruto de uma medida provisória posteriormente convertida na Lei 10.213/01, a CAMED, assim como sua sucessora CMED, surgiram no contexto da necessidade de retorno da ingerência estatal no setor farmacêutico, com o propósito de facilitar o acesso a medicamentos.

Depois da alta dos preços dos produtos farmacêuticos na década de 90, que culminou na CPI dos medicamentos, o momento era de grande pressão da sociedade civil por uma resposta do Estado ao dever constitucional de promover a assistência farmacêutica. Assim, segundo explica a Agência Nacional de Vigilância Sanitária (ANVISA), o novo órgão regulador do mercado de medicamentos surgiu como “incremento da política de genéricos, com o objetivo de reduzir o preço médio dos tratamentos dos consumidores $[\ldots]^{\prime 151}$

As mais importantes diferenças entre as duas câmaras são quanto à competência. Os poderes e funções da CMED são muito mais amplos que os da CAMED, conforme será analisado mais adiante. A regulação dos preços exercida pela CAMED limitava-se à análise e aprovação dos preços dos medicamentos que eram lançados no mercado, a fixar os limites para reajustes de preços praticados pela indústria farmacêutica (estavam excluídas da regulação os distribuidores, as farmácias e drogarias) e a instaurar processos administrativos apenas contra laboratórios, em caso de desobediência à legislação. A CMED, por sua vez, além de absorver todas as competências da CAMED, agregou avanços em outros pontos, tais como a possibilidade de fixar margens de comercialização para toda a cadeia produtiva; a faculdade de propor a celebração de acordos e convênios

explicitado na Introdução, o controle de preços, assim como são o tabelamento e o congelamento, é espécie do gênero regulação de preços (Cf. Capítulo 1: Introdução).

${ }^{150}$ Art. $9^{0}$, da Lei $n^{0} 10.742$, de 6 de outubro de 2003: "Fica extinta a Câmara de Medicamentos, criada pela Lei $\mathrm{n}^{0} 10.213$, de 27 de março de 2001, cujas competências e atribuições são absorvidas pela CMED.

Parágrafo único: Os processos, documentos e demais aexpedientes relativos às competências e atribuições absorvidas pela CMED terão sua tramitação por ela disciplinada".

${ }^{151}$ BRASIL. Agência Nacional de Vigilância Sanitária (ANVISA). Política vigente para a regulamentação de medicamentos no Brasil. Disponível em: 〈http://www. anvisa.gov.br/medicamentos/politica.htm >. Acesso em: 28 mai.2012. 
internacionais relativos ao setor de medicamentos; solicitar informações sobre a produção, os insumos utilizados e as vendas; além de poder auxiliar na tarefa de monitoramento dos preços do mercado.

A CMED ainda pode opinar sobre regulamentações referentes à tributação de medicamentos e sugerir aos órgãos competentes da administração direta diretrizes e procedimentos voltados às políticas públicas de acesso a medicamentos pela população. No último caso, a CMED atuaria como "órgão de apoio às políticas planejadas e a serem implementadas pelo Executivo". 152

A CMED também representou um fortalecimento da legislação punitiva, se comparada com a legislação anterior, podendo o órgão regulador responsabilizar, em caso de não observância das normas regulatórias, os laboratórios produtores e importadores de medicamentos; as farmácias e drogarias; os representantes; as distribuidoras de medicamentos; e quaisquer pessoas jurídicas de direito público ou privado, inclusive associações de entidades ou pessoas, de fato ou de direito, ainda que temporárias, com ou sem personalidade jurídica que, de alguma forma, exerçam atividade no setor de medicamentos (Tabela 5). ${ }^{153}$

${ }^{152}$ BRASIL. Agência Nacional de Vigilância Sanitária (ANVISA). Política vigente para a regulamentação de medicamentos no Brasil. Disponível em: 〈http://www. anvisa.gov.br/medicamentos/politica.htm >. Acesso em: 28 mai.2012.

${ }^{153}$ ROMANO, L.A.N. Intervenção e regulação no Brasil: a indústria farmacêutica. São Paulo: FEBRAFARMA, 2005. p.72. 
Tabela 5. CAMED x CMED

\begin{tabular}{|c|c|c|}
\hline & CAMED (Lei 10.213/01 & CMED (Lei 10.742/03) \\
\hline \multirow[t]{3}{*}{$\begin{array}{l}\text { Instrumentos } \\
\text { regulatórios }\end{array}$} & $\begin{array}{l}\text { Teto de preços embora sem a } \\
\text { aplicação do price cap }\end{array}$ & $\begin{array}{l}\text { Teto de preços. Aplicação do price cap. Leva em } \\
\text { consideração a produtividade da indústria e os fatores de } \\
\text { ajuste intra e extra setor }\end{array}$ \\
\hline & $\begin{array}{l}\text { Utilização da Fórmula Paramétrica de } \\
\text { Reajuste de Preços (FPR) }\end{array}$ & \\
\hline & Congelamento & \\
\hline \multirow[t]{4}{*}{ Competências } & $\begin{array}{l}\text { Julgar pedidos de reajustes } \\
\text { extraordinários de preços }\end{array}$ & $\begin{array}{l}\text { Absorveu as competências da CAMED e possui } \\
\text { competências que extravasam o exercício da regulação } \\
\text { dos preços dos medicamentos propriamente dita, tais }\end{array}$ \\
\hline & $\begin{array}{l}\text { Decidir pela exclusão de grupos ou } \\
\text { classes de medicamentos do regime }\end{array}$ & como: \\
\hline & regulatório & $\begin{array}{l}\text { Opinar sobre normas que envolvam a tributação de } \\
\text { medicamentos }\end{array}$ \\
\hline & $\begin{array}{l}\text { Regulamentar a redução dos preços } \\
\text { dos medicamentos que forem objeto } \\
\text { de redução de tributos }\end{array}$ & $\begin{array}{l}\text { Sugerir a celebração de acordos e convênios } \\
\text { internacionais concernentes aos setores de medicamentos }\end{array}$ \\
\hline Compras públicas & Não regulava as compras públicas & $\begin{array}{l}\text { Regula compras públicas mediante o Coeficiente de } \\
\text { Adequação de Preços (CAP). }\end{array}$ \\
\hline $\begin{array}{l}\text { Agentes } \\
\text { econômicos } \\
\text { regulados }\end{array}$ & Apenas a indústria farmacêutica & $\begin{array}{l}\text { Regula a indústria farmacêutica (mediante o preço- } \\
\text { fábrica) e as farmácias e drogarias (mediante o preço } \\
\text { máximo ao consumidor). }\end{array}$ \\
\hline
\end{tabular}

Fonte: Elaboração própria.

\subsection{Competências da CMED}

A atuação da Câmara de Regulação do Mercado de Medicamentos está relacionada, ao mesmo tempo, à assistência farmacêutica prestada pelo Sistema Único de Saúde e às compras diretas de medicamentos pela população. No que toca ao SUS, a CMED é responsável por estabelecer o coeficiente de adequação de preços - CAP, que consiste em descontos obrigatórios a serem praticados nas compras públicas dos medicamentos pertencentes às categorias arroladas no art. $2^{\circ}$, da Resolução $\mathrm{n}^{\circ} 4$, de 18 de dezembro de 2006. ${ }^{154}$ Os medicamentos que se enquadram nessas categorias são definidos pela

\footnotetext{
${ }^{154}$ Art.2 ${ }^{\circ}$. "O CAP será aplicado ao preço dos produtos nos seguintes casos:

I- Produtos que estejam ou venham a ser incluídos no componente de medicamentos de dispensação excepcional, conforme definido na Portaria $\mathrm{n}^{\circ}$ 698, de 30 de março de 2006.

II- Produtos que estejam ou venham a ser incluídos no Programa Nacional de DST/AIDS.

III- Produtos que estejam ou que venham a ser incluídos no Programa de Sangue e Hemoderivados.

IV- Medicamentos antineoplásicos ou medicamentos utilizados como adjuvantes no tratamento do câncer.

V- Produtos comprados por força de decisão judicial, independente de constarem da relação de que trata o $\S 1^{\circ}$ deste artigo.

VI-Produtos classificados na categorias I,II e V, de acordo com o disposto na Resolução n², de 5 de março de 2004, desde que constem da relação de que trata o $\$ 1^{\circ}$ deste artigo.

$\S 1^{\circ}$ A Secretaria-Executiva editará, em até 90 (noventa) dias da entrada em vigor desta Resolução, comunicado com a relação de produtos cujos preços serão submetidos ao CAP, conforme decisão do Comitê Técnico-Executivo.
} 
Secretaria-Executiva da CMED em lista de produtos que são submetidos ao CAP através de comunicado.

A regulação exercida pela CMED merece destaque também no que concerne à compra direta de medicamentos pelos consumidores. Conforme mencionado na Introdução deste trabalho, a maior parte da população brasileira adquire os medicamentos de que necessita mediante a compra em varejo. Assim, a regulação dos preços realizada pela CMED interfere diretamente no processo de aquisição dos produtos farmacêuticos, influenciando na decisão de compra do consumidor e no acesso a medicamentos.

A regulação do mercado farmacêutico pela CMED é praticada, principalmente, por meio do controle de preços dos medicamentos. Essa câmara deve propor critérios de composição dos fatores presentes no modelo de teto de preços para o ajuste dos preços dos medicamentos, nos termos da Lei 10.742/03. ${ }^{155} \mathrm{O}$ modelo de teto de preços utilizado pela CMED é baseado no price cap e é calculado por meio de um índice composto pelo fator produtividade e fatores de ajuste de preços relativo intra-setor e entre setores, ${ }^{156}$ conforme será explicitado em tópico específico. A CMED também deve definir diretrizes e procedimentos relativos à regulação econômica do mercado farmacêutico; estabelecer critérios para a fixação e o ajuste dos preços dos medicamentos pela indústria, o que inclui fármacos novos e novas apresentações ${ }^{157}$.

Além disso, no que diz respeito à regulação dos preços, a CMED pode decidir pela exclusão ou reinclusão de grupos, classes, subclasses de medicamentos e produtos farmacêuticos da incidência de critérios de estabelecimento ou de ajuste de $\operatorname{preços}^{158}$. No mais, compete também à CMED estabelecer critérios para a fixação de margens de comercialização de medicamentos a serem observados pelos representantes, distribuidores, farmácias e drogarias, inclusive de farmácias voltadas para o atendimento privativo de unidades hospitalares ou equivalentes. ${ }^{159}$ Vale registrar que o ajuste dos preços dos medicamentos deverá ocorrer anualmente. ${ }^{160}$

\footnotetext{
$\S 2^{\circ} \mathrm{O}$ Comitê Técnico-Executivo da CMED poderá incluir ou excluir produtos da relação de que trata o $\S 1^{\circ}$ deste artigo.

${ }^{155}$ Art. $4^{0}, \S 1^{0}$, da Lei $n^{0} 10.742$, de 6 de outubro de 2003.

${ }^{156}$ Art. $4^{0}, \S 1^{0}$ e $\S 5^{0}$, da Lei $n^{0} 10.742$, de 6 de outubro de 2003.

${ }^{157}$ Art. $6^{0}$, incisos I a III, da Lei ${ }^{0} 10.742$, de 6 de outubro de 2003.

${ }^{158}$ Art. $6^{0}$, inciso IV, da Lei ${ }^{0} 10.742$, de 6 de outubro de 2003.

${ }^{159}$ Art. $6^{0}$, inciso V, da Lei $n^{0} 10.742$, de 6 de outubro de 2003.

${ }^{160}$ Art. $4^{0}$, da Lei $n^{0} 10.742$, de 6 de outubro de 2003.
} 
A Câmara de Regulação do Mercado de Medicamentos também possui competências extravasam a regulação dos preços dos produtos farmacêuticos, a saber: ${ }^{161}$

- Propor a adoção de legislações e regulamentações referentes à regulação econômica do mercado de medicamentos e opinar sobre regulamentações que envolvam a tributação de medicamentos;

- Assegurar o efetivo repasse aos preços dos medicamentos de qualquer alteração da carga tributária;

- Sugerir a celebração de acordos e convênios internacionais concernentes ao setor de medicamentos;

- Monitorar o mercado de medicamentos, podendo requisitar informações sobre a produção, insumos, matérias-primas, vendas e quaisquer outros dados que julgar necessários, em poder de pessoas jurídicas de direito público ou privado;

- Zelar pela proteção dos interesses do consumidor de medicamentos;

- Decidir sobre a aplicação de penalidades previstas na Lei $10.742 / 03$ e na Lei ${ }^{0}$ 8.078, de 11 de setembro de 1990, sem prejuízo das competências dos demais órgãos do Sistema Nacional de Defesa do Consumidor;

- Elaborar seu regimento interno.

Apesar das inúmeras competências atribuídas à CMED pela Lei 10.742/03, na prática, conforme será visto adiante, as ações desse órgão se concentram no controle de reajustes e na fixação de preços de entrada de novos produtos e de novas apresentações medicamentosas no mercado. ${ }^{162}$

Importa mencionar que a competência regulatória da CMED no tocante à sua ingerência sobre a determinação dos preços dos medicamentos já teve sua constitucionalidade questionada no Supremo Tribunal Federal, por meio de controle difuso de constitucionalidade. No julgamento do recurso ordinário em mandado de segurança (RMS) $\mathrm{n}^{\circ} 26575$, no qual se discutiu a definição do preço máximo ao consumidor pela CMED, o Relator Ministro Eros Grau afirmou a constitucionalidade da atividade reguladora da CMED, no quadro do direito positivo brasileiro. No entanto, nesta decisão o Ministro Eros Grau optou por anular a decisão da CMED quanto à fixação do preço inicial de medicamento, dando provimento ao recurso interposto pela Novo Nordisk Farmacêutica

\footnotetext{
${ }^{161}$ As demais competências da CMED estão previstas no art. $6^{0}$, incisos VII ao XV, da Lei ${ }^{0} 10.742$, de 6 de outubro de 2003.

${ }^{162}$ ROMANO, L.A.N. Intervenção e regulação no Brasil: a indústria farmacêutica. São Paulo: FEBRAFARMA, 2005. p. 71.
} 
do Brasil Ltda., por entender que o Conselho de Ministros desse órgão agiu contrariamente as próprias resoluções emanadas dessa Câmara. ${ }^{163}$

A atividade reguladora da CMED também já foi questionada no Superior Tribunal de Justiça em dois casos que passaram a constituir importantes precedentes: MS $\mathrm{n}^{\circ}$ 1211796/DF e MS n 12730/DF.

No primeiro caso, foi impetrado mandado de segurança pela Novo Nordisk Farmacêutica do Brasil Ltda. contra ato do Conselho de Ministros da Câmara de Regulação do Mercado de Medicamentos - CMED, objetivando, em síntese, autorização para comercializar o medicamento "Levemir" pelos preços submetidos a esse conselho. A impetrante alegou violação ao princípio da isonomia e da livre concorrência, sob o argumento de que são desproporcionais os preços admitidos pela CMED para medicamentos concorrentes. ${ }^{164}$ A segurança foi denegada por unanimidade, tendo os demais julgadores acompanhado o voto do Ministro Relator Castro Meira que afirmou que a atividade de determinação dos preços exercida pela CMED é constitucional, ante a complexidade da matéria; e que os critérios para a determinação dos preços inciais de um medicamento são baseados no mercado internacional. Em resumo, segundo o Ministro, não haveria no caso examinado vulneração so princípios da isonomia, livre concorrência, razoabilidade e proporcionalidade.

O segundo caso, por sua vez, teve maior repercussão, vez que o voto da Ministra Relatora Eliana Calmon abriu precedente para que as empresas farmacêuticas deixassem de participar de licitações públicas, conforme será visto mais adiante, no Capítulo 5. Tratase de mandado de segurança coletivo impetrado pela Associação da Indústria Farmacêutica de Pesquisa - Interfarma, contra ato praticado pelo Conselho de Ministros da Câmara de Regulação do Mercado de Medicamentos - CMED. A Interfarma questionou a legalidade da Resolução CMED n 4, de 18 de dezembro de 2006, que instituiu o coeficiente de

\footnotetext{
${ }^{163}$ BRASIL. Supremo Tribunal Federal. Recurso ordinário em mandado de segurança ${ }^{\circ} 26575$. Recorrente: Novo Nordisk Farmacêutica do Brasil Ltda. Recorrido: União. Relator: Ministro Luiz Fux. Brasília 20 de abril de 2007.2 Disponível em: <http://www.stf.jus.br/portal/processo/verProcessoAndamento.asp?incidente=2509385>. Acesso em: 5 set. 2012. Importa anotar que a relatoria originária do processo era do Ministro Eros Grau, contudo, tendo em vista a aposentadoria desse ministro, o processo foi redistribuído ao Ministro Luiz Fux, em 2 de abril de 2012, atual relator.

${ }^{164}$ BRASIL. Superior Tribunal de Justiça. Mandado de Segurança n ${ }^{\circ}$ 11706-DF (2006/0075344-0). Impetrante: Novo Nordisk Farmacêutica do Brasil LTDA. Impetrado: Ministro do Estado da Saúde. Relator: Ministro Castro Meira. Brasília, 17 de abril de 2006. Disponível em: < http://www.stj.jus.br/webstj/processo/Justica/detalhe.asp?numreg=200600753440\&pv=010000000000\&tp=5 1>. Acesso em: 5 set. 2012
} 
adequação de preços (CAP). ${ }^{165}$ Segundo essa entidade representativa dos laboratórios farmacêuticos a Lei 10.742/03 não confere à CMED atribuição de modificar unilateralmente os preços dos medicamentos. Ao violar a Lei 10.742/03 a CMED teria agido contra a segurança jurídica e a previsibilidade essenciais a qualquer processo regulatório. Tal comportamento do órgão regulador também teria transgredido o princípio da isonomia, vez que estabeleceu critérios diferentes de tratamento dos consumidores públicos e privados. Teria ocorrido transgressão também do direito à propriedade, da livre concorrência, da proporcionalidade e da razoabilidade. Para a Interfarma a referida medida normativa também teria violado a Lei $10.742 / 03$, por não estimular a competitividade e a produtividade no setor.

A ministra relatora negou a segurança pleiteada e teve seu voto acolhido pelos demais ministros, tendo sido a decisão do tribunal por unanimidade. De acordo com a relatora, não houve transgressão à Lei 10.742/03:

Ao impor a limitação dos preços dos medicamentos, elencados no art. $2^{\circ}$ da Resolução 04/2006, a serem adquiridos pelos entes públicos, a CMED nada mais fez do que valer-se da competência que lhe foi outorgada pelo art. $6^{\circ}$, incisos II, III, V, VII, VIII, XII e XIII da Lei 10.472/2003 (acima transcritos), com destaque especial para a implementação da política de acesso a medicamentos pela população em geral. ${ }^{166}$

Além disso, para a ministra relatora, os princípios da propriedade e da livre concorrência, bem como os outros princípios cuja violação foi alegada, não são absolutos. Tais princípios cedem em face do interesse social e coletivo. A determinação do CAP está de acordo com a Constituição e a Lei Orgânica da Saúde (LOS) que prevêem, respectivamente, no art. 198, inciso III, e no art. $2^{\circ}$, que o direito à saúde pressupõe deveres da família, de empresas e da sociedade e comunidade, incluindo, portanto, a indústria farmacêutica.

\footnotetext{
${ }^{165}$ BRASIL. Superior Tribunal de Justiça. Mandado de Segurança $\mathrm{n}^{\circ}$ 12730-DF (2007/0068561-2). Impetrante: Associação da Indústria Farmacêutica de Pesquisa (INTERFARMA). Impetrado: Ministro do Estado da Saúde. Relatora: Ministra Eliana Calmon. Brasília, 28 de março de 2007. Disponível em: < http://www.stj.jus.br/webstj/processo/Justica/detalhe.asp?numreg=200700685612\&pv=010000000000\&tp=5 1>. Acesso em: 5 set. 2012

${ }^{166}$ BRASIL. Superior Tribunal de Justiça. Mandado de Segurança ${ }^{\circ}$ 12730-DF (2007/0068561-2). Impetrante: Associação da Indústria Farmacêutica de Pesquisa (INTERFARMA). Impetrado: Ministro do Estado da Saúde. Relatora: Ministra Eliana Calmon. Brasília, 28 de março de 2007. Disponível em: < http://www.stj.jus.br/webstj/processo/Justica/detalhe.asp?numreg=200700685612\&pv=010000000000 \&tp=5 1>. Acesso em: 5 set. 2012
} 
O princípio da isonomia também não teria sido transgredido, pois ninguém é obrigado a contratar com a Administração Pública e aqueles que se dispõem a fazê-lo devem ser regidos pelas mesmas regras. A legislação impugnada não trata de forma desigual aqueles que se encontram em situação semelhante.

Por fim, a criação do CAP também não teria sido arbitrária e unilateral, pois, conforme logrou comprovar a CMED, tal norma regulatória foi discutida com Febrafarma (Federação Brasileira da Indústria Farmacêutica - entidade da qual é integrante a Interfarma), que manifestou sua anuência.

\subsection{Processos Administrativos}

À Câmara de Regulação do Mercado de Medicamentos compete também investigar, preliminarmente, bem como processar e julgar administrativamente as infrações praticadas contra atos normativos dela emanados, conforme previsto em lei. ${ }^{167} \mathrm{O}$ descumprimento da Lei 10.742/03 ou de resoluções da CMED autorizam essa câmara a

decidir sobre a aplicação das penalidades e sanções administrativas previstas no Código de Defesa do Consumidor, no que diz respeito ao mercado de medicamentos, sem prejuízo das competências dos demais órgãos do Sistema Nacional de Defesa do Consumidor. ${ }^{168}$

Além disso, casos de recusa, omissão, falsidade ou retardamento injustificado de informações ou documentos requeridos pelo órgão regulador ensejam a aplicação de multa de natureza administrativa pela CMED. ${ }^{169}$

As infrações objeto de processos administrativos devem ser investigadas pela CMED, na atividade de fiscalização do cumprimento das normas regulatórias do mercado

\footnotetext{
${ }^{167}$ Art. $6^{0}$, inciso XIV e art. $8^{0}$, caput e parágrafo único, da Lei n ${ }^{0} 10.742$, de 6 de outubro de 2003.

${ }^{168}$ Art. $6^{\circ}$, inciso XIV, da Lei ${ }^{\circ} 10.742$, de 6 de outubro de 2003.

${ }^{169}$ Nesse sentido estão os seguintes artigos da Lei $\mathrm{n}^{0} 10.742$, de 6 de outubro de 2012:

"Art. $6^{0}$ : Compete à CMED, dentre outros atos necessários à consecução dos objetivos a que se destina esta lei:

$[\ldots]$

XIV - decidir sobre a aplicação de penalidades previstas nesta Lei e, relativamente ao mercado de medicamentos, aquelas previstas na Lei $\mathrm{n}^{0}$ 8.078, de 11 de setembro de 1990, sem prejuízo das competências dos demais órgãos do Sistema Nacional de Proteção ao Consumidor"; e

"Art. $8^{0}$ : O descumprimento de atos emanados pela CMED, no exercício de suas competências de regulação e monitoramento do mercado de medicamentos, bem como o descumprimento de norma prevista nesta Lei, sujeitam-se às sanções administrativas previstas no art. 56, da Lei n ${ }^{0}$ 8.078, de 1990.

Parágrafo único: A recusa, omissão, falsidade ou retardamento injustificado de informações ou documentos requeridos nos termos desta Lei ou por ato da CMED, sujeitam-se à multa diária de $\mathrm{R} \$ 10.000,00$ (dez mil reais), podendo ser aumentada em até 20 (vinte) vezes, se necessário, para garantir a eficácia."
} 
de medicamentos. Nesse caso, os processos administrativos são instaurados de ofício pela Secretaria-Executiva da CMED. No entanto, procedimentos investigatórios e processos administrativos também podem ser determinados por força de denúncias dos consumidores, do Ministério Público e de gestores públicos (informação verbal). ${ }^{170}$

Os processos administrativos instaurados pela Câmara de Regulação do Mercado de Medicamentos são referidos no site da Agência Nacional de Vigilância Sanitária. Vale destacar que algumas decisões proferidas pela CMED são contestadas pelos laboratórios na esfera judicial. Segundo informaram os assessores e membros da Secretaria-Executiva da CMED, houve casos em que o Poder Judiciário estabeleceu que fosse utilizado outro método de reajuste de preço, impedindo a aplicação do modelo de teto de preços adotado pela CMED, em determinado caso concreto (informação verbal). ${ }^{171}$ A título de ilustração, é possível citar o caso de contestação do Comunicado $n^{0}$ 15/2006, da CMED, por parte das empresas farmacêuticas Novartis e Wyeth.

Em 2007, os laboratórios Novartis e Wyeth conseguiram liminares que autorizaram a venda de medicamentos para entidades da Administração Pública sem a aplicação do desconto obrigatório. No ano seguinte, a Actelion Pharmaceuticals do Brasil conseguiu antecipação de tutela no mesmo sentido. Assim, o Poder Judiciário já contrariou a aplicação das normas regulatórias, tendo decidido contra as regras emanadas da CMED.

\subsection{Estrutura organizacional, composição e funcionamento da CMED}

Conforme determinou a lei, a composição da Câmara de Regulação do Mercado de Medicamentos foi definida por ato do Poder Executivo, consubstanciado na Resolução $\operatorname{CMED~}^{0}{ }^{3}$, de 29 de julho de 2003, posteriormente alterada pela Resolução CMED n ${ }^{0} 3$, de 15 de junho de 2005. O referido ato normativo corresponde ao Regimento Interno da CMED e foi elaborado pelos próprios membros desta câmara.

A CMED é formada por três órgãos, a saber: o Conselho de Ministros, o Conselho Técnico Executivo, e a Secretaria-Executiva. ${ }^{172}$

O Conselho de Ministros é o órgão de deliberação superior e final da CMED, devendo os seus componentes decidir por meio de resoluções com a presença de todos os

\footnotetext{
${ }^{170}$ Informação fornecida por assessores da Secretaria-Executiva da CMED, em entrevista realizada em Brasília, em 5 de julho de 2012 (vide transcrição do áudio da entrevista com assessores da SecretariaExecutiva da CMED, no Anexo C).

${ }^{171}$ Informação fornecida por assessores da Secretaria-Executiva da CMED, em entrevista realizada em Brasília, em 5 de julho de 2012 (vide transcrição do áudio da entrevista com assessores da SecretariaExecutiva da CMED, no Anexo C).

${ }^{172}$ Art. $3^{0}$, da Resolução CMED n ${ }^{0}$ 3, de 29 de julho de 2003.
} 
membros titulares ou de suplentes formalmente indicados. Esse conselho é composto pelo Chefe da Casa Civil da Presidência da República e pelos Ministros de Estado da Saúde, que o presidirá; da Justiça; da Fazenda; e do Desenvolvimento, Indústria e Comércio Exterior. ${ }^{173}$ Dentre as inúmeras competências do Conselho de Ministros, destacam-se aquelas que coincidem com as próprias atribuições da Câmara de Regulação do Mercado Farmacêutico, tais como a definição de diretrizes e procedimentos relativos à regulação econômica do mercado de medicamentos; o estabelecimento de critérios para a fixação e ajuste de preços de medicamentos; e a definição, com clareza, dos critérios para a fixação dos preços dos produtos novos e novas apresentações de medicamentos, que venham a ser incluídos na lista de produtos comercializados pela empresa produtora. ${ }^{174}$ Além disso, o Conselho de Ministros possui importantes competências privativas. Cabe, unicamente, a esse órgão, decidir pela aprovação de critérios para reajustes ordinários e extraordinários de preços de medicamentos. Ademais, é atribuição exclusiva do Conselho de Ministros deliberar sobre inclusão ou exclusão de produtos no rol de medicamentos a serem submetidos ao regime regulatório; aprovar o Regimento Interno da CMED; e autorizar o reajuste de preços dos produtos que forem objeto de alteração da carga tributária. ${ }^{175}$

O Comitê Técnico-Executivo é o núcleo executivo colegiado da CMED e deverá tomar as suas decisões por unanimidade. ${ }^{176}$ Os membros desse órgão colegiado são: o Secretário da Ciência, tecnologia e Isumos Estratégicos do Ministério da Saúde, que o coordenará; o Secretário-Executivo da Casa Civil; o Secretário de Direito Econômico do Ministério da Justiça; o Secretário de Acompanhamento Econômico do Ministério da Fazenda; o Secretário de Desenvolvimento da Produção, do Ministério do Desenvolvimento, Indústria e Comércio Exterior. ${ }^{177}$ No que diz respeito à esfera das atribuições, ao Comitê Técnico-Executivo compete, eminentemente, realizar sugestões e proposições ao Conselho de Ministros, aprovando e encaminhando a esse órgão propostas de edição de atos normativos e de diretrizes complementares para implementação da política de regulação de medicamentos. ${ }^{178}$ Dentre as demais competências do Comitê Técnico-Executivo, importa ressaltar a função de pronunciar-se sobre pedidos de reajustes

\footnotetext{
${ }^{173}$ Art. $4^{0}$, da Resolução CMED n ${ }^{0}$ 3, de 29 de julho de 2003.

${ }^{174}$ Essas e as demais competências do Conselho de Ministros da CMED estão previstas no art. $6^{0}$, incisos I ao XVII, da Resolução CMED n ${ }^{0}$ 3, de 29 de julho de 2003.

${ }^{175}$ Art. $7^{0}$, da Resolução CMED n ${ }^{0} 3$, de 29 de julho de 2003.

${ }^{176}$ Art. $8^{0}$ e art. $9^{0}$, parágrafo $2^{0}$, da Resolução CMED n ${ }^{0} 3$, de 29 de julho de 2003.

${ }^{177}$ Art. $9^{0}$, da Resolução CMED n ${ }^{0} 3$, de 29 de julho de 2003.

${ }^{178}$ Art. 10, incisos I ao III, V, VI, IX , XVI, e XV, da Resolução CMED nº 3, de 29 de julho de 2003.
} 
extraordinários de preços e decidir, em instância final, os recursos interpostos contra as deliberações da Secretaria-Executiva. ${ }^{179}$

Por fim, a CMED é constituída por uma Secretaria-Executiva, exercida pela Agência Nacional de Vigilância Sanitária - ANVISA, vinculada ao Ministério da Saúde. ${ }^{180}$ Esse órgão exerce as atividades mais essenciais da Câmara de Regulação do Mercado de Medicamentos. De forma resumida, é possível dizer que a Secretaria-Executiva é responsável, principalmente, por conceber, implementar e controlar a política regulatória, prestando apoio técnico, jurídico e administrativo à CMED. ${ }^{181}$ Dentre as várias funções da Secretaria-Executiva destacam-se:

g) Prestar assistência direta ao Conselho de Ministros da CMED; ${ }^{182}$

h) Implementar as deliberações e diretrizes fixadas pelo Conselho de Ministros e pelo Comitê Técnico-Executivo; ${ }^{183}$

i) Coordenar grupos técnicos intragovernamentais, realizar e promover estudos e preparar propostas sobre matérias de competências da CMED para serem submetidas ao Conselho de Ministros e ao Comitê Técnico-Executivo; ${ }^{184}$

j) Requisitar informações sobre produção, insumos, matérias-primas, vendas e quaisquer outros dados que julgar necessários, em poder de direito público e privado, com vistas a monitorar, para os fins da Lei 10.742/03, o mercado de medicamentos; ${ }^{185}$

k) Realizar investigações preliminares, instaurar e julgar processos administrativos para a apuração das infrações de que trata o art. $8^{0}$, caput e parágrafo único, da Lei 10.742/03, podendo, inclusive, aplicar as penas ali previstas quando cabíveis; ${ }^{186}$

1) Submeter ao Comitê Técnico-Executivo propostas de edição de atos normativos; ${ }^{187}$

m) Executar decisões tomadas pelo Conselho de Ministros e pelo Comitê Técnico-Executivo. ${ }^{188}$

\footnotetext{
${ }^{179}$ Art.10, incisos X e XIII, da Resolução CMED n ${ }^{0} 3$, de 29 de julho de 2003.

${ }^{180}$ Art. 11, da Resolução CMED n ${ }^{0}$ 3, de 29 de julho de 2003.

${ }^{181}$ Art. 12, inciso X, da Resolução CMED n ${ }^{0}$ 3, de 29 de julho de 2003.

${ }^{182}$ Art. 12, inciso I, da Resolução CMED n ${ }^{0}$ 3, de 29 de julho de 2003.

${ }^{183}$ Art. 12, inciso III, da Resolução CMED n ${ }^{0}$ 3, de 29 de julho de 2003.

${ }^{184}$ Art. 12, inciso IV, da Resolução CMED n ${ }^{0} 3$, de 29 de julho de 2003.

${ }^{185}$ Art. 12, inciso VI, da Resolução CMED n ${ }^{0} 3$, de 29 de julho de 2003.

${ }^{186}$ Art. 12, inciso VI, da Resolução CMED n ${ }^{0}$ 3, de 29 de julho de 2003.

${ }^{187}$ Art. 12, inciso IX, da Resolução CMED n ${ }^{0}$ 3, de 29 de julho de 2003.

${ }^{188}$ Art. 12, inciso XII, da Resolução CMED n ${ }^{0} 3$, de 29 de julho de 2003.
} 
n) Realizar investigações preliminares e instaurar processos administrativos, com base no descumprimento de normas emitidas pela CMED; ${ }^{189}$

o) Decidir sobre a existência de infração e aplicar sanção, em razão de descumprimento de atos normativos da CMED; ${ }^{190}$

p) Comunicar o Comitê Técnico-Executivo as decisões sobre a apuração de infrações e aplicação de sanções administrativas; ${ }^{191} \mathrm{e}$

q) Realizar juízo de adminissibilidade de recurso administrativo a ser interposto perante o Comitê Técnico-Executivo. ${ }^{192}$

${ }^{189}$ Art. 14, da Resolução CMED n ${ }^{0} 3$, de 29 de julho de 2003.

${ }^{190}$ Art. 14, da Resolução CMED n ${ }^{0}$ 3, de 29 de julho de 2003.

${ }^{191}$ Art. 15, da Resolução CMED n ${ }^{0} 3$, de 29 de julho de 2003.

${ }^{192}$ Art. 16, inciso II, da Resolução CMED n ${ }^{0}$ 3, de 29 de julho de 2003. 


\section{A POLÍtica DE REGULAÇÃO DOS PREÇOS DOS MEDICAMENTOS}

\subsection{Breve análise da dimensão jurídica das políticas de saúde de assistência} farmacêutica

A regulação do mercado de medicamentos pela CMED possui respaldo jurídico não só na Lei 10.742/03, mas também nas seguintes políticas de saúde que têm por objetivo promover a assistência farmacêutica ${ }^{193}$ : Política Nacional de Promoção da Saúde ${ }^{194}$, Política Nacional de Medicamentos $(\mathrm{PNM})^{195}$ e Política Nacional de Assistência Farmacêutica (PNAF). ${ }^{196}$

Conforme mencionado na Introdução deste trabalho, a Política Nacional de Promoção da Saúde traça as diretrizes para a elaboração das demais políticas sanitárias. Um de seus objetivos gerais é promover o acesso a bens e serviços essenciais no âmbito da saúde. ${ }^{197}$ Dela decorre a Política Nacional de Medicamentos (PNM) que, com o propósito de assegurar o acesso da população a medicamentos ao menor custo possível, tem como uma de seus prioridades a assistência farmacêutica. ${ }^{198}$

Segundo a Política Nacional de Medicamentos, a reorientação da assistência farmacêutica deve estar fundamentada no desenvolvimento de iniciativas que "possibilitem a redução nos preços dos produtos, viabilizando, inclusive, o acesso da população aos produtos no âmbito do setor privado". ${ }^{199}$ Nesse sentido, é possível verificar que a assistência farmacêutica pode ser prestada tanto no âmbito do Sistema Único de Saúde, quanto no âmbito privado, pela aquisição direta de medicamentos pelo consumidor em

\footnotetext{
${ }^{193} \mathrm{O}$ art. $1^{\circ}$, inciso III, da Resolução CNS n ${ }^{\circ} 38$, de 6 de maio de 2004, define assistência farmacêutica como: "conjunto de ações voltadas à promoção, proteção e recuperação da saúde, tanto individual como coletivo, tendo o medicamento como insumo essencial e visando o acesso e o seu uso racional." (BRASIL. Conselho Nacional de Saúde. Resolução CNS $n^{\circ}$ 38, de 6 de maio de 2004. Disponível em: <http://portal.saude.gov.br/portal/arquivos/pdf/resol_cns338.pdf>. Acesso em: 8 jun. 2012.

${ }^{194}$ A Política Nacional de Promoção da Saúde foi aprovada pela Portaria n ${ }^{0} 687$ MS/GM, de 30 de março de 2006.

${ }^{195}$ A Política Nacional de Medicamentos (PNM) foi aprovada pela Portaria $n^{0} 3.916$ MS/GM, de 30 de outubro de 1998

${ }^{196}$ A Política Nacional de Assistência Farmacêutica (PNAF) foi aprovada pela Resolução $\mathrm{n}^{0}$ 338, do Conselho Nacional de Saúde (CNS), de 6 de maio de 2004.

${ }^{197}$ BRASIL. Ministério da Saúde. Política Nacional de Promoção da Saúde. Disponível em: <http://portal.saude.gov.br/portal/arquivos/pdf/Politica_nacional_\%20saude_nv.pdf >. Acesso em: 8 jun. 2012.

${ }^{198}$ BRASIL. Ministério da Saúde. Portaria n’3.916/MS/GM, de 30 de outubro de 1998. Disponível em: <http://www.anvisa.gov.br/legis/consolidada/portaria_3916_98.pdf >. Acesso em: 8 jun.2012.

${ }^{199}$ Ibid.
} 
drogarias e farmácias a um preço justo. Ambas as modalidades de assistência farmacêutica estão contempladas como objetivos da PNM.

Após a publicação da Lei 10.742/03, responsável pela criação da CMED e por estabelecer normas de regulação do setor farmacêutico com a finalidade de promover a assistência farmacêutica à população, ${ }^{200}$ o Conselho Nacional de Saúde instituiu, mediante a Resolução CNS n 338/04, a Política Nacional de Assistência Farmacêutica (PNAF). Perfeitamente em harmonia com a Lei 10.742/03, essa resolução previu expressamente como eixo estratégico da assistência farmacêutica o "estabelecimento de mecanismos adequados para a regulação e monitoração do mercado de insumos e produtos estratégicos para a saúde, incluindo os medicamentos". ${ }^{201}$

Assim como mencionado na Introdução, será realizada uma breve análise das políticas de saúde que visam a promoção do acesso a medicamentos, mediante a verificação dos papéis e funções que o direito assume em cada uma delas. O propósito é propiciar uma visão mais ampla do cenário em que se insere a regulação do mercado de medicamentos, explicitando sua relação com as políticas de saúde. Também conforme dito anteriormente, são papéis do direito definir e delinear objetivos, ferramentas, arranjos institucionais e instrumentos de participação popular e controle social, atuando, neste último caso, como vocalizador de demandas.

\section{Direito como objetivo}

Pode-se dizer que, dentre outras funções, o direito fixa objetivos a serem concretizados, ou seja, define "pontos de chegada" das políticas públicas. São estabelecidas finalidades e diretrizes normativas que devem ser perseguidas pelas políticas governamentais. $\mathrm{O}$ direito entendido como objetivo de políticas públicas retira do plano das intenções determinada decisão concebida no âmbito político e confere-lhe caráter vinculante $^{202}$. Nesse sentido, a Política Nacional de Promoção da Saúde, a PMN e a PNAF possuem como objetivo a promoção da assistência farmacêutica.

\footnotetext{
${ }^{200}$ Art. $1^{\circ}$, da Lei ${ }^{\circ} 10.748$, de 6 de outubro de 2003.

${ }^{201}$ Art. $2^{\circ}$, inciso XII, da Resolução CNS n 38 , de 6 de maio de 2004.

${ }^{202}$ COUTINHO, D. R. O direito nas políticas públicas. A ser publicado em Eduardo Marques e Carlos Aurélio de Pimenta de Faria (eds.) "Política Pública como Campo Disciplinar", São Paulo, Ed. Unesp, no prelo.
} 


\section{Direito como ferramenta}

O direito compreendido como ferramenta de políticas públicas pode ser tido como meio para a concretização de objetivos pré-fixados, atuando em uma dimensão funcional. Consiste em estratégias e racionalidades jurídicas que podem ser utilizadas como forma de operacionalizar uma política. ${ }^{203}$ São exemplos de ferramentas jurídicas utilizadas para a promoção da assistência farmacêutica o controle de preços com base no price cap e as normas legais sancionatórias, que estabelecem penalidades previstas no Código de Defesa do Consumidor aos atores econômicos que descumprirem decisões emanadas da CMED. Essas ferramentas estão previstas na Lei 10.742/03 e atuam, respectivamente, como mecanismos de indução (o price cap estimula a produtividade da indústria ${ }^{204}$ ) e direção (normas sancionatórias são utilizadas para coibir comportamentos indesejados).

É dentro da categoria "direito como ferramenta" que reside o foco da presente pesquisa, uma vez que se pretende analisar a regulação dos preços no mercado de medicamentos e a atuação da CMED sobre esse setor da economia. Isso, pois a política regulatória em questão foi o instrumento jurídico-econômico escolhido pelo legislador para implementar o objetivo de políticas públicas de saúde que visam a promoção da assistência farmacêutica. Nesse sentido, as políticas regulatórias podem ser utilizadas como ferramentas de consecução de políticas públicas, estando vinculadas a elas de tal modo que não podem negá-las, contrariá-las ou esvaziá-las. É também no âmbito das políticas regulatórias que se define o timing e o resultado de uma política pública destinada a determinado setor da economia. ${ }^{205}$

\section{Direito como arranjo institucional}

A implementação de políticas públicas pode implicar na criação de instituições e na disciplina de novas estruturas organizacionais. Como vetor de arranjo institucional, o direito estrutura o funcionamento, regula procedimentos, estabelece competências e articula os atores envolvidos nas políticas públicas. Desse modo, cria, extingue e modifica

\footnotetext{
${ }^{203} \mathrm{O}$ direito como ferramenta envolve "o estudo das diferentes possibilidades de modelagem jurídica de políticas públicas, a escolha dos instrumentos de direito administrativo mais adequados (dados os fins a serem perseguidos), o desenho de mecanismos de indução ou recompensa para certos comportamentos, a seleção do tipo de norma a ser utilizada (mais ou menos flexível, mais ou menos estável, mais ou menos genérica) [...]"(COUTINHO, D. R. O direito nas políticas públicas. A ser publicado em Eduardo Marques e Carlos Aurélio de Pimenta de Faria (eds.) "Política Pública como Campo Disciplinar", São Paulo, Ed. Unesp, no prelo).

${ }^{204}$ Como será visto mais adiante, a CMED utiliza o price cap como instrumento jurídico-econômico na atividade de regulação dos preços de medicamentos.

${ }^{205}$ MARQUES NETO, F. A. Agências Reguladoras Independentes: Fundamentos e seu Regime Jurídico. Belo Horizonte: Fórum, 2005. p. 87-88.
} 
órgãos, coordena relações público-privadas, atribui competências e reparte responsabilidades entre os diferentes atores políticos. ${ }^{206}$ Para implementar a assistência farmacêutica, mediante a regulação do mercado, a Lei 10.742/03 criou a Câmara de Regulação do Mercado de Medicamentos. Assim, foram provocadas mudanças de natureza institucional, no que diz respeito à estrutura organizacional da Administração Pública, à articulação de competências (principalmente entre a CMED e a ANVISA) e à origem de novos processos que produzem efeitos sobre o mercado de medicamentos e sobre a atuação dos atores econômicos nele envolvidos.

\section{Direito como vocalizador de demandas}

O direito é capaz de conduzir as políticas públicas e as políticas regulatórias a serem mais democráticas, assegurando a participação dos interessados na conformação, implementação ou avaliação da política. Para isso, explica Coutinho:

[...] o direito pode prover (ou desprover) as políticas de mecanismos de deliberação, participação, consulta, colaboração e decisão conjunta assegurando, com isso, que elas sejam permeáveis à participação e não insuladas em anéis burocráticos." 207

No caso em questão, para garantir que tanto a assistência farmacêutica quanto a regulação do mercado farmacêutico sejam balizadas por princípios de natureza democrática, as decisões subjacentes às políticas de saúde e à regulação do mercado farmacêutico devem ser formuladas não apenas com base na opinião dos gestores de saúde ou do ente regulador, mas também mediante a participação dos interessados na sua implementação. É através de normas jurídicas que canais de participação são definidos, bem como formas de prestação de contas por parte dos órgãos formuladores das referidas políticas (accountability).

São diretamente interessados na promoção da assistência farmacêutica, mediante a regulação dos preços dos medicamentos, os laboratórios farmacêuticos nacionais e internacionais, os consumidores desses produtos e, em última instância, o próprio Estado que, por meio da Administração Pública, destina recursos à compra de medicamentos para

${ }^{206}$ COUTINHO, D. R. O direito nas políticas públicas. A ser publicado em Eduardo Marques e Carlos Aurélio de Pimenta de Faria (eds.) "Política Pública como Campo Disciplinar", São Paulo, Ed. Unesp, no prelo. ${ }^{207}$ Ibid. 
o abastecimento do Sistema Único de Saúde (SUS). Na legislação atinente às políticas de sáude foi possível identificar como forma de participação da população na elaboração e definição dos objetivos das políticas de saúde a participação popular nos Conselhos de Saúde. Contudo, não foi possível identificar na legislação atinente à Câmara de Regulação do Mercado de Medicamentos a previsão de instrumentos jurídicos que assegurem a participação dos interessados ou o accountability. Com o propósito de averiguar se existem mecanismos extralegais nesse sentido, o questionário aplicado a membros da CMED conteve perguntas sobre o tema.

\subsection{A política de regulação econômica dos preços de medicamentos no Brasil}

Neste tópico será abordada a regulação do mercado farmacêutico realizada pela Câmara de Regulação do Mercado de Medicamentos, mediante o controle de preços, tal como delineada pela Lei 10.742/03.

Conforme mencionado anteriormente, quando do estudo da CMED, a Lei 10.742/03 criou este órgão regulador e estabeleceu normas de regulação do setor farmacêutico, com a finalidade de promover a assistência farmacêutica à população, por meio de mecanismos que estimulem a oferta de medicamentos e a competitividade do setor. Essa política regulatória se insere, em última análise, no contexto da Política Nacional de Promoção da Saúde e, nos termos da lei, é centrada no controle de preços dos medicamentos.

Mais do que corrigir falhas, a fim de tornar o mercado mais competitivo (regulação econômica), a política regulatória foi concebida como ferramenta de promoção do acesso a medicamentos por parte da população (regulação social). Nesse sentido, vale lembrar da diferença entre regulação econômica e regulação social do mercado de medicamentos. A regulação econômica fundamenta-se em razões de natureza econômica, relativas à eficiência do mercado (eficiência dinâmica e estática). Em contrapartida, a regulação social justifica-se por motivos de natureza não econômica, tais como distribuição de renda, bemestar, dentre outros. ${ }^{208}$

O controle de preços em sentido estrito utilizado no mercado farmacêutico consiste no acompanhamento e limitação dos preços dos medicamentos (diferente do tabelamento e

${ }^{208}$ COUTINHO, D. R. Regulação e redistribuição: a experiência brasileira de universalização das telecomunicações. 2003. Tese (Doutorado em Direito) - Faculdade de Direito, Universidade de São Paulo, São Paulo, 2003. p.162-163. 
do congelamento) $)^{209}$ e pode ser exercido mediante diversas técnicas, conforme será visto no próximo tópico. O instrumento de controle de preços adotado pela CMED é direto e consiste em uma "variante" do mecanismo do price cap ou modelo de teto de preços que tem como principal objetivo repassar para o consumidor reduções de custos decorrentes de aumentos de produtividade. Sua principal vantagem é que a determinação de um valor máximo para o preço estimula o aumento da eficiência produtiva: as firmas têm estímulos para minimizar custos, para poderem, assim, apropriar-se de lucros excedentes. ${ }^{210}$

O modelo de teto de preços foi criado na Inglaterra, em 1984, e estabelece que o ajuste de preços é dado pela variação de um índice de preços, menos um "fator x" que incorpora a estimativa do aumento futuro de produtividade. Mediante a ferramenta do price cap, é realizado controle sobre as margens de distribuição e de comercialização. ${ }^{211}$

É através do controle de margens de distribuição e de comercialização que são estabelecidos os preço-fábrica (PF) e o preço máximo ao consumidor (PMC), respectivamente. $^{212}$

Em se tratando de reajustes de preços, o PF será obtido mediante a seguinte fórmula ${ }^{213}$ :

$\mathrm{VPP}=\mathrm{IPCA}-\mathrm{X}+\mathrm{Y}+\mathrm{Z}$, em que:

VPP: representa a variação do percentual do preço do medicamento (preço-fábrica do medicamento);

IPCA: a taxa de inflação medida pela variação percentual do Índice de Preços do Consumidor Amplo, calculados pelo Instituto Brasileiro de Geografia e Estatística - IBGE. O IPCA utilizado no cálculo é o acumulado no último ano;

$\mathrm{X}$ : o fator produtividade. Esse fator é expresso em percentual e consiste no "mecanismo que permite repassar aos consumidores, por meio dos preços dos medicamentos, projeções de ganhos de produtividade das empresas produtoras de medicamentos". ${ }^{214} \mathrm{O}$ fator produtividade é determinado com base na estimativa de ganhos futuros de produtividade da indústria farmacêutica.

\footnotetext{
${ }^{209}$ GRAU, E. R. A ordem econômica na Constituição de 1988. 13 ${ }^{\text {a }}$ ed. São Paulo: Malheiros, 2008. p.102. ${ }^{210}$ TEIXEIRA, L. S. Reajustes de preços administrados no setor da saúde: consultoria legislativa (2006), jul. 2010. p.15.

${ }^{211}$ PIRES J. L.; PICCININI M. S., Modelos de regulação tarifária do setor elétrico. In: BNDES. Modelos de regulação tarifária: a experiência internacional e o caso brasileiro. Rio de Janeiro: BNDES, 1998. p.5.

${ }^{212}$ Lei $\mathrm{n}^{\circ} 10.742$, de 6 de outubro de 2003.

${ }^{213}$ Resolução CMED n ${ }^{\circ} 1$, de 27 de fevereiro de 2004.

${ }^{214}$ ROMANO, L.A.N. Intervenção e regulação no Brasil: a indústria farmacêutica. São Paulo: FEBRAFARMA, 2005. p.71.
} 
Y: o fator de ajuste de preços entre setores. Assim como o fator X, o fator Y é expresso em percentual. Foi criado para corrigir choques de câmbio. Ele é calculado com base na variação dos custos dos insumos, "desde que tais custos não sejam recuperados pelo cômputo do índice de preços"; 215 e

Z: o fator de ajuste de preços intra-setores. Também expresso em percentual, esse fator é calculado com base no poder de mercado que a empresa exerce na comercialização de determinado medicamento pertencente a uma classe. Ele é determinado pela assimetria de informação, pelas barreiras à entrada e pelo poder de monopólio, dentre outros fatores. Quanto maior a participação de medicamentos genéricos em determinada classe terapêutica, menor o fator $\mathrm{Z}$ e maior o reajuste. ${ }^{216}$

A margem de distribuição, responsável por até $50 \%$ do preço ao consumidor é controlada por meio da fixação do preço-fábrica. O preço-fábrica incorpora o preço do laboratório, o custo de financiamento da venda, o frete, o PIS/COFINS, o ICMS e o desconto para distribuição. ${ }^{217}$

É com base também no preço-fábrica que é calculado o preço máximo ao consumidor (PMC). O PMC é obtido mediante a divisão do PF pelo fator definido pela CMED. Os fatores variam conforme a carga tributária do ICMS do Estado de destino e a incidência do PIS/PASEP e COFINS, nos termos do disposto na Lei $\mathrm{n}^{\circ} 10.147$, de 21 de dezembro de 2001. Além disso, os preços de venda ao consumidor não podem ultrapassar o PMC. ${ }^{218}$

Para a determinação dos preços iniciais de novos produtos ou novas apresentações $^{219}$ a CMED classifica os medicamentos em seis categorias, para as quais são adotados critérios de precificação distintos. Os produtos novos e novas apresentações são classificados nas seguintes categorias:

Categoria I: produto novo com molécula que seja objeto de patente no país e que traga ganho para o tratamento em relação aos medicamentos já utilizados para a mesma indicação terapêutica, com a comprovação de um dos seguintes requisitos ${ }^{220}$ :

\footnotetext{
${ }^{215}$ ROMANO, L.A.N. Intervenção e regulação no Brasil: a indústria farmacêutica. São Paulo: FEBRAFARMA, 2005. p.71.

${ }^{216}$ Ibid.p. 71 e p. 77.

${ }^{217}$ TEIXEIRA, L. S. Reajustes de preços administrados no setor da saúde: consultoria legislativa (2006), jul. 2010. p.20.

${ }^{218}$ Resolução CMED n ${ }^{\circ} 2$, de 8 de março de 2010.

${ }^{219}$ Consideram-se novos produtos os medicamentos com moléculas novas no país; enquanto que as novas apresentações são todos os medicamentos que não se enquadrem na primeira definição $\left(\operatorname{art.} 1^{0}\right.$, $\S \S 1^{0}$ e $2^{0}$, do Anexo da Resolução $n^{0}$ 2, de 5 de março de 2004).

${ }^{220}$ Art. $2^{0}$, inciso I, do Anexo da Resolução CMED n ${ }^{0}$ 2, de 5 de março de 2004.
} 
a) maior eficácia em relação aos medicamentos existentes para a mesma indicação terapêutica;

b) mesma eficácia com diminuição significativa dos efeitos adversos; ou

c) mesma eficácia com redução significativa do custo global de tratamento.

O preço fábrica dos medicamentos pertencentes a essa categoria não pode ser superior ao menor preço fábrica praticado para o mesmo produto nos países relacionados no inciso VII, do $\S 2^{0}$, do art. $4^{0}$, do Anexo da Resolução $n^{0}$ 2, de 5 de março de 2004 (Austrália, Canadá, Espanha, Estados Unidos da América, França, Grécia, Itália, Nova Zelândia, Portugal e o preço fabricante praticado no país de origem do produto), agregando-se os impostos incidentes, conforme o caso. ${ }^{221}$

Categoria II: produtos novos que não se enquadrem na definição do inciso anterior. ${ }^{222}$ No caso dos medicamentos pertencentes a esta categoria, o preço fábrica será definido tendo como base o custo de tratamento com os medicamentos utilizados para a mesma indicação terapêutica (medicamento comparador), não podendo, em qualquer hipótese, ser superior ao menor preço praticado dentre os países relacionados no inciso VII, do $\$ 2^{0}$, do art. $4^{0}$, do Anexo da Resolução $n^{0} 2$, de 5 de março de 2004. O medicamento a ser utilizado como comparador será definido com base em parecer técnico da ANVISA, que deverá considerar, em sua análise, os medicamentos utilizados para tratamento em questão no país e as evidências científicas existentes. ${ }^{223}$

Categoria III: nova apresentação de medicamento já comercializado pela própria empresa, em uma mesma forma farmacêutica. ${ }^{224} \mathrm{O}$ preço fábrica permitido para os produtos classificados nesta categoria não poderá ser superior à média aritimética dos preços das apresentações do medicamento, com igual concentração e mesma forma farmacêutica, já comercializadas pela própria empresa. ${ }^{225}$

Categoria IV: nova apresentação de medicamento que se enquadrar em uma das situações: 226

\footnotetext{
${ }^{221}$ Art. $5^{0}$, caput, do Anexo da Resolução CMED n ${ }^{0}$ 2, de 5 de março de 2004.

${ }^{222}$ Art. $2^{0}$, inciso I, do Anexo da Resolução CMED n ${ }^{0} 2$, de 5 de março de 2004.

${ }^{223}$ Art. $6^{0}, \S 2^{0}$, do Anexo da Resolução n ${ }^{0} 2$, de 5 de março de 2004.

${ }^{224}$ Art. $3^{0}$, inciso I, do Anexo da Resolução ${ }^{0}$ 2, de 5 de março de 2004.

${ }^{225}$ Art. $7^{0}$, caput, do Anexo da Resolução n ${ }^{0}$ 2, de 5 de março de 2004.

${ }^{226}$ Art. $3^{0}$, inciso II, do Anexo da Resolução n ${ }^{0} 2$, de 5 de março de 2004.
} 
a) medicamento que seja novo na lista dos comercializados pela empresa, à exceção dos casos previstos no inciso III deste artigo;

b) medicamento já comercializado pela empresa, em nova forma farmacêutica.

O preço fábrica dos medicamentos pertencentes à categoria IV não poderá ultrapassar o preço médio das apresentações dos medicamentos com o mesmo princípio ativo e a mesma concentração disponíveis no mercado, na mesma forma farmacêutica, ponderado pelo faturamento de cada apresentação, com base no que segue ${ }^{227}$ :

1. A média deverá ser calculada com base nas apresentações de igual concentração existentes no mercado; ${ }^{228}$

2. Não existindo apresentações com igual concentração, a média deverá ser calculada com base em todas as apresentações da mesma fórmula e mesma forma farmacêutica existentes no mercado, seguindo o critério da proporcionalidade direta da concentração de princípio ativo. ${ }^{229}$

Categoria V: medicamento que se enquadrar em uma das seguintes situações: ${ }^{230}$

a) nova forma farmacêutica no país;

b) nova associação de princípios ativos já existentes no país.

No caso de nova associação no país de monodrogas que sejam comercializadas separadamente, o preço da associação não poderá ser superior à soma dos preços das monodrogas e desde que o referido preço não implique em custo de tratamento superior ao já existente. ${ }^{231}$ Quanto ao preço de uma nova associação de monodrogas já comercializada no país que substitua com vantagens comprovadas o tratamento com as monodrogas tomadas isoladamente, a empresa poderá apresentar justificativa para o preço proposto, cuja relevância será analisada pelo Comitê Técnico-Executivo. ${ }^{232}$

Categoria VI: medicamento classificado como genérico, de acordo com a redação dada pela Lei $\mathrm{n}^{\circ}$ 9.787, de 10 de fevereiro de 1999, ao inciso XXI do artigo $3^{\circ}$, da Lei $\mathrm{n}^{\circ}$ 6.360, de 23 de setembro de $1976 .{ }^{233} \mathrm{O}$ preço fábrica dos medicamentos genéricos não

\footnotetext{
${ }^{227}$ Art. $9^{0}$, caput, do Anexo da Resolução ${ }^{0} 2$, de 5 de março de 2004.

${ }^{228}$ Art. $9^{0}$, inciso I, do Anexo da Resolução $n^{0} 2$, de 5 de março de 2004.

${ }^{229}$ Art. $9^{0}$, inciso II, do Anexo da Resolução n ${ }^{0} 2$, de 5 de março de 2004.

${ }^{230}$ Art. $3^{0}$, inciso III, do Anexo, da Resolução n ${ }^{0}$ 2, de 5 de março de 2004.

${ }^{231}$ Art. $9^{0}$, inciso I, do Anexo da Resolução n ${ }^{0} 2$, de 5 de março de 2004.

${ }^{232}$ Art. $9^{0}$, inciso I, do Anexo da Resolução n ${ }^{0} 2$, de 5 de março de 2004.

${ }^{233}$ Art. $3^{0}$, inciso IV, do Anexo da Resolução $n^{0} 2$, de 5 de março de 2004.
} 
poderá ser superior a $65 \%$ do preço atribuído ao medicamento de referência correspondente. $^{234}$

Os produtos de comercialização liberada são os sem tarja, de venda livre, que tenham $\mathrm{HHI}^{235}$ menor que 1800; os expectorantes; analgésicos não-narcóticos; antigripais, excluindo antiinfecciosos; antisépticos e desinfetantes; estomatológicos; polivitamínicos; fitoterápicos e homeopáticos. ${ }^{236}$ Tais medicamentos não são submetidos ao controle de preços, nos termos da Resolução CMED n ${ }^{0}$ 3, de 5 de março de 2004, e da Resolução CMED n ${ }^{0} 3$, de 18 de março de 2010.

Conforme mencionado no item que trata das competências da CMED, esse órgão regulador também é responsável pela fixação do Coeficiente de Adequação de Preços CAP. O CAP é definido como razão entre o índice do produto interno bruto (PIB per capita) do Brasil e o índice do PIB per capita do país em que o medicamento apresentou o menor preço. ${ }^{237}$ Vale registrar que, conforme esclareceu em entrevista membro da Secretaria-Executiva da CMED, o CAP só é aplicado às vendas públicas, não se estendendo essa espécie de desconto às vendas realizadas as hospitais particulares que atendem pacientes do Sistema Único de Saúde (informação verbal). ${ }^{238}$

Por sua vez, a atuação estatal ${ }^{239}$ no mercado farmacêutico não se restringe ao controle direto de preços estabelecido pela Lei 10.742/03. Embora não estejam previstos na mencionada lei e não sejam praticados pela CMED, existem outros mecanismos regulatórios que contribuem para o acesso a medicamentos. Alguns desses instrumentos atuam indiretamente sobre os preços e são utilizados no Brasil. Outros ainda não foram adotados nesse país, conforme será visto no próximo item.

\footnotetext{
${ }^{234}$ Art. 12, inciso IV, do Anexo, da Resolução n ${ }^{0}$ 2, de 5 de março de 2004.

${ }^{235} \mathrm{O}$ Índice Herfindahl-Hirschman (HHI) "avalia o grau de concentração do mercado relevante sendo calculado por meio da soma dos quadrados dos market shares individuais das firmas participantes no mercado relevante, tendo a vantagem de refletir a distribuição do tamanho das firmas, posto que o peso conferido às firmas com elevado market share é maior do que aquele relativo às firmas com baixo market share" (BRASIL Agência Nacional De Telecomunicações. Concentração do mercado de SMP. Dispoinível em: <http://www.anatel.gov.br/Portal/verificaDocumentos/documento.asp?numeroPublicacao〉. Acesso em 5 jan. 2013).

${ }^{236}$ ROMANO, L.A.N. Intervenção e regulação no Brasil: a indústria farmacêutica. São Paulo: FEBRAFARMA, 2005. p.76.

${ }^{237}$ Art. $5^{0}, \S 4^{0}$, inciso I, do Anexo da Resolução ${ }^{0} 2$, de 5 de março de 2004.

${ }^{238}$ Informação fornecida por assessores da Secretaria-Executiva da CMED, em entrevista realizada em Brasília, em 5 de julho de 2012 (vide transcrição do áudio da entrevista com assessores da SecretariaExecutiva da CMED, no Anexo C).

${ }^{239}$ Segundo Eros Grau, a expressão "atuação estatal" consiste na atuação do Estado no campo da atividade econômica em sentido amplo, dizendo respeito à "globalidade da atuação estatal como agente normativo e regulador" (GRAU, E. A ordem econômica na Constituição de 1988. 13ª ed. São Paulo: Malheiros, 2008. p. 91 e p.107).
} 


\subsection{Outras técnicas regulatórias}

As técnicas regulatórias do mercado farmacêutico podem incidir sobre os preços (controle direto ou indireto de preços) ou sobre os gastos dos consumidores. Os instrumentos de regulação pertencentes ao primeiro grupo incidem sobre a oferta de medicamentos; enquanto que os mecanismos representantes do segundo grupo procuram influenciar o comportamento dos médicos, pacientes e do próprio sistema público de saúde, incidindo sobre a demanda. ${ }^{240}$

A seguir serão analisadas técnicas regulatórias que incidem sobre a oferta (política dos medicamentos genéricos; criação de órgãos certificadores de qualidade, de eficácia e segurança e restrição ao registro, comercialização e distribuição; defesa da concorrência; controle do tempo de duração das patentes de fármacos; controle de lucros; análise de custo-efetividade; e controle direto de preços) e sobre a demanda (restrições à propaganda de medicamentos; preço de referência, reembolso e listas de prescrição; diretrizes e fiscalização sobre a atividade médica de prescrição de medicamentos; orçamento de prescrição; e co-pagamento ou cost sharing). ${ }^{241}$

- $\quad$ Técnicas regulatórias que incidem sobre a oferta:

\section{Política dos medicamentos genéricos}

Os medicamentos genéricos foram introduzidos no Brasil pela Lei 9.787, de 10 de fevereiro de 1999. O objetivo da política dos medicamentos genéricos é criar uma alternativa viável ao mercado farmacêutico brasileiro, reduzindo a dependência externa de importação de medicamentos, bem como os preços e custos desses produtos. ${ }^{242}$ Também tem como propósito promover a concorrência entre os medicamentos comercializados. Segundo a Lei 9.787/99, o medicamento genérico é:

[o] medicamento similar a um produto de referência ou inovador, que se pretende ser com este intercambiável, geralmente produzido após a expiração ou renúncia da proteção patentária ou de outros direitos de

${ }^{240}$ RÊGO, E.C.L. Políticas de regulação do mercado de medicamentos: a experiência internacional. Revista do BNDES, Rio de Janeiro, v.7, n.14, p.367-400, dez. 2000.

${ }^{241}$ Ibid. p. 377-384.

${ }^{242}$ ZUCCHI, P.; VIEIRA, F.S. Diferenças de preços entre medicamentos genéricos e de referência no Brasil. Revista de Saúde Pública, São Paulo, v.40, n.3, p.444-449.2006. p.445. 
exclusividade, comprovada a sua eficácia, segurança e qualidade, e designado pela DCB ou, na sua ausência, pela DCI. ${ }^{243} 244$

Os medicamentos genéricos diferem dos medicamentos similares, uma vez que nestes medicamentos não é realizado o teste de bioequivalência, de modo que não podem substituir os remédios de marca ou referência, porque "não passaram por análises capazes de atestar se seus efeitos no paciente são exatamente iguais aos dos medicamentos de referência nos quesitos quantidade absorvida e velocidade de absorção". ${ }^{245}$

Sobre a introdução dos medicamentos genéricos no mercado farmacêutico e seu impacto sobre o acesso a medicamentos não há consenso entre os estudiosos.

Segundo Hasenclever, no Brasil, foi possível verificar que a inserção dos genéricos não contribuiu para um aumento significativo do acesso a medicamentos. ${ }^{246}$ Conforme é possível extrair da tabela abaixo, no período inicial da comercialização de medicamentos genéricos, embora a venda desses produtos tenha crescido, o mercado farmacêutico apresentou contração de 15,3\% das unidades vendidas (Tabela 6).

\footnotetext{
${ }^{243} \mathrm{O}$ art. $2^{\circ}$ da Resolução ANVISA RDC n. 96 de 17 de dezembro de 1998 define DCB e DCI, da seguinte forma:

Denominação Comum Brasileira (DCB): "denominação do fármaco ou princípio farmacologicamente ativo aprovado pelo órgão federal responsável pela vigilância sanitária".

Denominação Comum Internacional (DCI): "denominação do fármaco ou princípio farmacologicamente ativo recomendado pela Organização Mundial da Saúde".

${ }^{244}$ Art. $1^{\circ}$, da Lei 9.787, de 10 de fevereiro de 1999.

${ }^{245}$ BRASIL. Agência Nacional de Vigilância Sanitária. Diferenças entre embalagem de genérico e similar. 10 de fevereiro de 2000. Disponível em: <http://www.anvisa.gov.br/divulga/noticias/100300.htm〉. Acesso em: 19 dez.2012. O art. $1^{\circ}$, da Lei $9.787 / 99$ fornece as seguintes definições de medicamentos similares e de referência:

Medicamento similar: "aquele que contém o mesmo ou os mesmos princípios ativos, apresenta a mesma concentração, forma farmacêutica, via de administração , posologia e indicação terapêutica, e que é equivalente ao medicamento registrado no órgão federal responsável pela vigilância sanitária, podendo diferir somente em características relativas ao tamanho e forma do produto, prazo de validade, embalagem, rotulagem, excipientes e veículos, devendo sempre ser identificado por nome comercial ou marca".

Medicamento de referência: "produto inovador registrado no órgão federal responsável pela vigilância sanitária e comercializado no País, cuja eficácia, segurança e qualidade foram comprovadas cientificamente junto ao órgão federal competente, por ocasião do registro".

Referido artigo da lei 9.787/99 também define "produto intercambiável" da seguinte maneira: "equivalente terapêutico de um medicamento de referência, comprovados, essencialmente, os mesmos efeitos de eficácia e segurança".

${ }^{246}$ HASENCLEVER, L. Diagnóstico da indústria farmacêutica brasileira. Rio de Janeiro: UNESCO, 2002. p.9.
} 
Tabela 6. Evolução da venda dos medicamentos genéricos e dos medicamentos de referência no início dos anos 2000

\begin{tabular}{lccccccccc}
$\begin{array}{l}\text { Unidade } \\
\text { (000) }\end{array}$ & Genérico & \% & Referência & \% & $\begin{array}{c}\text { Similar } \\
\text { sem } \\
\text { marca }\end{array}$ & \% & Similar & \% & Total \\
\hline Maio/00 & & & & & & & \\
\hline Junho/00 & 532,1 & 1,3 & 18300,9 & 65,9 & 1634,0 & 5,9 & 7463,4 & 26,9 & 27760,4 \\
\hline Julho/00 & 674,9 & 2,7 & 15897,9 & 64,6 & 1528,8 & 6,2 & 6485,2 & 26,4 & 24568,8 \\
\hline Agosto/00 & 794,1 & 3,2 & 15624,5 & 63,1 & 1624,7 & 6,6 & 6702,5 & 27,1 & 24745,8 \\
\hline Setembro/00 & 904,2 & 4,0 & 14269,6 & 62,7 & 1491,1 & 6,6 & 6076,2 & 26,7 & 22741,2 \\
\hline Outubro/00 & 1093,3 & 4,6 & 14936,9 & 62,3 & 1456,1 & 6,1 & 6482,6 & 27,0 & 23968,8 \\
\hline Novembro/00 & 1227,2 & 5,2 & 14839,9 & 62,9 & 1382,2 & 5,9 & 6134,9 & 26,0 & 23584,2 \\
\hline Dezembro/00 & 1505,8 & 6,5 & 14242,4 & 61,3 & 1530,4 & 6,6 & 5945,6 & 25,6 & 23233,3 \\
\hline Janeiro/01 & 1840,2 & 7,8 & 14001,1 & 59,4 & 1640,3 & 7,1 & 6047,6 & 25,7 & 23565,4 \\
\hline Fevereiro/01 & 1706,7 & 8,8 & 11455,0 & 59,2 & 1351,8 & 7,0 & 4826,8 & 25,0 & 19340,3 \\
\hline Março/01 & 2296,6 & 9,6 & 13996,9 & 58,8 & 1640,3 & 6,9 & 5883,9 & 24,7 & 23817,6 \\
\hline Abril/01 & 2578,4 & 11,2 & 13165,6 & 57,3 & 1576,0 & 6,9 & 5644,3 & 24,6 & 22964,4 \\
\hline Total & 15514,6 & 5,4 & 178029,1 & 61,7 & 18507,9 & 6,5 & 74644,7 & 26 & 286697,4 \\
\hline
\end{tabular}

Fonte: Adaptado de HASENCLEVER, L. Diagnóstico da indústria farmacêutica brasileira. Rio de Janeiro: UNESCO, 2002. p.9.

Em contrapartida, Zucchi e Vieira chegaram a conclusão diversa, depois de analisar os resultados obtidos em pesquisa realizada em 2006. Nessa pesquisa, as autoras acompanharam a evolução dos preços de determinada amostra de medicamentos de referência e de seus substitutos genéricos. O resultado obtido indicou que $99 \%$ dos medicamentos genéricos analisados apresentaram preços inferiores àqueles dos respectivos medicamentos de referência. A média da diferença de preços foi de $40 \%$. O acompanhamento dos preços foi feito no período de 4 anos, possibilitando que as pesquisadoras constatassem que, durante esse espaço temporal, a diferença de preços entre os medicamentos genéricos e os medicamentos de referência aumentou com o passar do tempo. O aumento dessa diferença provavelmente ocorreu em função do aumento da concorrência no mercado causada pela introdução dos genéricos. No que diz respeito aos preços dos medicamentos de referência, foi observado aumento de preços com o decurso do tempo. ${ }^{247}$

${ }^{247}$ ZUCCHI, P.; VIEIRA, F.S. Diferenças de preços entre medicamentos genéricos e de referência no Brasil. Revista de Saúde Pública, São Paulo, v.40, n.3, p.444-449.2006. p.448-449. 
Nesse sentido também estão os resultados obtidos por Fiúza e Lisboa, em estudo concluído em 2004. ${ }^{248}$ Os resultados de ambas as pesquisas mostraram que a introdução de medicamentos genéricos contribuiu para a oferta de medicamentos a menores preços, embora tenha prejudicado parcela dos consumidores que se manteve fiel ao medicamento de marca.

Nishijima e Biasoto Jr. chegaram a conclusões diversas dos estudos supramencionados. Os resultados obtidos por esses autores indicam que os medicamentos de referência que possuem correspondentes genéricos apresentaram diminuição dos preços, após a implementação da política dos genéricos. No entanto, tal estudo não leva em consideração a relação direta de preços entre o medicamento genérico e o de referência, conforme mencionado pelos próprios autores. ${ }^{249}$

Levando em consideração os resultados obtidos pelo estudo de Zucchi e Vieira, bem como pela pesquisa de Fiúza e Lisboa, e que o consumo de medicamentos genéricos aumentou com o passar dos anos ${ }^{250}$, em geral, é possível concluir que a política brasileira de medicamentos genéricos foi bem sucedida, tendo colocado ao alcance do consumidor medicamentos intercabiáveis a preços mais acessíveis.

Criação de órgãos certificadores de qualidade, eficácia e segurança dos medicamentos e restrição ao registro, comercialização e distribuição

A certificação da qualidade, eficácia e segurança dos medicamentos e as condições para a aquisição de registro junto ao Ministério da Saúde, comercialização e distribuição de medicamentos estão diretamente interligadas, razão pela qual serão abordadas em conjunto.

O registro de medicamentos é instrumento por meio do qual o governo determina a inscrição prévia no órgão ou na entidade competente pela avaliação do cumprimento de

\footnotetext{
${ }^{248}$ FIUZA, E.; LISBOA, M. Bens credenciais e poder de mercado: um estudo econométrico da indústria farmacêutica brasileira. Disponível em: <http://www.ipea.gov.br/pub/td/2001/td_0846.pdf.> Acesso em: 22 jul. 2010. Segundo esses autores: "Esse resultado sugere que medidas que facilitem a entrada de genéricos terão efeitos diferenciados sobre os consumidores, de acordo com os segmentos a que pertencem: consumidores mais conservadores, que se recusarem a substituir o medicamento líder por um genérico mais barato, sofrerão um aumento nos seus custos de tratamento, enquanto aqueles mais flexíveis, que efetuarem a troca, encontrarão preços, em média, mais baixos à medida que o mercado se pulverizar entre diversos fornecedores".

${ }^{249}$ NISHIJIMA M., BIASOTO Jr., G. Os preços dos medicamentos de referência após a entrada dos medicamentos genéricos no mercado brasileiro. São Paulo, 2003. Disponível em:< http://www.anpec.org.br/encontro2003/artigos/D29.pdf>. Acesso em: 19 dez. 2012.

${ }^{250}$ BRASIL. Agência Nacional de Vigilância Sanitária. Resultado de pesquisas. Disponível em:< http://www.anvisa.gov.br/hotsite/ genericos/index.htm>. Acesso em: 19 dez. 2012.
} 
caráter jurídico-administrativo e técnico-científico relacionada à eficácia, segurança e qualidade destes produtos, para sua introdução no mercado e sua comercialização ou consumo. ${ }^{251}$ Sem o registro, um medicamento não pode ser distribuído ou comercializado.

O registro pressupõe uma forma de controle da qualidade, segurança e eficácia do medicamento, dados os aspectos de toxicidade e nocividade à saúde desses produtos. As análises dos medicamentos, nos termos da legislação sanitária, têm o propósito de eliminar, minimizar e evitar riscos à saúde, confirmando ou não a qualidade mínima aceitável do medicamento e de sua matéria-prima, complementando a ação de fiscalização. ${ }^{252}$

A Lei 6.360/76 e a Lei 9.782/99 disciplinam a competência para a concessão de registro de medicamentos que, hoje, é atribuída à Agência Nacional de Vigilância Sanitária - ANVISA. O registro como instrumento de controle da qualidade dos medicamentos apresenta relevância no que diz respeito à eficácia da política dos medicamentos genéricos. Essa política só pode ser bem sucedida, na medida em que os consumidores estiverem seguros em relação à qualidade dos medicamentos genéricos comercializados. Apenas dessa maneira os médicos estarão dispostos a prescrever e os pacientes estarão dispostos a consumir os mediamentos genéricos.

Os medicamentos genéricos estão sujeitos ao teste de bioequivalência, antes da concessão do registro. Esse teste é realizado por centros habilitados e autorizados pela Agência Nacional de Vigilância Sanitária e consiste

na demonstração de que o medicamento genérico e seu respectivo medicamento de referência (aquele para o qual foi efetuada pesquisa clínica para comprovar sua eficácia e segurança antes do registro) apresentam a mesma biodisponibilidade no organismo. O teste de bioequivalência assegura que o medicamento genérico é equivalente terapêutico do medicamento de referência, ou seja, que apresenta a mesma eficácia clínica e a mesma segurança em relação ao seu de referência. ${ }^{253}$

\footnotetext{
${ }^{251}$ Vide Decreto 3961/01.

${ }^{252}$ ORGANIZAÇÃO MUNDIAL DA SAÚDE; ORGANIZAÇÃO PAN-AMERICANA DA SAÚDE; MINISTÉRIO DA SAÚDE. Avaliação da assistência farmacêutica no Brasil: estrutura, processo e resultados. Brasília: OPAS/OMS, 2005. p. 76.

${ }^{253}$ BRASIL. Agência Nacional de Vigilância Sanitária. Registro de Medicamentos. Como a ANVISA avalia o registro de medicamentos novos no Brasil. Disponível em:< http://www.anvisa.gov.br/faqdinamica/asp/usuario.asp?usersecoes=38\&userassunto=81>. Acesso em 18 . Dez. 2012.
} 
Resumidamente, o processo de registro passa pela fase de apresentação de documentação técnica e sanitária acerca do medicamento a ser registrado e inclui as análises farmacotécnica e de eficácia e segurança. ${ }^{254}$ Além disso, o registro de um medicamento deve ser renovado de 5 em 5 anos, nos termos do art. $14, \S 1^{\circ}$, do Decreto 79.094, de 5 de janeiro de 1977.

\section{Defesa da concorrência}

A defesa da concorrência também pode exercer importante papel na contenção dos preços dos medicamentos. Considerando que o mercado de medicamentos é marcado pela concentração econômica por classe terapêutica, ${ }^{255}$ muitos agentes abusam do poder econômico, o que pode caracterizar infração às normas de defesa da concorrência. Contudo, jamais uma empresa farmacêutica foi condenada por violação da Lei Antitruste, conforme pesquisa realizada para este estudo ${ }^{256}$. Isso parece ocorrer pela dificuldade de apuração da existência do abuso de poder econômico e não necesariamente por sua ausência. O maior obstáculo reside na dificuldade de verificar o mercado relevante, principalmente no que concerne aos medicamentos éticos ${ }^{257}$. A razão disso é que a determinação do mercado relevante por meio do critério de indicação ou classe terapêutica do medicamento, comumente utilizado, não é tarefa fácil, sendo necessária avaliação de alta complexidade científica capaz de apontar o grau de substituição técnica de um medicamento. ${ }^{258}$

Além disso, há indícios de que o mercado farmacêutico é suscetível à cartelização, que foi favorecida pelo aumento de fusões e incorporações de empresas farmacêuticas nacionais e estrangeiras nos últimos vinte anos. ${ }^{259}$ Nesse período, empresas consideradas

${ }^{254}$ BRASIL. Agência Nacional de Vigilância Sanitária. Registro de Medicamentos. Como a ANVISA avalia o registro de medicamentos novos no Brasil. Disponível em: $<$ http://www.anvisa.gov.br/faqdinamica/asp/usuario.asp?usersecoes=38\&userassunto=81>. Acesso em 18 . Dez. 2012.

${ }^{255}$ Cf. Capítulo 2, item 2.2.

${ }^{256} \mathrm{Cf}$. Capítulo 3, item 3.1, nota 150.

${ }^{257}$ Medicamento ético é aquele medicamento prescrito por médicos que, legalmente, não pode ser anunciado na mídia de massa, ficando a propaganda restrita apenas às publicações especializadas e, ainda assim, direcionada aos médicos através de propagandistas de laboratórios farmacêuticos (CAMARGO DE JESUS, P.R. A presença do medicamento ético na mídia de massa. Disponível em: <http://www.comtexto.com.br/convicomartigopropPaulaRenata.htm>. Acesso em 12 jan. 2012).

${ }^{258}$ SAFATLE et al. Procedimentos para a definição e análise antitruste de mercados relevantes de medicamentos. Disponível em:< portal.mj.gov.br/.../FileDownload.EZTSvc.asp?>. Acesso em: 26 dez. 2012.

${ }^{259}$ BATISTA, L. B. Regulação econômica do mercado farmacêutico brasileiro. Dissertação (Mestrado em Direito). Universidade Cândido Mendes, Rio de Janeiro, 2005. p. 46. Sobre fusões e aquisições na indústria farmacêutica, cf. Capítulo 2, item 2.3. 
líderes de mercado se uniram, tendo formado blocos ainda mais poderosos no tocante à participação do mercado farmacêutico. ${ }^{260}$

\section{Controle do tempo de duração das patentes de fármacos}

Em abril de 1994, o Brasil assinou o acordo "Trade-Related Aspects of Intellectual Property Rights" (TRIPS Agreement), também conhecido como "Acordo sobre Aspectos dos Direitos de Propriedade Intelectual Relacionados ao Comércio" (ADPIC). Em função do disposto nesse acordo internacional ${ }^{261}$, o Brasil modificou seu regime de proteção da propriedade intelectual, inclusive no que diz respeito aos produtos farmacêuticos, editando a Lei $n^{0}$ 9.729, de 14 de maio de 1996 (Lei de Propriedade Industrial). Essa lei estipulou proteção rígida à inovação, no entanto, estabeleceu limites à vigência da proteção patentária. $\mathrm{O}$ art. 40, da Lei 9.729/96, adotou o limite mínimo de 20 anos estabelecido pelo TRIPS para a vigência das patentes de invenção. Essa limitação é essencial para possibilitar que, no futuro, outros agentes econômicos possam produzir o mesmo medicamento, estimulando a concorrência e barateando os preços desses produtos, de modo a beneficiar o consumidor.

No entanto, vale registrar que é polêmica a viabilidade da adoção de regimes patentários em países subdesenvolvidos, bem como o período ideal de vigência de patentes de medicamentos. Contudo, conforme mencionado na Introdução, este trabalho não se propõe a aprofundar o assunto.

\section{Controle de Lucros}

O controle de lucros das empresas farmacêuticas é uma forma de controlar indiretamente os preços dos medicamentos. Poucos países a utilizam. Na Europa, apenas a Inglaterra e a Espanha adotam essa ferramenta regulatória.

O caso inglês merece destaque, uma vez que o controle de lucros tem se mostrado capaz de de reduzir os gastos do sistema público de saúde com a compra de medicamentos $^{262}$. Nesse país, o governo e a indústria farmacêutica realizam periodicamente acordos, a fim de negociar o patamar de lucro a ser atingido pelos

\footnotetext{
${ }^{260}$ BATISTA, L. B. Regulação econômica do mercado farmacêutico brasileiro. Dissertação (Mestrado em Direito). Universidade Cândido Mendes, Rio de Janeiro, 2005. p. 46.

${ }^{261} \mathrm{O}$ art. 33 do TRIPS estabelece que o período mínimo de proteção patentária a ser adotado pelos países signatários deve ser de 20 anos contados da data do registro ("Article 33: The term of protection available shall not end before the expiration of a period of twenty years counted from the filing date").

${ }^{262}$ MRAZEK, M.F. Comparative Approaches to Pharmaceutical Price Regulation in the European Union. CMJ, Zagreb, n. 4, v.43, p. 371-515, ago. 2002. p.459.
} 
laboratórios com a venda de medicamentos para o sistema público de saúde. Esse acordo é denominado Pharmaceutical Price Regulation Scheme (PPRS) ${ }^{263}$. O PPRS estabelece que, se os lucros excederem a margem de tolerância acordada, a indústria deve reduzi-los por meio da diminuição de preços de medicamentos em vendas futuras ou do reembolso do sistema público de saúde. ${ }^{264}$

$\mathrm{Na}$ Inglaterra, o controle de lucros é usado em substituição ao controle direto de preços. Sua vantagem em relação ao controle direto consiste em levar em consideração os custos de pesquisa e desenvolvimento de forma global, sem analisar os gastos em P\&D em relação a cada um dos medicamentos. No entanto, o controle de lucros pode incentivar que as empresas farmacêuticas aumentem os preços dos medicamentos quando houver a probabilidade de diminuição de vendas. Além disso, apresenta a desvantagem de não estimular que os sistema público de saúde leve em consideração o critério do custoefetividade no momento da compra e da prescrição medicamentosa, mesmo sendo este critério imprescindível para a redução de gastos com medicamentos. ${ }^{265}$

\section{Análise de custo-efetividade}

A análise de custo-efetividade se baseia na comparação de diferentes estratégias de tratamento para a cura de determinado problema de saúde, com o propósito de aferir qual é a mais eficiente do ponto de vista clínico e de alocação de recursos. ${ }^{266}$

O custo-efetividade é uma das modalidades de análise farmacoeconômica ${ }^{267}$ e norteia a inclusão ou manutenção de drogas na lista de medicamentos fornecidos e utilizados pelos sistemas públicos de saúde, buscando racionalizar os gastos com saúde. ${ }^{268}$

\footnotetext{
${ }^{263}$ Pharmaceutical Price Regulation Scheme é o acordo voluntário entre o Departamento de Saúde e a Associação da Indústria Farmacêutica Britânica em que as companhias negociam os lucros almejados em relação às vendas de medicamentos para Sistema Nacional de Saúde. (BLOOR, K.; MAYNARD, A.; FREEMANTLE, N. Lessons from international experience in controlling pharmaceutical expenditure III: regulating industry. British Medical Journal, London, n. 7048, v. 313, p.33-35, jul. 1996. p. 34. Tradução livre de: "[t]he Pharmaceutical Price Regulation Scheme is a voluntary agreement between the Department of Health and the Association of the British Pharmaceutical Industry, which Companies negotiate target profits from sales of drugs to the NHS [National Health Service]").

${ }^{264}$ MRAZEK, M.F. Comparative Approaches to Pharmaceutical Price Regulation in the European Union. CMJ, Zagreb, n. 4, v.43, p. 371-515, ago. 2002. p.458.

${ }^{265}$ BLOOR, K.; MAYNARD, A.; FREEMANTLE, N. op. cit., p. 34.

${ }^{266}$ RÊGO, E.C.L. Políticas de regulação do mercado de medicamentos: a experiência internacional. Revista do BNDES, Rio de Janeiro, v.7, n.14, p.367-400, dez. 2000. p. 383.

${ }^{267}$ SECOLI, S.R. et al. Farmacoeconomia: perspectiva emergente no processo de tomada de decisão. Revista de Ciência e Saúde Coletiva, Rio de Janeiro, v.10, p. 287-297, set-dez. 2005. p.291.

${ }^{268}$ Farmacoeconomia tem sido definida como a descrição e análise do custo do tratamento medicamentoso para os sistemas de saúde e a sociedade. Ela identifica, mede e compara os custos e as consequências dos produtos e serviços farmacêuticos (Tradução livre de: "Pharmacoeconomics has been defined as the description and analysis of the costs of drug therapy to health care systems and society. [...]" RASCATI, K.L.
} 
No Brasil, essas listas são baseadas na Relação Nacional de medicamentos essenciais (RENAME), que deve ser atualizada a cada dois anos. O Decreto 7.508, de 28 de junho de 2011, que regulamenta a Lei 8.080/90, dispõe sobre as diretrizes de elaboração da RENAME. Dentre as diretrizes arroladas nessa norma, não há a previsão de análise farmacoeconômica obrigatória de qualquer espécie para a inclusão de medicamentos na RENAME, ficando essa avaliação a critério da Comissão Intergestora Tripartite responsável pela elaboração dessa relação de medicamentos.

\section{Controle direto de preços e suas diferentes modalidades}

O controle de preços é uma das formas de regulação do mercado farmacêutico mais utilizadas pelos países europeus, conforme se extrai das informações a seguir (Tabela 7):

Tabela 7. Técnicas de regulação do mercado de medicamentos utilizadas pelos países europeus.

\begin{tabular}{|c|c|c|}
\hline País & Preço & Reembolso \\
\hline Alemanha & Livres $\mathrm{p} /$ novos produtos & Preço de referência p/ produtos sem patente \\
\hline Bégica & Controle de preços: redução $\mathrm{p} /$ produtos antigos & - \\
\hline Canadá & Controle de preços & - \\
\hline Dinamarca & Acordos de preços & Preços de referência p/ produtos "análogos" \\
\hline Espanha & Controle de preços via negociação c/ base em custos & Preços de referência p/ drogas múltiplas \\
\hline Finlândia & Controle via reembolso & $\begin{array}{l}\text { Novos produtos reembolsados em } 50 \% \text { por } 2 \text { anos; preços } \\
\text { dos existentes revisados a cada dois anos; uso de dados. } \\
\text { Farmacoeconômicos quando Firmas recorrem por preço } \\
\text { razoável }\end{array}$ \\
\hline França & Negociação e comparação com outros países & - \\
\hline Grécia & $\begin{array}{l}\text { Controle de preços pelo menor preço europeu p/ mesma } \\
\text { molécula }\end{array}$ & - \\
\hline Holanda & Preço máximo por comparação com a Europa & Preço de referência terapêutica \\
\hline Irlanda & $\begin{array}{l}\text { Acordo de preço seguido de congelamento (1997/2001), } \\
\text { seguida de revisão cl base em comparaçôes } \\
\text { internacionais. }\end{array}$ & - \\
\hline Itália & $\begin{array}{l}\text { Preço médio europeu } \mathrm{p} / \text { alguns produtos; } \\
\text { negociação/produtos novos e inovativos }\end{array}$ & - \\
\hline Noruega & Controle de reembolso é desejado & $\begin{array}{l}\text { Preço de referência (inclusive em drogas c/ patente e } \\
\text { importações paralelas) }\end{array}$ \\
\hline Portugal & Controle de preços (preço médio): RPI-X em 1998/99 & - \\
\hline $\begin{array}{l}\text { Reino } \\
\text { Unido }\end{array}$ & $\begin{array}{l}\text { Acordo com indústria em controlar lucros. Renovado em } \\
1999 \text { por } 5 \text { anos }\end{array}$ & - \\
\hline Suécia & $\begin{array}{l}\text { Controle se reembolso é desejado. Base em } 10 \text { países. } \\
\text { Deve ser menor doq eu Dinamarca, Holanda, Alemanha e } \\
\text { Suiça; Similar a Noruega e Finlândia. }\end{array}$ & - \\
\hline Suiça & $\begin{array}{l}\text { Livres } \mathrm{p} / \text { novos produtos. Intervenção em reembolso. } \\
\text { Corte lineai de preços } \mathrm{p} / \text { produtos reembolsados }\end{array}$ & - \\
\hline
\end{tabular}

Fonte: Adaptado de FIUZA, E.; LISBOA, M. Bens credenciais e poder de mercado: um estudo econométrico da indústria farmacêutica brasileira. Disponível em: <http://www.ipea.gov.br/pub/td/2001/td_0846.pdf.> Acesso em: 22 jul. 2010.

Essentials of pharmacoeconomics: an introduction. Philadelphia: Lippincott Williams Wilki, 2009. 250 p. p.2.). 
Esse instrumento regulatório admite diversas modalidades e, em sentido amplo, abrange os mecanismos de determinação de preços por referência interna, referência internacional, adicional ao custo (cost plus), controle de lucros, moratória ou congelamento e tabelamento, e controle de margens. ${ }^{269}$ Por meio da referência interna, o preço de entrada de um medicamento é definido com base no preço de um medicamento comparador já lançado no mercado doméstico. Outro método de definição do preço de entrada é a a referência internacional. Esse mecanismo estabelece o preço inicial de um medicamento novo, mediante comparações de preços com países onde o produto já foi lançado. Assim como a referência interna, a referência internacional é adotada pela CMED. O adicional de custo ou cost plus contribui para a determinação dos preços dos medicamentos, tendo como referência os custos de produção para produtos individuais. Já o controle de lucros é realizado não sobre o preço de produtos individuais, mas sobre a rentabilidade geral da empresa. ${ }^{270}$ Referidos mecanismos não são adotados no Brasil.

Em sentido estrito, o controle de preços é a forma de regulação direta utilizada pelo Estado na implementação de políticas econômicas relativas a preços. É integrado ao ordenamento jurídico dos preços principalmente ao lado de outros institutos que dele diferem, tais como o tabelamento e o congelamento de preços. O tabelamento consiste no bloqueio dos preços a um patamar máximo determinado, sem levar em consideração a evolução dos preços e a variação dos custos de produção e comercialização. Já o congelamento dos preços consiste na manutenção dos preços contratados, ou seja, fixados mediante contratos celebrados entre particulares. O controle de preços, por sua vez, implica no acompanhamento e limitação dos preços, de sorte que sua evolução seja coerente com suas variações e não a simples determinação de um valor máximo ou congelamento. ${ }^{271}$ Conhecido também como controle de margens, vez que o governo determina o mark-up que pode ser praticado por distribuidores e varejistas ${ }^{272}$, esse instrumento jurídico regulatório utilizado no Brasil será melhor analisado no próximo capítulo.

\footnotetext{
${ }^{269}$ ROMANO, L.A.N. Intervenção e regulação no Brasil: a indústria farmacêutica. São Paulo: FEBRAFARMA, 2005. p.79-80.

${ }^{270}$ Ibid. p.80.

${ }^{271}$ GRACE, C. Equitable Pricing of newer essential medicines for developing countries: evidence for the potential of different mechanisms. Genebra: Organização Mundial da Saúde (OMS), 2003. p.102.

${ }^{272}$ ROMANO, L.A.N., op. cit., p.80.
} 
- Técnicas regulatórias que incidem sobre a demanda:

\section{Restrições à propaganda de medicamentos}

A promoção e publicidade de medicamentos no Brasil é regulada pelas Leis 6.360/76, 6.437/77 e pela Resolução ANVISA RDC $\mathrm{n}^{\circ}$ 102/2000. As normas de publicidade de medicamentos envolvem critérios éticos e proíbem a propaganda explícita de medicamentos com venda mediante receita. Há, também, uma série de restrições sobre a publicidade de medicamentos vendidos livremente.

A propaganda de medicamentos não é direcionada apenas aos consumidores finais, mas também aos médicos prescritores. Em 2010, o Conselho Regional de Medicina do Estado de São Paulo - CREMESP - realizou pesquisa com os médicos do Estado de São Paulo sobre as condições das propagandas realizadas pela indústria farmacêutica, que revelou uma situação preocupante: ${ }^{273}$

- 93\% afirmaram ter recebido produtos e benefícios da indústria considerados de pequeno valor, nos últimos 12 meses;

- 80\% recebiam regularmente visita de propagandistas de laboratórios;

- 33\% souberam ou presenciaram o recebimento de comissão por indicação de medicamento, órtese ou prótese;

- 74\% declararam que presenciaram ou receberam alguns benefícios da indústria ainda durante os 6 anos do curso de medicina.

De acordo com Ricardo D’Ávila, esse quadro revela "tentativas de suborno ou de influência da indústria farmacêutica na prescrição" ${ }^{274}$. Isso pode levar o consumidor a ter prejuízo e gastar muito mais do que o necessário com a compra de medicamentos.

Com o objetivo de combater a influência da indústria farmacêutica, a Resolução $\mathrm{n}^{\circ}$ 1595/00 do Conselho Federal de Medicina proíbe a a vinculação da prescrição ao recebimento de vantagens materiais oferecidas por agentes econômicos interessados na produção ou comercialização de produtos farmacêuticos ou equipamentos de uso na área médica. Com o mesmo propósito, o Conselho Federal de Medicina celebrou acordo com a

${ }^{273}$ CONSELHO REGIONAL DE MEDICINA DO ESTADO DE SÃO PAULO - CREMESP. Médicos reprovam acordo do Conselho Federal com a indústria farmacêutica. São Paulo, 2012. Disponível em:<www.viomundo.com.br/denuncias/medicos-reprovam-acordo-do-cfm-com-a-industria-

farmaceutica.html>. Acesso em 18 dez. 2012; e DÁVILA, R.L. Revista ser médico. São Paulo, 2007. Disponível em:<www.cremesp.org.br/?siteAcao=Revista\&id=336>. Acesso em: 18 dez.2012.

${ }^{274}$ D’ÁVILA, R.L. Revista ser médico. São Paulo, $2007 . \quad$ Disponível em:<www.cremesp.org.br/?siteAcao=Revista\&id=336>. Acesso em: 18 dez.2012. 
Interfarma permitindo presentes cujo valor individual não ultrapasse $1 / 3$ do salário mínimo, limitados a três ocorrências ao ano. ${ }^{275}$

A ANVISA também possui normas restritivas em relação a propagandas de medicamentos e concessão de brindes e benefícios aos profissionais prescritores. ${ }^{276}$ Assim, cumpre a essa agência reguladora fiscalizar a observância dessas normas pelos médicos e empresas farmacêuticas.

\section{Preço de referência, reembolso e listas de prescrição}

O preço de referência consiste no preço do medicamento mais barato, normalmente, o genérico, sendo o custo reembolsável pelo Estado apenas até esse valor. Os pacientes pagam a diferença entre o valor médio e o preço do remédio adquirido.

Esse preço pode ser determinado mediante lista positiva ou negativa de medicamentos. Segundo estudo realizado por Pavcnik (2000), na Alemanha, o efeito dessa política foi a redução geral dos preços dos medicamentos, inclusive dos medicamentos de marca. $^{277}$

Sabe-se que as agências de saúde podem aprovar um medicamento, mas isso não significa que ele seja custo efetivo, ou seja, que tenha a eficácia dos mesmos medicamentos existentes no mercado para o tratamento proposto e, ao mesmo tempo, seja mais barato. Por essa razão, muitos países da Europa ocidental não incluem esses medicamentos na lista dos medicamentos reembolsáveis, sendo as listas, nesse caso, designadas por "listas negativas". 278

No Brasil, os preços de referência sem reembolso estatal foram estabelecidos na década de 70, pela CIP, mas, logicamente, os efeitos não foram os mesmos que os observados por Pavcnik. ${ }^{279}$ Atualmente, embora não haja uma política de reembolso do

\footnotetext{
${ }^{275}$ CONSELHO REGIONAL DE MEDICINA DO ESTADO DE SÃO PAULO - CREMESP. Médicos reprovam acordo do Conselho Federal com a indústria farmacêutica. São Paulo, 2012. Disponível em: <www.viomundo.com.br/denuncias/medicos-reprovam-acordo-do-cfm-com-a-industria-

farmaceutica.html>. Acesso em 18 dez. 2012; e DÁVILA, R.L. Revista ser médico. São Paulo, 2007. Disponível em:<www.cremesp.org.br/?siteAcao=Revista\&id=336>. Acesso em: 18 dez.2012.

${ }^{276} \mathrm{O}$ art. $5^{\circ}$, da Resolução ANVISA RDC n ${ }^{0}$ 96, de 17 de dezembro de 2008, estabelece que: "as empresas não podem outorgar, oferecer, prometer ou distribuir brindes, benefícios e vantagens aos profissionais prescritores ou dispensadores, aos que exerçam atividade de venda direta ao consumidor, bem como ao público em geral".

${ }^{277}$ PAVCNIK, N. Do pharmaceutical prices respond to insurance? Disponível em: < http://www.nber.org/papers/w7865.pdf>. Acesso em: 29 mai. 2012.

${ }^{278}$ FIUZA, E.; LISBOA, M. Bens credenciais e poder de mercado: um estudo econométrico da indústria farmacêutica brasileira. Disponível em: <http://www.ipea.gov.br/pub/td/2001/td_0846.pdf.> Acesso em: 22 jul. 2010.

${ }^{279}$ PAVCNIK, N., op. cit.
} 
custo de medicamentos, tentou-se fazer uma lista positiva, semelhante àquelas existentes na Europa, para o Sistema Único de Saúde. Esta lista é a Relação Nacional de Medicamentos Essenciais (RENAME) e deve ser observada na elaboração do rol de medicamentos fornecidos pelas diferentes unidades do Sistema Único de Saúde, de modo que nenhum medicamento que não esteja nela arrolado pode ser comprado e fornecido pelo SUS.

Diretrizes e fiscalização sobre a atividade médica de prescrição de medicamentos

A fiscalização sobre a prescrição medicamentosa tem a finalidade de minimizar a falha de mercado consistente na assimetria de informações. Conforme dito anteriormente: quem consome não é quem decide sobre a droga, quem decide não paga, e quem paga, muitas vezes, é terceiro, como por exemplo no caso de medicamentos cobertos por seguros públicos ou privados. ${ }^{280}$

No momento da prescrição, o médico se depara com um conjunto crescente de substâncias ativas, em relação às quais desconhece a eficácia e segurança, o que dificulta a tomada de decisão. Um problema enfrentado pelos médicos é a falta da fluidez de informações sistematizadas e consolidadas acerca comparação da efetividade entre os medicamentos disponíveis no mercado. ${ }^{281}$

Berndt, Pindyck e Azoulay identificam no comportamento da prescrição médica a predominância do costume e da inércia causada pela ausência de conhecimento sobre os verdadeiros efeitos dos medicamentos disponíveis no mercado ${ }^{282}$. Essa situação deixa o profissional prescritor mais suscetível à influência da indústria farmacêutica no momento da prescrição. Para evitar as externalidades negativas advindas desse comportamento, é necessário o fornecimento de guias terapêuticos que indiquem ao médico "a efetividade no tratamento das diversas doenças, reações adversas observadas, significância estatística e,

\footnotetext{
${ }^{280}$ RÊGO, E.C.L. Políticas de regulação do mercado de medicamentos: a experiência internacional. Revista do BNDES, Rio de Janeiro, v.7, n.14, p.367-400, dez. 2000. p. 373

${ }^{281}$ FIUZA, E.; LISBOA, M. Bens credenciais e poder de mercado: um estudo econométrico da indústria farmacêutica brasileira. Disponível em: <http://www.ipea.gov.br/pub/td/2001/td_0846.pdf.> Acesso em: 22 jul. 2010.

${ }^{282}$ BERNDT, E.; PINDYCK, R.S.; AZOULAY,P. Consumption externalities and diffusion in pharmaceutical markets: antiulcer drugs. Journal of Industrial Economics, Marshall, v. LI, n. 2, p.243-270, jun. 2003. p. 268-269.
} 
por fim, custo estimado do tratamento". ${ }^{283}$ Esses guias terapêuticos devem conter informações sobre a eficácia de todos os tratamentos disponíveis para determinada doença.

Além disso, é indispensável fiscalização sobre a prescrição médica, garantindo a prescrição do remédio com maior custo-efetividade, como medida de enforcement. ${ }^{284}$ Para garantir que os guias terapêuticos sejam realmente consultados pelos médicos no momento da prescrição, deve haver um monitoramento, nem sempre existente, sobre as prescrições. Em alguns países da Europa, a figura do "guardião" é responsável pelo monitoramento sobre o cadastro dos pacientes. O "guardião" é um clínico geral que realiza a triagem das prescrições efetuadas em determinada instituição de saúde. ${ }^{285}$ Os fatores que interferem sobre a prescrição precisam ser controlados, garantindo o melhor para o paciente.

A prescrição de medicamentos, no Brasil é regulada, basicamente, pelo disposto nas Leis Federais 5.991/73 e 9.787/99; no Decreto 74.170/74; bem como na Resolução 357/01 do Conselho Federal de Farmácia e nas Resoluções 1.552/99, 1.477/97 e 1885/08 o Conselho Federal de Medicina. Essas normas visam, dentre outros propósitos, diminuir os gastos dos consumidores com medicamentos. A título de ilustração, no âmbito do Sistema Único de Saúde, a Lei 9.787/99 estabelece a obrigatoriedade de que os medicamentos sejam prescritos pelo nome genérico, adotando-se a Denominação Comum Brasileira (DCB) e, em sua ausência, a Denominação Comum Internacional (DCI).

Nos serviços privados de saúde, essa obrigatoriedade não existe, de tal sorte que a prescrição pode ser feita utilizando o nome genérico ou comercial do medicamento. Por essa razão, a ANVISA editou a Resolução RDC n 16/07, segundo a qual "será permitida ao profissional farmacêutico a substituição do medicamento prescrito pelo medicamento genérico correspondente, salvo restrições expressas pelo profissional prescritor."286

\section{Orçamento de prescrição}

Em alguns países, médicos individuais ou grupos de médicos estão sujeitos a restrições orçamentárias que, se desobedecidas, causam multas por excesso de despesa ou partilha de ganhos em caso de economia de recursos. O problema dessa espécie de

\footnotetext{
${ }^{283}$ LISBOA,M.; FIÚZA, E.; VIEGAS, M.; FERRAZ, L. Política governamental e regulação do mercado de medicamentos. Disponível em:< www.seae.fazenda.gov.br/central.../doctrab08.pdf >. Acesso em: 19 dez.2012.

284 Ibid.

${ }^{285}$ FIUZA, E.; LISBOA, M. Bens credenciais e poder de mercado: um estudo econométrico da indústria farmacêutica brasileira. Disponível em: <http://www.ipea.gov.br/pub/td/2001/td_0846.pdf.> Acesso em: 22 jul. 2010.

${ }^{286}$ Item 2.1, da Resolução ANVISA RDC n 16, de 2 de março de 2007.
} 
regulação é que os pacientes podem receber diferentes tratamentos, em função dos preços dos medicamentos no ciclo orçamentário. Além disso, já foi apurado um excesso de condução de pacientes a tratamentos hospitalares, por não haver recursos para o tratamento com medicamentos. ${ }^{287}$

\section{Co-Pagamento ou "cost sharing"}

Co-pagamento ou cost-sharing consiste no "mecanismo de recuperação de custos adotado por muitos sistemas de saúde, segundo o qual o paciente arca com parte dos custos dos bens serviços, quando destes fizer uso". ${ }^{288}$

Há quem sustente que, ao fazer o paciente pagar parcialmente pelos medicamentos, o sistema de saúde dá-lhe incentivo a cobrar do médico, mas as assimetrias de informação já apontadas dificultam o processo, o que acaba onerando o próprio paciente. ${ }^{289}$ Por essa razão, essa medida não pode ser jamais adotada sem que haja controle sobre as prescrições médicas, conforme mencionado anteriormente.

Um dos maiores impactos do co-pagamento recai sobre a equidade no acesso aos serviços de saúde. Para que não exista iniquidade quanto ao acesso a medicamentos, a participação o custeio deve ser seletiva no que diz respeito à renda dos usuários e aos serviços passíveis de taxação. No entanto, o co-pagamento pode ser uma boa medida de cotenção de custos. ${ }^{290}$

No Brasil, essa medida de contenção de gastos que age sobre o lado da demanda é adotada mediante o Programa Farmácia Popular ${ }^{291}$, embora sem diferenciação de renda dos usuários. Esse programa tem como objetivo

[1]evar remédios essenciais a um baixo custo para mais perto da população, melhorando o acesso e beneficiando uma maior quantidade de pessoas. Isso acontece por meio de parcerias do Governo Federal com o

\footnotetext{
${ }^{287}$ SAIANDA, A. Constrangimentos à prescrição. Disponível em: <http://www.semanamedica.com>. Acesso em: 4 jun.2011.

${ }^{288}$ VIANNA, S.M.; PIOLA, S.F.; REIS, C.O.O. Gratuidade no SUS: controvérsia em torno do copagamento. Instituto de Pesquisa Econômica Aplicada - IPEA. Brasília, 1998. Disponível em:<www.ipea.gov.br/pub/td/td_587.pdf>. Acesso em: 19 dez. 2012.

${ }^{289}$ LISBOA,M.; FIÚZA, E.; VIEGAS, M.; FERRAZ, L. Política governamental e regulação do mercado de medicamentos. Disponível em:< www.seae.fazenda.gov.br/central.../doctrab08.pdf >. Acesso em: 19 dez.2012.

${ }^{290}$ MOSSIALOS, E. Associação Portuguesa de Economia da Saúde. Regulação das despesas com medicamentos nos países da União Européia. Lisboa, 1998. Disponível em:< www.apes.pt/files/dts/dt_011998.pdf >. Acesso em: 27 dez. 2012.

${ }^{291}$ O Programa Farmácia Popular foi criado pelo Decreto 5.090, de 20 de maio de 2004. Esse programa de copagamento se baseia na disponibilição de medicamentos básicos e essenciais a baixo custo.
} 
setor varejista farmacêutico. Funciona da seguinte maneira: o Governo Federal paga uma parte do valor do medicamento e o cidadão paga o restante. $^{292}$

Vale registrar, que o co-pagamento é uma boa alternativa para a racionalização dos gastos e recuperação de custos que pode ser utilizada pelos sistemas públicos de saúde. No Brasil, se o co-pagamento levasse em consideração a renda dos consumidores, poderia contribuir para a correção de certo grau de iniquidade e injustiça causadas pela extensão da gratuidade do fornecimento de medicamentos e serviços de saúde àqueles que podem pagar pela sua utilização, mesmo que já o façam via tributação. Nessa hipótese, o co-pagamento diminuiria, parcialmente, a regressividade das fontes que financiam o sistema público de saúde no Brasil. ${ }^{293}$

Com exceção da Irlanda e da Holanda, todos os países da União Européia utilizam esse recurso para certos medicamentos. Existem isenções para pessoas de rendimento baixo e outras categorias de pacientes, variando de país para país. A proporção custeada pelo paciente também varia de acordo com o tipo de medicamento. ${ }^{294}$

No que diz respeito aos meios utilizados para a regulação do mercado farmacêutico, importa fazer breves observações sobre o país responsável por $47 \%$ da produção mundial de medicamentos, os Estados Unidos da América. ${ }^{295}$ Nos EUA, a regulação econômica do mercado de medicamentos existe, porém em menor intensidade. Nesse país, a intervenção do Estado no mercado farmacêutico é mínima, inexistindo qualquer tipo de controle oficial dos preços de medicamentos, ou qualquer sistema de reembolso ou co-pagamento governamental para a população como um todo. ${ }^{296}$

\footnotetext{
${ }^{292}$ BRASIL. Ministério da Saúde. Programa Farmácia Popular. Disponível em:< http://bvsms.saude.gov.br/bvs/publicacoes/farmacia_popular_manual_sistema_copagamento_2ed.pdf>. Acesso em: 7 jan.2012.

${ }^{293}$ VIANNA, S.M.; PIOLA, S.F.; REIS, C.O.O. Gratuidade no SUS: controvérsia em torno do copagamento. Instituto de Pesquisa Econômica Aplicada - IPEA. Brasília, 1998. Disponível em:<www.ipea.gov.br/pub/td/td_587.pdf >. Acesso em: 19 dez. 2012.

${ }^{294}$ MOSSIALOS, E. Associação Portuguesa de Economia da Saúde. Regulação das despesas com medicamentos nos países da União Européia. Lisboa, 1998. Disponível em:< www.apes.pt/files/dts/dt_011998.pdf >. Acesso em: 27 dez. 2012.

${ }^{295}$ FIUZA, E.; LISBOA, M. Bens credenciais e poder de mercado: um estudo econométrico da indústria farmacêutica brasileira. Disponível em: <http://www.ipea.gov.br/pub/td/2001/td_0846.pdf.> Acesso em: 22 jul. 2010.

${ }^{296}$ RÊGG, E.C.L. Políticas de regulação do mercado de medicamentos: a experiência internacional. Revista do BNDES, Rio de Janeiro, v.7, n.14, p.367-400, dez. 2000. p. 392.
} 
O sistema de seguro-saúde, preponderante na economia americana até a década de 80, realizava reembolsos por serviços prestados (fee for service), inclusive por medicamentos prescritos. Com o tempo, em razão da introdução de novas tecnologias e remédios para o tratamento de doenças e diagnósticos com custos crescentes, esse sistema de contratos terminou por levar ao aumento dos gastos com saúde de forma ineficiente. Desse modo, a partir de meados dos anos 1970, surgiram novas formas de seguro, usualmente denominadas de Managed Care. Esses contratos se caracterizam por introduzir incentivos para que os provedores de serviços médicos considerem tanto os benefícios terapêuticos dos procedimentos e dos medicamentos utilizados quanto seus custos. ${ }^{297}$

Na década de 1990, o Congresso Americano entendeu ser necessária a utilização da regulação dos preços, embora de forma bastante diversa daquela realizada na Europa e no Brasil. Os preços dos medicamentos e os lucros da indústria farmacêutica eram excessivos e mobilizaram a opinião pública, de tal sorte que o Congresso aprovou a Lei 101/508, de 1990, obrigando descontos especiais para medicamentos passíveis de reembolso. Essa lei também determinou que todo excesso obtido pela diferença entre os preços cobrados no varejo e os preços praticados com atacadistas, em relação às drogas inclusas no programa de ressarcimento Medicaid, fosse repassado para o governo. O Medicaid cobre somente os mais pobres e estabelece descontos na compra de medicamentos consumidos fora dos hospitais. Ao contrário do que ocorre nos países da Europa, nos EUA, os financiamentos para a saúde são exercidos pelos seguros privados. ${ }^{298}$

Nesse país, outras medidas de menor impacto também foram tomadas, como a obrigatoriedade de descontos especiais nos preços de medicamentos desenvolvidos pelo Estado, em parceria com a indústria, assim como o aprimoramento da Lei Orphan Drugs. ${ }^{299}$ Anteriormente, na década de 80, também com o propósito de conter os preços dos produtos farmacêuticos, havia sido implementada a política de medicamentos

\footnotetext{
${ }^{297}$ FIUZA, E.; LISBOA, M. Bens credenciais e poder de mercado: um estudo econométrico da indústria farmacêutica brasileira. Disponível em: <http://www.ipea.gov.br/pub/td/2001/td_0846.pdf.> Acesso em: 22 jul. 2010.

${ }^{298}$ RÊGO, E.C.L. Políticas de regulação do mercado de medicamentos: a experiência internacional. Revista do BNDES, Rio de Janeiro, v.7, n.14, p.367-400, dez. 2000. p. 392.

${ }^{299}$ O Departamento de Saúde e Serviços Humanos dos EUA explica que a Lei Orphan Drugs foi concebida com o propósito de estimular o desenvolvimento de medicamentos destinados ao tratamento de doenças raras. Antes dessa lei, a indústria farmacêutica tinha poucos incentivos para investir em tratamentos que beneficiassem poucos pacientes, tendo em vista a baixa lucratividade do comércio desses produtos (Estados Unidos da América. Department of Health and Human Services - Office of Inspector General. The Orphan Drug Act, Implementation and Impact. Disponível em: < http://oig.hhs.gov/oei/reports/oei-09-00-00380.pdf >. Acesso em: 29 mai. 2012.
} 
genéricos nos EUA. Em 1989, os genéricos correspondiam a 30\% das vendas em farmácias. $^{300}$

${ }^{300}$ FIUZA, E.; LISBOA, M. Bens credenciais e poder de mercado: um estudo econométrico da indústria farmacêutica brasileira. Disponível em: <http://www.ipea.gov.br/pub/td/2001/td_0846.pdf.> Acesso em: 22 jul. 2010. 


\section{A POLÍtica REGUlatória NA PRÁticA: "PRÓS", “CONTRAS" E DIFICULDADES JURÍDICAS DA REGULAÇÃO DO MERCADO DE MEDICAMENTOS NO BRASIL}

O principal instrumento utilizado na regulação do mercado farmacêutico brasileiro é o controle direto de preços, chamado também de controle de margens, como visto no capítulo anterior. Esse controle é realizado pela Câmara de Regulação do Mercado de Medicamentos, mediante o mecanismo do price cap. Ao lado desse instrumento, a CMED utiliza também o Coeficiente de Adequação de Preços (CAP) como forma de regular as compras públicas de medicamentos.

Neste capítulo, pretende-se verificar como funciona na prática a mais importante forma de regulação econômica do mercado farmacêutico que é praticada pela CMED. Para testar as hipóteses de pesquisa ${ }^{301}$, foram analisados artigos científicos e estudos de órgãos oficiais e não oficiais, bem como realizadas entrevistas com membros da CMED e representantes dos consumidores. ${ }^{302}$ Mais especificamente, foram examinadas pesquisas de preços de medicamentos realizadas pelo Instituto de Defesa do Consumidor (IDEC) e pela Fundação de Proteção e Defesa do Consumidor do Estado de São Paulo (PROCON-SP). Posteriormente, foi elaborado um banco de dados composto por preços de medicamentos coletados diretamente nos pontos de venda, em 2009, 2010, 2011 e 2012, pelo IDEC e pelo PROCON-SP. Esses preços foram cruzados com os respectivos preços máximo ao consumidor, definidos pela CMED, com o objetivo de analisar a evolução e

\footnotetext{
${ }^{301}$ Conforme mencionado no Capítulo 1, as hipóteses de pesquisa deste trabalho são:

a) A política de regulação dos preços empreendida pela CMED, principalmente mediante o controle de preços, apresenta "prós" e "contras”, bem como dificuldades e problemas de implementação. Essa política revela, possivelmente, mais aspectos positivos do que negativos, no Brasil, onde os custos dos medicamentos são muito elevados e o controle de preços de desses produtos tende a favorecer o consumidor, facilitando o acesso a medicamentos.

b) A regulação da CMED é efetiva, uma vez que é capaz de pressionar os preços dos medicamentos a patamares mais baixos, mitigando o arbítrio da indústria farmacêutica na fixação dos preços dos medicamentos, de modo a favorecer os interesses dos consumidores. No entanto, os preços dos medicamentos se encontram em patamares elevados, em razão do descumprimento das normas regulatórias pelos agentes regulados. De acordo com essa hipótese, os preços praticados no mercado seriam superiores àqueles estabelecidos como teto pela CMED, caracterizando um problema de enforcement da regulação.

${ }^{302}$ Inúmeras tentativas de entrevista foram realizadas também com membros da Indústria Farmacêutica, tendo sido enviadas cartas formais, com o questionário a ser aplicado anexo, às entidades representativas dos laboratórios farmacêuticos: Interfarma e Sindusfarma. Dentre os membros da Interfarma, foram contatados o diretor de assuntos regulatórios (Ronaldo Pires) e de assuntos econômicos (Marcelo Liebhardt). Dentre os membros do Sindusfarma, foram contatados a gerente de legislação industrial farmacêutica (Rosana Mastelaro) e o gerente de economia (Luiz Antônio Diório). No entanto, por razões desconhecidas, mesmo depois de uma série de telefonemas e envio de e-mails, nenhum membro dessas entidades se dispôs a conceder entrevistas.
} 
comportamento dos preços dos medicamentos no mercado, em relação aos critérios regulatórios.

Ao longo da realização da pesquisa, foi identificada a existência de um debate acerca das vantagens da utilização de mecanismos que alterem a estrutura de formação de preços no mercado (tais como ferramenta de proteção antitruste) sobre o controle direto de preços. Por essa razão, antes de adentrar especificamente no tema das características da política de controle de preços no Brasil, objeto deste capítulo, vale a pena tecer algumas considerações sobre referido assunto, que envolve reflexões acerca das vantagens e desvantagens da utilização do controle de preços a longo prazo.

\subsection{Controle de preços $X$ mecanismos antitruste}

Existe um debate sobre as vantagens e desvantagens da utilização da ferramenta do controle de preços, em face do uso exclusivo de mecanismos de proteção da concorrência. Autores de diferentes vertentes teóricas, principalmente no campo da economia, escreveram sobre o tema, polemizando o assunto. Neste trabalho não se pretende aprofundar a questão, mas é imprescindível reconhecer a existência do debate e expressar um posicionamento.

O principal argumento contrário ao controle direto de preços de medicamentos é centrado no trade-off existente entre beneficiar as presentes gerações, com preços mais baixos, ou favorecer as gerações futuras, com a promoção de inovação no setor farmacêutico e com o desenvolvimento de novas drogas. ${ }^{303}$ Há quem sustente que o controle direto de preços diminuiria a receita da indústria farmacêutica que, então, investiria menos em pesquisa e desenvolvimento, comprometendo a inovação no mercado farmacêutico. ${ }^{304}$

Referido debate gira em torno, também, da efetividade do controle direto em manter os preços de medicamentos em patamares acessíveis ao consumidor. Patricia Danzon, por exemplo, questiona as conclusões obtidas por estudos que demonstram que os preços de medicamentos praticados nos Estados Unidos são muito superiores àqueles de países europeus que adotam o controle de preços. ${ }^{305}$

\footnotetext{
${ }^{303}$ ADAMSON, $\quad$ D. $\quad$ M. Regulating drug prices. $\quad$ Disponível em:<http://www.rand.org/pub/research_briefs/RB9412/index1.html>. Acesso em: 12 nov. 2010. ${ }^{304}$ Nesse sentido, ver SCHERER, F. M. Price controls and global pharmaceutical progress. Health Affairs, Bethesda, v.28, n.1, p.161-4, dez. 2008.

${ }^{305}$ DANZON, P. Making sense of drug prices. Regulation, Washington D.C., v.23, n.1, p.56-63. 2000.
} 
Outro argumento contrário ao controle de preços é que ele provocaria a demora do lançamento de medicamentos novos. Nos países em que os preços de comercialização de medicamentos novos é inferior à expectativa das indústrias farmacêuticas inovadoras, bem como onde o mercado consumidor é pequeno, existem menos lançamentos e mais atrasos na introdução de novas drogas. ${ }^{306}$ Os defensores do controle de preços contra-argumentam afirmando que mesmo que esse instrumento regulatório implicasse o atraso do lançamento de novas drogas, essa ferramenta ainda apresentaria melhor custo-benefício, pois a maioria da população não teria acesso às novas drogas lançadas, caso não houvesse qualquer tipo de regulação dos preços.

Fato é que nos últimos anos a utilização do controle direto de preços de medicamentos aumentou dentre os países desenvolvidos e subdesenvolvidos. ${ }^{307} \mathrm{~A}$ justificativa para o uso dessa ferramenta jurídico-econômica se fundamenta em razões de saúde pública e possui respaldo na teoria econômica. No Capítulo 2 deste trabalho, foi visto que no mercado farmacêutico a competição não é perfeita. Bronfenbrenner afirma que em situações de competição imperfeita o controle de preços aumenta o output e, ao mesmo tempo, diminui os preços. De acordo com esse autor, tal proposição é antiga e remete à doutrina da economia do bem-estar. ${ }^{308}$ Para essa linha de posicionamento, o controle de preços é uma forma de combater o poder econômico da indústria farmacêutica, principalmente, nos casos de reserva de mercado em função da vigência de patentes.

Por sua vez, qualquer análise sobre o custo-benefício do controle de preços não deve ser a mesma para os países desenvolvidos e subdesenvolvidos. A renda da população é notadamente inferior nos últimos países em comparação com os primeiros, o que agrava o problema do acesso a medicamentos. Além disso, os países subdesenvolvidos compõem pequena parte do mercado farmacêutico mundial ${ }^{309}$. Mesmo assim, em geral, apesar de possuírem rígida regulação de preços, a receita obtida nesses mercados é capaz de financiar

\footnotetext{
${ }^{306}$ DANZON, P; WANG, Y. R.; WANG, L. The impact of Price regulation on the launch delay of new drugs. Health Economics, Washington D.C., v.14, n.3, p.269-292, mar. 2005. p.285.

${ }^{307}$ ADAMSON, D.M. $\quad$ Regulating drug $\quad$ prices. $\quad$ Disponível em:<http://www.rand.org/pub/research_briefs/RB9412/index1.html>. Acesso em: 12 nov. 2010.

${ }^{308}$ BRONFENBRENNER, M. Price control under imperfect competition. The American Economic Review, Pittsburgh, v. 17, n.1, p.107-120, mar. 1947. p.108.

${ }^{309}$ Menos de $20 \%$ dos lucros das indústrias farmacêuticas multinacionais decorre da comercialização de medicamentos nos países periféricos (ROSENBERG, B. Patentes de medicamentos e comércio internacional: os parâmetros do TRIPS e do direito concorrencial para a outorga de licenças compulsórias. 2004. 290 p. Dissertação (Doutorado em Direito) Faculdade de Direito da Universidade de São Paulo. São Paulo. p. 170.)
} 
boa parte da pesquisa e desenvolvimento das indústrias farmacêuticas. ${ }^{310}$ Isso significa que, a despeito do controle de preços, as indústrias multinacionais de medicamentos são capazes de lucrar com a comercialização de seus produtos nos países subdesenvolvidos, recuperando o investido em inovação no estrangeiro.

Ademais, resta comprovado que o controle mediante o price cap é uma ferramenta capaz de reduzir os preços dos medicamentos, quando baseado em frequente monitoramento do mercado, tal como demonstra a experiência norueguesa. ${ }^{311}$ Nesse país, foi instituído o controle por meio do emprego do price cap, no ano de 2003, e, desde então, são feitos levantamento de preços e monitoramento do mercado, trimestralmente. ${ }^{312}$

Quanto à utilização exclusiva de mecanismos antitruste na contenção dos preços dos medicamentos, na década de 1990, o Brasil experimentou a liberação do mercado e o uso isolado de referidas ferramentas. Nesse período, os preços dos medicamentos saltaram e o acesso a esses produtos pela população foi prejudicado, o que culminou na instauração da CPI dos medicamentos. ${ }^{313}$ Desse modo, a experiência brasileira revelou que a utilização isolada do antitruste na contenção dos preços em um mercado liberalizado não é suficiente para promover a assistência farmacêutica, sendo necessário algum tipo de regulação direta sobre o mercado de medicamentos.

Assim, o controle de preços parece ser uma ferramenta capaz de promover os objetivos sociais da regulação, principalmente, no que concerne à assistência farmacêutica. Mas é verdade que sua utilização isolada ou apenas ao lado de ferramentas de antitruste não é suficiente para a concretização desse objetivo. Há outras formas de regulação do mercado de medicamentos, tais como co-pagamento, reembolso, política de genéricos e regulamentação da prescrição e análise de custo-efetividade, que também devem ser utilizadas. Alguns desses instrumentos já são adotados no Brasil, assim como a política dos medicamentos genéricos. Falta, contudo, maior rigor na regulamentação das prescrições médicas e fiscalização, evitando a prescrição de medicamentos de referência, quando existentes medicamentos genéricos com o mesmo princípio ativo no mercado. ${ }^{314}$ Além disso, não é possível deixar de lado a necessidade de melhoria da gestão do Sistema Único

\footnotetext{
${ }^{310}$ SCHERER, F. M. Pricing, Profits and Technological Progress in the Pharmaceutical Industry. The Journal of Economic Perspectives, Nashville, v.7, n.3, p.97-115, summer. 1993. p. 106.

${ }^{311}$ DALEN, D.M.; STRØM, S.; Haabeth, T. Price Regulation and Generic Competition in the Pharmaceutical Market. The European Journal of Health Economics, v. 7, n. 3, p. 208-214, set. 2006. p. 214.

${ }^{312}$ Ibid. p. 210.

${ }^{313}$ Cf. Capítulo 3, item 3.1.

${ }^{314}$ Sobre a influência dos hábitos de prescrição médica sobre os preços de medicamentos, ver: DALEN, D.M.; STRØM, S.; Haabeth, T. Price Regulation and Generic Competition in the Pharmaceutical Market. The European Journal of Health Economics, v. 7, n. 3, p. 208-214, set. 2006.
} 
de Saúde e racionalização dos gastos, bem como maiores investimentos no setor. A análise de custo-efetividade deve ser obrigatória para nortear a decisão sobre medicamentos prescritos e fornecidos pelo sistema público de saúde ${ }^{315}$. Ademais, é preciso evitar o desabastecimento de produtros farmacêuticos nas unidades do SUS e garantir que todos os medicamentos da Relação Nacional de Medicamentos Essenciais (RENAME) estejam presentes na lista de remédios fornecidos pelo sistema público de saúde, o que não ocorre na atualidade. Por fim, é imprescindível a redução da carga tributária incidente sobre os medicamentos vendidos em varejo que, atualmente, representa cerca de $34 \%$ do preço pago pelo consumidor final, conforme será visto adiante. ${ }^{316}$

\subsection{Quais são os "prós" e os “contras" da política regulatória prevista na Lei} 10.742/03?

Esta é, ao lado da questão da efetividade da regulação do mercado farmacêutico empreendida pela CMED, uma das perguntas centrais da presente pesquisa e será analisada neste tópico. Conforme dito na Introdução, a hipótese de pesquisa correspondente ao referido problema consiste na seguinte: a política de regulação dos preços apresenta "prós" e "contras", bem como dificuldades e problemas de implementação; mas revela, possivelmente, mais aspectos positivos do que negativos, no Brasil, onde os custos dos medicamentos são elevados e o controle dos preços desses produtos tende a favorecer o consumidor, facilitando o acesso a medicamentos.

Tendo em vista o fato dos preços dos medicamentos serem, em média, muito altos no Brasil, pensou-se, inicialmente, que a indústria, farmácia e drogarias desrespeitassem, com frequiência, o teto de preços estipulado pela CMED. O descumprimento das normas regulatórias explicariam o patamar elevado no qual se encontram os preços dos produtos farmacêuticos. Aventou-se, portanto, que o problema seria exclusivamente de enforcement das normas regulatórias, entretanto, não foi isso, simplesmente, o que foi apurado. De fato, como será visto adiante, existe o problema de enforcement de regras que regulam as

\footnotetext{
${ }^{315}$ Segundo MRAZEK, a utilização isolada de instrumentos regulatórios que atuam sobre a oferta, tal como o controle direto de preços, não é suficiente para reduzir os gastos com medicamentos. Para essa autora, é necessário, também, regulação sobre a demanda (MRAZEK, M.F. Comparative approaches to pharmaceutical price regulation in the European Union. CMJ, Zagreb, n. 4, v.43, p. 453-461, ago. 2002. p. 460).

${ }^{316}$ FEBRAFAR. Lideranças empresariais apóiam redução do ICMS nos medicamentos. Disponível em: <http://www.ibpt.com.br/home/publicacao.view.php?publicacao_id=14406\&PHPSESSID=6c09c02806dfb5d d09c0ea91f9161d8e>. Acesso em: 21 ago. 2012; e GARNETT, G. Medicamentos e a carga tributária. Disponívelem:<http://www.conexaoitajuba.com.br/itajuba/Pagina.do;jsessionid=h0298s51f76f?idSecao=141 \&idNoticia=27108>. Acesso em: 21 ago.2012.
} 
vendas de medicamentos ao governo, que devem ser realizadas mediante a aplicação de desconto obrigatório, nem sempre observado.

Quanto às vendas de medicamentos em varejo, verificou-se, conforme será explicitado adiante, que a política de controle de preços praticada pela CMED apresenta mais problemas do que o esperado quando da formulação da hipótese de pesquisa. A primeira falha constatada não se refere às dificuldades de implementação das normas regulatórias determinantes do reajuste máximo permitido, mas à qualidade das normas propriamente ditas que, por si só, permitem reajustes de preços superiores àqueles teoricamente autorizados pela CMED.

O maior problema diagnosticado foi em relação ao reajuste dos preços dos medicamentos vendidos em varejo. Nesse ponto, a política regulatória da CMED não é efetiva, porque é incapaz de influenciar os preços determinados pela indústria farmacêutica, farmácias e drogarias. Na prática, os percentuais de reajustes reais são bem maiores do que aqueles permitidos pelo governo. Isso ocorre porque, anualmente, ao determinar o preço máximo ao consumidor (PMC), que serve como teto para os reajustes de preços formulados pelas farmácias e drogarias, o governo não leva em consideração os preços realmente praticados nos pontos de venda. Essa situação, contudo, não é ilegal, pois os novos preços fixados pelas farmácias e drogarias não ultrapassam o teto de preço fixado pelo órgão regulador (preço máximo ao consumidor). ${ }^{317}$

O Instituto de Defesa do Consumidor (IDEC) realizou nos anos de 2009, 2010 e 2011, pesquisas sobre os preços de medicamentos nos pontos de venda de diversas cidades do Brasil. Essas pesquisas apontaram para a seguinte conclusão: existe uma diferença significativa entre os preços praticados nos pontos de venda e o preço máximo ao consumidor (PMC) estabelecido pela CMED. Além disso, os reajustes realizados na prática são notadamente superiores ao percentual máximo de reajuste fixado pela CMED.

A realidade do mercado farmacêutico é de que os preços máximos fixados pelo governo ficam bem acima do que é praticado pelo mercado. Segundo o IDEC, isso não representa benefícios concedidos pelas farmácias aos consumidores, mas problemas na maneira como a regulação dos preços de medicamentos é feita no Brasil. ${ }^{318}$ Conforme dito anteriormente, a Câmara de Regulação do Mercado de Medicamentos estabelece um preço máximo para a venda de cada produto pelas farmácias e drogarias, mas estas acabam

\footnotetext{
${ }^{317}$ MEIO cheio ou meio vazio? Revista do IDEC. São Paulo, n.142, p. 22-25, abr. 2010. p. 22.

${ }^{318}$ REMÉDIO pro bolso. Revista do IDEC. São Paulo, n. 130, p.16-20, mar. 2009. p.16.
} 
cobrando bem menos, o que não significa que os preços dos medicamentos estejam baratos, mas que o teto estabelecido pelo governo está elevado demais.

Vera Luiza, pesquisadora da Escola Nacional de Saúde Pública- Fiocruz acredita que isso aconteça porque os laboratórios repassam aos preços os ganhos com aumento de eficiência e redução do custo de produção, além de modular os valores cobrados para seus produtos, reduzindo, por exemplo, o preço de um medicamento e aumentando o de outro. De acordo com essa pesquisadora, os distribuidores e as farmácias também vendem mais barato, em função dos descontos que obtêm junto à indústria farmacêutica através de acordos comerciais e compras em grande volume. ${ }^{319}$ No entanto, Vera Luiza afirma que o preço final dos medicamentos tem muito mais a ver com o quanto o mercado está disposto a pagar do que necessariamente com o custo de produção. Por essa razão que é possível encontrar medicamentos fabricados em países desenvolvidos e subdesenvolvidos que são mais caros nos últimos países, embora a mão de obra, o custo de produção e o poder aquisitivo da população sejam comparativamente maiores nos primeiros países.

Em 2009, o IDEC coletou o preço de 76 medicamentos de referência: 17 únicos no mercado, 11 com similares também à venda, e 48 com similares e genéricos disponíveis no mercado. ${ }^{320}$ Essa pesquisa ficou circunscrita à cidade de São Paulo e incluiu farmácias e drogarias de pequeno, médio e grande porte. Técnicos do IDEC visitaram 267 farmácias nas cinco regiões da capital paulista. Em cada região foram coletados três preços por medicamento, de 23 classes terapêuticas diversas. A coleta dos preços foi diretamente nos pontos de venda.

Por não sofrerem com a concorrência, esperava-se que os preços dos medicamentos de referência únicos no mercado se afastassem menos do teto estabelecido pela CMED, em comparação com os demais medicamentos de referência que possuem como substitutos genéricos e similares. No entanto, não foi esse o resultado encontrado, tendo sido considerável a diferença entre a média dos preços desses grupos e a média do teto de preços. Essa diferença incidiu no patamar de 19\%, no caso de medicamentos de referência

\footnotetext{
${ }^{319}$ No mesmo sentido está a explicação concedida por Basilia Aguirre, especialista em economia da saúde e pesquisadora da FIPE, quando indagada sobre os motivos da significativa diferença entre os preços dos medicamentos praticados nos pontos de venda e o preço máximo ao consumidor estabelecido pela CMED (informação verbal). Informação fornecida por Basilia Aguirre em entrevista realizada em São Paulo, em 28 de agosto de 2012 - vide transcrição do áudio da entrevista com Basilia Aguirre, no Anexo E.

${ }^{320}$ Conforme explicou Ione Amorim na entrevista constante do anexo deste trabalho (informação verbal) a lista de medicamentos para coleta de preços foi elaborada com o auxílio de técnicos da Vigilância Sanitária, e com base no tratamento prescrito às doenças de maior ocorrência no Brasil. Foram selecionados medicamentos de referência, genéricos e similares, cuja demanda é grande em drogarias e farmácias de todo o país. Informação fornecida por Ione Amorim, em entrevista realizada em São Paulo, em 20 de fevereiro de 2012 (vide transcrição do áudio da entrevista com Ione Amorim, no Anexo B).
} 
que possuem como substitutos genéricos ou similares, e foi superior a $20 \%$, para os medicamentos de referência únicos no mercado. ${ }^{321}$

No que concerne aos medicamentos similares, no mesmo ano, o IDEC pesquisou o preço de 34 produtos. Estes foram, em média, 77\% mais baratos do que o teto estipulado pela CMED (Tabela 8).

Tabela 8. Diferença entre preço médio em SP de medicamento similar versus preço máximo da CMED (em R\$)

\begin{tabular}{|c|c|c|c|c|c|c|}
\hline $\begin{array}{l}\text { Denominação genérica } \\
\text { (princípio ativo) }\end{array}$ & $\begin{array}{c}\text { Nome } \\
\text { comercial }\end{array}$ & Laboratório & Apresentação & $\begin{array}{c}\text { Preço médio } \\
\text { SP }\end{array}$ & $\begin{array}{l}\text { Preço } \\
\text { CMED }\end{array}$ & $\begin{array}{c}\text { Variações } \\
(\%)\end{array}$ \\
\hline Atenolol & Angipress & Biosintética & $\begin{array}{c}50 \mathrm{mg} \text { caixa } 28 \\
\text { comprimidos }\end{array}$ & 10,35 & 26,26 & 154 \\
\hline Cloridrato de sibutramina & Biomag & Aché & $\begin{array}{l}10 \text { mg caixa } 30 \\
\text { comprimidos }\end{array}$ & 21,16 & 42,12 & 99 \\
\hline Maleato de enalapril & Angiopril & $\begin{array}{c}\text { Diffucap } \\
\text { Chemobras }\end{array}$ & $\begin{array}{c}20 \text { mg caixa } 30 \\
\text { comprimidos }\end{array}$ & 16,84 & 32,31 & 92 \\
\hline $\begin{array}{l}\text { Amoxicilina + Clavulanato } \\
\text { de potássio }\end{array}$ & Clav air & Biofarma & $\begin{array}{c}500 \mathrm{mg}+125 \mathrm{mg} \\
\text { Caixa } 18 \\
\text { comprimidos }\end{array}$ & 36,95 & 67,45 & 83 \\
\hline
\end{tabular}

Média de variação (34 medicamentos pesquisados) - 77\%

Fonte: Adaptado de REMÉDIO pro bolso. Revista do IDEC. São Paulo, n. 130, p.16-20, mar. 2009. p.19.

Ainda na pesquisa de 2009, foram apurados os preços de 44 medicamentos genéricos. A média de diferença dos preços desses produtos praticados nas farmácias com relação ao teto da CMED foi de $40 \%$ (Tabela 9). ${ }^{322}$

Tabela 9. Diferença entre preço médio em SP de medicamento genérico versus preço máximo da CMED (em Reais)

\begin{tabular}{|c|c|c|c|c|}
\hline Denominação genérica (princípio ativo) & Apresentação & Preço médio SP & Preço CMED & Variação (\%) \\
\hline Cloridrato de sibutramina & $10 \mathrm{mg}$ caixa 30 cápsula & 24,46 & 106,65 & 330 \\
\hline Sinvastatina & $20 \mathrm{mg}$ caixa 30 comprimidos & 33,45 & 65,79 & 97 \\
\hline Loridrato de sertralina & $50 \mathrm{mg}$ caixa 28 comprimidos & 37,18 & 66,78 & 80 \\
\hline Atenolol & $50 \mathrm{mg}$ caixa 28 comprimidos & 10,05 & 17,95 & 79 \\
\hline Omeprazol & $20 \mathrm{mg}$ caixa 28 cápsulas & 33,35 & 59,23 & 78 \\
\hline
\end{tabular}

Média de variação (44 produtos pesquisados) - 40\%

Fonte: Adaptado de REMÉDIO pro bolso. Revista do IDEC. São Paulo, n. 130, p.16-20, mar. 2009. p. 19.

Todos os medicamentos pesquisados pelo IDEC em 2009 (foram 2.175 preços no total) apresentaram variações muito abaixo do teto estabelecido pela Câmara de Regulação

\footnotetext{
${ }^{321}$ REMÉDIO pro bolso. Revista do IDEC. São Paulo, n. 130, p.16-20, mar. 2009. p.18.

${ }^{322}$ Ibid., p. 19.
} 
do Mercado de Medicamentos. O fato dessas variações terem sido superiores para os medicamentos similares e genéricos demonstra que a concorrência pode exercer um papel importante na diminuição dos preços, principalmente quando há várias empresas produzindo o mesmo medicamento. ${ }^{323}$

Essa situação, por sua vez, denota um problema crucial no modelo regulatório de teto de preços implementado pela CMED, cuja base não é revista de acordo com a prática do mercado. Tal problema consiste, assim como mencionado anteriormente, no fato dos laboratórios e farmácias poderem reajustar os preços dos medicamentos a qualquer momento, desde que dentro do "colchão" existente entre o preço praticado pelo mercado e o teto estipulado pelo governo. ${ }^{324}$ Pesquisas semelhantes, realizadas pelo IDEC em 2010 e 2011 apontaram um agravamento da diferença entre a média de preços praticada no mercado e o teto de preços estabelecido pela CMED.

Em 2010, foram levantados os preços de 25 medicamentos, genéricos e de referência, desta vez, em dez cidades do país: Belo Horizonte (MG), Campo Grande (MS), Curitiba (PR), Fortaleza (CE), Natal (RN), Porto Alegre (RS), Recife (PE), Salvador (BA), São Paulo (SP) e Tubarão (SC). Em cada cidade, os pesquisadores visitaram diferentes pontos de venda, atentando para que cada medicamento pesquisado tivesse, ao menos, três cotações de preços por município. A base de dados obtida foi composta por 1.092 preços (824 de medicamentos de referência e 268 de medicamentos genéricos), coletados em 135 pontos de venda. Os medicamentos pesquisados foram selecionados entre os produtos mais prescritos para o tratamento de doenças crônicas, além de anti-inflamatórios, antidepressivos, ansiolíticos e antibióticos. ${ }^{325}$

O resultado dessa pesquisa indicou que $44 \%$ dos 1.092 preços de medicamentos apurados apresentaram diferença entre $20 \%$ e $295 \%$, em relação ao respectivo teto estabelecido pela CMED. Para o IDEC, quanto maior essa diferença, menor o poder de regulação da CMED sobre os preços reais oferecidos pelo consumidor (Tabela 10). ${ }^{326}$

\footnotetext{
${ }^{323}$ REMÉDIO pro bolso. Revista do IDEC. São Paulo, n. 130, p.16-20, mar. 2009. p. 19

${ }^{324}$ Ibid., p. 19.

${ }^{325}$ MEIO cheio ou meio vazio? Revista do IDEC. São Paulo, n.142, p. 22-25, abr. 2010. p. 23.

${ }^{326}$ Ibid., p. 23.
} 
Tabela 10. Variação entre os preços praticados no mercado e o respectivo teto (pesquisa IDEC publicada em 2010).

\begin{tabular}{|c|c|c|c|c|c|c|}
\hline \multirow{2}{*}{$\begin{array}{l}\text { Faixa de } \\
\text { variação de } \\
\text { preço }(\%)\end{array}$} & \multicolumn{2}{|r|}{ Total } & \multicolumn{2}{|c|}{ Referência } & \multicolumn{2}{|c|}{ Genérico } \\
\hline & $\begin{array}{l}\text { Quantidade } \\
\text { de preços }\end{array}$ & $\begin{array}{c}\text { Participação } \\
(\%)\end{array}$ & $\begin{array}{l}\text { Quantidade } \\
\text { de preços }\end{array}$ & $\begin{array}{c}\text { Participação } \\
\text { (\%) }\end{array}$ & $\begin{array}{l}\text { Quantidade } \\
\text { de preços }\end{array}$ & $\begin{array}{c}\text { Participação } \\
(\%)\end{array}$ \\
\hline $0-2$ & 268 & 25 & 234 & 28 & 34 & 13 \\
\hline $2,1-20$ & 338 & 31 & 284 & 34 & 54 & 20 \\
\hline $20,1-40$ & 272 & 25 & 228 & 28 & 44 & 16 \\
\hline $40,1-60$ & 88 & 8 & 19 & 2 & 69 & 26 \\
\hline $60,1-80$ & 43 & 4 & 28 & 3 & 15 & 6 \\
\hline $80,1-100$ & 37 & 3 & 20 & 2 & 17 & 6 \\
\hline $100,1-150$ & 29 & 3 & 5 & 1 & 24 & 9 \\
\hline $150,1-295$ & 15 & 1 & 4 & 0 & 11 & 4 \\
\hline $\begin{array}{l}\text { Acima do } \\
\text { preço da }\end{array}$ & 2 & 0 & 2 & 0 & - & - \\
\hline CMED & & & & & & \\
\hline Total & 1092 & 100 & 824 & 100 & 268 & 100 \\
\hline
\end{tabular}

Fonte: Adaptado de MEIO cheio ou meio vazio? Revista do IDEC. São Paulo, n.142, p. 22-25, abr. 2010. p. 24.

Os genéricos apresentaram maior variação entre o PMC e o preço de varejo. $51 \%$ do total de preços dos medicamentos genéricos apurados apresentaram variação entre $40 \%$ e $295 \%$, em relação ao preço teto determinado pela CMED. ${ }^{327}$ Ione Amorim explica que os preços dos genéricos tendem a variar mais porque a concorrência é maior nesse segmento. ${ }^{328}$

Nessa pesquisa, a maior diferença apurada foi em relação ao medicamento genérico Losartana Potássica, fabricado pela Medley, na apresentação de 50 mg e uma caixa de 50 comprimidos. Em uma farmácia de Natal $(\mathrm{RN})$, o medicamento foi encontrado a $\mathrm{R} \$ 9,90$, enquanto que o seu teto é de $\mathrm{R} \$ 39,15$. Isso significa que, da noite para o dia, o preço desse medicamento pode aumentar, em tese, até $295 \% .{ }^{329}$

A mesma pesquisa verificou que, dentre os medicamentos de referência, aquele que apresentou maior variação em relação ao teto estipulado foi o Frontal da Pfizer. A caixa de 0,5 mg e 30 comprimidos foi encontrada a $\mathrm{R} \$$ 8,80 em farmácias de Recife (PE), estando $211 \%$ abaixo do teto de $\mathrm{R} \$ 27,35 .{ }^{330}$

\footnotetext{
${ }^{327}$ MEIO cheio ou meio vazio? Revista do IDEC. São Paulo, n.142, p. 22-25, abr. 2010. p. 23.

${ }^{328}$ Ibid., p. 24 .

${ }^{329}$ Ibid., p. 24.

${ }^{330}$ Ibid. p. 24
} 
O resultado final da pesquisa apontou que entre janeiro de 2009 e janeiro de 2010, os preços dos medicamentos subiram em média 14,75\% em São Paulo, ao passo que o reajuste máximo permitido pelo governo foi de 5,9\% (Tabela 11).

Tabela 11. Variação entre preços (pesquisa IDEC publicada em 2010).

\begin{tabular}{|c|c|c|c|c|c|c|}
\hline \multirow[t]{2}{*}{ Medicamentos de referência } & \multicolumn{2}{|c|}{ Janeiro de 2009} & \multicolumn{2}{|c|}{ Janeiro de 2010} & \multicolumn{2}{|c|}{$2009 \times 2010$} \\
\hline & $\begin{array}{l}\text { Mercado (preço } \\
\text { médio) }\end{array}$ & $\begin{array}{l}\text { CMED } \\
2008\end{array}$ & $\begin{array}{c}\text { Mercado (preço } \\
\text { médio) }\end{array}$ & CMED 2009 & $\begin{array}{c}\text { Mercado } \\
(\%)\end{array}$ & $\begin{array}{c}\text { MED } \\
(\%)\end{array}$ \\
\hline $\begin{array}{l}\text { Adalat Retard } 10 \mathrm{mg} \text { frasco } 30 \\
\text { comprimidos }\end{array}$ & 13,5 & 15,47 & 13,76 & 16,38 & 5,4 & 5,88 \\
\hline $\begin{array}{l}\text { Avandia } 4 \text { mg caixa } 14 \\
\text { comprimidos }\end{array}$ & 8000 & 100,43 & 91,46 & 106,35 & 14,33 & 5,89 \\
\hline $\begin{array}{l}\text { Biopress } 8 \text { mg caixa } 30 \\
\text { comprimidos }\end{array}$ & 64,58 & 91,28 & 74,98 & 85,90 & 16,10 & $-5,89$ \\
\hline $\begin{array}{l}\text { Cataflan } 500 \mathrm{mg} \text { caixa } 20 \\
\text { comprimidos }\end{array}$ & 16,73 & 19,81 & 19,09 & 20,98 & 14,09 & 5,91 \\
\hline Ebix & 145,15 & 195,22 & 192,25 & 206,72 & 32,45 & 5,89 \\
\hline $\begin{array}{l}\text { Imuran } 50 \mathrm{mg} \text { caixa } 50 \\
\text { comprimidos }\end{array}$ & 108,53 & 133,69 & 122,25 & 141,58 & 12,65 & 5,90 \\
\hline $\begin{array}{l}\text { Meticorten } 20 \text { mg caixa } 10 \\
\text { comprimidos }\end{array}$ & 15,87 & 18,25 & 17,69 & 19,32 & 11,49 & 5,86 \\
\hline $\begin{array}{l}\text { Peprazol } 20 \text { mg caixa } 28 \\
\text { comprimidos }\end{array}$ & 63,33 & 96,74 & 43,41 & 54,89 & $-31,45$ & $-43,26$ \\
\hline $\begin{array}{l}\text { Zitromax } 500 \text { mg caixa } 2 \\
\text { comprimidos }\end{array}$ & 34,84 & 40,74 & 39,23 & 43,14 & 12,61 & 5,89 \\
\hline $\begin{array}{l}\text { Zocor } 20 \text { mg caixa } 30 \\
\text { comprimidos }\end{array}$ & 94,91 & 116,44 & 105,18 & 123,31 & 10,82 & 5,90 \\
\hline $\begin{array}{l}\text { Zoloft } 50 \text { mg caixa } 28 \\
\text { comprimidos }\end{array}$ & 93,05 & 115,21 & 109,35 & 122,00 & 17,51 & 5,89 \\
\hline Média de reajustes & & & & & 14,75 & 5,89 \\
\hline
\end{tabular}

Fonte: Adaptado de MEIO cheio ou meio vazio? Revista do IDEC. São Paulo, n.142, p. 22-25, abr. 2010. p. 25.

Em janeiro de 2009, por exemplo, o Ebix, fabricado pela Lundbeck, era comercializado em média a $\mathrm{R} \$ 145,15$, na capital paulista. Após um ano, sua média de preço subiu para $\mathrm{R} \$ 192,25$, tendo um aumento de $33 \%$. Em contrapartida, nesse mesmo período, o teto oficial desse medicamento subiu apenas $5,9 \% .{ }^{331}$

O antigo secretário executivo da CMED, Luiz Milton Veloso Costa, entende que essas grandes variações de preços se justificam em razão da política de descontos dos

${ }^{331}$ MEIO cheio ou meio vazio? Revista do IDEC. São Paulo, n.142, p. 22-25, abr. 2010. p. 21-22. 
laboratórios e redes de varejo. Segundo ele, se o preço de um medicamento subir repentinamente, a causa é a aplicação de um desconto menor e não de um aumento de preço. Contudo, conforme explicam os pesquisadores do IDEC:

[i]ndependentemente de chamarmos a alta repentina de preços de "retirada de desconto" ou de "reajuste abusivo", o fato é que em muitos casos os preços sobem em percentuais maiores que os dos reajustes legais estipulados $^{332}$

O IDEC também entende que o fato da suposta política de descontos ser usual revela que os preços mais baixos são na verdade os preços de mercado. Mirtes Peinado, coordenadora da área de testes e pesquisas desse instituto, afirma que foi possível constatar que "são raras as situações que uma empresa vende um produto sem ter margem de lucro satisfatória". 333

Segundo Ivo Bucaresky, atual Secretário Executivo da CMED, o descompasso entre o teto e o preço efetivo remonta ao começo da regulação do setor, em 2003, que foi iniciada sobre os preços de medicamentos já praticados em patamares muito altos:

[n]a época em que os preços dos medicamentos começaram a ser tabelados, o mercado praticava sobrepreço, pois até então a indústria aumentava o valor dos remédios como queria. A partir do controle, a indústria passou a dar descontos e assim começou a defasagem. ${ }^{334}$

Para Basilia Aguirre, especialista em Economia da Saúde e pesquisadora da Fundação Instituto de Pesquisas Econômicas, a prática dos laboratórios e redes varejistas lembra à que era utilizada na época do Plano Cruzado pela indústria farmacêutica. Nesse período, dois tipos de preços eram estabelecidos, os "normais" e os "com desconto". Em havendo um congelamento de preços repentino, a indústria farmacêutica dizia que este deveria ser aplicado sobre os preços "normais", ou seja, os sem desconto, anulando qualquer tentativa de controle da inflação. Para essa especialista, os estudos que acompanhem as oscilações dos preços finais dos medicamentos são fundamentais para que a CMED possa efetuar um papel regulador, pois "só assim será possível saber se os preços

\footnotetext{
${ }^{332}$ MEIO cheio ou meio vazio? Revista do IDEC. São Paulo, n.142, p. 22-25, abr. 2010. p. 24.

${ }^{333}$ Ibid., p. 25.

${ }^{334}$ DIFERENÇA além da conta. Revista do IDEC. São Paulo, n.162, p.16-19, fev. 2012. p. 19.
} 
praticados ao consumidor são reais, com descontos verdadeiros ou com descontos 'para inglês ver'", 335

Em entrevista ao IDEC, o antigo Secretário Executivo da CMED, Luiz Milton Veloso Costa, reconheceu que esse tipo de estudo não é realizado pela CMED: "no caso dos genéricos, por exemplo, não há estudos sobre os preços de mercado. Não dá para saber se os preços atuais são reais ou se estão com descontos"336

O IDEC entende que uma saída para proteger o consumidor, evitando que os preços de mercado sejam majorados de uma hora para outra, seria garantir que os tetos de preços fossem mais próximos aos preços de mercado praticados. Contudo, para a CMED, essa aproximação tem como obstáculo dificuldades operacionais e técnicas da regulação do setor. Operacionais porque acompanhar os preços praticados nos milhares de pontos de venda espalhados pelo território nacional não é algo simples, sendo, ao mesmo tempo, custoso. Técnica, vez que qualquer revisão dos métodos regulatórios de reajustes dos PMCs e PFs exigiria mudanças na Lei 10.742/03. Segundo Luiz Milton: "não adianta, por exemplo, baixar uma resolução que reduza o teto em 50\%. No dia seguinte as empresas entrariam na Justiça e a derrubariam, e exigiriam indenizações milionárias".337

Nesse sentido, o atual Secretário Executivo da CMED, Ivo Bucaresky, reconheceu em entrevista ao IDEC que a distorção entre o teto e o valor efetivamente praticado é de fato ruim, mas a atual legislação que rege a atuação da CMED (Lei 10.742/03) impede a diminuição do PMC. Ele afirmou que "da forma como a lei foi montada, não há flexibilidade para reajustar os preços para baixo". Disse ainda que os tetos de preços só são reduzidos a requerimento da indústria farmacêutica, o que costuma ocorrer quando a patente de um medicamento está prestes a expirar. ${ }^{338}$ Segundo Joana Cruz, advogada do IDEC, a redução do teto realizada apenas a pedido da indústria, com o intuito de obstar a concorrência e não de beneficiar o consumidor, é mais uma prova de que quem controla os preços dos produtos farmacêuticos, na prática, é a indústria farmacêutica e não o governo. ${ }^{339}$

\footnotetext{
${ }^{335}$ REMÉDIO pro bolso. Revista do IDEC. São Paulo, n. 130, p.16-20, mar. 2009. p.25.

${ }^{336}$ Ibid., p. 25.

${ }^{337}$ Ibid., p.25. Registra-se que cabe discussão se diminuições menos significativas de preço do que aquela exemplificada pelo antigo secretário executivo da CMED (50\%) seriam capazes de gerar tamanho inconformismo da indústria farmacêutica, a ponto de ingressarem com ações judiciais requerendo a invalidade das normas regulatórias. Contudo, é verdade que não está previsto na Lei 10.742/03 qualquer possibilidade de redução de preços de medicamentos, o que poderia gerar contestação da legalidade de medidas reguladoras nesse sentido.

${ }^{338}$ DIFERENÇA além da conta. Revista do IDEC. São Paulo, n.162, p.16-19, fev. 2012. p. 19.

${ }^{339}$ Ibid., p. 19.
} 
Além disso, o antigo Secretário Executivo da CMED, Luiz Milton Veloso Costa, acredita que qualquer notícia de mudança do atual modelo regulatório pode fazer as empresas majorarem os preços abruptamente até o teto, antes que qualquer medida seja efetivamente tomada. ${ }^{340}$

Fato é, consoante explica a advogada e pesquisadora do IDEC, Joana Cruz, que se as farmácias conseguem praticar grandes descontos em relação ao preço máximo, é sinal de que esse máximo deveria ser muito menor. ${ }^{341}$ Desse problema, decorrem outras dificuldades tais como a possibilidade do valor de um medicamento subir de uma hora para outra. O suposto "desconto" sobre o preço do medicamento pode ser retirado de forma abrupta, comprometendo a continuidade do tratamento de saúde. ${ }^{342}$

Ademais, essa situação dá margem para a imensa diferença de preços entre drogarias e farmácias, causando insegurança ao consumidor que ao consultar uma farmácia não sabe se o preço praticado é adequado ou se poderia pagar muito mais barato em outra drogaria. Conforme relata Joana Cruz: "se não pesquisar bastante antes da compra, o consumidor pode ser prejudicado". 343

Em 2011, o IDEC fez uma nova pesquisa de preços de medicamentos, desta vez, mediante levantamento de preços de 24 medicamentos, entre genéricos e de referência, no sítio eletrônico das cinco principais drogarias da capital paulista (Droga Raia, Drogasil, Drogaria São Paulo, Onofre e Ultrafarma). O resultado revelou que os preços variam muito de uma drogaria para outra. Em 33\% dos casos, a diferença é de mais de $60 \%$ entre o menor e o maior valor praticado, e há situações em que a variação passa dos $200 \%$. De acordo com o IDEC, tamanha discrepância é possível porque os preços máximos ao consumidor fixados pelo governo para os medicamentos ainda são bem maiores que os preços encontrados nas farmácias. ${ }^{344}$ Nessa pesquisa foram identificados 91 preços para os 24 medicamentos observados. Em alguns casos, o remédio não estava disponível ou o valor não era apresentado no site da drogaria. Para uma boa parte dos medicamentos, a diferença de preço entre as farmácias é enorme: a variação entre o menor e o maior preço verificado para cada droga é de $11 \%$ a $235 \%$, sendo que as maiores diferenças foram observadas entre os medicamentos genéricos. Dentre esses medicamentos, a menor variação encontrada foi de $66 \%$, caso do anti-inflamatório diclofenaco potássico, do

\footnotetext{
${ }^{340}$ MEIO cheio ou meio vazio? Revista do IDEC. São Paulo, n.142, p. 22-25, abr. 2010. p. 25.

${ }^{341}$ DIFERENÇA além da conta. Revista do IDEC. São Paulo, n.162, p.16-19, fev. 2012. p. 19.

${ }^{342}$ Ibid., p. 17.

${ }^{343}$ Ibid. p. 16.

${ }^{344}$ Ibid. p. 16.
} 
laboratório Medley, cujo menor preço foi identificado a $\mathrm{R} \$ 3,59$ e o maior a $\mathrm{R} \$ 7,18$. A maior variação foi verificada no caso dos antibióticos amoxicilina e azitromicina (ambos do laboratório EMS), cuja diferença entre o menor e o maior preço encontrado nas drogarias é de $233,1 \%$ e $235,3 \%$, respectivamente (Tabela 12). ${ }^{345}$

Tabela 12. Variação de preço dos medicamentos (pesquisa IDEC publicada em 2012).

\begin{tabular}{|c|c|c|c|c|c|c|c|}
\hline Medicamento & $\begin{array}{c}\text { Maior } \\
\text { preço }(\mathbf{R} \$)\end{array}$ & $\begin{array}{c}\text { Menor } \\
\text { preço (R\$) }\end{array}$ & $\begin{array}{c}\text { Variação } \\
\text { entre o maior } \\
\text { e o menor } \\
\text { preço }(\%)\end{array}$ & $\begin{array}{l}\text { Preço } \\
\text { teto } \\
\text { CMED } \\
\text { (R\$) }\end{array}$ & $\begin{array}{c}\text { Desconto } \\
\text { praticado entre o } \\
\text { menor preço e o } \\
\text { teto da CMED }(\%)\end{array}$ & $\begin{array}{c}\text { Preço } \\
\text { médio } \\
\text { (R\$) }\end{array}$ & $\begin{array}{c}\text { Desconto } \\
\text { praticado entre o } \\
\text { preço médio e o } \\
\text { teto da CMED }(\%)\end{array}$ \\
\hline Alprazolam & $\begin{array}{l}6,64- \\
\text { Onofre }\end{array}$ & $\begin{array}{c}2,65- \\
\text { Ultrafarma }\end{array}$ & 150,57 & 13,28 & 80,05 & 4,64 & 65,02 \\
\hline Amoxicilina & $\begin{array}{c}\text { 20,09-Droga } \\
\text { Raia }\end{array}$ & 60,3 Onofre & 233,17 & 20,09 & 69,99 & 11,38 & 43,34 \\
\hline Atenolol & $\begin{array}{c}12,05 \\
\text { Drogasil }\end{array}$ & 5,17 Onofre & 133,08 & 17,22 & 69,98 & 8,26 & 52,01 \\
\hline Azitromicina & $\begin{array}{c}19,28 \text { - } \\
\text { Droga Raia }\end{array}$ & $\begin{array}{c}5,75 \\
\text { Ultrafarma }\end{array}$ & 235,30 & 19,28 & 70,18 & 11,56 & 40,06 \\
\hline $\begin{array}{l}\text { Diclofenaco } \\
\text { potássico }\end{array}$ & $\begin{array}{c}7,18 \\
\text { Drogaria SP }\end{array}$ & 3,59 Onofre & 66,57 & 11,96 & 69,98 & 5,5 & 54,01 \\
\hline $\begin{array}{l}\text { Losartana } \\
\text { potássica }\end{array}$ & $\begin{array}{c}19,90 \\
\text { Drogasil }\end{array}$ & $\begin{array}{c}11,37 \text { Droga } \\
\text { Raia }\end{array}$ & 75,02 & $*$ & * & * & * \\
\hline Sinvastatina & $\begin{array}{c}40,78 \\
\text { Drogasil }\end{array}$ & $\begin{array}{c}23,30 \\
\text { Ultrafarma }\end{array}$ & 75,02 & $*$ & $*$ & $*$ & $*$ \\
\hline Adalat Retard & $\begin{array}{c}15,47 \\
\text { Ultrafarma }\end{array}$ & $\begin{array}{c}13,65 \\
\text { Drogasil }\end{array}$ & 13,33 & 18,20 & 25 & 4,40 & 20,88 \\
\hline Amaryl & $\begin{array}{l}21,12 \text { Droga } \\
\text { Raia }\end{array}$ & $\begin{array}{c}13,81 \\
\text { Ultrafarma }\end{array}$ & 52,93 & 27,61 & 49,98 & 5,82 & 42,7 \\
\hline $\begin{array}{l}\text { Aspirina } \\
\text { prevent }\end{array}$ & $\begin{array}{l}10,08 \\
\text { Ultrafarma }\end{array}$ & 8,89 Drogasil & 13,39 & $*$ & $*$ & $*$ & $*$ \\
\hline Blopress & $\begin{array}{c}81,13 \\
\text { Ultrafarma }\end{array}$ & $\begin{array}{c}71,59 \\
\text { Drogasil }\end{array}$ & 13,33 & 95,45 & 25 & 75,21 & 21,2 \\
\hline Cataflan & $\begin{array}{c}18,65 \\
\text { Drogaria SP }\end{array}$ & $\begin{array}{c}16,31 \\
\text { Ultrafarma }\end{array}$ & 14,35 & 23,31 & 30,03 & 7,72 & 24 \\
\hline $\begin{array}{l}\text { Cymbalta } \\
\text { Retard }\end{array}$ & $\begin{array}{c}240,97 \\
\text { Ultrafarma }\end{array}$ & $\begin{array}{c}240,97 \\
\text { Ultrafarma }\end{array}$ & 0 & 83,50 & $* *$ & 240,97 & 15 \\
\hline Ebix & $\begin{array}{c}223,54 \\
\text { Droga Raia }\end{array}$ & $\begin{array}{l}160,95 \\
\text { Onofre }\end{array}$ & 38,89 & 23,54 & 28 & 187,77 & 16 \\
\hline Fosamax & $\begin{array}{c}137,48 \\
\text { Ultrafarma }\end{array}$ & $\begin{array}{c}121,31 \\
\text { Drogasil }\end{array}$ & 13,33 & 161,75 & 25 & 127,46 & $21,221,2$ \\
\hline Frontal & $\begin{array}{l}\text { 30,77 Droga } \\
\text { Raia }\end{array}$ & 22,15 Onofre & 38,92 & 30,77 & 28,01 & 25,84 & 16,01 \\
\hline Imuran & $\begin{array}{c}130,15 \\
\text { Ultrafarma }\end{array}$ & $\begin{array}{c}114,84 \\
\text { Drogasil }\end{array}$ & 13,33 & $*$ & $*$ & $*$ & $*$ \\
\hline Meticorten & $\begin{array}{c}17,18 \\
\text { Drogaria SP }\end{array}$ & $\begin{array}{c}12,88 \\
\text { Ultrafarma }\end{array}$ & 33,39 & 21,48 & 40,04 & 9,81 & 7,76 \\
\hline Peprazol & $\begin{array}{c}45,75 \\
\text { Drogasil }\end{array}$ & $\begin{array}{c}27,45 \\
\text { Ultrafarma e } \\
\text { Drogaria SP }\end{array}$ & 66,67 & 61,00 & 55 & 33,55 & 45 \\
\hline Profenid & $\begin{array}{c}24,65 \\
\text { Ultrafarma }\end{array}$ & $\begin{array}{c}21,75 \\
\text { Drogasil }\end{array}$ & 13,33 & 29,00 & 25 & 22,85 & 21,2 \\
\hline Singulair & $\begin{array}{c}83,43 \\
\text { Ultrafarma e } \\
\text { Drogaria SP }\end{array}$ & $\begin{array}{l}75,09 \text { Droga } \\
\text { Raia }\end{array}$ & 11,11 & $*$ & $*$ & $*$ & $*$ \\
\hline Zitromax & $\begin{array}{c}\text { 19,18 Droga } \\
\text { Raia }\end{array}$ & 14,86 Onofre & 25,03 & 19,18 & 20,02 & 16,46 & 14,18 \\
\hline Zocor & $\begin{array}{c}51,70 \\
\text { Drogaria SP }\end{array}$ & $\begin{array}{c}38,77 \\
\text { Ultrafarma }\end{array}$ & 33,35 & 64,63 & 40,01 & 7,1 & 27,13 \\
\hline Zoloft & $\begin{array}{c}\text { 61,01 Droga } \\
\text { Raia }\end{array}$ & 43,93 Onofre & 38,88 & 61,01 & 28 & 1,25 & 16 \\
\hline
\end{tabular}

Fonte: Adaptado de "DIFERENÇA além da conta". Revista do IDEC. São Paulo, n.162, p.16-19, fev. 2012. p.18.

${ }^{345}$ DIFERENÇA além da conta. Revista do IDEC. São Paulo, n.162, p.16-19, fev. 2012. p. 19. 
Dentre os medicamentos de referência também foi possível observar diferenças significativas de preço entre drogarias. A título de ilustração, o Peprazol@, usado para tratamento gástrico foi vendido em uma drogaria por $\mathrm{R} \$ 27,45$ na Ultrafarma e em outra por R $\$ 47,75$ na Drogasil - uma variação de 66,6\%. 346

Juan Carlos Lijos, diretor executivo do Sindicato do Comércio Varejista de Produtos Farmacêuticos no Estado de São Paulo (SINCOFARMA), disse ao IDEC que existem muitos fatores que conduzem a uma grande variação de preço dos remédios entre as drogarias, como a concorrência na região, os custos de cada loja e até a política de vendas dos laboratórios, que oferecem preços diferentes conforme o volume de produtos adquiridos, por exemplo. No entanto, para ele, o fator mais importante capaz de explicar essa diferença de valores é a fixação de preços máximos pela CMED: “o PMC [preço máximo ao consumidor] em geral está muito acima do valor de aquisição dos medicamentos pelas farmácias. Alguns [varejistas] vão vender pelo valor máximo e outros não". ${ }^{347}$

Ivo Bucaresky, Secretário Executivo da CMED, acredita que o medicamento que hoje é vendido com desconto em relação ao seu respectivo teto seria muito mais caro se não houvesse o controle de margens de comercialização. Segundo ele, existe o risco dos preços aumentarem, "mas só até o teto". Entretanto, conforme acentua o IDEC, subir "só até o teto" pode significar um aumento considerável de preços para o consumidor, vez que os valores encontrados nas farmácias e drogarias estão muito aquém do máximo permitido. O IDEC assegura que: "com tanta liberdade para diminuir e aumentar o preço dos medicamentos, o consumidor fica sujeito a alterações repentinas, o que coloca em xeque a efetividade da regulação do setor". 348

O diretor da SINCOFARMA disse ao IDEC que não há risco de os preços subirem significativamente de forma abrupta, em função do alto grau de competitividade entre as farmácias e da existência de medicamentos genéricos. ${ }^{349}$ Mesmo assim, ainda que o reajuste de preços não ocorra, é possível verificar que a regulação do setor poderia ser mais efetiva, sendo crucial, para tanto, que as margens de comercialização definidas pelo governo estivessem de acordo com a realidade. Conforme mencionado anteriormente, se as farmácias são capazes de praticar descontos que atingem o patamar de até $80 \%$, significa

\footnotetext{
${ }^{346}$ DIFERENÇA além da conta. Revista do IDEC. São Paulo, n.162, p.16-19, fev. 2012. p.16.

${ }^{347}$ Ibid., p. 17.

${ }^{348}$ Ibid., p.18-19.

${ }^{349}$ Ibid., p. 19.
} 
que o preço máximo ao consumidor poderia ser bem menor que o estabelecido pela CMED. ${ }^{350}$

Para Basilia Aguirre, o PMC atua como uma "couraça" que impede os preços de descerem. Na opinião da pesquisadora, "se você não tivesse o PMC você teria muito mais concorrência, principalmente entre os genéricos" (informação verbal). ${ }^{351}$

Os resultados obtidos pelas pesquisas do IDEC puderam ser confirmados mediante análise de pesquisas de preços realizadas pela Fundação de Proteção e Defesa do Consumidor do Estado de São Paulo (PROCON-SP). Esse órgão pertencente à Administração Pública Estadual, frequentemente, realiza pesquisas de preços de medicamentos na capital paulista. Estão disponíveis no sítio eletrônico do PROCON-SP planilhas relativas aos preços dos medicamentos genéricos e de referência na cidade de São Paulo, desde 2010. Os medicamentos pesquisados estão dentre os mais consumidos nessa região do país. ${ }^{352}$ Para analisar o comportamento dos preços dos medicamentos, comparouse os preços apurados pelo PROCON-SP e os respectivos PMCs do período, disponíveis no sítio eletrônico da ANVISA e definidos pela $\mathrm{CMED}^{353}$. Para o cruzamento dos preços e dos PMCs foram selecionados apenas os medicamentos de referência pela seguinte razão: as pesquisas do PROCON-SP não especificam o laboratório fabricante do medicamento genérico cujo preço foi coletado. Desse modo, não foi possível saber qual era o PMC aplicado ao medicamento em questão, uma vez que, para tanto, é necessário especificar a marca do medicamento.

Com o propósito de verificar se estes dados confirmariam os resultados obtidos pelo Instituto Nacional de Defesa do Consumidor, selecionou-se as pesquisas de preços de medicamentos relativas aos meses de maio de 2010, 2011 e 2012, para a capital paulista, e as pesquisas de maio de 2012, para 11 cidades do interior do Estado de São Paulo ${ }^{354}$ : Posteriormente, cruzou-se a média de preços dos medicamentos pesquisados nos pontos de

\footnotetext{
${ }^{350}$ DIFERENÇA além da conta. Revista do IDEC. São Paulo, n.162, p.16-19, fev. 2012. p.19.

${ }^{351}$ Informação fornecida por Basilia Aguirre, em entrevista realizada em São Paulo, em 28 de agosto de 2012 (vide transcrição do áudio da entrevista co Basilia Aguirre, no Anexo E).

${ }^{352}$ SÃO PAULO (Estado). Fundação de Defesa e Proteção do Consumidor. Pesquisa comparativa de preços de medicamentos, São Paulo, maio 2010. Disponível em: <http://www.procon.sp.gov.br/categoria.asp?id=903>. Acesso em: 4 set. 2012.

${ }^{353}$ Vide relatórios técnicos do PROCON-SP, no Anexo G.

${ }^{354}$ No caso dos preços coletados em cidades do interior do Estado de São Paulo, o PROCON-SP apenas divulgou os preços referentes ao mês de maio de 2012, em seu sítio eletrônico.
} 
venda com o PMC correspondente ao período analisado. As informações obtidas estão nas tabelas anexas a este trabalho. ${ }^{355}$

Foi possível constatar, no que concerne aos medicamentos pesquisados pelo PROCON-SP, que, de fato, a diferença entre o preço médio e o PMC é considerável. Para a capital paulista, no ano de 2010, a menor diferença foi de $12,94 \%$, relativa ao medicamento Anafranil (25 mg, 20 comprimidos por caixa); enquanto que a maior diferença atingiu o patamar de 348, 05\%, no caso do medicamento Aerolin (2 mg/5ml, xarope, $120 \mathrm{ml})$. Em 2011, a diferença entre o preço médio em reais e o PMC estabelecido pela CMED aumentou para todos os medicamentos, exceto para o medicamento Aerolin $(2 \mathrm{mg} / 5 \mathrm{ml}$, xarope, $120 \mathrm{ml}$ ), que incidiu no patamar de $25,51 \%$. Nesse ano, a menor desproporção apurada entre o preço médio no ponto de venda e o PMC foi de 22,94\%, no caso do Plasil (10 mg, 20 comprimidos por caixa); enquanto que a maior ocorreu com o Dexason $(1 \mathrm{mg} / \mathrm{g}$, creme dermatológico de 10g), incidindo no patamar de 49,75\%. Por sua vez, em 2012, na capital paulista, a desigualdade entre preço médio no ponto de venda e PMC também foi apurada, sendo a menor diferença verificada no caso do Pantelmin (20 mg/ml, suspensão, $30 \mathrm{ml}$ ), incidindo no patamar de $15,91 \%$. Já a maior diferença foi aferida, novamente, em relação ao Dexason (1mg/g, creme dermatológico de $10 \mathrm{~g})$, recaindo sobre o patamar de $72,32 \%$.

A pesquisa realizada pelo PROCON-SP possibilitou que fosse observado o comportamento dos preços dos medicamentos também no interior do Estado de São Paulo. No sítio eletrônico dessa fundação foi possível encontrar informações sobre preços de medicamentos praticados no mês de maio de 2012, nas seguintes cidades: Bauru, Caçapava, Campinas, Jundiaí, Presidente Prudente, Santos, Sorocaba, São José dos Campos e Taubaté. ${ }^{356} \mathrm{Em}$ todas as cidades do interior, a variação entre as médias dos preços dos medicamentos pesquisados praticadas nos pontos de venda e o PMC do respectivo período foram inferiores à correspondente variação apurada na capital do Estado de São Paulo, para todos os medicamentos pesquisados. ${ }^{357}$ Isso pode ser explicado pelo fato de nessas cidades a concorrência entre drogarias e farmácias ser menor do que na

\footnotetext{
${ }^{355}$ Importa ressaltar que nem todos os medicamentos presentes na lista elaborada pelo PROCON-SP foram estudados, mas apenas aqueles cujo PMC está disponível na base de dados da ANVISA, no sítio eletrônico http://portal. anvisa.gov.br (direção: setor regulado - listas de preços de medicamentos).

${ }^{356}$ As pesquisas de preços realizadas pelo PROCON-SP no interior do estado correspondem apenas ao ano de 2012.

${ }^{357}$ Vide tabelas com dados coletados pelo do PROCON-SP, no Anexo F.
} 
capital do Estado, fato que estimularia a prática de preços mais altos. ${ }^{358}$ Além disso, pela demanda das drogarias ser menor no interior, é possível que esses estabelecimentos consigam descontos inferiores em relação ao preço-fábrica praticado pelos laboratórios no momento da compra, o que pode ser demonstrado pelo fato da média dos preços dos medicamentos ser superior ao da capital na maioria das cidades do interior pesquisadas. Sobre esse assunto, a especialista em economia da saúde, Basilia Aguirre, diz que um dos fatores que explica o fato da a média de preços ser mais alta no interior do estado é a menor presença de redes de farmácias e drogarias nesses locais. Em regra, são as redes que estabelecem os maiores "descontos", pois compram medicamentos em maior quantidade e diretamente da indústria, conseguindo obter melhores preços que são repassados ao consumidor (informação verbal). ${ }^{359}$

Tal como no caso da capital paulista, nas cidades do interior, também foi possível verificar que, em relação a todos os medicamentos pesquisados, o teto estipulado pela CMED se encontrou em patamares superiores àqueles da média de preços apurada nos pontos de venda, embora a diferença entre PMC e preço praticado no ponto de venda tenha sido menor no interior do que na capital. Conforme resta demonstrado nas tabelas anexas, ${ }^{360}$ a média da diferença entre a média dos preços praticados nos pontos de venda e do respectivo PMC do período, em maio de 2012, foram as seguintes para:Araçatuba: 26,4\%; Bauru: 14,28\%; Caçapava: 15,03\%; Campinas: 14,45\%; Jundiaí: 8,48\%; Marília: 16,71\%; Presidente Prudente: 11,33\%; Santos: 14,02\%; São José dos Campos: 25,18\%; São Paulo: 22,35\%; Sorocaba: 17,01\%; Taubaté: 19,70\%.

Contudo, importa ressaltar que, conforme explica Basilia Aguirre, a média não significa muito do ponto de vista da eficiência da regulação. Isso porque se dois ou três medicamentos dentre cem puderam ser comercializados com um desconto significativo, enquanto que os demais apresentaram desconto pequeno, a média de desconto será levada para baixo. Assim, a regulação continua sendo ineficiente, pois, se dois ou mais

\footnotetext{
${ }^{358}$ Ione Amorim explicou que uma das dificuldades de realizar a pesquisa de preços de medicamentos no interior do país é que, nesses locais, a variedade de medicamentos disponíveis para um mesmo princípio ativo é menor, sendo difícil uniformizar a lista de medicamentos cujos preços serão coletados (informação verbal) - informação fornecida por Ione Amorim, em entrevista realizada em São Paulo, em 20 de fevereiro de 2012 (vide transcrição do áudio da entrevista com Ione Amorim, no Anexo B).

${ }^{359}$ Informação fornecida por Basilia Aguirre, em entrevista realizada em São Paulo, 28 de agosto de 2012 (vide transcrição do áudio da entrevista com Basilia Aguirre, no Anexo E).

${ }^{360}$ Vide tabelas no Anexo F.
} 
medicamentos puderam ser comercializados a preços muito inferiores ao estipulado pelo teto da CMED, significa que os demais também poderiam sê-lo (informação verbal). ${ }^{361}$

No caso da pesquisa do PROCON-SP, embora a média da diferença entre PMC e preço praticado nos pontos de venda seja inferior a 30\%, alguns medicamentos apresentaram variações imensas, tais como o medicamento Dexason, em São José dos Campos, cuja discrepância entre média de preço praticado no ponto de venda e PMC chegou ao patamar de 81,73\%; e o medicamento Aerolin cuja diferença atingiu o patamar de $348 \%$, em 2010, na capital paulista.

Ademais, acredita-se que, na realidade, a diferença entre a média dos preços dos medicamentos apurada nos pontos de venda e o PMC respectivo, tanto na cidade de São Paulo, quanto nas cidades do interior pesquisadas, deva ser maior do que aquela concluída a partir dos dados coletados pela Fundação de Defesa e Proteção do Consumidor. Isso porque, conforme explicou a coordenadora da pesquisa de preços de medicamentos do PROCON-SP, em entrevista cuja gravação não foi permitida, ${ }^{362}$ os farmacêuticos entrevistados por essa fundação pública foram indagados acerca dos preços dos medicamentos, sem a ressalva da existência de quaisquer políticas de desconto ou de benefícios de cartões fidelidade, frequentemente concedidos aos consumidores. Diferentemente da pesquisa efetuada pelo PROCON-SP, a pesquisa do IDEC orientou os técnicos responsáveis pela coleta dos preços que perguntassem sobre os preços dos medicamentos com descontos e benefícios de fidelidade, o que possiblitou a apreensão dos preços praticados na realidade com menor margem de erro (informação verbal). ${ }^{363}$ Além disso, no momento da coleta dos preços, os pequisadores do PROCON-SP entregavam planilhas aos funionários de farmácias e drogarias com o PMC de cada medicamento pesquisado anotado ao lado, o que também pode ter acarretado distorções quanto à fidedignidade dos dados. Mesmo assim, os resultados obtidos pelas pesquisas do IDEC foram facilmente confirmados pelo cruzamento de dados coletados pelo PROCON-SP com os respectivos PMCs obtidos no sítio eletrônico da ANVISA. Além disso, a pesquisa de preços realizada por essa fundação pública demonstrou que a variação da média dos preços

\footnotetext{
${ }^{361}$ Informação fornecida por Basilia Aguirre, em entrevista realizada em São Paulo, em 28 de agosto de 2012 (vide transcrição do áudio da entrevista com Basilia Aguirre, no Anexo E).

${ }^{362}$ Em julho de 2012, foi entrevistada a coordenadora do Departamento de Pesquisas do PROCON-SP, com o objetivo de entender como foram realizadas as pesquisas de preços de medicamentos realizadas por essa fundação pública. No entanto, não foi permitido que tal entrevista fosse gravada, razão pela qual não consta desta dissertação de mestrado a respectiva transcrição do áudio.

${ }^{363}$ Informação fornecida por Ione Amorim, em entrevista realizada em São Paulo, em 20 de fevereiro de 2012 (vide transcrição do áudio da entrevista com Ione Amorim, no Anexo B).
} 
praticados no interior e o teto estabelecido pela CMED é bem menor do que o observado na capital. Essa situação pode ser explicada pelo fator concorrência que é menor no interior do Estado, conforme já mencionado.

Desse modo, quanto à regulação econômica relativa ao reajuste de preços dos medicamentos lançados antes de 2003, ou seja, antes da criação da CMED, é possível concluir que o principal gargalo a ser enfrentado consiste na diferença, na maioria dos casos, superior a $20 \%$, entre o teto estipulado pelo órgão regulador e a média de preços praticada no mercado. Conforme visto anteriormente, tal disparidade é prejudicial ao consumidor, vez que os preços dos medicamentos podem ser reajustados, a qualquer momento; além de demonstrar que as normas regulatórias são inócuas no que diz respeito à influência que exercem sobre a determinação dos preços.

É interessante verificar, também, a evolução da variação entre o preço médio dos medicamentos e respectivos PMCs, no tempo. Para tanto, foram elaboradas as seguintes tabelas, com base nas pesquisas realizadas pelo IDEC ${ }^{364}$ e pelo PROCON -Tabelas 13 e 14:

Tabela 13. Pesquisas IDEC realizadas na cidade de São Paulo (publicações: 2009 e 2012)

\begin{tabular}{|c|c|c|c|c|}
\hline Medicamento & Laboratório & Apresentação & $\begin{array}{c}\text { Variação (\%) Pesquisa } \\
2009\end{array}$ & Variação (\%) Pesquisa 2012 \\
\hline Adalat Retard & Bayer & $\begin{array}{l}10 \mathrm{mg} \text {, frasco } 30 \\
\text { comprimidos de } \\
\text { liberação retardada }\end{array}$ & 19 & 26,3 \\
\hline Blopress & Abbott & $\begin{array}{l}8 \mathrm{mg} \text {, caixa } 30 \\
\text { comprimidos }\end{array}$ & 41 & 26,9 \\
\hline Cataflam & Novartis & $\begin{array}{c}50 \text { mg, caixa } 20 \\
\text { cápsulas }\end{array}$ & 18 & 31,5 \\
\hline Cymbalta & Eli Lilly & $\begin{array}{l}30 \text { mg, caixa } 14 \\
\text { cápsulas }\end{array}$ & 27 & 17,6 \\
\hline Ebix & Lundbeck & $\begin{array}{l}10 \text { mg, caixa } 28 \\
\text { comprimidos }\end{array}$ & 34 & 19 \\
\hline Frontal & Pfizer & $\begin{array}{l}0,5 \mathrm{mg} \text {, caixa } 20 \\
\text { comprimidos }\end{array}$ & 17 & 19 \\
\hline Meticorten & $\begin{array}{l}\text { Schering } \\
\text { Plough }\end{array}$ & $\begin{array}{l}20 \mathrm{mg} \text {, caixa } 10 \\
\text { comprimidos }\end{array}$ & 15 & 8,4 \\
\hline
\end{tabular}

Fonte: Elaboração própria a partir de dados presentes nos seguintes artigos: REMÉDIO pro bolso. Revista do IDEC. São Paulo, n. 130, p.16-20, mar. 2009; e DIFERENÇA além da conta. Revista do IDEC. São Paulo, n.162, p.16-19, fev. 2012.

Embora a tabela 13 demonstre que a variação entre preço médio e PMC se manteve significativa no intervalo de dois anos entre a conclusão das duas pesquisas realizadas pelo

\footnotetext{
${ }^{364}$ No que diz respeito à tabela relativa às pesquisas realizadas pelo IDEC, selecionou-se apenas os medicamentos cujos preços foram coletados tanto para a pesquisa publicada em 2009, quanto para a pesquisa publicada em 2012. Para a elaboração da tabela foi excluída a pesquisa do IDEC publicada em 2010, pois referida pesquisa abrange outras cidades além da cidade de São Paulo, impedindo uma comparação perfeita.
} 
IDEC, apenas nos casos dos medicamentos Adalat Retard e Cataflam essa variação aumentou.

Tabela 14. Pesquisas PROCON-SP realizadas na cidade de São Paulo (publicações: 2010/2011/ 2012)

\begin{tabular}{|c|c|c|c|c|c|}
\hline Medicamento & Laboratório & Apresentação & $\begin{array}{l}\text { Variação (\%) } \\
\text { Pesquisa } 2010\end{array}$ & $\begin{array}{l}\text { Variação (\%) } \\
\text { Pesquisa } 2011\end{array}$ & $\begin{array}{r}\text { Variação (\%) } \\
\text { Pesquisa } 2012\end{array}$ \\
\hline Dexason & $\begin{array}{c}1 \mathrm{mg} / \mathrm{g} \text { creme } \\
\text { dermatológico } \\
10 \mathrm{~g}\end{array}$ & Teuto & 39,22 & 49,75 & 72,32 \\
\hline Carbolitium & $\begin{array}{c}300 \mathrm{mg} 50 \\
\text { comprimidos }\end{array}$ & Eurofarma & 15,35 & 26,11 & 22,13 \\
\hline Rivotril & $\begin{array}{l}2 \mathrm{mg} \text { caixa } 20 \\
\text { comprimidos }\end{array}$ & Roche & 20,13 & 36,01 & 17,27 \\
\hline Anafranil & $25 \mathrm{mg} 20$ drágeas & Novartis & 12,94 & 25,78 & 17,52 \\
\hline Plasil & $\begin{array}{c}10 \mathrm{mg} 20 \\
\text { comprimidos }\end{array}$ & Sanofi-Aventis & 17,03 & 22,94 & 16,90 \\
\hline Pamelor & $\begin{array}{l}25 \mathrm{mg} 30 \\
\text { cápsulas }\end{array}$ & Novartis & 17,23 & 25,78 & 21,05 \\
\hline Fenergan & $\begin{array}{c}25 \mathrm{mg} 20 \\
\text { comprimidos }\end{array}$ & Sanofi-Aventis & 17,60 & 23,61 & 16,58 \\
\hline Voltaren & $\begin{array}{c}50 \mathrm{mg} 20 \\
\text { comprimidos }\end{array}$ & Novartis & 22,58 & 28,51 & 21,86 \\
\hline Mesigyna & $\begin{array}{c}50+5 \mathrm{mg} / \mathrm{ml} \\
\text { injeção, } 1 \text { seringa/ } \\
1 \mathrm{ml}\end{array}$ & Bayer & 21,35 & 26,29 & 17,98 \\
\hline Gardenal & $\begin{array}{c}100 \mathrm{mg} 20 \\
\text { comprimidos }\end{array}$ & Sanofi-Aventis & 20,76 & 24,94 & 18,34 \\
\hline Lasix & $\begin{array}{c}\text { 40mg } 20 \\
\text { comprimidos }\end{array}$ & Sanofi-Aventis & 21,57 & 26,36 & 18,76 \\
\hline Clorana & $\begin{array}{c}25 \mathrm{mg} 30 \\
\text { comprimidos }\end{array}$ & Sanofi-Aventis & 17,70 & 25,38 & 19,22 \\
\hline Pantelmin & $\begin{array}{c}20 \mathrm{mg} / \mathrm{ml} \\
\text { suspensão } 30 \mathrm{ml}\end{array}$ & Janssen-Cilag & 15,86 & 26,08 & 15,91 \\
\hline Flagyl & $\begin{array}{c}250 \mathrm{mg} 20 \\
\text { comprimidos }\end{array}$ & Sanofi-Aventis & 19,19 & 26,39 & 17,50 \\
\hline Aerolin & $\begin{array}{c}2 \mathrm{mg} / 5 \mathrm{ml} \text { xarope } \\
120 \mathrm{ml}\end{array}$ & Glaxosmithkline & 348,05 & 25,51 & 21,97 \\
\hline Gardenal & $\begin{array}{c}100 \text { mg } 20 \\
\text { comprimidos }\end{array}$ & Sanofi-Aventis & 39,22 & 49,75 & 72,32 \\
\hline Lasix & $\begin{array}{c}\text { 40mg } 20 \\
\text { comprimidos }\end{array}$ & Sanofi-Aventis & 15,35 & 26,11 & 22,13 \\
\hline Clorana & $\begin{array}{c}25 \mathrm{mg} 30 \\
\text { comprimidos }\end{array}$ & Sanofi-Aventis & 20,13 & 36,01 & 17,27 \\
\hline
\end{tabular}

Fonte: Elaboração própria a partir de dados obtidos pelo PROCON-SP (cf. Anexo F).

No que diz respeito às pesquisas realizadas pelo PROCON-SP, na cidade de São Paulo, foi possível observar um padrão de aumento da variação entre preço médio e PMC, entre os anos de 2010 e 2011; e uma diminuição dessa variação, entre 2011 e 2012. 
Diante dessas constatações, cumpre indagar qual seria o motivo da considerável diferença entre os tetos estabelecidos pela CMED e os preços praticados nos pontos de venda que chegaram, conforme mencionado antes, a patamares superiores a 300\%, para alguns medicamentos. A explicação para essa situação reside, resumidamente, em três fatores:

(i) Distorção inicial dos preços dos medicamentos sobre os quais incidiram as primeiras normas regulatórias referentes a reajustes;

(ii) Ausência de previsão de mecanismos de flexibilização pela Lei 10.742/03, que pudessem permitir a redução dos preços praticados, salvo se a requerimento da indústria quando do vencimento de patentes;

(iii) Ausência de monitoramento dos preços dos medicamentos nos pontos de venda, o que faz com que a CMED trabalhe com poucas informações sobre os "preços reais" desses produtos.

Cada um desses fatores será analisado detalhadamente a seguir:

\subsubsection{Distorção inicial dos preços dos medicamentos}

Conforme o atual Secretário Executivo da CMED, Ivo Bucaresky, declarou ao IDEC, um dos fatores responsáveis pela disparidade entre preços praticados no ponto de venda e o teto estabelecido pela CMED é o fato de que, momentos antes da criação da CMED, a indústria farmacêutica praticava preços demasiadamente elevados, pois, até então, tinha liberdade na sua fixação. ${ }^{365}$ Tal justificativa prestada pelo atual Secretário Executivo da CMED ao IDEC de que "na época em que os preços dos medicamentos começaram a ser tabelados, o mercado praticava o sobrepreço, pois até então a indústria aumentava o valor dos remédios como queria”, de modo que passou a fornecer descontos após o retorno da regulação, não parece ser muito coerente. ${ }^{366}$ Por que a indústria ou as farmácias e drogarias iniciariam uma política de "desconto" apenas depois da regulação da CMED?

Ademais, não é possível dizer que momentos antes da criação da CMED a indústria elevou os preços praticados como bem entendia, pois, nesse período, estava em vigor a regulação dos preços imposta pela Lei 10.213/01. Os aumentos dos preços com base na referida lei eram extraordinários e excepcionais, permitidos apenas por meio do Índice Paramétrico de Medicamentos (IPM) e para as empresas produtoras de medicamentos que

\footnotetext{
${ }^{365}$ DIFERENÇA além da conta. Revista do IDEC. São Paulo, n.162, p.16-19, fev. 2012. p. 19.
}

${ }^{366}$ Ibid. p. 19. 
tivessem apresentado Evolução Média de Preços (EMP) do período inferior a esse índice. ${ }^{367}$ Assim, a total liberdade da indústria farmacêutica, distribuidores, farmácias e drogarias na determinação dos preços apenas ocorreu até a criação da Câmara de Medicamentos (CAMED), em 2001. ${ }^{368}$

Vale mencionar que, no que diz respeito à forma de regulação praticada pela antiga CAMED, a assessoria da CMED disse, em entrevista, que:

[e]la se baseava numa fórmula paramétrica, que permitia o ajuste dos medicamentos com base na inflação até determinado teto. Qualquer preço abaixo do teto poderia ser praticado pela indústria. Assim como a CMED, a CAMED utilizava o modelo de teto de preços, com a diferença que não usava o price cap. Não se tratava, portanto, de congelamento ou tabelamento de preços" (informação verbal). ${ }^{369}$

Todavia, decorre do art. $6^{\circ}$, da Lei 10.231/01, a utilização do congelamento de preços para empresas classificadas no Grupo I. ${ }^{370}$

Segundo Ione Amorim, o antigo Secretário Executivo da CMED, Luiz Milton Veloso Costa, afirmou em mesa redonda realizada pelo IDEC com membros da CMED que, quando de sua criação, o órgão regulador requisitou da indústria farmacêutica informações sobre os preços praticados. Com medo da possibilidade de congelamento, os laboratórios prestaram informações sobre os preços incluindo uma "margem de garantia ou conforto" acima do preço realmente praticado no mercado, a fim de assegurar-lhes o lucro almejado (informação verbal). ${ }^{371}$ Essa margem foi capaz de permitir que a indústria

\footnotetext{
${ }^{367}$ Art. $6^{\circ}$, da Lei $\mathrm{n}^{\circ} 10.213 / 01$.

${ }^{368} \mathrm{~A}$ Lei $10.213 / 01$ estabelecia que o reajuste dos preços dos medicamentos produzidos pelas empresas do Grupo II (as empresas produtoras de medicamentos que tiverem apresentado Evolução Média de Preços do período inferior ao Índice Paramétrico de Medicamentos ) deveria obedecer o reajuste máximo de preços (RMP), determinado a partir da fórmula paramétrica de reajuste de preços de medicamentos (FPR).

${ }^{369}$ Informação fornecida por assessores da Secretaria-Executiva da CMED, em entrevista realizada em Brasília, em 5 de julho de 2012 (vide transcrição do áudio da entrevista com assessores da SecretariaExecutiva da CMED, no Anexo).

370“'Art. $6^{\circ}$ Em janeiro de 2001, cumprida integralmente a exigência de que trata o caput do artigo anterior, os reajustes de preços de medicamentos, permitidos para cada empresa, observarão os seguintes critérios:

I - para as empresas classificadas no Grupo I não serão permitidas elevações de preços;

$[\ldots]^{\prime \prime}$

${ }^{371}$ Informação fornecida por Ione Amorim, em entrevista realizada em São Paulo, em 20 de fevereiro de 2012 (vide transcrição do áudio da entrevista com Ione Amorim, no Anexo B). Em 2 de abril de 2009, foi realizada no IDEC mesa redonda sobre o seguinte tema: "acesso a medicamentos: a política de controle de preços qual o efetivo impacto no bolso do consumidor?" (Acesso a medicamentos: a política de controle de preços - qual o efetivo impacto no bolso do consumidor. Disponível em: <www.crfsp.org.br/cf/.../Progr_Mredonda.pdf>. Acesso em 31 ago. 2012.
} 
farmacêutica manipulasse os preços praticados, sempre mantendo a lucratividade em patamares altos. ${ }^{372}$ Tais preços foram repassados ao órgão regulador que estabeleceu o teto de comercialização com base nessas informações.

$\mathrm{O}$ argumento de que a indústria teria repassado os preços com uma "margem de conforto", por medo de eventual congelamento, também não parece ser coerente com o contexto econômico do momento. Quando indagada sobre a suposta reação da indústria farmacêutica em face da possibilidade de congelamento de preços no ano de 2003, a especialista em economia da saúde e pesquisadora da FIPE, Basilia Aguirre, respondeu da seguinte forma: "[p]ra começar: em 2003, congelamento de preços? Nunca ninguém pensaria isso" (informação verbal) ${ }^{373}$.

Outra questão que surge acerca do argumento utilizado pelo antigo Secretário Executivo da CMED, Luiz Milton Costa, é a seguinte: por que foi necessário requisitar informações de preços da indústria farmacêutica, se a Câmara de Medicamentos (CAMED) já possuía informações sobre os preços praticados nos pontos de venda, em função dos estudos contratados com a FIPE e o IPEAD? ${ }^{374}$ De acordo com Basilia Aguirre, pesquisadora responsável pelo monitoramento de preços realizado pela FIPE, o contrato para o levantamento dos preços em 11 cidades do Brasil perdurou até o final do mandato do Presidente Fernando Henrique Cardoso, em 2002, tendo sido definitivamente extinto, em 2003, quando da criação da CMED. ${ }^{375}$ Sobre o levantamento e monitoramento dos preços dos medicamentos nos pontos de venda realizados no aludido período, Basilia Aguirre disse:

[o] levantamento era no nível das farmácias, os nossos pesquisadores iam nas farmácias e em cada farmácia eles coletavam em média 30 itens. Eram coletados mais ou menos uns 600 itens todo mês, por mês, e a partir disso a gente calculava o índice e mandava os preços, máximo, mínimo e

\footnotetext{
${ }^{372}$ Conforme é possível inferir da declaração do Secretário Executivo da CMED ao IDEC (vide DIFERENÇA além da conta. Revista do IDEC. São Paulo, n.162, p.16-19, fev. 2012. p. 19).

${ }^{373}$ Informação fornecida por Basilia Aguirre, em entrevista realizada em São Paulo, em 28 de agosto de 2012 (vide transcrição do áudio da entrevista com Basilia Aguirre no Anexo E).

${ }^{374}$ Conforme informou a Professora Basilia Aguirre em entrevista, o órgão regulador havia contratado com a Fundação Instituto de Pesquisas Econômicas (FIPE) e com a Fundação Instituto de Pesquisa Econômicas, Administrativas e Contábeis de Minas Gerais (IPEAD) o levantamento de preços de medicamentos nos pontos de venda de 11 cidades do Brasil (informação verbal). Informação fornecida por Basilia Aguirre, em entrevista realizada em São Paulo, em 28 de agosto de 2012 (vide transcrição do áudio da entrevista com Basilia Aguirre, no Anexo E).

${ }^{375}$ Informação fornecida por Basilia Aguirre, em entrevista realizada em São Paulo, em 28 de agosto de 2012 (vide transcrição do áudio da entrevista com Basilia Aguirre, no Anexo E).
} 
médio, e os índices de preços pra câmara de medicamentos (informação verbal) $)^{376}$

Ainda sobre o levantamento de preços, a pesquisadora da FIPE, explicou ser esta uma atividade muito dispendiosa, tendo em vista a grande quantidade de medicamentos a ser apurada e de farmácias e drogarias a ser visitada em um território extenso como o brasileiro. Anos após o término do contrato de levantamento de preços com a FIPE e o IPEAD, a CMED chegou a encaminhar à primeira instituição uma solicitação de formulação de projeto de monitoramento de preços de medicamentos no território brasileiro. Contudo, tal solicitação não foi atendida, pois, conforme afirmou Basilia Aguirre, a proposta orçamentária para a contratação estava significativamente aquém do que seria necessário para custear a realização de uma pesquisa desse porte. ${ }^{377}$

Deste modo, no momento da criação da CMED, estariam disponíveis ao órgão regulador informações atualizadas sobre os preços dos medicamentos praticados no mercado. Conforme mencionado, esses dados foram fruto de pesquisa realizada pela FIPE, mediante a metodologia acima informada.

\subsubsection{Falta de flexibilidade da Lei $10.742 / 03$ que estabelece as diretrizes} regulatórias

A Lei 10.742/03 apenas permite o reajuste dos preços "para cima" o que agrava o problema da significativa diferença entre preço máximo ao consumidor e preços praticados nos pontos de venda. De fato, a referida lei que estabelece as diretrizes da regulação do mercado farmacêutico autoriza, apenas, a majoração dos preços até o limite do teto estabelecido por meio de critérios que, consoante mencionado no capítulo anterior, levam em conta a produtividade e os fatores extra e intra setor.

Ivo Bucaresky e Luiz Milton Veloso Costa, atual e antigo Secretário Executivo da CMED, respectivamente, tentaram justificar a discrepância entre os "descontos" fornecidos pela indústria farmacêutica e o teto estabelecido pela CMED remetendo aos altos preços praticados e informados pela indústria momentos antes da criação do novo órgão regulador. Independentemente da consistência dos fundamentos desses argumentos, é fato

\footnotetext{
${ }^{376}$ Informação fornecida por Basilia Aguirre, em entrevista realizada em São Paulo, em 28 de agosto de 2012 (vide transcrição do áudio da entrevista com Basilia Aguirre, no Anexo E).

${ }^{377}$ Informação fornecida por Basilia Aguirre, em entrevista realizada em São Paulo, em 28 de agosto de 2012 (vide transcrição do áudio da entrevista com Basilia Aguirre, no Anexo E).
} 
que os preços que serviram como ponto de partida para a incidência da regulação exercida pela CMED eram significativamente elevados. Tanto era assim, que o governo optou por uma mudança na estratégia regulatória, criando a CMED em substituição à CAMED, com o objetivo de promover assistência farmacêutica à população e conter a elevação exagerada dos preços dos medicamentos, nos termos da Lei 10.742/03.

No entanto, a possibilidade de redução dos preços dos medicamentos não é contemplada pela Lei 10.742/03, de modo que as normas regulatórias emanadas da CMED não podem implicar diminuição dos preços, sob pena de ilegalidade. O problema da referida lei é que ela não previu nenhum mecanismo regulatório com flexibilidade suficiente para pressionar os preços a patamares inferiores aos já estabelecidos. Tal previsão, entretanto, poderia minimizar os efeitos negativos causados pelos preços dos medicamentos notadamente altos sobre os quais o controle pela CMED foi inaugurado.

$\mathrm{O}$ artifício de permitir que a autoridade regulatória reduza os preços dos medicamentos abaixo do patamar praticado em anos anteriores é utilizado em países da Europa, como Alemanha e Grécia. Essa prática, entretanto, contraria diretamente interesses da indústria farmacêutica que contrapõe argumentos no sentido de que reduções de preço podem causar impactos negativos sobre a produção de inovação, o lançamento de novos medicamentos e empregos no continente europeu. ${ }^{378}$

\subsubsection{Ausência de monitoramento de preços nos pontos de venda}

Outro fator capaz de explicar falta de efetividade regulatória, bem como a disparidade entre os preços praticados e o teto de preço permitido é a questão do monitoramento dos preços. Em entrevista realizada com assessores da CMED e do Núcleo de Regulação Econômica da ANVISA (NUREM), foi possível constatar que nem a CMED e nem a ANVISA monitoram os preços dos medicamentos nos pontos de venda.

O banco de preços de medicamentos é comum a ambos os órgãos e ele se baseia apenas em informações extraídas dos relatórios anuais dos laboratórios farmacêuticos e nas publicações da ABCFARMA (informação verbal). ${ }^{379}$ Essas publicações, por sua vez, possuem como fonte direta a indústria farmacêutica e também não realizam pesquisa

\footnotetext{
${ }^{378}$ Nesse sentido, vide o artigo GlaxoSmithkline warns on European Drug Prices. Disponível em:〈http://www.guardian.co.uk/business/2012/oct/31/glaxosmithkline-european-drug-prices〉. Acesso em: $12 \mathrm{dez} .2012$.

${ }^{379}$ Informação fornecida por assessores da Secretaria-Executiva da CMED, em entrevista realizada em Brasília, em 5 de julho de 2012 (vide transcrição do áudio da entrevista com assessores da SecretariaExecutiva da CMED, no Anexo C).
} 
diretamente nos locais onde os medicamentos são vendidos (informação verbal). ${ }^{380}$ Isso significa que a CMED não possui dados reais acerca dos preços praticados pelo mercado, mas sim dados fornecidos pela indústria farmacêutica, enviesados, e, por isso, não tem como apurar se a regulação praticada é ou não efetiva. Para Basilia Aguirre, especialista em economia da saúde, atualmente, a CMED não realiza qualquer tipo de monitoramento, vez que o acompanhamento dos preços através das revistas da ABCFARMA não pode ser equiparado a tal atividade (informação verbal). ${ }^{381}$

A ANVISA e a CMED também não realizam monitoramento dos preços de venda de medicamentos estabelecidos pela indústria às farmácias e drogarias. Tal acompanhamento apresenta relevante importância, na medida em que o preço máximo ao consumidor é determinado com base no preço fábrica ${ }^{382}$.

Como resultado da ausência de monitoramento dos preços reais, o que ocorre na prática é que a fórmula elaborada para a determinação do teto permitido a título de reajuste não contempla os preços verdadeiramente praticados pelo mercado e incidem sobre os preços iniciais, fornecidos pela indústria farmacêutica, ao órgão regulador.

\subsubsection{O caso dos medicamentos lançados depois da criação da CMED}

A CMED reconhece o problema regulatório que a disparidade entre preços reais e preços máximos estabelecidos representa. Assim como já mencionado, uma das justificativas apontadas pelos Secretários Executivos (atual e antigo) do órgão regulador é de que as normas regulatórias incidiram sobre preços iniciais distorcidos, antes da criação desse órgão, por motivos diversos. Esse fator somado ao fato da Lei 10.742/03 não permitir a redução dos preços dos medicamentos explicaria a discrepância entre o teto estabelecido pela CMED e os preços realmente praticados.

Neste trabalho, pretendeu-se verificar a solidez desses argumentos. Caso o raciocínio dos Secretários Executivos da CMED seja verdadeiramente consistente, os preços de mercado dos medicamentos lançados após a criação do órgão regulador não devem apresentar grande discrepância com relação ao PMC estipulado pela CMED. Isso, porque os medicamentos lançados depois 26 de junho de 2003, data da criação da CMED,

\footnotetext{
${ }^{380}$ Informação fornecida por assessores da Secretaria-Executiva da CMED, em entrevista realizada em Brasília, em 5 de julho de 2012 (vide transcrição do áudio da entrevista com assessores da SecretariaExecutiva da CMED, no Anexo C).

${ }^{381}$ Informação fornecida por Basilia Aguirre, em entrevista realizada em São Paulo, em 28 de agosto de 2012 (vide transcrição do áudio da entrevista com Basilia Aguirre, no Anexo E).

${ }^{382}$ Vide item 4.2.
} 
tiveram os preços iniciais determinados de acordo com os critérios regulatórios estabalecidos por esse órgão.

Desse modo, tendo sido os preços iniciais desses medicamentos fixados com base em critérios da própria CMED, não deve ser possível a existência de grande divergência entre o preço de mercado o respectivo PMC desses medicamentos, uma vez que não teria ocorrido o problema de preços iniciais distorcidos. Com o propósito de investigar essa hipótese de trabalho que surgiu ao longo da pesquisa, procedeu-se da seguinte maneira:

1a etapa: Composição da Base de Dados (Formação do Universo de Medicamentos)

$\left.1^{\circ}\right)$ Foi elaborada uma base de dados com todos os preços médios de mercado dos medicamentos apurados pelo IDEC, nas pesquisas de 2009, 2010 e 2011, ${ }^{383}$ bem como pelas pesquisas do PROCON-SP, em 2010, 2011 e 2012. ${ }^{384}$ No último caso, foram selecionados apenas os medicamentos de marca, vez que os medicamentos genéricos e similares pesquisados pelo PROCON-SP não possuíam indicação do nome comercial, o que tornou impossível a apuração do PMC no sítio eletrônico ds ANVISA. ${ }^{385}$ Para identificar o PMC de determinado medicamento nesse sítio da internet é necessário o conhecimento do nome comercial do medicamento.

Referida base de dados incluiu, também, os números dos processos administrativos de registro na ANVISA para cada medicamento e o ano da respectiva instauração. Além disso, foi explicitada a data da publicação do registro mais antiga constante do banco público de dados da ANVISA ${ }^{386}$ para cada um dos medicamentos selecionados. O resultado foi a formação de uma base de dados com, aproximadamente, 130 medicamentos.

$2^{\circ}$ ) Foi acrescentado à base de dados o PMC de cada medicamento, conforme o ano em que os preços foram coletados. Por exemplo: no caso da apuração do preço médio de mercado de determinado medicamento em 2009, cruzou-se essa informação com o PMC do mesmo medicamento relativo a esse período.

\footnotetext{
${ }^{383}$ Sabe-se que o IDEC apurou quantidade de preços maior do que a divulgada nos relatórios publicados na Revista do IDEC. Contudo, no banco de dados elaborado para esta pesquisa de mestrado foram utilizados apenas os preços publicados nos relatórios, únicos aos quais foi obtido acesso.

${ }^{384} \mathrm{~A}$ base de dados elaboradas com os preços coletados das pesquisas do IDEC e do PROCON-SP estão nos Anexos desta dissertação.

${ }^{385}$ Direção da consulta: http://portal.anvisa.gov.br, setor regulado e listas de preços de medicamentos.

${ }^{386} \mathrm{O}$ banco público de dados sobre medicamentos pode ser consultado no sítio eletrônico da Agência Nacional de Vigilância Sanitária, so seguinte endereço: http://www7.anvisa.gov.br/datavisa/consulta_produto/Medicamentos/frmConsultaMedicamentos.asp. Esse banco de dados inclui informações sobre o número do processo de registro, apresentações, princípios ativos e laboratórios dos medicamentos, bem como algumas datas de publicação dos registros no Diário Oficial da União.
} 
$3^{\circ}$ ) Com essas informações, foi possível verificar a variação entre preço médio praticado no mercado e PMC para cada medicamento arrolado na base de dados. Essa variação consistiu na seguinte fórmula:

Variação $(\%)=($ Preço Máximo ao Consumidor - Preço Médio $)$ X $100 /$ Preço Médio

\section{$\underline{2^{a} \text { etapa: Seleção da Amostra de Medicamentos }}$}

$\left.4^{\circ}\right)$ Em um segundo momento, foi necessário definir uma amostra de medicamentos que tivessem sido lançados após a criação da CMED, em 26 de junho de 2003. Essa tarefa, por sua vez, não foi fácil. O banco de dados público da ANVISA (disponível no sítio eletrônico dessa agência reguladora) não informa a data do lançamento do medicamento no Brasil. Essa data corresponderia ao dia da publicação do primeiro registro do medicamento no Diário Oficial da União. No banco de dados da ANVISA, consta apenas a data da publicação do registro que foi renovado mais recentemente (vale lembrar que os registros dos medicamentos devem ser renovados quinquenalmente). Desse modo, foi necessário encontrar outro meio de seleção da amostra.

$5^{\circ}$ ) Em telefonema realizado à Coordenação de Registro de Medicamentos da ANVISA (CRMED), em agosto de 2012, obteve-se a informação de que os medicamentos lançados após 2003 poderiam ser identificados por meio de análise do número de processo de registro (processo administrativo de petição de registro) que, por sua vez, está presente no banco de dados público, no sítio eletrônico da ANVISA. Segundo a coordenadora Rejane Gomes Silva, não é possível verificar a data exata da instauração ou "entrada" do processo de registro, mas sim o ano em que foi realizada. Em e-mail enviado em resposta à solicitação de envio de informação prestada por telefone na forma escrita, a Coordenadora da ANVISA, Rejane Gomes Silva, explicou o modo de analisar o número do processo de registro:

Como exemplo, no caso do processo de registro (Cymbalta) 25351.218227/2002-21, a sua data de entrada na ANVISA foi em 2002, pois após a barra (/) consta "2002”.

Isso ocorre porque a padronização na criação de números para processos foi consolidada somente após a criação da ANVISA, no ano de 1999, em que todos os números de processos passaram a seguir uma sequência lógica e mais organizada. Portanto, todos os números de processo 
administrativo da Anvisa têm o ano de entrada do protocolo na sua numeração, facilitando assim buscas por outros detalhes.

Por isso, podemos afirmar que todos os processos protocolados na ANVISA após a data da criação da Agência (1999) seguem a ordem mencionada, qual seja, o ano de protocolo após o sinal de barra (/).

Até o momento, esse é o método que identifica apenas o ano de entrada, não fazendo referência nenhuma ao mês ou dia do protocolo. A data exata de pedido de solicitação de registro somente pode ser visualizada no site da Anvisa e ainda assim para aqueles que já estão atualizados no novo eletrônico, pelo atual sistema chamado Datavisa.

O mesmo não ocorre com o processo 25992.022149/72 (Amoxil), o qual entrou no sistema da Anvisa no ano de 1955. Os processos antigos eram da extinta Secretaria Nacional de Vigilância Sanitária, SNVS, e tinham uma lógica de entrada de numeração de processo da qual desconheço. ${ }^{387}$

Importa frisar que o número presente no banco de dados público da ANVISA é do processo administrativo de petição de registro e não do processo administrativo de renovação do registro.

$6^{\circ}$ ) Desse modo, observados os anos de instauração dos processos de registro de cada medicamento, foram selecionados aqueles medicamentos cuja data da instauração do referido processo foi a partir do ano de 2004. Os processos de 2003 não foram utilizados, pois existe a possibilidade de que os medicamentos cujo processo de registro foi instaurado nesse ano tenham sido lançados antes de 26 de junho, ou seja, antes da criação da CMED.

Portanto, mediante o método de seleção adotado, foi possível determinar, com total grau de certeza, quais medicamentos componentes do universo da base de dados elaborada foram lançados após à criação da CMED. De um universo de 128 medicamentos, apenas 6 medicamentos tiveram o processo administrativo de petição de registro instaurado depois do ano de 2004. Foram eles: Mesigyna (Bayer), Tapazol (Biolab), Zyban (GlaxoSmithKline), Biomag (Aché), Bup (Eurofarma) e Nac (Sigma Pharma).

Apesar de se tratar de uma amostra pequena e sem representatividade estatística, optou-se pela análise do comportamento dos preços desses medicamentos. O resultado está expresso na Tabela 15:

\footnotetext{
${ }^{387}$ SILVA, R. G. ENC: Universidade de São paulo - Informação por escrito [mensagem pessoal]. Mensagem recebida por <nathalia.miziara@usp.br> em 9 nov. 2012. Vide Anexo H.
} 
Tabela 15. Medicamentos cujo processo administrativo de registro foi instaurado a partir de 2004

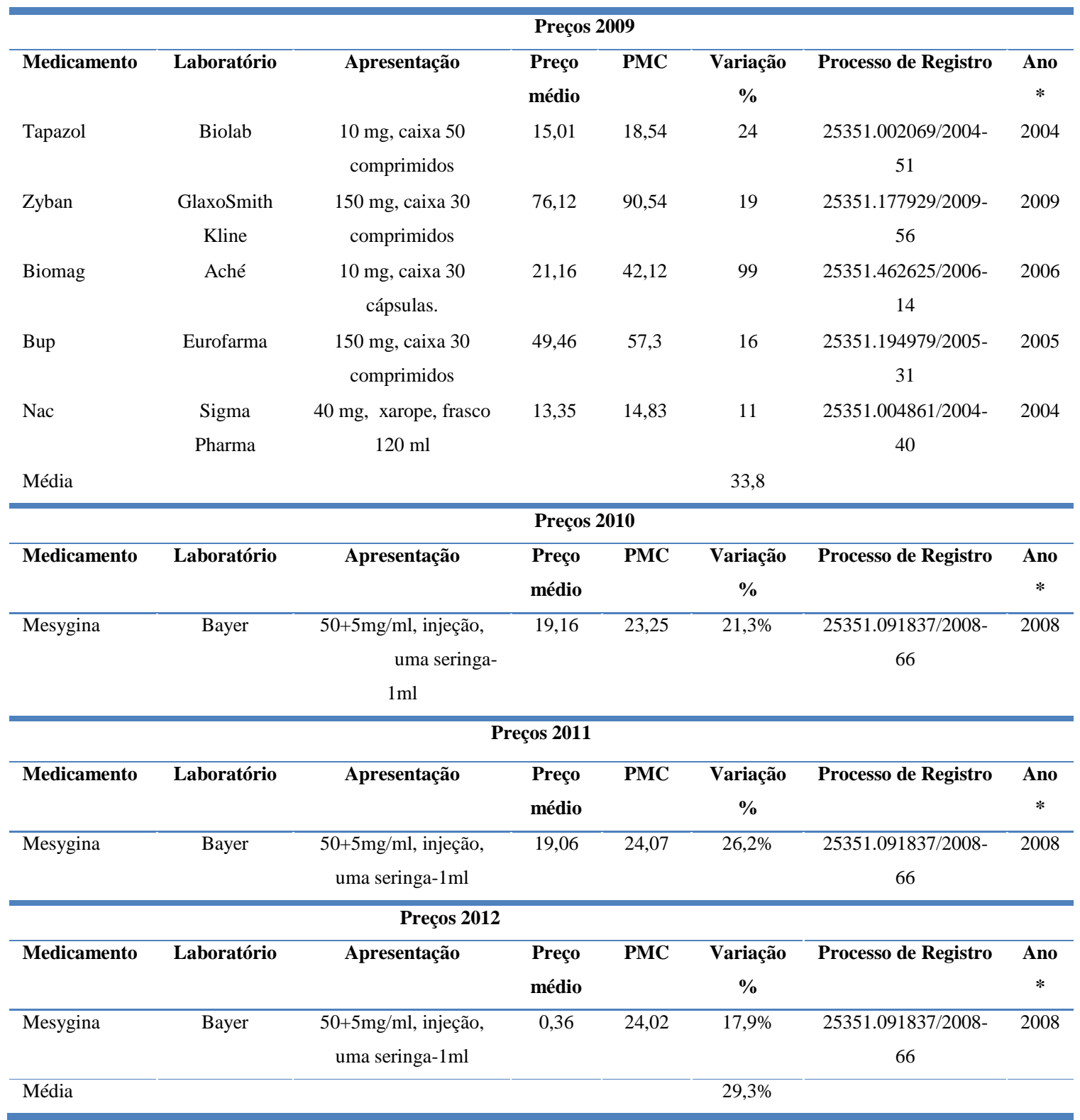

* Ano de instauração do processo administrativo de petição de registro

Fonte: Elaboração própria, a partir de dados do IDEC, PROCON-SP e ANVISA (cf. Anexo F e G).

A média da variação entre preço médio praticado no ponto de venda e PMC, no ano de 2009, incidiu no patamar de 33,8\%. Incluindo os dados obtidos para o medicamento Mesiyna, cujos preços foram coletados, na cidade de São Paulo, em 2010, 2011 e 2012, a média da variação é $29,3 \%$.

Não foi possível chegar a nenhum resultado conclusivo, pois não foi possível trabalhar com uma amostra estatisticamente significativa, mas os dados obtidos apontam para o fato de que, mesmo para os medicamentos lançados a partir de 2004, isto é, depois da criação da CMED, e, portanto, cujos preços iniciais foram fixados já de acordo com os 
critérios estipulados por esse órgão, a defasagem entre o preço médio praticado no mercado e o PMC é considerável. Segundo Ione Amorim, seria aceitável uma variação inferior a $20 \%$ (informação verbal $)^{388}$ e as médias de variação foram consideravelmente superiores ao patamar de variação tido como aceitável. Dentre os oito preços analisados de medicamentos lançados a partir de 2004 no mercado brasileiro, cinco apresentaram variação superior a $20 \%$ com relação ao PMC.

Conforme dito anteriormente, é verdade que em razão das dificuldades enfrentadas na obtenção de dados acerca de preços de medicamentos no Brasil tal análise não foi realizada com base em critérios de amostragem estatística. Mesmo assim, ela indica que uma boa parte dos medicamentos lançados após 2003 apresentam os mesmos problemas daqueles lançados antes da criação da CMED e que, supostamente, apresentariam grande variação entre preço médio e PMC, em função de um aumento nos preços antes da incidência do novo critério regulatório. O medicamento Biomag, da Aché, lançado após a criação da CMED, apresentou variação entre o preço médio e o PMC tão significativa quanto os produtos que apenas o reajuste dos preços se submeteu aos critérios regulatórios da CMED, incidindo no patamar de 99\%. Essa situação coloca em xeque os argumentos dos Secretários Executivos da CMED (antigo e atual) de que o problema da regulação seria trabalhar com preços distorcidos "para cima".

\subsubsection{O exercício das competências previstas na Lei 10.742/03}

No entanto, apesar da Lei 10.742/03 apresentar "furos", tais como a impossibilidade de redução das margens de comercialização estipuladas pela CMED, que permitiria a diminuição dos preços dos medicamentos, essa lei prevê aspectos positivos, tais como amplas atribuições à CMED que extravasam a competência regulatória propriamente dita desse órgão. Essas atribuições fortalecem a atuação do órgão regulador no sentido de promover a assistência farmacêutica e são as seguintes:

r) Propor a adoção de legislações e regulamentações referentes à regulação econômica do mercado de medicamentos e opinar sobre regulamentações que envolvam a tributação de medicamentos;

s) Sugerir a celebração de acordos e convênios internacionais concernentes ao setor de medicamentos.

\footnotetext{
${ }^{388}$ Informação fornecida por Ione Amorim, em entrevista realizada em São Paulo, em 20 de fevereiro de 2012 (vide transcrição do áudio da entrevista com Ione Amorim, no Anexo B).
} 
No entanto, apenas a competência fixada no art. $6^{\circ}$, inciso IX, da Lei 10.742 (opinar sobre regulamentações que envolvam tributação de medicamentos") é exercida, na prática, pela CMED. Segundo os assessores da Secretaria Executiva do órgão regulador, entrevistados para esta pesquisa, todos os projetos de lei acerca da tributação de medicamentos são enviados previamente à CMED para que esta demonstre sua opinião. Os assessores da Secretaria Executiva também informaram que a CMED nunca exerceu a atribuição prevista no inciso XI do mencionado artigo, qual seja, "sugerir a celebração de acordos e convênios internacionais relativos ao setor de medicamentos" (informação verbal). ${ }^{389}$

Quanto à competência relativa a opinar sobre regulamentação que envolva tributos de medicamentos, acredita-se que esta não tem sido exercida de forma benéfica ao consumidor. Isso porque a carga tributária sobre medicamentos é pesada demais, chegando a compor, aproximadamente, $34 \%$ do preço final desses produtos. ${ }^{390}$ Embora a questão da tributação não seja o foco do presente estudo, importa ressaltar que para fins de promover a assistência farmacêutica não é suficiente controlar de forma eficaz os preços dos medicamentos e deixar de discutir e repensar a inconveniência da pesada carga tributária à qual esses produtos estão submetidos.

\subsubsection{O coeficiente de adequação e preços (CAP)}

A regulação praticada pela CMED também enfrenta dificuldades de implementação. Sobre esse tema, merece destaque o obstáculo enfrentado no que se refere à aplicação do coeficiente de adequação de preços (CAP), uma espécie de desconto obrigatório, a medicamentos previamente relacionados pela $\mathrm{CMED} .{ }^{391} \mathrm{Na}$ prática, muitos

\footnotetext{
${ }^{389}$ Informação fornecida por assessores da Secretaria-Executiva da CMED, em entrevista realizada em Brasília, em 5 de julho de 2012 (vide transcrição do áudio da entrevista com assessores da SecretariaExecutiva da CMED, no Anexo).

${ }^{390}$ FEBRAFAR, Lideranças empresariais apóiam redução do ICMS nos medicamentos. Disponível em: <http://www.ibpt.com.br/home/publicacao.view.php?publicacao_id=14406\&PHPSESSID=6c09c02806dfb5d d09c0ea91f9161d8e>. Acesso em: 21 ago. 2012; e GARNETT, G. Medicamentos e a carga tributária. Disponível

em:<http://www.conexaoitajuba.com.br/itajuba/Pagina.do;jsessionid=h0298s51f76f?idSecao=141\&idNoticia $=27108>$. Acesso em: 21 ago.2012.

${ }^{391}$ Art. $2^{\circ}$, da Resolução CMED n ${ }^{\circ}$, de 18 de dezembro de 2006: “ O CAP será aplicado ao preço dos produtos nos seguintes casos:

I- Produtos que estejam ou venham a ser incluídos no componente de medicamentos de dispensação excepcional, conforme definido pela Portaria $n^{\circ}$ 698, de 30 de março de 2006.

II- Produtos que estejam ou venham a ser incluídos no Programa Nacional de DST/AIDS.

III- Produtos que estejam ou venham a ser incluídos no Programa de Sangue e Hemoderivados.

IV- Medicamentos antineoplásicos ou medicamentos utilizados como adjuvantes no tratamento do câncer.
} 
laboratórios têm deixado de aplicar esse desconto de 24,69\% aos medicamentos vendidos aos Departamentos Regionais de Saúde, que se vêem obrigados a pagar o sobrepreço, sob pena de desabastecimento do sistema público de saúde.

A Interfarma, entidade que representa trinta laboratórios estrangeiros no Brasil, contestou judicialmente a Resolução CMED 4/06, que estabeleceu o CAP, mas perdeu a demanda no Superior Tribunal de Justiça. ${ }^{392}$ No entanto, o voto proferido pela Ministra Eliana Calmon abriu um precedente em favor dos laboratórios farmacêuticos. Em seu voto, com a finalidade de demonstrar que a atividade regulatória da CMED respeitava o princípio da livre concorrência, a ministra Eliana Calmon afirmou o seguinte:

O contrato administrativo, sabidamente, não obedece às regras de Direito Privado, governando-se por princípios específicos porque, nas palavras de Caio Tácito, "a tônica do contrato se desloca da simples harmonia de interesses para a consecução de um fim de interesse público" (in Direito Administrativo, Ed. Saraiva, 1975, p. 292). Nesse diapasão, o particular que opta por contratar com a Administração, por conseguinte, deve se submeter às regras do Direito Administrativo e isso não significa que o direito de propriedade do contratado esteja sendo violado, ou desvirtuada a sua função social. Ademais, a lei não obriga (e nem poderia fazê-lo) que o particular firme contrato com aAdministração para fornecimento de bens ou prestação de serviços. Por isso, não vejo porque estaria sendo contrariado o princípio da livre concorrência. ${ }^{393}$

V- Produtos comprados por força de ação judicial, independente de constarem da relação de que trata o $\S 1^{\circ}$ deste artigo

VI- Produtos classificados nas categorias I, II e V, de acordo com o disposto na Resolução $\mathrm{n}^{\circ} 2$, de 5 de março de 2004, desde que constem da relação de que trata o $\S 1^{\circ}$ deste artigo.

$\S 1^{\circ}$ A Secretaria-Executiva editará, em até 90 (noventa) dias da entrada em vigor desta Resolução, comunicado com a relação de produtos cujos preços serão submetidos ao CAP, conforme decisão do Comitê Técnico-Executivo.

$\S 2^{\circ} \mathrm{O}$ Comitê Técnico-Executivo da CMED poderá incluir ou excluir produtos da relação de que trata o $\S 1^{\circ}$ deste artigo.

${ }^{392}$ BRASIL. Superior Tribunal de Justiça. Mandado de Segurança n ${ }^{\circ}$ 12730-DF (2007/0068561-2). Impetrante: Associação da Indústria Farmacêutica de Pesquisa (INTERFARMA). Impetrado: Ministro do Estado da Saúde. Relatora: Ministra Eliana Calmon. Brasília, 28 de março de 2007. Disponível em: $<$ http://www.stj.jus.br/webstj/processo/Justica/detalhe.asp?numreg=200700685612\&pv=010000000000\&tp= 51>. Acesso em: 5 set. 2012

${ }^{393}$ BRASIL. Superior Tribunal de Justiça. Mandado de Segurança $n^{\circ}$ 12730-DF (2007/0068561-2). Impetrante: Associação da Indústria Farmacêutica de Pesquisa (INTERFARMA). Impetrado: Ministro do Estado da Saúde. Relatora: Ministra Eliana Calmon. Brasília, 28 de março de 2007. Disponível em: <http://www.stj.jus.br/webstj/processo/Justica/detalhe.asp?numreg=200700685612\&pv=010000000000\&tp= 51>. Acesso em: 5 set. 2012. 
Desde então, muitos laboratórios têm fundamentado suas decisões de não participar de licitações para compras públicas de medicamentos na ausência de obrigação legal de contratar com o poder público.

Em defesa da atividade reguladora da CMED, o Ministério Público Federal intentou ação contra quatorze empresas farmacêuticas que se recusaram a vender medicamentos para entidades do Governo do Estado de São Paulo com o desconto previsto na Resolução CMED 4/06. ${ }^{394}$ Essa recusa deixou os Departamentos Regionais de Saúde da Secretaria de Saúde do Estado de São Paulo sem outra alternativa a não ser adquirir os medicamentos com sobrepreço, sob pena de desabastecimento da rede pública de saúde. Referida ação judicial pretendeu fazer com que os laboratórios respeitassem a norma reguladora da CMED e devolvessem o dinheiro cobrado a mais do governo paulista. Por sua vez, essa demanda foi julgada improcedente em primeiro grau de jurisdição, sob o argumento de que o CAP só poderia ser aplicado às empresas farmacêuticas que comercializassem exclusivamente com a Administração Pública, mesmo sem haver qualquer previsão nesse sentido na mencionada Resolução CMED 4/06. ${ }^{395}$ O Ministério Público Federal interpôs recurso de agravo de instrumento que ainda não obteve julgamento definitivo. Nesse recurso, o Ministério Público Federal enfatiza a necessidade dos hospitais públicos e demais órgãos públicos responsáveis pela aquisição de medicamentos denunciarem os laboratórios que descumprirem a Resolução 4/06. ${ }^{396}$ Segundo esse órgão, muitas compras com sobrepreço deixaram de ser notificadas à Secretaria de Saúde, evidenciando uma importante falha de comunicação entre as unidades regionais e seu órgão central que, por essa razão, deixou de notificar a CMED, responsável por aplicar as penalidades cabíveis. ${ }^{397}$ As penalidades aplicadas pela CMED àqueles laboratórios que não observam o CAP nos casos definidos na Resolução 4/06 estão previstas no Código de Defesa do Consumidor, conforme estipula a Lei 10.742/03 (informação verbal). ${ }^{398} 399$

\footnotetext{
${ }^{394}$ MPF recorre de decisão que limita desconto na venda de medicamentos ao poder público. Disponível em: 〈http://www.prsp.mpf.gov.br/sala-de-imprensa/noticias_prsp/12-12-11-2013〉. Acesso em: 18 ago. 2012. ${ }^{395}$ Ibid.

${ }^{396}$ BRASIL. Tribunal Regional Federal (3 ${ }^{\mathrm{a}}$. Região). Agravo de Instrumento $\mathrm{n}^{\circ}$ 2011.03.00.037364-0. Agravante: Ministério Público Federal. Agravado: Merck Sharp \& Dohme Farmacêutica Ltda. Relator: Desembargador Federal André Nabarrete. São Paulo, 7 de dezembro de 2011. Disponível em:< http://web.trf3.jus.br/consultas/Internet/ConsultaProcessual/Processo?NumeroProcesso=201103000373640>. Acesso em: 6 set. 2012.

${ }^{397}$ AMEAÇA à atividade empresarial. O Estado de São Paulo, São Paulo, 1 out. 2011. Notas e Informações, Caderno 1, p.3.

${ }^{398}$ Art. $8^{\circ}$, da Lei n ${ }^{\circ} 10.742$, de 6 de outubro de 2003: "O descumprimento dos atos emanados pela CMED, no exercício de suas competências de regulação e monitoramento do mercado de medicamentos, bem como o descumprimento de norma prevista nesta lei, sujeitam-se às sanções administrativas previstas no art. 56, da Lei n ${ }^{\circ} 8.078$, de 1990".
} 
O caso descrito acima não é isolado e muitos laboratórios têm se recusado a participar de licitações quando obrigados a vender medicamentos com preço menor. Conforme publicou o jornal Folha de S.Paulo, laboratórios e distribuidores vêm, frequentemente, boicotando licitações de órgãos públicos para a compra de medicamentos, nos casos em que a legislação obriga a concessão de desconto. ${ }^{400}$ Segundo o Ministério da Saúde, a correta observância do CAP possibilitaria a economia de R \$ 120 milhões por ano pela União, Estados e Municípios. ${ }^{401}$ Entrevistada pela Folha de S. Paulo, representante da Secretaria de Saúde do Estado de São Paulo apontou que, só nesse estado, 66 laboratórios deixaram de participar de licitações. O Ministério Público e a Controladoria Geral da União afirmaram que no Amazonas e no Distrito Federal ocorreram situações idênticas. Indagada pela Folha, a CMED disse não ter competência legal para punir empresas que não se apresentem em licitações, sendo competente, apenas, para punir os laboratórios que vendem os produtos farmacêuticos ao governo sem desconto. ${ }^{402}$ De fato, não há como obrigar os laboratórios a participarem de processos licitatórios, o que pode gerar duas situações perniciosas: prejuízo ao erário público e comprometimento do orçamento destinado à saúde, em função da não observância do CAP e do pagamento de sobrepreço; ou desabastecimento do sistema público de saúde.

Art. 56, da Lei $\mathrm{n}^{\circ}$ 8.078, de 11 de setembro de 1990: “As infrações das normas de defesa do consumidor ficam sujeitas, conforme o caso, às seguintes sanções administrativas, sem prejuízo das de natureza civil, penal e das definidas em normas específicas:

I - multa;

II - apreensão do produto;

III - inutilização do produto;

IV - cassação do registro do produto junto ao órgão competente;

V - proibição de fabricação do produto;

VI - suspensão de fornecimento de produtos ou serviço;

VII - suspensão temporária de atividade;

VIII - revogação de concessão ou permissão de uso;

IX - cassação de licença do estabelecimento ou de atividade;

$\mathrm{X}$ - interdição, total ou parcial, de estabelecimento, de obra ou de atividade;

XI - intervenção administrativa;

XII - imposição de contrapropaganda.

Parágrafo único. As sanções previstas neste artigo serão aplicadas pela autoridade administrativa, no âmbito de sua atribuição, podendo ser aplicadas cumulativamente, inclusive por medida cautelar, antecedente ou incidente de procedimento administrativo.

${ }^{399}$ Informação fornecida por assessores da Secretaria-Executiva da CMED, em entrevista realizada em Brasília, em 5 de julho de 2012 (vide transcrição do áudio da entrevista com assessores da SecretariaExecutiva da CMED, no Anexo C).

${ }^{400}$ CREDENDIO, J. E.; PINHO, A. Laboratório boicota remédio com desconto. Folha de S.Paulo, São Paulo, 4 abr. 2011,. Cotidiano, Caderno 3, p.3.

${ }^{401}$ Ibid.

${ }^{402}$ CREDENDIO, J. E.; PINHO, A. Laboratório boicota remédio com desconto. Folha de S.Paulo, São Paulo, 4 abr. 2011, Cotidiano, Caderno 3, p.3. 


\subsubsection{Participação, transparência e accountability ${ }^{403}$ na regulação da CMED}

Sabe-se que com o surgimento do Estado Regulador adveio o debate acerca da legitimidade democrática das decisões regulatórias, considerando que, muitas vezes, essas decisões não são meramente técnicas, mas envolvem escolhas valorativas entre, por exemplo, valores de eficiência econômica, objetivos sociais e ambientais, além de questões que versam sobre segurança e demandas essenciais da população. ${ }^{404}$ Essas decisões podem ser vistas como tendo sido deslocadas de instituições representativas para órgãos não representativos, como aqueles responsáveis pela regulação econômica. Por essa razão, há quem diga que o Estado Regulador baseia-se em um conceito reduzido de cidadania. ${ }^{405}$

Com o objetivo de imprimir maior caráter democrático às decisões emanadas das autoridades reguladoras, surgiram demandas da sociedade civil pela abertura e maior transparência das normas regulatórias, além da necessidade de maior participação e atribuição de obrigações aos órgãos reguladores de justificar e publicar suas decisões. Com base nessas questões, o presente trabalho se propôs, embora de maneira breve e pontual, a examinar a existência de transparência, participação e accountability na atividade reguladora da Câmara de Regulação do Mercado de Medicamentos.

\section{a) Transparência}

As decisões tomadas pela CMED e que se consubstanciam em normas regulatórias, tais como resoluções e comunicados (dois dos atos normativos mais utilizados por esse órgão regulador), são divulgados no sítio eletrônico da ANVISA. Frequentemente, esses atos normativos contêm anexos detalhando conceitos técnicos relevantes. Portanto, no que diz respeito às normas regulatórias, a CMED parece atingir os objetivos de transparência.

Quanto ao aspecto da transparência que envolve o acesso a informação, vale sublinhar que nem a CMED e nem a ANVISA divulgam dados sobre preços de

\footnotetext{
${ }^{403}$ A noção de accountability possui duas conotações básicas: capacidade de resposta, que implica a obrigação dos funcionários públicos informarem e explicarem os seus atos, e enforcement, que é a capacidade dos órgãos que devem prestar contas de impor sanções aos detentores do poder que violaram seus deveres públicos (Tradução livre para: "the notion of accountability carries two basic conotations: answerability, the obligation of public officials to inform about and to explain what they are doing and enforcement, the capacity of accounting agencies to impose sanctions on powerholders who have violated their public duties") - SCHEDLER, A. Conceptualizing Accountability. In: SCHEDLER, A.; DIAMOND, L.; PLATTNER, M. (Eds.). The Self Restraining State: Power and Accountability in New Democracies. Boulder: Lynne Rienner Publishers, 1999. p. 14. Assim, a noção de accountability é bidimensional e inclui capacidade de resposta e capacidade de punição.

${ }^{404}$ LODGE, M. Accountability and transparency in regulation: critiques, doctrines and instruments. In: Jordana, Jacint and Levi-Faur, David, (eds.). Politics of Regulation: CRC Series on Competition, Regulation and Development . Londres: Edward Elgar Publishing, Cheltenham, 2004. pp. 124-144. p. 125.

${ }^{405}$ Ibid.
} 
medicamentos, sendo publicados no sítio eletrônico dessa agência reguladora, apenas os valores dos PMCs dos períodos atual e pretérito. Ainda, no que diz respeito à data dos primeiros registros dos medicamentos, as informações constantes do banco de dados presente no site da mencionada agência reguladora estão incompletas, constando, apenas, as datas das publicações mais recentes de renovação dos registros (o prazo para renovação do registro é quinquenal). A ANVISA, mesmo depois de receber solicitação por meio do Serviço de Informação ao Cidadão (SIC), manifestou, via e-mail, recusa em fornecer as informações relativas às datas dos primeiros registros dos medicamentos componentes do banco de dados elaborado para este trabalho.

Outro aspecto que não restou claro e que veio à tona quando da realização das entrevistas com membros do órgão regulador e da leitura de entrevistas que o Secratário Executivo desse órgão forneceu ao IDEC $^{406}$ consiste nos termos (principalmente, em que momentos e por que motivos específicos) ocorre a relação entre a CMED e a indústria farmacêutica. Em entrevista concedida ao IDEC, o Secretário Executivo da CMED, Ivo Bucaresky, afirmou que os tetos de preço só são reduzidos a pedido da indústria farmacêutica, o que acontece, em geral, quando a patente de um medicamento está prestes a expirar. Ainda nessa entrevista, Bucaresky asseverou que:

[a] indústria pede para baixar o PMC com o objetivo de afastar alguns interessados em produzir genéricos daquele medicamento. $\mathrm{O}$ genérico tem de ser pelo menos $35 \%$ mais barato que o preço teto do medicamento de referência, por isso, quanto menor for o teto, menor a margem de manobra para a entrada de concorrentes. ${ }^{407}$

O problema da transparência quanto a essa questão advém da ausência de qualquer previsão na Lei 10.742/03 sobre a possibilidade de redução dos tetos estabelecidos pela CMED, mesmo quando solicitado pela indústria farmacêutica, o que, de acordo com o princípio da legalidade administrativa, seria vedado ao órgão regulador. Essa situação suscita também dúvida quanto o grau de influência e participação da indústria farmacêutica no processo regulatório.

\footnotetext{
${ }^{406}$ DIFERENÇA além da conta. Revista do IDEC. São Paulo, n.162, p.16-19, fev. 2012. p. 18-19.

${ }^{407}$ Ibid., p. 19 .
} 


\section{b) Participação}

Por meio de canais de atendimento ao consumidor da ANVISA, via telefone ou email, os consumidores podem se manifestar acerca da qualidade da regulação realizada pela CMED, fazendo críticas ou elogios. O Ministério da Saúde, em seu sítio eletrônico, também disponibiliza, por meio do serviço de informação ao cidadão (SIC), um canal para a requisição de informações da Secretaria-Executiva da CMED. Contudo, isso não implica na participação direta do processo regulatório pelos consumidores. A legislação também não prevê nada nesse sentido.

Conforme afirmou membro da Secretaria-Executiva da CMED, em entrevista, sobre o assunto:

[a]té o momento, a legislação da CMED implementada não vai para consulta pública tal como as outras normas da ANVISA. Agora, com a indústria esse contato ocorre. [...] Há uma certa interação com, vamos dizer assim, os 'órgãos de classe' da indústria, o Interfarma e o Sindusfarma, e quando há uma proposta de nova regulamentação, há mesmo que, informalmente, uma discussão com eles. Eles trazem as suas reivindicações aqui, que a gente também analisa (informação verbal). ${ }^{408}$

Ao ser indagado se há mecanismos específicos previstos na legislação, ou seja, formas institucionalizadas de comunicação entre a indústria farmacêutica e a CMED, um dos assessores da Secretaria-Executiva respondeu que:

não existe um fluxo obrigatório nesse processo [...]. Mesmo quando não há uma regulamentação, ela [indústria farmacêutica] traz suas reivindicações e pode ser que gere alguma regulamentação ali dentro do que elas estão querendo (informação verbal) ${ }^{409}$.

Nessa entrevista, ainda foi revelado que, quando há a elaboração de uma nova norma reguladora, as entidades representantes dos consumidores não são contatadas

\footnotetext{
${ }^{408}$ Informação fornecida por assessores da Secretaria-Executiva da CMED, em entrevista realizada em Brasília, em 5 de julho de 2012 (vide transcrição do áudio da entrevista com assessores da SecretariaExecutiva da CMED, no Anexo C).

${ }^{409}$ Informação fornecida por assessores da Secretaria-Executiva da CMED, em entrevista realizada em Brasília, em 5 de julho de 2012 (vide transcrição do áudio da entrevista com assessores da SecretariaExecutiva da CMED, no Anexo C).
} 
(informação verbal). ${ }^{410}$ Esse quadro revela que os consumidores de medicamentos não participam do processo regulatório, enquanto que a indústria farmacêutica exerce participação tanto no momento de elaboração das normas regulatórias, quanto nos momentos em que leva ao órgão regulador demandas que podem ocasionar a expedição de novas normas nesse sentido.

Desse modo, a indústria farmacêutica é beneficiada em face do consumidor, vez que, frequentemente, estabelece comunicação com o órgão regulador, opinando sobre as normas regulatórias a serem elaboradas e explicitando demandas, por meio de canais informais de comunicação, porquanto não previstos na legislação.

\section{c) Accountability}

Na legislação referente à regulação do mercado farmacêutico (normas reguladoras expedidas pela CMED e a Lei 10.742/03), assim como nos casos da transparência e da participação, não há previsão de mecanismos que assegurem o accountability. A CMED não possui qualquer obrigação legal expressa de prestar contas de sua atividade reguladora a outros órgãos da Administração Pública ou aos entes regulados.

$\mathrm{O}$ accountability não pode ser dissociado da noção de transparência ${ }^{411} \mathrm{e}$, nesse sentido, quando inquirido sobre a existência de mecanismos capazes de garanti-lo em relação à atividade reguladora da CMED, um dos assessores da Secretaria-Executiva desse órgão, entrevistado para esta pesquisa, respondeu que:

[...]agora com a Lei de Acesso a Informação, está começando a ser discutido no Comitê [Comitê Técnico-Executivo]. Na última reunião do Comitê, que foi no final de maio, foi tratado desse assunto para um início de regulamentação de informação, de acesso, dentro da CMED. Mas está muito no início (informação verbal). ${ }^{412}$

\footnotetext{
${ }^{410}$ Informação fornecida por assessores da Secretaria-Executiva da CMED, em entrevista realizada em Brasília, em 5 de julho de 2012 (vide transcrição do áudio da entrevista com assessores da SecretariaExecutiva da CMED, no Anexo C).

${ }^{411}$ LODGE, M. Accountability and transparency in regulation: critiques, doctrines and instruments. In: Jordana, Jacint and Levi-Faur, David, (eds.). Politics of Regulation: CRC Series on Competition, Regulation and Development . Londres: Edward Elgar Publishing, Cheltenham, 2004. pp. 124-144. p. 127.

${ }^{412}$ Informação fornecida por assessores da Secretaria-Executiva da CMED, em entrevista realizada em Brasília, em 5 de julho de 2012 (vide transcrição do áudio da entrevista com assessores da SecretariaExecutiva da CMED, no Anexo C).
} 
Assim, é possível verificar que no que concerne à transparência, participação e accountability a regulação da CMED deixa a desejar, não havendo nem na legislação e nem na prática mecanismos garantidores desses processos.

\subsection{Nos moldes em que foi concebida e conforme é praticada, a política de} regulação dos preços contribui para a promoção da assistência farmacêutica, isto é, ela é efetiva?

Conforme mencionado da Introdução deste trabalho e no início deste capítulo, entende-se, para fins dessa pesquisa, que a regulação dos preços dos medicamentos é efetiva se ela facilitar o acesso a esses produtos pela população. A regulação pode ser efetiva, nesse sentido, se for capaz de: deter o aumento dos preços dos medicamentos, evitando reajustes significativos de uma hora para a outra; pressionar os preços a patamares mais baixos; incentivar a concorrênca; e diminuir os gastos do governo nas compras públicas.

Após a análise realizada no item 5.2, foi possível concluir que a regulação dos preços realizada pela CMED não é efetiva por diversas razões:

Em primeiro lugar, é verdade que o modelo regulatório escolhido pela CMED, qual seja, o controle de preços mediante a aplicação do price cap, é uma ferramenta jurídica moderna e capaz de estimular a concorrência e a produtividade dos agentes econômicos. No entanto, os resultados de sua aplicação poderiam ser melhores se a regulação incidisse sobre os preços reais praticados no mercado, ou seja, nos pontos de venda. O maior problema do controle de preços realizado pela CMED reside na ausência de um monitoramento de preços que permita ao órgão regulador conhecer o comportamento real do mercado. Afinal, são sobre os preços reais, que são aqueles praticados nos pontos de venda, que as normas regulatórias devem incidir e não sobre preços iniciais, defasados, e que supostamente incluiriam uma "margem de conforto ou garantia" inserida pela indústria farmacêutica. No decorrer da implementação da regulação, os preços nos pontos de venda deixaram de ser acompanhados e monitorados pelo órgão regulador. Atualmente, os preços sobre os quais incide o controle são aqueles apurados pelas Revistas da ABCFARMA, única fonte utilizada pela CMED para o suposto monitoramento (informação verbal). ${ }^{413}$

\footnotetext{
${ }^{413}$ Informação fornecida por assessores da Secretaria-Executiva da CMED, em entrevista realizada em Brasília, em 5 de julho de 2012 (vide transcrição do áudio da entrevista com assessores da SecretariaExecutiva da CMED, no Anexo C).
} 
Contudo, importa ressaltar que a Lei 10.742/03 não permite que, de uma hora para a outra, o controle de preços passe a incidir sobre os preços reais praticados no mercado. Essa lei permite apenas o reajuste dos preços para cima e, caso os preços tal como são praticados nos pontos de venda passem a ser utilizados como parâmetro para a regulação, isso implicaria numa redução formal do preço máximo ao consumidor, o que ensejaria disputas judiciais iniciadas pela indústria farmacêutica. A Lei 10.742/03 não confere à CMED a flexibilidade e a liberdade necessárias ao exercício da atividade reguladora. Desse modo, para que a regulação da CMED seja mais efetiva, é imprescindível a alteração da Lei 10.742/03, no sentido de permitir ao órgão regulador a redução de preços, quando necessário.

Em segundo lugar, a regulação da CMED parece ser ineficaz também em relação aos preços dos medicamentos lançados depois da criação da CMED, em 2003. Este trabalho analisou o comportamento de medicamentos lançados nesse período e os resultados apontaram para um comportamento dos preços semelhante àquele observado em relação aos medicamentos lançados antes da criação da CMED (importa registrar, mais uma vez, que esses resultados não são conclusivos, pois a amostra analisada não é estatisticamente representativa). Desse modo, a diferença entre preço praticado no ponto de venda e PMC apresenta-se, indiscriminadamente, tanto no caso dos medicamentos lançados antes criação da CMED, quanto no caso daqueles medicamentos lançados após a criação desse órgão e que tiveram seus preços iniciais fixados com base nas normas reguladoras atualmente vigentes. Essa situação é perniciosa ao consumidor e ao acesso a medicamentos, porquanto sujeita o paciente a aumentos significativos e abruptos de preços, bem como demonstra que a regulação econômica é inócua e não afeta o arbítrio da indústria na fixação dos preços.

Em terceiro lugar, é verdade que a Lei 10.742/03 inova ao permitir que o órgão regulador estabeleça desconto obrigatório às compras públicas. Isso permite que o governo, comprador de medicamentos em grande quantidade, principalmente após a Constituição de 1988, que estabeleceu o direito universal à saúde, racionalize seus gastos. Porém, conforme visto anteriormente, a CMED tem enfrentado dificuldades na implementação dos descontos para as compras públicas. Muitos laboratórios têm deixado de participar de licitações e a eles não cabe qualquer espécie de sanção, sendo estas previstas apenas para os casos em que há cobrança de sobrepreço. 
O que acontece, na prática, é que o governo acaba pagando o sobrepreço para garantir o abastecimento do SUS. Além disso, assim como já mencionado, muitos dos laboratórios não são penalizados, porque os departamentos regionais de saúde deixam de notificar as respectivas secretarias estaduais de saúde que, por sua vez, têm como funçao notificar a CMED, que é o órgão responsável por fiscalizar e aplicar as penalidades cabíveis.

A Folha de S. Paulo noticiou que a prática de vendas ao governo mediante a cobrança de sobrepreço é comum, o que significa que a atuação fiscalizadora da CMED tem sido insuficiente. ${ }^{414}$ Além disso, constata-se uma falta de articulação interna na Administração Pública que permita melhor comunicação entre os Departamentos Regionais de Saúde, as respectivas Secretarias de Sáude e a CMED para que notifiquem a prática abusiva e imponham sanções, respectivamente.

Deste modo, é possível concluir que o controle de preços realizado pela CMED, nos moldes da Lei 10.742/03, não facilita o acesso a medicamentos ao consumidor que compra em varejo por dois motivos principais:

a) $\mathrm{O}$ controle de preços não incide sobre os preços reais praticados no mercado e não permite a redução do preço máximo ao consumidor. O problema, nesse caso, é eminentemente de ordem operacional e legislativa. Isso gera considerável diferença ou variação entre os preços reais praticados no mercado e o teto estabelecido pelo órgão regulador.

b) $\mathrm{O}$ controle de preços também não parece ser eficiente no que diz respeito às compras públicas, tendo em vista o comportamento da indústria farmacêutica ao burlar a aplicação do coeficiente de adequação de preços (CAP). Nesse caso, o problema é de implementação da regulação, o que exigiria maior força fiscalizatória da CMED sobre as compras realizadas com sobrepreço e, provavelmente, a realização de estudo sobre a possibilidade alterar a legislação, com o propósito de permitir a aplicação de penalidades aos laboratórios que deixarem de participar de procedimentos licitatórios para evitar a aplicação do CAP.

\subsection{Possíveis soluções}

Conforme já mencionado, os dois maiores problemas do controle de preços realizado pela CMED são: a) a considerável diferença ou variação entre preços praticados

\footnotetext{
${ }^{414}$ CREDENDIO, J. E.; PINHO, A. Laboratório boicota remédio com desconto. Folha de S.Paulo, São
} Paulo, 4 abr. 2011,. Cotidiano, Caderno 3, p.3. 
nos pontos de venda e preço máximo ao consumidor que, frequentemente, ultrapassam o patamar de $20 \%{ }^{415}$; e dificuldade de implementação do CAP, tendo em vista o fato dos laboratórios, comumente, se recusarem a vender medicamentos ao poder público mediante desconto ou deixarem de participar de licitações para as compras públicas.

Diante desse quadro, pode-se pensar em algumas soluções:

Primeiro, é imprescindível que a CMED monitore os preços dos medicamentos nos pontos de venda. Isso permitirá que o órgão regulador realize um controle da eficiência da regulação e trabalhe com dados fidedignos sobre o mercado, deixando de depender de informações enviesadas da indústria farmacêutica, farmácias e drogarias, tal como aquelas constantes das Revistas da ABCFARMA. O monitoramento permite, também, que a CMED contemple essas informações na elaboração dos índices anuais de reajuste de preços. Importa anotar que toda a atividade de levantamento e monitoramento de preços custa caro ao poder público, mas diante de sua importância para a efetividade da regulação, é imprescindível que maior quantidade de recursos públicos sejam destinados a essa finalidade. ${ }^{416}$

Entretanto, não basta a realização do monitoramento dos preços para resolver o problema da diferença entre a média de preços dos medicamentos praticados nos pontos de venda e o PMC. É necessária um alteração na Lei 10.742/03, no sentido de permitir a redução do preço-fábrica e do preço máximo ao consumidor. Isso permitirá que o teto de preços determinado pela CMED pressione a baixa dos preços em geral, favorecendo o consumidor que compra em varejo.

Segundo, no que diz respeito ao coeficiente de adequação de preços (CAP), deve-se melhorar a comunicação e o fluxo de informações entre os órgãos públicos de saúde. É necessário que os departamentos regionais de saúde sempre notifiquem as compras realizadas mediante sobrepreço às secretarias de saúde e estas, por sua vez, comuniquem a CMED para que esse órgão possa aplicar as penalidades previstas na Lei 10.742/03 aos laboratórios. O poder fiscalizatório da CMED também deve ser fortalecido, fazendo com

\footnotetext{
${ }^{415}$ Ione Amorim disse que uma variação de $20 \%$ entre a média dos preços praticados nos pontos de venda e o preço máximo ao consumidor seria aceitável. O que preocupa são as variações que ultrapassam esse patamar, pois indicam que o preço dos medicamentos poderia ser, na verdade, muito menor, do que é praticado (informação verbal) - informação fornecida por Ione Amorim, em entrevista realizada em São Paulo, em 20 de fevereiro de 2012 (vide transcrição do áudio da entrevista com Ione Amorim, no Anexo A).

${ }^{416}$ Registra-se que, Basilia Aguirre afirmou que a CMED teve interesse de contratar a FIPE para a realização de contrato de levantamento de preços em diversas cidades do país. No entanto, os recursos destinados pelo órgão regulador para esse fim estavam muito aquém do necessário para o custeio dessa atividade (informação verbal). Informação fornecida por Basilia Aguirre, em entrevista realizada em São Paulo, em 28 de agosto de 2012 (vide transcrição do áudio da entrevista com Basilia Aguirre, no Anexo E).
} 
que essa câmara deixe de depender apenas das notificações das secretarias de saúde para aplicar as penalidades de desrespeito ao CAP. A CMED deve, eventualmente, fiscalizar diretamente as compras públicas realizadas nas cidades brasileiras e, para isso, precisará de uma reforma organizacional que contemple essas necessidades.

Com o objetivo de fazer com que a CMED fiscalize diretamente o cumprimento das normas regulatórias, é necessário que seja destinada maior quantidade de recursos a esse órgão, possibilitando a contratação de funcionários para a realização dessa atribuição. Atualmente, o quadro de pessoal da CMED não possui o número necessário de servidores para realizar essa função. Ademais, conforme mencionado anteriormente, maior apoio financeiro à CMED é fundamental para possibilitar o monitoramento dos preços dos medicamentos diretamente nos pontos de venda, que consiste em atividade custosa, assim como pontuado pela pesquisadora da FIPE, Basilia Aguirre (informação verbal) ${ }^{417}$.

${ }^{417}$ Informação fornecida por Basilia Aguirre, em entrevista realizada em São Paulo, em 28 de agosto de 2012 (vide transcrição do áudio da entrevista com Basilia Aguirre, no Anexo E) 


\section{CONCLUSÃO}

Ao longo deste trabalho, foi possível chegar a uma série de constatações e conclusões a respeito da regulação econômica realizada pela Câmara de Regulação do Mercado de Medicamentos, as quais passa-se a enumerar de modo sucinto:

(1) No Brasil, a principal forma de regulação econômica é o controle direto dos preços. Esse controle é realizado pela Câmara de Regulação do Mercado de Medicamentos (CMED). A CMED também regula as compras públicas, mediante o estabelecimento de um desconto obrigatório que deve ser aplicado por parte dos laboratórios vencedores dos processo licitatórios para compras de medicamentos, chamado coeficiente de adequação de preços (CAP).

(2) O controle direto dos preços consiste no controle de margens, mediante a aplicação do mecanismo do price cap. Tal ferramenta jurídica limita o reajuste de preços a determinado teto que é estipulado levando em consideração os fatores produtividade, intrasetor e extra-setor. Esses fatores compõem o preço-fábrica (PF), que deve ser aplicado nas compras diretas da indústria farmacêutica e o preço máximo ao consumidor (PMC) que é aquele aplicado nas compras realizadas pelos consumidores finais, em farmácias e drogarias.

(3) Na prática, as competências da CMED se resumem ao controle de preços dos medicamentos; à fiscalização e à punição dos laboratórios, distribuidores, farmácias e drogarias que não obedecem o preço-fábrica e o preço médio ao consumidor; bem como, no caso de compras públicas, a estabelecer o coeficiente de adequação de preços (CAP).

(4) A política de regulação dos preços empreendida pela CMED, no que diz respeito especificamente ao controle direto dos preços, apresenta mais "contras" do que "prós", bem como dificuldades de implementação.

(4.1) A política regulatória da CMED não contribui para a contenção da evolução dos preços dos medicamentos e não contempla o comportamento real dos preços no mercado. A causa dessa situação é o fato dos tetos de preços estabelecidos pelo órgão regulador serem, na grande maioria das vezes, muito superiores à média dos preços dos medicamentos praticada no mercado. Sendo assim, a indústria de medicamentos, farmácias e drogarias têm grande liberdade na fixação e no reajuste dos preços que se encontram muito abaixo da margem de comercialização estabelecida pela CMED.

(4.2) O argumento do Secretário Executivo da CMED para justificar a discrepância entre preços praticados no mercado e teto fixado pela CMED é de que essa 
situação remete à criação do órgão regulador, em 2003, quando a indústria farmacêutica praticava preços exacerbados. Tal justificativa não parece condizer com a realidade, pois antes da criação da CMED estava em vigor o controle de preços realizado pela Câmara de Medicamentos (CAMED), mediante as ferramentas do congelamento de preços e da Fórmula Paramétrica de Reajuste de Preços, embora a regulação tenha sido exercida apenas em relação aos preços praticados pela indústria, excluindo os preços praticados por farmácias e drogarias. Ainda, no que concerne a esse argumento, ressalta-se que, caso ele fosse consistente, os preços dos medicamentos lançados após a criação da CMED (inicialmente estipulados de acordo com os critérios regulatórios desse órgão) não poderiam apresentar grandes variações entre média praticada no mercado e o PMC. Boa parte desses medicamentos (metade dos medicamentos da amostra analisada), entretanto, parecem repetir o padrão de variação constatado no caso dos medicamentos lançados antes da criação da CMED, tal como apontaram os resultados obtidos nesse trabalho, em razão da comparação da média de preços apurada no mercado e o preço máximo ao consumidor (a média de variação chegou ao patamar de 33,8\%, para os preços coletados me 2009, estando bem acima do patamar de $20 \%$, que seria considerado razoável, segundo o IDEC informação verbal). ${ }^{418} 419$

(4.3) Não foi possível chegar a qualquer conclusão sobre a evolução da variação entre preço médio e PMC, no tempo, no que diz respeito ao aumento ou diminuição. Foi observado, apenas, conforme mencionado anteriormente, que referida variação se manteve em patamares altos.

(5) Uma das razões que gera dificuldades à política regulatória é o fato da Lei 10.742/03, que estabelece as diretrizes regulatórias, não prever a possibilidade de redução dos preços, mas apenas de reajustes "para cima". Essa situação impede que a CMED diminua os tetos relativos ao preço-fábrica e ao preço máximo ao consumidor, na tentativa de pressionar os preços praticados no mercado para baixo e diminuir o excedente econômico extraído do consumidor por parte da indústria farmacêutica, distribuidores, farmácias e drogarias. ${ }^{420}$

\footnotetext{
${ }^{418}$ Importa ressalvar, no entanto, que sobre os medicamentos lançados a partir de 2004, não foi possível chegar a resultados conclusivos, vez que o presente estudo não trabalhou com uma amostra representativa, em termos estatísticos, desses medicamentos.

${ }^{419}$ Informação fornecida por Ione Amorim, em entrevista realizada em São Paulo, em 20 de fevereiro de 2012 (vide transcrição do áudio da entrevista com Ione Amorim, no Anexo B).

${ }^{420}$ Importa anotar que com o aumento da produtividade da indústria farmacêutica (fator X) o reajuste anual pode diminuir, embora isso não implique na diminuição do preço praticado no ano anterior.
} 
(6) A regulação da CMED não possui apenas desvantagens. O coeficiente de adequação de preços (CAP), previsto na Lei 10.742/03 e disciplinado pela Resolução CMED 4/06, é um avanço do ponto de vista regulatório. Esse desconto obrigatório às compras públicas tem o potencial de permitir maior racionalização dos gastos públicos com saúde. No entanto, existem problemas de implementação desse coeficiente. Na prática, muitos laboratórios se recusam a vender medicamentos com o desconto obrigatório, obrigando a Administração Pública a pagar o preço cheio, sob pena de desabastecimento do sistema público de saúde. Além disso, há notícias de que os laboratórios têm deixado de participar de licitações, caso o CAP seja aplicado. Sabe-se também que a fiscalização e aplicação de penalidades às empresas farmacêuticas que desrespeitam referida norma regulatória não são eficientes, uma vez que as secretarias estaduais de saúde deixam, muitas vezes, de comunicar a CMED sobre as compras realizadas com sobrepreço. No que diz respeito à recusa de algumas empresas farmacêuticas em participarem de licitações, a CMED não sabe como agir, uma vez que não possui poder polícia para obrigar os laboratórios a participarem licitações.

(7) A política de regulação do mercado de medicamentos necessita de reformas que devem começar mediante alteração da Lei 10.742/03, que estabelece as diretrizes regulatórias.

(7.1) A Lei 10.742/03 deve ser alterada no sentido de permitir que o órgão regulador reduza os tetos de preços, na medida em que achar necessário.

(7.2) O monitoramento de preços deve ser realizado, com frequência, pelo órgão regulador nos pontos de venda das cidades do país e, para isso, mais recursos públicos devem ser destinados à CMED, pois essa é uma atividade notadamente dispendiosa. Isso permitirá que a CMED trabalhe com dados atualizados e fidedignos sobre o mercado e não com informações sobre preços oriundas da indústria farmacêutica, drogarias e farmácias, tal qual ocorre hoje, por meio do acompanhamento isolado dos supostos preços de mercado através das publicações da ABCFARMA.

(7.3) Devem ser criados na Administração Pública mecanismos facilitadores de notificações de compras mediante sobrepreço, melhorando a comunicação e fluxo de informação entre os departamentos regionais de saúde, as secretarias de saúde estaduais e a CMED, a fim de que sejam aplicadas as penalidades previstas para os laboratórios que se recusam a vender mediante desconto. 
(7.4) A CMED deve ser fortalecida, ampliando o seu poder fiscalizatório sobre os agentes econômicos que descumprem as normas regulatórias. Atualmente, a CMED só aplica penalidades depois de verificadas irregularidades por meio do "monitoramento" de preços realizado pelo acompanhamento das Revistas da ABCFARMA, ou após o recebimento de denúncias das secretarias estaduais de saúde ou dos próprios consumidores. ${ }^{421}$ A CMED não exerce, portanto, uma fiscalização ativa sobre o cumprimento das normas regulatórias, o que seria necessário para o enforcement da regulação.

(7.5) A Lei 10.742/03 deve ser reformada também no sentido de prever mecanismos de transparência, participação e accountability. Atualmente, não existem ferramentas jurídicas legalmente previstas nesse sentido. $\mathrm{Na}$ prática, a indústria farmacêutica acaba tendo voz no processo regulatório por canais informais de comunicação, enquanto que os consumidores não participam da regulação, vez que não há previsão normativa nesse sentido.

(8) O controle direto dos preços realizado pela CMED apresenta muitos problemas, o que não significa que deva ser extinto. O controle direto, mediante o price cap, é uma boa maneira de promover o acesso a medicamentos, embora, diante das dificuldades $\mathrm{e}$ gargalos enfrentados, atualmente, este papel não esteja sendo realizado. No Brasil, país subdesenvolvido, em que a maior parte da população apresenta grandes dificuldades de adquirir os medicamentos de que necessita, o controle de preços deve ser melhorado e fortalecido, para cumprir a função de promover a assistência farmacêutica.

\footnotetext{
${ }^{421}$ Informação fornecida por assessores da Secretaria-Executiva da CMED, em entrevista realizada em Brasília, em 5 de julho de 2012 (vide transcrição do áudio da entrevista com assessores da SecretariaExecutiva da CMED, no Anexo C).
} 


\section{REFERÊNCIAS*}

* De acordo com:

UNIVERSIDADE DE SÃO PAULO. Sistema Integrado de Bibliotecas da USP. Diretrizes para a apresentação de dissertações e teses da USP: documento eletrônico e imprsso Parte I (ABNT)/Sistema Integrado de Bibliotecas da USP; Vânia Martins Bueno de Oliveira Funaro, coordenadora. et. al. $2^{\mathrm{a}}$ ed. rev. ampl. São Paulo: Sistema Integrado de Bibliotecas da USP, 2009. 102 p. Cadernos de Estudo 9.

ADAMSON, D. M. Regulating drug prices. Disponível em:<http://www.rand.org/pub/research_briefs/RB9412/index1.html>. Acesso em: 12 nov. 2010.

ALÉM, Ana Claudia. Finanças públicas. São Paulo: Campus Elsevier, 2001.

ALENCAR, R. S. de. Medicamentos no Brasil: uma análise crítica da dinâmica técnicasetorial (1996-2006). 2007. Dissertação (Mestrado em Desenvolvimento Sustentável) Centro de Desenvolvimento Sustentável, Universidade de Brasília, Brasília, 2007.

AMORIM, M. C. S. Regulação dos preços e acesso ao consumo de medicamento no Brasil. In: ANTAS JR., R. M. Os desafios do consumo. Petrópolis: Vozes, 2007. p. 133138.

ANDRADE, A.; ANDRADE, C.A.P.; UILIAM, F.O. Controle de preços de remédios. Disponível em: <http://intertemas.unitoledo.br/revista/index.php/ETIC>. Acesso em: 20 fev. 2011.

ANDRADE, M.; LISBOA, M. Regulação do setor de saúde no Brasil. Rio de Janeiro: EPE/FGV, 2001.

ANGELL, M. A verdade sobre os laboratórios farmacêuticos. São Paulo: Record, 2007. 
BATISTA, L. B. Regulação econômica do mercado farmacêutico brasileiro. Dissertação (Mestrado em Direito). Universidade Cândido Mendes, Rio de Janeiro, 2005.

BAPTISTA, F. Regulação econômica do mercado farmacêutico. Disponível em: <http://idec.org.br/pdf/fernando-baptista.pdf>. Acesso em: 27 out. 2009.

BARROS, Henrique. M. Motivations to patent: the case of pharmaceuticals. REAd, Porto Alegre, v.14, n.3, set./dez.2008.

BASSO, Maristela. et al. Direitos de propriedade intelectual \& saúde pública: o acesso universal aos medicamentos anti-retrovirais no Brasil. São Paulo: Instituto de Direito do Comércio Internacional e Desenvolvimento -IDCID, 2007.

BELTRAME, A. Ampliação do acesso a medicamentos de alto custo: uma análise da política brasileira, 2002. Dissertação (Mestrado em Administração de Saúde) - Instituto de Medicina Social, Universidade do Estado do Rio de Janeiro, Rio de Janeiro.

BERNDT, E.; PINDYCK, R.S.; AZOULAY, P. Consumption externalities and diffusion in pharmaceutical markets: antiulcer drugs. Journal of Industrial Economics, Marshall, v. LI, n. 2, p.243-270, jun. 2003.

BERMUDEZ, J. A. Z. Indústria farmacêutica, estado e sociedade: análise crítica da política de medicamentos no Brasil, 1995. Tese (Doutorado em Saúde Pública) - Escola Nacional de Saúde Pública, FIOCRUZ, Rio de Janeiro.

BIROLI, A.V.R.; GALVÃO, R.G. Controle de preços de remédios. Disponível em: <www.intertemas.unitoledo.br/revista/index.php/ETIC/article/viewFile/.../2120>. Acesso em: 20 fev. 2011.

BRASIL Agência Nacional De Telecomunicações. Concentração do mercado de SMP. Dispoinível em: <http://www.anatel.gov.br/Portal/verificaDocumentos/documento.asp?numeroPublicacao> . Acesso em 5 jan. 2013. 
BRASIL. Agência Nacional De Vigilância Sanitária- ANVISA. Informes sobre regulação de medicamentos e sistema de infecção hospitalar. Disponível em: <http://www.scielosp.org/pdf/rsp/v38n1/18467.pdf.> Acesso em: 20 jul. 2010.

- Medicamentos - conceitos técnicos. Disponível em: <http://www.anvisa.gov.br/medicamentos/conceito.htm\#1.15>. Acesso em: $20 \mathrm{dez}$. 2012.

Política vigente para regulamentação de medicamentos no Brasil.

Disponível em: <http://www.anvisa.gov.br/medicamentos/manual_política_medicamentos.pdf.> Acesso em: 20 jul 2010.

Regulação e defesa do consumidor. Disponível em: <portal.anvisa.gov.br>. Acesso em: 28 fev. 2011.

Regulação econômica do mercado farmacêutico. Disponível em: <www.scribd.com/.../Regulacao-Economica-do-Mercado-Farmaceutico>. Acesso em: 03 mar. 2011.

BRASIL. Instituto Brasileiro de Geografia e Estatística - IBGE. Pesquisa de orçamentos familiares. 2009. Disponível em: 〈www.ibge.gov.br>. Acesso em 12 nov. 2012.

Pesquisa de orçamentos familiares. 2008. Disponível em: <www.ibge.gov.br>. Acesso em 12 nov. 2012.

Pesquisa de orçamentos familiares. 2007. Disponível em: <www.ibge.gov.br>. Acesso em 12 nov. 2012.

Pesquisa nacional por amostra de domicílios. 2003. Disponível em: <www.ibge.gov.br>. Acesso em 12 nov. 2012. 
BRASIL. Instituto Nacional da Propriedade Intelectual -INPI. Guia prático: patentes. Disponível em: <http://www.inpi.gov.org> Acesso em 18 jan. 2012

Guia básico: marcas. Disponível em: <www.inpi.gov.br> Acesso em: 18 jan. 2012

BRASIL. Ministério da Saúde. Programa Farmácia Popular. Disponível em:< http://bvsms.saude.gov.br/bvs/publicacoes/farmacia_popular_manual_sistema_copagament o_2ed.pdf>. Acesso em: 7 jan.2012.

BRASIL. Supremo Tribunal Federal. Recurso ordinário em mandado de segurança ${ }^{\circ}$ 26575. Recorrente: Novo Nordisk Farmacêutica do Brasil Ltda. Recorrido: União. Relator: Ministro Luiz Fux. Brasília 20 de abril de 2007. Disponível em: <http://www.stf.jus.br/portal/processo/verProcessoAndamento.asp?incidente=2509385 >. Acesso em: 5 set. 2012.

BRASIL. Superior Tribunal de Justiça. Mandado de segurança $\mathbf{n}^{\circ}$ 11706-DF (2006/0075344-0). Impetrante: Novo Nordisk Farmacêutica do Brasil LTDA. Impetrado: Ministro do Estado da Saúde. Relator: Ministro Castro Meira. Brasília, 17 de abril de 2006. Disponível em: <http://www.stj.jus.br/webstj/processo/Justica/detalhe.asp?numreg=200600753440\&pv=0 $10000000000 \&$ tp=51>. Acesso em: 5 set. 2012

Mandado de segurança $n^{\circ}$ 12730-DF (2007/0068561-2). Impetrante: Associação da Indústria Farmacêutica de Pesquisa (INTERFARMA). Impetrado: Ministro do Estado da Saúde. Relatora: Ministra Eliana Calmon. Brasília, 28 de março de 2007. Disponível em: <http://www.stj.jus.br/webstj/processo/Justica/detalhe.asp?numreg=200700685612\&pv=0 10000000000\&tp=51>. Acesso em: 5 set. 2012

BRONFENBRENNER, M. Price control under imperfect competition. American economic review, Pittsburgh, v. 17, n.1, p.107-120, mar. 1947. 
CALDAS, M. A. E. Estudos de revisão de literatura: fundamentação e estratégia metodológica. São Paulo: Hucitec, 1986.

CALIARI, T.; RUIZ R. Structure and innovation in pharmaceutical industry in Brazil: the impact of generic drugs. Paper apresentado na Academia DRUID - DIME, inverno de 2010. Disponível em:<http://petecounb.files.wordpress.com/2012/05/teste12.pdf >. Acesso em: 12 jan. 2013.

CÂMARA, M.R.G. Indústria farmacêutica: grupos estratégicos, tecnologia e regulamentação: a experiência brasileira em debate, 1993. Dissertação (Doutorado em Economia) - Faculdade de Economia, Administração e Contabilidade, Universidade de São Paulo, São Paulo.

.; OLIVEIRA, A.L.R.; GODOY, M.R.G. O controle de preços na indústria farmacêutica no Brasil. Disponível em: <www.bnb.com.br/content/aplicacao/ETENE/Anais/.../2004-o-controle. pdf.>Acesso em: 20 fev. 2011.

CÂMARA DOS DEPUTADOS DA REPÚBLICA FEDERATIVA DO BRASIL. Relatório da CPI - Medicamentos: relatório final da comissão parlamentar de inquérito destinada a investigar reajustes de preços e a falsificação de medicamentos, materiais hosppitalares e insumos laboratoriais. Brasília: Câmara dos Deputados, 2000.

CAMARGO DE JESUS, P.R. A presença do medicamento ético na mídia de massa. Artigo apresentado no Congresso Brasileiro de Comunicação Empresarial. Disponível em: <http://www.comtexto.com.br/convicomartigopropPaulaRenata.htm>. Acesso em 12 jan. 2012.

CAPANEMA, L. X. de. A indústria farmacêutica brasileira e a atuação do BNDES. BNDES Setorial, Rio de Janeiro, n.23, p.193-216, mar.2006. 
; PALMEIRA FILHO, P. L. Indústria farmacêutica brasileira: reflexões sobre sua estrutura e potenciais de investimento in TORRES FILHO, E.T.; PUGA, F.P. Perspectivas do investimento 2007/2010. Rio de Janeiro: BNDES, p. 163-206, 2007.

.; P.L. PIERONI, J.P. Apoio do BNDES ao complexo industrial da saúde: a experiência do PROFARMA e seus desdobramentos. BNDES Setorial, Rio de Janeiro, n. 27, p. 3-20, mar. 2008.

CONSIDERA, C. M. Uma breve história da economia política da defesa da concorrência.

<www.seae.fazenda.gov.br/central_documentos/.../doctrab22.pdf>. Acesso em 4 jun.2011.

CORREIA DA SILVA, R.A. Regulamentação econômica da saúde: Constituição de 1988, CMED, ANVISA, ANS e CADE. São Paulo: LCTE, 2008.

COUTINHO, D. R. Linking promises to policies: Law and development in an unequal Brazil. The Law and Development Review. Berkeley, v.3, n.2, artigo 2, 2010.

O direito nas políticas públicas. A ser publicado em Eduardo Marques e Carlos Aurélio Pimenta de Faria (eds.) 'Política Pública como Campo Disciplinar', São Paulo, Ed. Unesp, no prelo.

. Entre eficiência e equidade: a universalização das telecomunicações em países em desenvolvimento. Revista Direito GV. São Paulo, v.1, n.2, p. 137-160, jun/dez. 2005.

Regulação e redistribuição: a experiência brasileira de universalização das telecomunicações. São Paulo, 2003. Tese (Doutorado em Direito) - Faculdade de Direito da Universidade de São Paulo, São Paulo.

CREDENDIO, J. E.; PINHO, A. Laboratório boicota remédio com desconto. Folha de S.Paulo, São Paulo, 4 abr. 2011,. Cotidiano, Caderno 3, p.3. 
DALEN, D.M.; STRØM, S.; Haabeth, T. Price regulation and generic competition in the pharmaceutical market. European Journal of Health Economics, v. 7, n. 3, p. 208-214, set. 2006.

DANZON, P. Making sense of drug prices. Regulation, Washington D.C., v.23, n.1, p.5663. 2000 .

.; WANG, Y. R.; WANG, L. The impact of price regulation on the launch delay of new drugs. Health Economics, Washington D.C., v.14, n.3, p.269-292, mar. 2005.

D’ÁVILA, R.L. Revista ser médico. São Paulo, 2007. Disponível em: <www.cremesp.org.br/?siteAcao=Revista\&id=336>. Acesso em: 18 dez.2012.

DIAS, C. R. C.; ROMANO-LIEBER, N. S. Processo de implantação da política de medicamentos genéricos no Brasil. Cadernos de Saúde Pública, Rio de Janeiro, v.22, n.8,p. 1661-1669, ago. 2006.

DIMASI, J. A. et al. Cost of innovation in the pharmaceutical industry. Journal of Health Economics, Boston, v.10, n.2, p. 107-142, jul. 1991.

DI PIETRO, M. S. Z. Direito administrativo. 19ª ed. São paulo: Atlas, 2006.

DOIS gargalos na saúde: financiamento e acesso a medicamentos. Publicado em 07/12/2010. Disponível em <http://www.sindifarmajp.com.br/noticias.php?not_id=3190> Acesso em: 01 abr.2011.

ESTADOS UNIDOS DA AMÉRICA. Congresso dos Estados Unidos da América, Research and development in the pharmaceutical industry. Estudo realizado pelo Departamento de Orçamento do Congresso (Congressional Budget Office - CBO), em outubro de 2006 
. Department of Health and Human Services: Office of Inspector General, The Orphan Drug Act, implementation and impact. Disponível em: http://oig.hhs.gov/oei/reports/oei-09-00-00380.pdf. Acesso em: 29 mai. 2012.

FAGAN, P. As gigantes farmacêuticas: prontas para o século XXI? Cambridge: Harvard Business School, 1998.

FEBRAFAR. Lideranças empresariais apóiam redução do ICMS nos medicamentos. Disponível em: <http://www.ibpt.com.br/home/publicacao.view.php?publicacao_id=14406\&PHPSESSID $=6 \mathrm{c} 09 \mathrm{c} 02806 \mathrm{dfb} 5 \mathrm{dd} 09 \mathrm{c} 0 \mathrm{ea} 91 \mathrm{f} 9161 \mathrm{~d} 8 \mathrm{e}>$. Acesso em: 21 ago. 2012

FERRAZ, O. L.; VIEIRA, F. S. Direito à saúde, políticas públicas e desigualdades sociais no Brasil: a equidade como princípio fundamental. Paper apresentado na Faculdade de Direito da Universidade de São Paulo, em setembro de 2007.

FIUZA, E.; LISBOA, M. Bens credenciais e poder de mercado: um estudo econométrico da indústria farmacêutica brasileira. Disponível em: <http://www.ipea.gov.br/pub/td/2001/td_0846.pdf.> Acesso em: 22 jul. 2010.

FOLLADOR, W. Alguns aspectos da variação de preços de medicamentos no Brasil no período de 1980 a 2001, 2001. Dissertação (Mestrado em Ciências Farmacêuticas) Faculdade de Ciências Farmacêuticas, Universidade de São Paulo, São Paulo.

FRANK, R. G. Government commitment and regulation of prescription drugs. Health Affairs, Bethesda, v. 22, n.3, p. 46-58, mai./jun. 2003.

FRENKEL, J. O mercado farmacêutico brasileiro: a sua evolução recente, mercados e preços. In: NEGRI, B; DI GIOVANNI, G. Brasil: radiografia da saúde. Campinas: UNICAMP, 2001. p. 157-174.

GAETANI, F.; ALBUQUERQUE, K. Análise de impacto regulatório e melhoria regulatória. In: BRASIL. Agência Nacional de Vigilância Sanitária - ANVISA. 
RAMALHO, P. I. S. (Org.). Regulação e agências reguladoras: governança e análise de impacto regulatório. Brasília: Anvisa, 2009.

GARNETT, G. Medicamentos e a carga tributária. Disponível em: <http://www.conexaoitajuba.com.br/itajuba/Pagina.do;jsessionid=h0298s51f76f?idSec $\mathrm{ao}=141 \& \mathrm{idNoticia}=27108>$. Acesso em: 21 ago.2012.

GÉLEDAIN, A.; BRÉMOND, J. Dicionário econômico e social. Lisboa: Livros Horizonte, 1988.

GODOY, M. R.; OLIVEIRA, A. L. R. de; CÂMARA, M. R. G. O controle de preços na $\begin{array}{llll}\text { indústria } & \text { farmacêutica } & \text { do } & \text { Brasil. }\end{array}$ www.bnb.gov.br/content/aplicacao/ETENE/Anais/.../2004-o-controle-.pdf. Acesso em: 4 jun.2011.

GOLDBERG. S. Brasileiro gasta muito na compra de medicamentos. Valor Econômico, Rio de Janeiro, 9 jun.2010, Caderno Especial (F), p.2.

GOMES, C.A.P. A assistência farmacêutica no Brasil: análise e perspectivas. Disponível em: <www.cgee.org.br/arquivos/rhf_p1_af_carlos_gomes.pdf〉. Acesso em: 22 fev. 2011

GRACE, C. Equitable pricing of newer essential medicines for developing countries: evidence for the potential of different mechanisms. Genebra: Organização Mundial da Saúde (OMS), 2003.

GRAU, E. R. A ordem econômica na Constituição de 1988. 13ª. ed. São Paulo: Malheiros, 2008

. Tabelamento de preços. Revista de Direito Público, São Paulo, v.21, n.85, p. $100-108$, jan/mar. 1988 .

HASENCLEVER, L. O mercado de medicamentos genéricos no Brasil. Paper preparado para o Simpósio Franco-Brasileiro "O novo direito da propriedade intelectual no domínio 
da saúde e dos seres vivos (implicações para o acesso aos tratamentos anti-retroviraris), em Brasília (DF), junho de 2004.

HASSET, K.A. Price controls and the evolution of pharmaceutical markets. Journal of Public Health Policy, Brisbane, v. 29, p.106-120. 2008.

INSTITUTO BRASILEIRO DE DEFESA DO CONSUMIDOR - IDEC. Remédio pro bolso.

Disponível

em:<www.idec.org.br/rev_idec_texto_impressa.asp?pagina=1\&ordem=1\&id=980>.

Acesso em: 20 fev. 2011

. Remédio pro bolso. Revista do IDEC. São Paulo, n. 130, p.16-20, mar. 2009.

. Meio cheio ou meio vazio? Revista do IDEC. São Paulo, n.142, p. 22-25, abr. 2010.

Diferença além da conta. Revista do IDEC. São Paulo, n.162, p.16-19, fev. 2012

Faltam remédios essenciais no SUS. Disponível em: <http://www.idec.org.br>. Acesso em: 22 jun. 2011.

JENA, A.B. Cost-effectiveness as a price control. Heath Affairs, Bethesda, v.26, n.3, p.696-703. 2007.

KANAVOS, P. Overview of pharmaceutical pricing and reimbursement regulation in Europe. Londres: LSE Health, 2002.

KORNIS, G. E.; BRAGA, M. H.; ZAIRE, C. E. Os marcos legais das políticas de medicamentos no Brasil contemporâneo (1990-2006). Revista APS, São Paulo, v.11, n.1, p.85-99, jan./mar. 2008. 
KRIEGER, G.; ALBERTO JR. C. O truque dos importados. Disponível em: $<$ http://revistaepoca.globo.com/Revista/Epoca/0,,EMI160425-15259,00>. Acesso em: 13 mai. 2011.

LISBOA, M.; FIÚZA, E.; VIEGAS, M.; FERRAZ, L. Política governamental e $\begin{array}{lllll}\text { regulação do mercado de medicamentos. } & \text { Disponível }\end{array}$ em:<www.seae.fazenda.gov.br/central.../doctrab08.pdf > . Acesso em: 19 dez.2012.

LODGE, M. Accountability and transparency in regulation: critiques, doctrines and instruments. In: Jordana, Jacint and Levi-Faur, David, (eds.). Politics of Regulation: CRC Series on Competition, Regulation and Development . Londres: Edward Elgar Publishing, Cheltenham, 2004. pp. 124-144.

MACHADO DOS SANTOS, C. S. M. Melhoria na equidade no acesso aos medicamentos no Brasil: os desafios impostos pela competição extra-preço, 2001. Dissertação (Mestrado em Saúde Pública) - Escola Nacional de Saúde Pública, FIOCRUZ, Rio de Janeiro.

MAGAJEWSKI, F. L.; CURCIO, A. L. M. C. Direito de propriedade industrial: Uma Proposta de Regime Jurídico Especial às Patentes de Medicamentos. Disponível em: <http:// www.conpedi.org.br/anais/36/06_1423.pdf> . Acesso em: 15 mai.2012.

MARQUES NETO, F. A. Agências reguladoras independentes: fundamentos e seu regime jurídico. Belo Horizonte: Fórum, 2005.

MARTINS, H. T. S. Metodologia qualitativa de pesquisa. Educação e Pesquisa, São paulo, v.10, p.289-300, mai./ago. 2004.

MAYNARD, A.; BLOOR, K. Dilemas in regulation of the market for pharmaceuticals.Health Affairs, Bethesda, v.22, n.3, p.31-45, maio/jun. 2003.

; FREEMANTLE, N. Lessons from international experience in controlling pharmaceutical expenditure III: regulating industry. British Medical Journal, London, $\mathrm{n}$. 7048, v. 313, p.33-35, jul. 1996. 
MINISTÉRIO DO DESENVOLVIMENTO, DA INDÚSTRIA E DO COMÉRCIO EXTERIOR; et al. Diretrizes da política industrial, tecnológica e de comércio exterior. Disponível em: <www.ipea.gov.br/sites/000/2/download/diretrizes_oficial.pdf>. Acesso em: 9 dez. 2012.

MPF recorre de decisão que limita desconto na venda de medicamentos ao poder público. Disponível em: <http://www.prsp.mpf.gov.br/sala-de-imprensa/noticias_prsp/1212-11-2013>. Acesso em: 18 ago. 2012.

MOSSIALOS, E. Associação Portuguesa de Economia da Saúde. Regulação das despesas com medicamentos nos países da União Européia. Lisboa, 1998. Disponível em:< www.apes.pt/files/dts/dt_011998.pdf >. Acesso em: 27 dez. 2012.

MRAZEK, M.F. Comparative Approaches to Pharmaceutical Price Regulation in the European Union. CMJ, Zagreb, n. 4, v.43, p. 371-515, ago. 2002.

NEVES, J. L. Pesquisa qualitativa - características, usos e possibilidades. Disponível em: <www.ead.fea.usp.br/cad-pesq/arquivos/c03-art06.pdf>. Acesso em: 22 fev. 2011.

NIËNS. L. M.; et al. Quantifying the impoverishing effects of purchasing medicines: a cross-country comparison of the affordability of medicines in the developing world. PLoS Med, v.7, n.8, p.1-8, ago. 2010

NISHIJIMA, M. Análise econômica dos medicamentos genéricos no Brasil. 2003. Tese (Doutorado em Economia) - Faculdade de Economia, Administração e Contabilidade, Universidade de São Paulo, São Paulo.

NÓBREGA, O.T. et al. Retail prices of essential drugs in Brazil: an international comparison. Revista Panamericana de Salud Pública, Santiago, v.22, n.2. 2007

NORONHA, Daisy Pires; FERREIRA, Sueli Mara S. P. Revisões de literatura.In: CAMPELLO, Bernadete Santos; CONDÓN, Beatriz Valadares; KREMER, Jeannette 
Marguerite (orgs.) Fontes de informação para pesquisadores e profissionais. Belo Horizonte:UFMG, 2000.

OLIVEIRA, R. R. Os conceitos de regulação em saúde no Brasil, 2010. Dissertação (Mestrado em Medicina) - Faculdade de Medicina, Universidade de São Paulo, São Paulo.

ORGANIZAÇÃO MUNDIAL DA SAÚDE. Precios de los medicamentos: una nueva forma de medirlos.

Disponível em:<http://apps.who.int/medicinedocs/en/d/Js6163s/2.5.html>. Acesso em 27 mar. 2012.

The world medicines situation. Disponível em: $<$ http://www.who.int/medicines/areas/policy/world_medicines_situation/en/index.html.>. Acesso em: 27 mar. 2012

; ORGANIZAÇÃO PAN-AMERICANA DA SAÚDE; MINISTÉRIO DA SAÚDE. Avaliação da assistência farmacêutica no Brasil: estrutura, processo e resultados. Brasília: OPAS/OMS, 2005.

ORGANIZAÇÃO PAN-AMERICANA DA SAÚDE - OPAS. Assistência farmacêutica para gerentes municipais. 2003. Disponível em: <http://www.opas.org.br/medicamentos>. Acesso em: 20 dez. 2012.

OXFAM. Briefing paper: patents versus patients. Disponível em: <http://www.dochas.ie>. Acesso em: 30 jun. 2011.

PAVCNIK, N. Do pharmaceutical prices respond to insurance? Disponível em: < http://www.nber.org/papers/w7865.pdf>. Acesso em: 29 mai. 2012.

PANIZ, V. M. V. et al. Acesso a medicamentos de uso contínuo em adultos e idosos nas regiões Sul e Nordeste do Brasil. Cadernos de Saúde Pública, Rio de Janeiro, v.24, n.2, p.267-280, fev. 2008. 
PHILLIPS, B.S. Pesquisa social: estratégias e táticas. Rio de Janeiro: Agir, 1974. 460p.

PIRES J. L. ; PICCININI M. S., Modelos de regulação tarifária do setor elétrico. In: BNDES. Modelos de regulação tarifária: a experiência internacional e o caso brasileiro.

PORTELA, A. S. et al. Políticas públicas de medicamentos: trajetórias e desafios. Revista de Ciências Farmacêuticas Básica e Aplicada, São Paulo, v.31, n.1. p. 9-14, abr. 2010.

RASCATI, K.L. Essentials of pharmacoeconomics: an introduction. Philadelphia: Lippincott Williams Wilki, 2009. 250 p.

RÊGO, E.C.L. Políticas de regulação do mercado de medicamentos: a experiência internacional. Revista do BNDES, Rio de Janeiro, v.7, n.14, p.367-400, dez. 2000. p. 373.

ROMANO, L.A.N. Intervenção e regulação no Brasil: a indústria farmacêutica. São Paulo: FEBRAFARMA, 2005.

.; NICOLINA, S. Política de medicamentos. Mundo Saúde, São Paulo, v.24, n.1, p.45-50, jan/fev.2000.

ROMANO, R.; BERNARDO, P. J. B. Padrões de regulação de preços do mercado de medicamentos: experiência brasileira dos anos 90 e novos arranjos institucionais. In: NEGRI, B.; DI GIOVANNI, G. Brasil: radiografia da saúde.Campinas: UNICAMP, 2001. p. $445-464$.

ROSENBERG, B. Patentes de medicamentos e comércio internacional: os parâmetros do TRIPS e do direito concorrencial para a outorga de licenças compulsórias. 2004. 290 p. Tese (Doutorado em Direito) - Faculdade de Direito, Universidade de São Paulo, São Paulo.

ROSENBERG, G.; FONSECA, M.G.D; D’ÁVILA L.A. Análise comparativa da concentração industrial e de turnover da indústria farmacêutica no Brasil para os 
seguimentos de medicamentos de marca e genéricos. Economia e Sociedade, Campinas, v.19, n. 1(38), 107-134, abr.2010. p. 130.

SAFATLE et al. Procedimentos para a definição e análise antitruste de mercados relevantes de medicamentos. Disponível em: <portal.mj.gov.br/.../FileDownload.EZTSvc.asp?>. Acesso em: 26 dez. 2012.

SAIANDA, A. Constrangimentos à prescrição. Disponível em : <http://www.semanamedica.com>. Acesso em: 4 de jun. 2011.

SALOMÃO FILHO, C. Regulação e desenvolvimento. In: SALOMÃO FILHO, Calixto (coord.) Regulação e desenvolvimento. São Paulo: Malheiros, 2002. p. 29-63.

Razoabilidade e legalidade do licenciamento compulsório do ponto de vista concorrencial. In: BASSO, M. et al. Direito da propriedade intelectual e saúde pública: o acesso universal aos medicamentos anti-retrovirais. São Paulo: Instituto de Direito do Comércio Internacional e Desenvolvimento -IDCID, 2007. p.155

Regulação da atividade econômica: princípios e fundamentos jurídicos. São Paulo: Malheiros, 2001.

SÃO PAULO (Estado). Conselho Regional de Medicina do Estado de São Paulo CREMESP. CPI dos Medicamentos. Disponível em: $<$ http://www.cremesp.com.br/?siteAcao=PublicacoesConteudoSumario\&id=65>. Acesso em: 28 mar. 2012.

\section{Médicos reprovam acordo do Conselho Federal com a indústria}

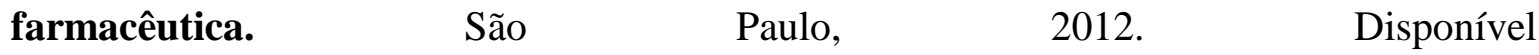
em:<www.viomundo.com.br/denuncias/medicos-reprovam-acordo-do-cfm-com-aindustria-farmaceutica.html>. Acesso em 18 dez. 2012

.; SÃO PAULO (Estado). Conselho Regional de Farmácia do Estado de São Paulo (CRF-SP); INSTITUTO BRASILEIRO DE DEFESA DO CONSUMIDOR (IDEC). 
Medicamento: um direito essencial. São Paulo, 2008. Disponível em:〈http://www.fabry.org.br/doc/publi/arquivo4.pdf>. Acesso em: 4 jan. 2013.

SÃO PAULO (Estado). Fundação de defesa e proteção do consumidor. Pesquisa comparativa de preços de medicamentos, São Paulo, maio 2010. Disponível em: <http://www.procon.sp.gov.br/categoria.asp?id=903>. Acesso em: 4 set. 2012.

Pesquisa comparativa de preços de medicamentos, São Paulo, maio 2011. Disponível em: <http://www.procon.sp.gov.br/categoria.asp?id=903>. Acesso em: 4 set. 2012.

Pesquisa comparativa de preços de medicamentos, São Paulo, maio 2012. Disponível em: <http://www.procon.sp.gov.br/categoria.asp?id=903>. Acesso em: 4 set. 2012.

Pesquisa comparativa de preços de medicamentos, Araçatuba, maio 2011. Disponível em: <http://www.procon.sp.gov.br/categoria.asp?id=903>. Acesso em: 4 set. 2012.

Pesquisa comparativa de preços de medicamentos, Bauru, maio 2011. Disponível em: <http://www.procon.sp.gov.br/categoria.asp?id=903>. Acesso em: 4 set. 2012.

Pesquisa comparativa de preços de medicamentos, Caçapava, maio 2011. Disponível em: <http://www.procon.sp.gov.br/categoria.asp?id=903>. Acesso em: 4 set. 2012.

Pesquisa comparativa de preços de medicamentos, Campinas, maio 2011. Disponível em: <http://www.procon.sp.gov.br/categoria.asp?id=903>. Acesso em: 4 set. 2012.

Pesquisa comparativa de preços de medicamentos, Jundiaí, maio 2011. Disponível em: <http://www.procon.sp.gov.br/categoria.asp?id=903>. Acesso em: 4 set. 2012. 
Pesquisa comparativa de preços de medicamentos, Marília, maio 2011.

Disponível em: <http://www.procon.sp.gov.br/categoria.asp?id=903>. Acesso em: 4 set. 2012.

Pesquisa comparativa de preços de medicamentos, Presidente Prudente, maio 2011. Disponível em: <http://www.procon.sp.gov.br/categoria.asp?id=903>. Acesso em: 4 set. 2012.

Pesquisa comparativa de preços de medicamentos, Santos, maio 2011.

Disponível em: <http://www.procon.sp.gov.br/categoria.asp?id=903>. Acesso em: 4 set. 2012.

. Pesquisa comparativa de preços de medicamentos, São José dos Campos, maio 2011. Disponível em: <http://www.procon.sp.gov.br/categoria.asp?id=903>. Acesso em: 4 set. 2012.

Pesquisa comparativa de preços de medicamentos, Sorocaba, maio 2011.

Disponível em: <http://www.procon.sp.gov.br/categoria.asp?id=903>. Acesso em: 4 set. 2012.

Pesquisa comparativa de preços de medicamentos, Taubaté, maio 2011.

Disponível em: <http://www.procon.sp.gov.br/categoria.asp?id=903>. Acesso em: 4 set. 2012.

SAUTU, R. et al. Manual de metodologia: construcción del marco teórico, formulación de los objetivos y elección de la metodologia. Buenos Aires: CLACSO, 2006. 187 p.

SECOLI, S.R. et al. Farmacoeconomia: perspectiva emergente no processo de tomada de decisão. Revista Ciência e Saúde Coletiva, Rio de Janeiro, v.10, p. 287-297, set-dez. 2005. 
SCHEDLER, A. Conceptualizing Accountability. In: SCHEDLER, A.; DIAMOND, L.; PLATTNER, M. (Eds.). The self restraining state: Power and Accountability in New Democracies. Boulder: Lynne Rienner Publishers, 1999.

SCHERER, F. M. Pricing, Profits and Technological Progress in the Pharmaceutical Industry. Journal of Economic Perspectives, Nashville, v.7, n.3, p.97-115, summer. 1993.

SINDICATO DO COMÉRCIO VAREJISTA DE PRODUTOS FARMACÊUTICOS SINDIFARMA, Dois gargalos na saúde: financiamento e acesso a medicamentos. Disponível em: <http://www.sindifarmajp.com.br/noticias.php?not_id=3190> . Acesso em 29 mai. 2011.

SILVA, R. G. ENC: Universidade de São Paulo - Informação por escrito [mensagem pessoal]. Mensagem recebida por<nathalia.miziara@usp.br> em 9 nov. 2012.

TEIXEIRA, L. S. Reajustes de preços administrados no setor da saúde - consultoria legislativa (2006), jul. 2010.

VARGAS, M. A. et al. Reestruturação na indústria farmacêutica mundial e seus impactos na dinâmica produtiva e inovativa do setor farmacêutico brasileiro. Disponível em:<http://www.fiocruz.br> Acesso em: 12 jan. 2012.

VENTURI, C. B. et al. Política de patentes e o direito da concorrência. In: Política de patentes em saúde humana. SANTINI, M. F.; ARANHA, M. I. (orgs.). São Paulo: Atlas, 2001, p.154-189.

VIANNA, S.M.; PIOLA, S.F.; REIS, C.O.O. Gratuidade no SUS: controvérsia em torno do co-pagamento. Instituto de Pesquisa Econômica Aplicada - IPEA. Brasília, 1998. Disponível em:<www.ipea.gov.br/pub/td/td_587.pdf >. Acesso em: 19 dez. 2012. 
VIANNA, C.M.M.; et al. Programas de benefício farmacêutico: experiências nacionais na área de saúde suplementar. Disponível em: <www.ans.gov.br/...saude/atencaoasaude/...>. Acesso em: 17 dez. 2012.

WORLD INTELLECTUAL PROPERTY ORGANIZATION - WIPO. Anual report 2000. Disponível em: <http:// wipo.int>. Acesso em: 22 jun. 2011.

ZOCKUN, M. Controle de preços de medicamentos pela CMED In: Revista Trimestral de Direito Público. 51 a e $2^{\mathrm{a}}$. ed. São Paulo: Malheiros, 2009.

\section{Legislacão consultada:}

BRASIL. Agência Nacional de Vigilância Sanitária. Resolução ANVISA/RDC nº 16, de 2 de março de 2007. Aprova o Regulamento Técnico para Medicamentos Genéricos, anexo I. Acompanha esse Regulamento o Anexo II, intitulado "Folha de rosto do processo de registro e pós-registro de medicamentos genéricos". Disponível em: <http://portal.anvisa.gov.br/wps/content/Anvisa+Portal/Anvisa/>. Acesso em: 4 jan. 2013.

BRASIL. Agência Nacional de Vigilância Sanitária. Resolução ANVISA/RDC n 96, de 17 de dezembro de 2008. Dispõe sobre a propaganda, publicidade, informação e outras práticas cujo objetivo seja a divulgação ou promoção comercial de medicamentos. Disponível

em: <http://portal.anvisa.gov.br/wps/wcm/connect/7504330048d1c2a2b2eebba3f2835ae8/Reso lucao_96_2008_consolidada_final_site_setembro2010.pdf?MOD=AJPERES >. Acesso em 4 jan. 2013.

BRASIL. Agência Nacional de Vigilância Sanitária. Resolução ANVISA/RDC n 102 , de 30 de novembro de 2000. Aprova o Regulamento sobre propagandas, mensagens publicitárias e promocionais e outras práticas cujo objeto seja a divulgação, promoção ou comercialização de medicamentos de produção nacional ou importados, quaisquer que sejam as formas e meios de sua veiculação, incluindo as transmitidas no decorrer da programação normal das emissoras de rádio e televisão. Disponível em: <http://www.anvisa.gov.br/propaganda/legis.htm>. Acesso em: 7 jan. 2013. 
BRASIL. Agência Nacional de Saúde Suplementar. Resolução ANS/RN n 310, de 30 de outubro de 2012. Dispõe sobre os princípios para a oferta de contrato acessório de medicação de uso domiciliar pelas operadoras de planos de assistência à saúde. Disponível em:

$<$ http://www.ans.gov.br/index2.php?option=com_legislacao\&view=legislacao\&task=Text oLei\&format=raw\&id=2283>. Acesso em: 4 jan. 2013.

BRASIL. Conselho Federal de Farmácia (CFF). Resolução n ${ }^{\circ}$ 357, de 20 de abril de 2001. Aprova o regulamento técnico das Boas Práticas de Farmácia. Disponível em:< http://www.cff.org.br/pagina.php?id=252\&menu=\&titulo=Resolu\%C3\%A7\%C3\%B5es+d o+CFF+de+2004+a+2000>. Acesso em: 7 jan. 2013.

BRASIL. Conselho Federal de Medicina. Resolução n 1552 , de 17 de setembro de 1999. A prescrição de antibióticos nas unidades hospitalares obedecerá às normas emanadas da Comissão de Controle de Infecção Hospitalar-CCIH. Disponível em: <http://www.portalmedico.org.br/php/pesquisa_resolucoes.php\#>. Acesso em: 7 jan. 2013.

BRASIL. Conselho Federal de Medicina. Resolução n 1885 , de 22 de outubro de 2008. É vedado ao médico participar de pesquisa envolvendo seres humanos utilizando placebo, quando houver tratamento disponível eficaz já conhecido. Disponível em: <http://www.portalmedico.org.br/php/pesquisa_resolucoes.php\#>. Acesso em: 7 jan. 2013.

BRASIL. Decreto Presidencial n 63.196, de 29 de agosto de 1968. Dispõe sobre o sistema regulador de preços no mercado interno e dá outras providências. Revogado. Disponível em: $<\quad$ http://www2.camara.leg.br/legin/fed/decret/1960-1969/decreto-63196-29-agosto1968-404693-norma-pe.html>. Acesso em 4 jan. 2013.

BRASIL. Decreto Presidencial $\mathrm{n}^{\circ} 74.170$, de 10 de junho de 1974. Regulamenta a Lei número 5.991, de 17 de dezembro de 1973, que dispõe sobre o controle sanitário do comércio de drogas, medicamentos, insumos farmacêuticos e correlatos. Disponível em:< http://www.planalto.gov.br/ccivil_03/decreto/Antigos/D74170.htm>. Acesso em 4 jan. 2013. 
BRASIL. Decreto Presidencial $n^{\circ} 3961$, de 10 de outubro de 2001. Altera o Decreto $\mathrm{n}^{\circ}$ 79.094, de 5 de janeiro de 1977, que regulamenta a Lei $\mathrm{n}^{\circ} 6.360$, de 23 de setembro de 1976. Disponível em: <http://www2.camara.leg.br/legin/fed/decret/2001/decreto-3961-10outubro-2001-406199-publicacaooriginal-1-pe.html>. Acesso em 4 jan. 2013.

BRASIL. Lei ${ }^{\circ} 1.522$, de 26 de dezembro de 1951. Autoriza o Governo Federal a intervir no domínio econômico para assegurar a livre distribuição de produtos necessários ao consumo do povo. Revogada. Disponível em:< http://legislacao.planalto.gov.br/legisla/legislacao.nsf/Viw_Identificacao/lei\%201.5221951? OpenDocument>. Acesso em: 4 jan. 2013.

BRASIL. Lei n ${ }^{\circ}$ 5.991, de 17 de dezembro de 1973. Dispõe sobre o Controle Sanitário do Comércio de Drogas, Medicamentos, Insumos Farmacêuticos e Correlatos, e dá outras Providências. Disponível em:< http://www.planalto.gov.br/ccivil_03/leis/L5991.htm>. Acesso em: 7 jan. 2013.

BRASIL. Lei ${ }^{\circ}$ 6.360, de 23 de setembro d 1976. Dispõe sobre a vigilância sanitária a que ficam sujeitos os medicamentos, as drogas, os insumos farmacêuticos e correlatos, cosméticos, saneantes e outros produtos, e dá outras providências. Disponível em: <http://www2.camara.leg.br/legin/fed/lei/1970-1979/lei-6360-23-setembro-1976-357079norma-pl.html>. Acesso em: 7 jan. 2013.

BRASIL. Lei ${ }^{\circ}$ 6.437, de 20 de agosto de 1977. Configura infrações à legislação sanitária federal, estabelece as sanções respectivas, e dá outras providências. Disponível em: <http://www.planalto.gov.br/ccivil_03/leis/L6437.htm>. Acesso em: 7 jan. 2013.

BRASIL. Lei $\mathrm{n}^{\circ}$ 8.078, de 11 de setembro de 1990. Dispõe sobre a proteção do consumidor e dá outras providências. Disponível em: <http://www.planalto.gov.br/ccivil_03/leis/L8078.htm>. Acesso em: 4 jan. 2013. 
BRASIL. Lei $\mathrm{n}^{\circ}$ 9.279, de 14 de maio de 1996. Regula direitos e obrigações relativos à propriedade industrial. Disponível em: <http://www.planalto.gov.br/ccivil_03/leis/L9279.htm>. Acesso em: 4 jan. 2013.

BRASIL. Lei $\mathrm{n}^{\circ}$ 9.787, de 10 de fevereiro de 1999. Altera a Lei $\mathrm{n}^{\circ} 6.360$, de 23 de setembro de 1976, que dispõe sobre a vigilância sanitária, estabelece o medicamento genérico, dispõe sobre a utilização de nomes genéricos em produtos farmacêuticos e dá outras providências. Disponível em: <http://www.anvisa.gov.br/legis/leis/9787_99.htm>. Acesso em: 4 jan. 2013.

BRASIL. Lei ${ }^{\circ}$ 10.213, de 27 de março de 2001. Revogada. Define normas de regulação para o setor de medicamentos, institui a Fórmula Paramétrica de Reajuste de Preços - FPR, cria a Câmara de Medicamentos e dá outras providências. Disponível em: <http://www.planalto.gov.br/ccivil_03/leis/LEIS_2001/L10213.htm>. Acesso em: 4 jan. 2013.

BRASIL. Lei ${ }^{\circ} 10.742$, de 6 de outubro de 2006. Define normas de regulação para o setor farmacêutico, cria a Câmara de Regulação do Mercado de Medicamentos - CMED, e altera a Lei $\mathrm{n}^{\circ}$ 6.360, de 23 de setembro de 1976, e dá outras providências. Disponível em: <http://www.planalto.gov.br/ccivil_03/leis/2003/L10.742.htm>. Acesso em: 4 jan. 2013.

BRASIL. Ministério do Desenvolvimento, Indústria e Comércio Exterior. Câmara de Regulação do Mercado de Medicamentos. Resolução CMED n³, de 29 de julho de 2003. Disponível em: <http://portal.anvisa.gov.br/wps/portal/anvisa/anvisa/posuso/regulacaodemercado>. Acesso em: 4 jan. 2013.

BRASIL. Ministério do Desenvolvimento, Indústria e Comércio Exterior. Câmara de Regulação do Mercado de Medicamentos. Resolução CMED n ${ }^{\circ}$, de 27 de fevereiro de 2004. Disponível em: <http://portal.anvisa.gov.br/wps/portal/anvisa/anvisa/posuso/regulacaodemercado>. Acesso em: 4 jan. 2013. 
BRASIL. Ministério do Desenvolvimento, Indústria e Comércio Exterior. Câmara de Regulação do Mercado de Medicamentos. Resolução CMED n², de 5 de março de 2004. Disponível em: <http://portal.anvisa.gov.br/wps/portal/anvisa/anvisa/posuso/regulacaodemercado>. Acesso em: 4 jan. 2013.

BRASIL. Ministério do Desenvolvimento, Indústria e Comércio Exterior. Câmara de Regulação do Mercado de Medicamentos. Resolução CMED n 4 , de 18 de dezembro de 2006. Disponível em:

<http://portal.anvisa.gov.br/wps/portal/anvisa/anvisa/posuso/regulacaodemercado>. Acesso em: 4 jan. 2013.

BRASIL. Ministério do Desenvolvimento, Indústria e Comércio Exterior. Câmara de Regulação do Mercado de Medicamentos. Resolução CMED n¹, de 19 de março de 2007. Disponível em: <http://portal.anvisa.gov.br/wps/portal/anvisa/anvisa/posuso/regulacaodemercado>. Acesso em: 4 jan. 2013.

BRASIL. Ministério do Desenvolvimento, Indústria e Comércio Exterior. Câmara de Regulação do Mercado de Medicamentos. Resolução CMED n, de 18 de dezembro de 2006. Disponível em: <http://portal.anvisa.gov.br/wps/portal/anvisa/anvisa/posuso/regulacaodemercado>. Acesso em: 4 jan. 2013.

BRASIL. Ministério do Desenvolvimento, Indústria e Comércio Exterior. Câmara de Regulação do Mercado de Medicamentos. Resolução CMED n², de 19 de março de 2007. Disponível em: <http://portal.anvisa.gov.br/wps/portal/anvisa/anvisa/posuso/regulacaodemercado>. Acesso em: 4 jan. 2013.

BRASIL. Ministério da Saúde .Portaria $n^{0}$ 2.438/MS-GM, de 7 de dezembro de 2005, do Ministério da Saúde. Disponível em: 
<http://www.anvisa.gov.br/legis/consolidada/portaria_2438_05.pdf >. Acesso em: 4 jan. 2013.

BRASIL. Ministério da Saúde. Portaria n³.916/MS-GM, de 30 de outubro de 1998. Disponível em: <http://www.anvisa.gov.br/legis/consolidada/portaria_3916_98.pdf>. Acesso em: 4 jan. 2013.

BRASIL. Ministério da Saúde. Portaria n 687/MS-GM, de 30 de março de 2006. Aprova a política de promoção da saúde. Disponível em: <http://portal.saude.gov.br/portal/arquivos/pdf/Politica_nacional_\%20saude_nv.pdf>. Acesso em: 4 jan. 2013.

BRASIL. Ministério da Saúde. Portaria nº 698/MS-GM, de 30 de março de 2006. Define que o custeio das ações de saúde é de responsabilidade das três esferas de gestão do SUS, observado o disposto na Constituição Federal e na Lei Orgânica do SUS. Disponível em: <http://dtr2001.saude.gov.br/sas/PORTARIAS/Port2006/GM/GM-698.htm>. Acesso em: 4 jan. 2013.

BRASIL. Ministério da Saúde. Conselho Nacional de Saúde. Resolução CNS n 338, de 6 de maio de 2004. Aprova a Política Nacional de Assistência Farmacêutica do Ministério da Saúde. Disponível em: <http://conselho.saude.gov.br/resolucoes/reso_04.htm>. Acesso em: 4 jan. 2013.

ORGANIZAÇÃO MUNDIAL DO COMÉRCIO. Agreement on Trade-Related Aspects of Intellectual Property Rights. Disponível em: <http://www.wto.org/english/tratop_e/trips_e/t_agm0_e.htm>. Acesso em: 4 jan. 2013. 


\begin{abstract}
ANEXOS:
Anexo A: primeira entrevista com Ione Amorim, economista do IDEC e coordenadora das pesquisas de preços de medicamentos realizadas por essa instituição
\end{abstract}

(E): A CMED se baseia na produtividade das indústrias farmacêuticas para estabelecer seus critérios e padrões regulatórios. Mas uma das conclusões da pesquisa do IDEC "Remédio pro Bolso" foi de que "o preço final [dos medicamentos] tem muito mais a ver com o quanto um mercado aceita pagar do que com o custo de produção". Foi mencionado também que há países cujo custo de produção é maior e os preços menores. Considerando isso, o que levaria o mercado brasileiro ter mais disposição para pagar preços mais altos em medicamentos? (isso chegou a ser questionado na pesquisa que embasou o artigo?);

(I): Não foi realizado um aprofundamento sobre o comportamento do consumidor. A citação do Prof. José Rubem no caso do Reino Unido sobre elevado nível de escolha dos medicamentos genéricos é devido ao esclarecimento da população sobre as condições de produção desses produtos e o benefício dos preços.

No Brasil, a baixa procura pelo medicamento genérico está relacionada à falta de informação do consumidor ao receber a prescrição médica. Essa questão, muitas vezes está associada ao assédio das indústrias junto aos médicos para indicar os medicamentos de referência.

Tendo em vista a aparente ineficácia dos parâmetros regulatórios adotados para a CMED, dentre os quais a variável "produtividade das indústrias", quais seriam outros possíveis critérios a serem adotados por esse órgão, capazes de fazer com que o processo regulatório leve em consideração as práticas de mercado e, por isso, reduzir ainda mais os preços dos medicamentos? Existe algum benchmark internacional que possa ajudar a CMED a "calibrar" sua regulação?

(I): A pesquisa realizada em São Paulo com 164 medicamentos teve como objetivo avaliar o preço praticado em relação ao preço teto estabelecido pela CMED. O resultado apontou uma variação grande entre os 2000 de preços pesquisados na cidade. Esse resultado indica uma distorção da realidade do consumidor sobre o possível controle de preços dos medicamentos. Conforme a política da CMED o preço controlado e reajustado é 
o preço teto e não o preço praticado nos pontos de vendas. No último caso, os preços são influenciados pelas práticas que envolvem os vários agentes quem atuam na cadeia de produção e distribuição de medicamentos.

Inicialmente o setor é representado por três grandes agentes, as indústrias, as distribuidoras e as redes de farmácias e drogarias. Em cada etapa do processo de comercialização existe a concorrência entre os setores e intra-setor, além da questão da distribuição regional, entre outros.

Atualmente o índice de reajustes da CMED é corrigido uma vez por ano e aplicado no mês de março. O indicador é composto pelo índice de inflação acumulado (IPCA) e mais três fatores que compreendem a produtividade da indústria farmacêutica, fator de preços relativos entre setor que representam os custos dos insumos e fator de preços intrasetor que está relacionado com a concorrência do setor, onde é medida a participação de medicamentos genéricos e classes terapêuticas.

Diante desse cenário para dar maior proteção ao consumidor sobre os preços justos e reajustes devidos é necessária uma revisão e aprimoramento da política atual, passando por uma maior fiscalização das políticas de comercialização entre indústria, distribuidoras e farmácias, inclusão do índice de preços de medicamentos (IPCA do setor) na composição do indicador de reajuste, monitoramento dos preços nos pontos de vendas.

Deve-se levar em conta que medicamentos não são bens de consumo facultativo, ou seja, o indivíduo compra ou usa quando quiser, deve ser preservado o seu acesso para o bem estar e direito a saúde. Portanto as regras de negociação e concorrência do mercado deve se adequar a natureza da atividade do setor, amparada por políticas públicas que garantam o acesso dos medicamentos à população.

(E): O artigo da Revista do IDEC menciona que a hipótese de pesquisa (os preços dos medicamentos de referência devem ser menos discrepantes em relação ao teto fixado pela CMED em razão de não sofrerem concorrência) não foi confirmada. Ao contrário, foi constatado que os preços dos similares e dos genéricos apresentaram maior distância em relação aos preços fixados pelo governo. No artigo não foram discutidas razões para essa constatação. Na sua opinião, quais seriam as causas para esse diagnóstico? (Variação gen > Variação sim > Variação ref)

(I): O objetivo da pesquisa foi avaliar o comportamento dos preços dos medicamentos nos pontos de vendas em relação ao preço teto estabelecido pela CMED na 
cidade de São Paulo. Foram pesquisados 164 medicamentos de referência, similares e genéricos.

Os preços dos medicamentos foram pesquisados em 267 farmácias (181 em grandes redes e 86 farmácias de pequeno porte. Cada medicamento foi pesquisado em cinco estabelecimentos nas regiões leste, oeste, norte, sul e centro de São Paulo. O preço médio utilizado na comparação com o preço teto da CMED é composto pela média dos 15 preços obtidos nos pontos de venda.

Foram selecionados 78 medicamentos de referência, 40 medicamentos similares e 48 medicamentos genéricos. Entre os medicamentos de referência, 17 medicamentos não possuem genéricos ou similares, 11 medicamentos possuem somente similares e 48 medicamentos possuem genéricos e similares no mercado.

Os medicamentos de referência sofreram menor variação entre os preços pesquisados em relação a CMED, justamente porque não possuem concorrentes no mercado, são produzidos pelo laboratório que desenvolveu a pesquisa e lançou o produto, tem sua patente preservada por vinte anos, por essa razão, não possuem genéricos e similares.

(E): A amostra de medicamentos estudados foi definida com base nos tratamentos das doenças de maiores ocorrência no Brasil. Quais são essas doenças e como foram identificados os tratamentos adequados? A representatividade geográfica da mostra pode enviesar seus resultados?

(I): A pesquisa foi estruturada a partir da coleta de preços de 164 medicamentos utilizados no tratamento de doenças mais frequentes no país. Foram selecionadas 21 categorias terapêuticas de acordo com a classificação da ANVISA. Ver tabela anexa

(E): A pesquisa de 2009 se limitou a capital paulista e os resultados obtidos apresentam características diferentes de vários municípios brasileiros, em função da densidade demográfica e consequentemente da concentração de pontos de vendas e centros de distribuição, acirra a concorrência entre os pontos de vendas.

A pesquisa concluiu que todos os medicamentos pesquisados apresentaram variações abaixo do teto estabelecido pela CMED. Quais são os fatores que poderiam explicar isso?

(I): O processo de acompanhamento dos preços passou a ser monitorado a partir do envio das planilhas de custos encaminhadas pelos laboratórios no momento em que a lei entrou em vigor em 2003. Possivelmente temendo um congelamento naquele período, a 
indústria teria adotado dois preços, enviando a tabela com maior valor para o acompanhamento e controle da CMED.

Outro aspecto que contribui para o distanciamento dos preços é decorrente da política de desconto e fidelização praticados pelas grandes redes de drogarias.

(E): São Paulo é uma cidade grande, com muitos habitantes. As farmácias e drogarias, mesmo aquelas de pequeno porte, apresentam maior demanda de medicamentos e, por isso, podem ter maior poder de negociação de preços em relação ao fabricante ou ao distribuidor. Essa premissa faz sentido? Se fizer, desse modo, as farmácias e drogarias paulistanas podem ser capazes de praticar maiores descontos, afastando os preços dos medicamentos do teto estabelecido pela CMED. Em cidades de pequeno e médio porte, será que essa situação se repete? Nessas cidades, será que a regulação da CMED é capaz de conter a elevação dos preços dos medicamentos? Nesse sentido, critérios regulatórios que levam em conta as diferenças regionais devem ser utilizados pela CMED?

(I): Em 2010 o Idec realizou uma nova pesquisa envolvendo 10 cidades (Porto Velho-RO, Natal-RN, Fortaleza-CE, Recife-PE, Jequié e Salvador-BA, S.Paulo-SP, Rio de Janeiro-RJ, Curitiba-PR, B.Horizonte-MG, Porto Alegre-RS, Tubarão-SC e Campo Grande-MS.

A pesquisa realizada nas dez cidades resultou na coleta de 1092 preços de 25 medicamentos coletados em 135 pontos de vendas. A análise dos dados coletados indicou que, a exemplo da pesquisa realizada pelo Idec no ano anterior, os medicamentos genéricos ou de referência, são vendidos em várias regiões do país com preços muito menores do que os preços-teto estabelecidos pela CMED, com margens até $295 \%$.

Entre os medicamentos de referência, o preço máximo obtido nos pontos de vendas, já excluído o ICMS indicaram forte equilíbrio entre as cidades pesquisadas. Em quatro cidades foram encontrados os preços estabelecidos pela CMED, indicando ausência de concorrência ou política de comercialização ou descontos.

A avaliação dos preços máximos e mínimos identificados na pesquisa nos pontos de vendas com diferentes perfis econômicos, não apresenta variações expressivas ou tendência de preços com maior ou menor margem de descontos. A única variação que se destacou nessa análise é a concentração do menor preço mínimo pesquisado na cidade de Tubarão no interior de Santa Catarina.

Desconsideradas as diferentes alíquotas do ICMS aplicadas nos diferentes estados, entre os sete medicamentos Genéricos pesquisados, os resultados indicaram que a cidade 
de Natal concentrou os maiores preços relativos, enquanto em Belo Horizonte foram registrados os menores preços.

(E): Por fim, na sua opinião, quais são as maiores dificuldades e os gargalos da política regulatória da CMED?

(I): Acredito que são:

- o desconhecimento do preço real dos medicamentos;

- os reajustes acima da inflação e em conformidade com a CMED, dificulta o acesso da população aos medicamentos, sobretudo, de uso continuo;

- o baixo nível de informação da população sobre os medicamentos genéricos;

-a ausência de fiscalização das práticas de comercialização entre as categorias de medicamentos (referência, similares e genéricos);

- a maior oferta de medicamentos genéricos;

- a política de comercialização que com abrangência das pequenas farmácias e drogarias;

- a pesquisa de monitoramento de preços nos pontos de vendas;

- a definição de indicadores de reajuste de preços;

- a ampliação dos programas de farmácias populares em âmbito federal e estadual;

- a maior fiscalização e definição de normas na política de comercialização entre laboratórios, distribuidoras e médicos;

- a inclusão do indicador de preços nos pontos de venda na composição do índice de reajuste vigente. 
Anexo B: segunda entrevista com Ione Amorim, economista do IDEC e coordenadora das pesquisas de preços de medicamentos realizadas por essa instituição

(I): Acho que seria interessante você conversar com outras pessoas também, uma delas é a professora Basília Aguirre, que foi responsável pelo índice de preços de medicamentos desenvolvido pelo governo durante até o fim da gestão do Serra enquanto Ministro da Saúde, só que quando entrou o governo Luala, não teve verba para continuar esse projeto. Antes de fazer a pesquisa [do Idec sobre preços dos medicamentos] eu fui procurá-la justamente para explicar a metodologia que a gente estava desenvolvendo e que elementos ela poderia contribuir para essa pesquisa. Teve esse problema, ela falou assim: é uma pesquisa muito cara, fazer pesquisa de preços de medicamentos no país inteiro em várias cidades como era feito pela FIPE, o índice FIPE, é muito caro e foi uma das razões que nessa troca de governo, parece que o Lula, afinal, o novo ministro, não quis dar continuidade

(E): Hoje em dia parece que há um sistema de monitoramento, mais é um pouco obscuro, né, a gente não sabe direito como funciona, porque não há nenhum dado no site.

(I): Não não tem, tem até um sistema dentro da CMED, que eu acho que eles autorizadarm a gente a fazer consulta em função do nosso acompanhamento, mas eu até questionei: você tem o preço, mas quando eles passaram essa ferramenta para a gente fazer consulta tava assimm desatualizado assim um ano, e eu falei: preço médio de um ano atrás, não tem assim uma referência,né, teria que ser algo atualizado,e algo que seja possível ser comparado com o preço teto. Bom... a própria CMED, o que eu senti, foi uma certa fragilidade da parte deles em tentar mexer ou negociar isso, acho que o poder da indústria é ainda muito grande e a pressão é como se eles falassem assim: bom, você é o órgão regulador e ema algum momento você parece estar enfraquecido diante da pressão que a indústria faz sobre qualquer possibilidade de mudança na política de preços de medicamentos. Então esse histórico todo que eu estou te passando é um pouco fruto dessas reuniões que nós tivemos. Bom, você já teve acesso às condições em que a CMED foi criada em 2003, acho que isso pra você está tranqüilo?

(E): Sim, está tranqüilo

(I): Tá, porque um pouco, nos temos na ocasião, não me recordo o número agora, mas enfim, e todos os medicamentos que existiam naquela data, o preço foi estabelecido e essa história da possibilidade de existência de dois preços partiu dali, o medo da indústria 
de que aquela política pudesse estabelecer algum congelamento então todas as tabelas que foram obrigadas a serem informadas à CMED elas foram já com esta margem.

(E): Entendi, uma margem de garantia de que ...

(I): Isso, com a garantia de que a com a possibilidade de congelamento ia possibilitá-los ainda ter um controle dos preços.

(E): Será que a CMED não solicita essas informações da indústria anualmente?

(I): Ela levanta, essas informações são passadas mensalmente, eles tem todo o histórico e aí, nós estamos falando, e aí eu não sei se são cerca de 200 mil medicamentos, eu não vou saber precisar isso agora. Mas enfim, o que nós tivemos depois disso já passa por esse controle também, todos os medicamentos que entraram no mercado depois de 2003, que é um número menor, que é onde eles acreditam que eles tenham um melhor controle, que é em cima desses medicamentos novos, e aí a gente ta falando de alguns genéricos, e alguns medicamentos de referência, mas são bem poucos, perto da quantidade que a gente tem que está em uso no mercado, mas tem vários aspectos que influenciam nisso, a gente teve a ajuda de uma técnica que foi da Vigilância Sanitaria, que tem muita familiaridade com a ANVISA e com essa questão de formação de planilhas. Então você tem desde o momento que o laboratório muda a composição só da embalagem, ou seja, você tem, um determinado antibiótico, amoxicilina, que é caixa com 30 comprimidos, sei lá, $5 \mathrm{mg}$, em caixa de 30 comprimidos, se um mesmo laboratório vai lançar uma segunda versão desse medicamento com 28 comprimidos, essas planilhas todas tem que ir, só que são um questionamento do por que era trinta e agora é 28 ? Isso tem muito e isso também é um dos fatores que, nessa questão de preço, ela também acaba ficando solta, você não consegue ver como é que esse preço está sendo tratado, porque você perde o referencial quando você muda a composição da caixa, então isso acontece em vários medicamentos.

(E): Parece ser extremamente complexo.

(I): É. É uma cadeia muito grande, e assim, a gente não tem, os modelos que foram citados, a gente não chegou a avaliar nenhum em profundidade. Em outros países, também apresentam um grau de complexidade muito grande. Acho que o nosso, a gente tem dois parâmetros, a gente tem aqui um programa de saúde pública que é o SUS que é até elogiado lá fora, porque é um modelo de abrangência que teria uma eficácia muito maior. O nosso problema com o SUS é a gestão do SUS, mas o SUS em si é um modelo extremamente interessante e muito elogiado em outros países, países, inclusive os EUA que tem um modelo extremamente precário perto do que a gente tem. 
(E): Excludente, né?

(I): Sim. Então quer dizer, você tem aqueles programas de farmácia popular, dá aí acesso a uma série de medicamentos que estaria dentro dessas listas. Então a gente teve essa iniciativa de procurar os preços dos medicamentos, alguns deles, que não estivesse nessas listas, por quê? Por que estaria toda a população, assim, exposta a esta política [a política de controle de preços da CMED], então quer dizer, você teria uma demanda muito maior por esse medicamento e isso dá mais poder à indústria na hora de formar os seus preços. Você tem a necessidade, é aquele princípio que eu acho que é o mais, que deve ser levado em consideração: a indústria de medicamentos não é uma indústria de produtos de qualquer natureza, né? É um produto essencial à saúde, é até um direito constitucional de ter acesso a medicamentos, então ele não pode ser tratado como quando você faz promoção de, sei lá, de arroz, de copo, sei lá, não é um produto de qualquer outra natureza, então o medicamento não pode seguir esse princípio. Então, tudo isso está dentro dessas políticas de governo que você tem a indústria com esse poder todo, o assédio aos médicos, saiu até uma medida na semana passada, não sei se você acompanhou?

(E): Eu vi.

(I): Que limitou as verbas que podem fornecer um brinde aos médicos. Então tudo isso é muito importante e tudo isso reflete dentro do que a gentes tá falando. Até essa questão da participação do genérico. Hoje, se você vai, algumas pessoas mais esclarecidas, eu nem vou dizer mais esclarecidas, porque tem muito esclarecido que sabe que pode ter acesso ao genérico, mas ainda subjulga o genérico e dá crédito ao medicamento de referência e deixa de comprar aquele medicamento. E outra parte da população que por desconhecimento mesmo, o médico passou a receita com aquele nome e ele não pergunta: olha, te o genérico desse medicamento? Então tem toda essa questão de comportamento do consumidor. Tá? Mas eu fui falando sem você perguntar.

(E): Foi ótimo, porque até algumas perguntas já foram respondidas. Quanto às primeiras perguntas, as respostas que você me enviou por email estão muito claras. Mas algumas novas dúvidas surgiram. Inicialmente, só para ver se eu entendi corretamente alguns conceitos de economia, quando você explicou na email como funciona exatamente a regulação da CMED, você disse que há no mercado de medicamentos uma concorrência intra-setor e uma concorrência extra-setor. A diferença é que a concorrência intra-setor é aquela entre medicamentos genéricos, similares e de referência e a concorrência extra-setor é aquela presente nos mercados dos insumos? 
(I): Exatamente.

(E): Certo. Foi só para checar se eu tinha entendido.

(I): Isso, porque você tem, até na parte dos insumos, uma parcela muito grande é importada, e aí tem um peso muito grande do câmbio nessa questão. Então esse é um item que tem um peso na formação dos fatores [regulatórios] são três os fatores hoje, a produtividade e esses outros dois.

(E): Na questão dois sobre quais práticas seriam interessantes para que a política da CMED fosse mais eficiente, você menciona em sua resposta que deve ser levada em consideração a questão da distribuição regional. Eu, contudo, não compreendi muito bem essa relação?

(I): Essa questão, por ter lido o primeiro questionário inteiro e tendo visto a sua colocação sobre a pesquisa ter sido feita só em São Paulo e como seria se a pesquisa tivesse tido maior abrangência, como eu participei da segunda pesquisa do IDEC que teve essa abrangência, a minha resposta foi no sentido de enxergar esse plano mais amplo, que de fato, quando a gente partiu para essa segunda etapa [segunda pesquisa - ano de 2010], foram 25 medicamentos. A idéia era fazer com uma amostragem maior essa pesquisa. Essa pesquisa foi desenvolvida em 10 cidades do país, com a ajuda dos movimentos de donas de casa, em entidades organizadas nessas 10 cidades. Apesar de ter a organização já definida e com ação local forte, eles não tem familiaridade, são pessoas assim sem técnica, voluntárias, não tem assim esse preparo para lidar com pesquisa e tal. Então, a gente teve que dar um treinamento mínimo e sabia que não ia conseguir faezr uma coisa assim muito abrangente, por isso já restringimos um pouco. Só que, a partir daí, a seleção de medicamentos proposta inicialmente, foi revisada, assim, várias vezes, porque a gente tentava buscar o mesmo medicamento, nas 10 cidades, com a mesma configuração, de quantidade de comprimidos, dosagem da medicação, e isso às vezes não era possível, não era possível por que alguns medicamentos, sobretudo os medicamentos genéricos, que você tem aí vários laboratórios produzindo e alguns chegam em algumas cidades e outros não chegam em outras cidades. Então, esse foi um fator que dificultou e a gente foi diminuindo até que tivesse uma amostra homogênea para fazer a pesquisa em todas as regiões. Então quando a gente está falando desse mundo ideal que é São Paulo, diante dessas outras cidades, por que assim, tem a concentração da industria, boa parte está aqui e essa questão do medicamento genérico, alguns medicamentos tem em média 3 ou 4 laboratórios produzindo, mas alguns chegam a 15 laboratórios produzindo o genérico. 
Então a forma com eles desenvolvem a composição das caixas, a quantidade de comprimidos, isso daí também sofre uma variação que a gente não consegue chegar lá e questionar a indústria do porquê que tem que ser assim. Isso as vezes a gente entende que seja mais por força de uma concorrência, que para diferenciar, para reduzir preço, assim, tipo aquela coisa de maquiagem que você reduz a quantidade e reduz o preço. Isto é, acaba utilizando os mesmo recursos quea publicidade da indústria em gera faz, que eu acho isso extremamente, ela já é perniciosa em qualquer mercado, né, você reduzir a quantidade de um produto, com o argumento de que você baixou o preço, e o consumidor desavisado vai comprar achando que está tendo alguma vantagem por levar esse produto nessas condições. De novo, a gente falando de medicamentos, isso acaba sendo duplamente prejudicial, porque quem faz uso de um medicamento contínuo quando ele tem essa redução ele tem que comprar duas caixas de medicamentos, porque um medicamento que tinha a caixa com 30 , passou a ter 28 , se ele tinha a necessidade de usar todos os dias ele tem que comprar duas caixas. Em algum momento ele está sempre comprando mais que em condições normais. Então, essa questão da distribuição passa por esse aspecto, por que se aquele preço teto é o único que chega lá, naquelas regiões ele tem menos flexibilidade para ter o acesso ao medicamento com preço de uso, que ele tá pagando aquele preço teto com toda aquela margem que a gente sabe que existe ainda que tenha frete nesse percurso, por que você tem hoje um processo de distribuidoras, a gente tem as grandes redes que acreditamos que elas comprem direto da indústria, mas as pequenas compram de distribuidoras. Entao tudo isso acaba fazendo com que mesmo em cidades pequenas a política ela guarda esse mecanismo. Então acho que um pouco passa por essa questão.

(E): Você aponta como critérios desejáveis a serem adotados pela CMED na política regulatória uma maior fiscalização das políticas de comercialização entre indústria, distribuidoras e farmácias, em que sentido isso seria interessante?

(I):Até um pouco dentro disso que a gente acabou de falar, a questão da distribuição, ode você tem uma menor presença de laboratórios, você tem uma menor disponibilidade de chegar a um preço competitivo. Você está praticando um preço teto que é influenciado por uma margem. Quando você tem maior competitividade, ou seja, maior acesso a esses medicamentos, você tem essa política mais presente. Quais são os fatores que determinam essas políticas de descontos? Por que a gente encontra redes de drogarias oferecendo medicamentos com 60 a 90\% de desconto? Acho que até eu tenho aqui, vou abrir por que eu acho que fica fácil de ver, foi uma apresentação que a gente fez 
questionando exatamente isso [me mostrou fotografias de propagandas de desconto de $25 \%$ a $90 \%$ sobre os preços de medicamentos em drogarias e farmácias]. Por que algumas farmácias oferecem o mesmo medicamento, mas com $90 \%$ de desconto? Qual é o preço desse medicamento? O que leva a isso? Então, teria um representante lá da Associação das indústrias farmacêuticas ao qual fizemos críticas severas, mas ele não chegou a explicar nenhum dos argumentos das críticas que a gente tava levantando. Então, a questão da fiscalização é para chegar justamente sobre esses aspectos. A gente ta falando em preço no ponto de venda, mas quando você está falando de industria e distribuidores não estamos falando em um campo tão amplo que não seja possível uma fiscalização.Afinal de contas as redes de laboratórios e as indústrias farmacêuticas são grandes no Brasil, mas passaram por uma série de fusões e aquisições o que vai fazendo que esse mercado seja grande em produção, mas são poucas as empresas.

(E): Esse quadro revela uma grande dificuldade em descobrir qual é o preço real do medicamento, porque se as indústrias não fornecem dados fidedignos sobre preços para a CMED isso dificulta muito a política de regulação.

(I): Exatamente. Eles argumentam várias coisas. Por que se a gente está falando só de preços para o consumidor. Se você for falar para o próprio setor, este é um dos itens que eles tem muito medo.Se formos pegar os aspecto de como os laboratórios se relacionam com as industrias, passando por planos de saúde, por hospitais, isso tudo é muito complexo e eles admite [a CMED] que não tem a musculatura para fazer toda essa investigação. Então é muito sensível por parte do governo enxergar, o poder da indústria é muito forte e acaba tendo essa influencia muito grande, mas vamos manter o foco no consumidor. Como o consumidor acaba sendo penalizado por essa situação? Agora mesmo a gente vai ter no dia 30 de março, sai o novo preço de reajuste de medicamentos. A gente questionou: sabendo que o preço teto não reflete o preço praticado e esse preço médio é bem inferior, por que há a necessidade de fazer o reajuste do preço teto? Eles alegaram que se mexer no preço teto eles vão naturalmente elevar os preços médios praticados. Mas aí é que cabe a fiscalização. Se não há necessidade de haver o reajuste por que a indústria vai reajustar o preço? É onde a gente tem o maior questionamento, porque o reajuste dado ao preço teto que fica lá em torno de 3 a 5\%, esse não é o preço verdadeiro, por que o consumidor que paga um determinado remédio paga 10 reais e daqui um ano ele ta pagando 15 reais, então ele ta pagando $50 \%$ de reajuste, só que a política atual não permite que seja identificado esse reajuste. Só o consumidor sente isso, porque a política do governo se limita a dizer 
que os preços subiram 5\%, mas esses $5 \%$ são sobre o preço teto que não é o preço praticado. Então o consumidor acaba ficando totalmente descoberto, sem a proteção de algo que faça com que os preços acompanhem a inflação ou se tem algum preço que por uma demanda muito grande de mercado ele foge dessa condição de reajuste de que o mercado, de que a própria inflação tá sendo, tá empurrando esses preços, né. Então, você pode ter eventuais casos, mas não todos sujeitos a uma política que ta dentro de uma margem onde ninguém observa o que acontece com esses preços. O consumidor não tem pra quem reclamar. Então a gente tem essa realidade.

(E): Agora, você diz que em 4 cidades, dentre as 10 cidades pesquisadas em 2010, vocês encontraram os preços dos medicamentos incidindo exatamente no teto fixado pela CMED. Será que nessas 4 cidades, talvez até por uma questão das características da distribuição e por menor demanda, talvez a regulação da CMED fosse eficaz, impedindo que os preços dos medicamentos subissem excessivamente? Sem a regulação da CMED, nesses casos, será que os preços não poderiam ultrapassar o teto?

(I): Eu acredito que não. Não ultrapassar, porque existe uma norma. Mas se esse preço teto estivesse fora do preço de mercado, obviamente, haveria uma pressão e alguém estaria descumprindo esse preço em algum momento, o que não aconteceu. Então, o que aconteceu, foi encontrar o preço teto em cidades onde você não teve as vezes nem uma concorrencia para aquele medicamento, só que, se for um genérico, o genérico você tem vários laboratórios, mas só um laboratório chega ali, então, quer dizer, ele sozinho não está sofrendo o assédio nem do medicamento representante dos demais laboratórios, possivelmente, dentro daquele núcleo, o médico que está receitando está receitando o de referência, ou ele está prescrevendo pelo princípio ativo e aí o que está disponível na farmácia, sei lá, EMS, Medley, etc., mas só tem uma opção. Então por conta disso, acredita-se que nesses casos se chegou a esse preço. Mas não necesssariamente que esse preço seja o preço de fato, o preço de mercado. O que falta é concorrência, então vamos manter o preço da tabela.

(E): Mas assim, se não tivesse esse preço teto, ou seja, se não tivesse a regulação da CMED, será que ultrapassaria, nessas cidades esse preço teto?

(I): Possivelmente.

(E): Então, nesses 4 casos, possivelmente, a regulação da CMED teria funcionado? Em casos em que as cidades têm problemas de concorrência entre medicamentos em razão dos problemas de distribuição, ou tenham uma demanda pequena... 
(I): Nesses casos sim, desde que o que se proponha seja manter os preços dentro de um teto. Mas levando em consideração todos os preços, foram pouquíssimos os preços que foram praticados dentro desse patamar.

(E): É engraçado o fato dos preços dos medicamentos variarem mais que o IPCA comum, porque na composição do índice de reajuste a CMED leva em consideração a variação do IPCA comum, né? Eu imaginei que isso significasse que ...

(I): O IPCA comum faz parte da composição do índice de reajuste.

(E): A idéia que eu tinha é que ao levar em conta a variação do IPCA na composição do índice de reajuste, os preços dos medicamentos deveriam variar apenas de acordo com a variação da inflação. Na prática a gente vê que isso não é suficiente, por que na prática vemos que, mesmo assim, a variação dos preços dos medicamentos ultrapassa a variação do IPCA.

(I): Na verdade, os preços ultrapassam na prática, porque na verdade esses preços [os levados em consideração na composição do índice] não são os preços que estão sendo monitorados. Os preços levados em conta na elaboração do índice são, digamos assim, preços referenciais e não aquele preço real. Então, o que aconteceu, nós pegamos os medicamentos, esses 25 que estavam dentro da primeira e da segunda pesquisa aqui em São Paulo, e nós encontramos variação de $14 \%$, ou seja, nós estamos falando de uma inflação que variou cerca de 5 a $6 \%$, então você tem o dobro e, infelizmente, se a gente tivesse feito em cima dos 164 medicamentos, mesmo só em São Paulo, a gente teria uma surpresa muito maior, porque esses reajustes são totalmente aleatórios, estão soltos, eles podem acontecer em qualquer parâmetro ou patamar.

(E): E aí você fala que para evitar isso seria interessante considerar o IPCA do setor e quando você diz isso, seria o IPCA baseado nos preços verdadeiros?

(I): Exatamente.

(E): E o que seria o preço verdadeiro do medicamento? Como ele seria determinado? Seria baseado no custo de produção real?

(I): O custo de produção, esse dado, a CMED já trabalha com ele. Os laboratórios são obrigados a informar isso à CMED. O que a gente precisa ter para evitar essa situação é o preço no ponto de venda. A partir do momento que você consegue fazer essa pesquisa levantando os preços que estão sendo praticados nos pontos de venda. E aí volta a questão da importância da pesquisa que era desenvolvida pela Professora Basília até o fim de 2002, você tinha o índice do setor, porque era pesquisado lá no ponto de venda. Então você tinha 
esse indicador e ele deveria fazer parte desse indicador que existe hoje, possivelmente, trazendo pra dentro dessa realidade esses preços.

(E): Sobre a monitoração de preços realizada pela CMED, acho até que eu já perguntei pra você antes, a gente não sabe como que é feita, né? Se eles medem com frequência os preços no ponto de venda, ...

(I); Eles dizem que é feito mensalmente. Dentro lá do IDEC, eu posso até ver, mas não é aberto, eu lembro que foi concdida uma senha para que a gente fizese esse acompanhamento. A ferramenta existe, agora...como é feita a coleta...é um trabalho caro, são necessários muitos pesquisadores. Isso foi importante a gente colocar para eles, nós não, porque seria um outro fator ainda que desvirtuaria a informação no nosso entendimento. Se nós tivessemos colocado na rua, pesquisadores, que se identificassem lá dentro da farmácia: sou pesquisador da FIPE ou do IDEC e vim aqui fazer uma pesquisa de preço de medicamento e quero que você me informe o preço desses medicamentos. Nós entendemos que se tivessemos feito dessa forma, a gente voltaria para o preço de referência e esse preço a gente tem, né, a CMED disponibiliza o preço de todos os medicamentos de referência, todos.

(E): Eu olhei no site da ANVISA outro dia e vi que eles disponibilizaram preços de medicamentos só para o ano de 2008-2009, o PMC, e nas planilhas elaboradas pela CMED eles colocam o PMC de acordo com a regra e também o preço que eles apuraram, que é muito mais baixo. Eles mesmos sabem disso e divulgam, né, achei interessante.

(I): Isso. Esse é um dado que mostra que existem elementos que eles podem, eles reconhecem que existe uma diferença, a gente tá falando desse colchão que começou em 2003. A gente está aqui e o colchão continua existindo para todos aqueles que vieram com as suas planilhas, vamos dizer assim, sofreram uma variação temendo um congelamento, ainda hoje... naquela época era tão mais preocupante isso...mas nós estamos aí já quase 10 anos depois do início da norma e esse colchão ainda é grande. Estamos falando que mesmo reajustando anualmente em torno de $5 \%$, você tem hoje margens de $40 \%$ a $200 \%$ de medicamentos aí, de diferença do preço praticado com o preço e o preço teto, né, o preço máximo ao consumidor. Então isso tudo acaba criando ainda mais um questionamento de por que tamanha margem? Se hoje você tem condição de fazer uma revisão disso, teria que contemplar esse preço que está sendo praticado. Uma outra questão que também foi discutida na época com um desses medicamentos, a Cibutramina, a explicação que foi dada para a variação do preço da Cibutramina que chegou a 500\%, acho que foi isso, tá aqui, 
isso, 568\%. Cibutramina é o nome do princípio ativo, então o medicamento de referência que tava no mercado ele tinha uma variação de $568 \%$ entre o preço do genérico e o preço do de referência e aí ele disse: ah não, esse medicamento, ele tá pra vencer a patente e foi por conta dessa razão. Mas mesmo assim, a gente tendo 3 laboratórios produzindo o medicamento de referência, quer dizer, o medicamento genérico, e esse medicamento genérico, os três laboratórios tinham o preço médio em torno de 100 reais, esse o PMC determinado pela CMED, e no ponto de venda ele foi encontrado por 24 reais. Em todos, independente dos 3 laboratórios que foram pesquisados, todos eles apresentaram preços muito inferior ao preço do próprio laboratório enquanto medicamento genérico e em função do medicamento de referência então nem se fala, isso porque o medicamento de referência vem todo amparado por aquela questão da pesquisa e do desenvolvimento, então o preço dele é muito diferente do preço do genérico. A explicação era: esse medicamento vai cair a patente dele. Mas essa é uma questão que espelha um pouco a realidade de muitos outros medicamentos que têm essa mesma variação, essa distância entre o que você está encontrando nas farmácias e o que você tem nos preços dos genéricos e o que você tem nos preços dos de referência. Por que é que está lá em baixo nas farmácias e nas tabelas está esse absurdo?

(E): Pelas suas respostas que fazem alusão à pesquisa de 2010, vocês puderam perceber que essa distorção é mais ou menos uniforme no país inteiro, né? Exceto por aqueles casos pontuais daquelas 4 cidades.

(I): Isso.

(E): Mas você acha que, por ser uma realidade mais ou menos uniforme no país todo, você acha que a concorrência e a distribuição na prática talvez não faça tanta diferença na determinação dos preços?

(I): Sim, na prática faz diferença. Principalmente a concorrência tem um peso muito relevante. Nós temos aí o peso de algumas redes de comprar em atacado, ter várias farmácias distribuídas pelo país, obviamente ela tem um poder de compra e de barganha muito maior do que até mesmo uma distribuidora que vai comprar em grande número para atender equenas drogarias seja lá onde for. Então esse é um fator que tem uma pressão muito grande.

(E): Então nas cidades pequenas vocês observaram se os preços costumam ser mais altos? 
(I): Não necessariamente. Em algumas cidades sim, foi algo pontual. Eu entendo que como a gente trabalhou 25 medicamentos a gente teve alguns comportamentos nesses preços que não fromaram uma tendência pra gente afirmar que nas cidades menores todos os preços tendem a ser maiores do que na cidade grande. Não. A gente inclusive teve situações diferentes em que preços menores foram encontrados em cidades pequenas, em relação às cidades grandes, e vários preços.

(E): Eu li na resposta que em Tubarão/SC foram praticados os menores preços. Por que será? Vocês pensaram em uma possível explicação para isso?

(I): Não, a gente não teve esse segundo aprofundamento da pesquisa, mas o que mostra é que existe essa desordem, se você tem a lógica de que onde você tem o maior número de farmácias e o maior número de possibilidades de medicamentos a concorrência vai ser sempre maior e em locais onde você tem menor oferta e não tem essa concorrência tão evidente entre as redes o preço vai ser mais inflexível, ou seja, tende a ser maior, ou seja, essa seria a situação mais lógica, mas a pesquisa contradiz essa lógica. A pesquisa mostra isso. Então, existe uma desordem nesse aspecto e como explicar essa relação, existem mtas possibilidades, você tem desde a oferta de lotes de medicamentos, tem alguns aspectos que também refletiram, a gente tá falando de preços de São Paulo, na pesquisa de 2009, é um preço médio que foi coletado em 15 farmácias, então em alguns pontos esse preço fornecido também foi o preço máximo, mas por que, como não houve a compra do medicamento mas a consulta como consumidor, muitas vezes o farmacêutico ele abria o livrinho e dava o preço, embora poucas vezes tenha sido feito isso, porque obviamente eles querem vender o medicamento, então você perguntava, a orientação do pesquisador nosso era pergunte se tem desconto, pergunte se tem que ter o cartão de fidelidade, então todos esses fatores eles interferem na hora de fornecer esse preço. Então mesmo nessas cidades onde foi informado o preço máximo, essa situação pode também ter sido a razão para ele ter dado o preço máximo, ele teria outro preço pra vender o medicamento, mas naquele momento, simplesmente abriu o livrinho e informou, olha o preço do medicamento é esse.

(E): O preço da regra e não da prática, né? Diante desse quadro, você acha que a CMED deveria utilizar critérios regulatórios diferentes que levem em conta os diferentes tamanhos das cidades brasileiras, diferentes graus de concorrência e tamanho da demanda?

(I): A CMED não teria condição de levar em consideração critérios de distribuição regional, a gente tá falando em âmbito nacional e a gente sabe que qualquer produto que seja produzido no país a distribuição não pode ser uniforme. A gente tem uma série de, o 
número de farmácias, vamos pegar a nossa realidade aqui, o número de farmácias, distância, frete, o próprio consumo, as doenças de maior incidência naquela localidade, o número de variáveis que interfere nesse processo é muito grande, mas pode existir um monitoramento, porque como você tem o preço de referência, o preço máximo ao consumidor e você tem o fluxo dessa distribuição, e a gente não tá falando que seja uma quantidade infinita pra que você não tenha alguma forma de fazer um acompanhamento, como as distribuidoras atuam, as grandes redes, como é que elas chegam nessas cidades, eu entendo até que as grandes redes estão muito concentradas nas capitais, nas cidades de economicamente maior porte, né, e as cidades de menor porte são atendidas pelas distribuidoras. As distribuidoras têm um papel muito relevante nessa cadeia, ela compra dos laboratórios e ela faz a distribuição ara esses pequenos comércios, essas pequenas redes de farmácia, né, e a gente não entrou nessa questão, até por que seria uma outra pesquisa saber como é que funciona todo esse mercado, mas tem um papel muito relevante.

(E): Nas grandes cidades você disse que os medicamentos são normalmente adquiridos diretamenta da indústria pelas farmácias...

(I): As grandes redes, né, porque mesmo se a gente pegar São Paulo, por exemplo, na primeira pesquisa, foram duzentas e poucas farmácias, deixa eu ver que eu tenho aqui, 267 farmácias e drogarias, se não me falha a memória foram 181 redes e 81 farmácias pequenas, então $2 / 3$ do que a gente pesquisou estava dentro das grandes redes e $1 / 3$ estava em farmácias de bairro, aquelas farmácias pequenas, agora essa realidade de São Paulo não se reflete em outras capitais com essa mesma proporção. Mas tem redes de menor porte e de porte intermediário, né, a gente tá falando de redes como Drogasil, Droga Raia, Onofre, mas a gente tem outras como a Ultrafarma que tem uma quantidade de lojas menor, acho que só tem 2 ou 3, mas ela tem um trabalho muito forte via telefone e internet para fazer a comercialização, o comércio eletrônico. Tem muitas redes que também tem essa força através desses canais o que torna também forte a questão das distribuidoras, porque provavelmente são essas distribuidoras que fazem a disponiblidades desses medicamentos junto a essas redes. E aí você tem a farmacinha do Seu João lá em Recife, em Recife não, lá em Feira de Santana, e quem atende essa farmacinha? Uma distribuidora. Obviamente não chega pra ele lá a EMS, a EMS não vai vender lá pra ele, é uma distribuidora que atende. Agora, essa política de preço que chega lá nessa farmácia lá em Feira de Santana é a mesma que vale aqui pra São Paulo, é esse preço. No argumento do Sr. Luís Milton, Secretário, é que até $20 \%$, ele entende que seja razoável essas margens, por conta dessas 
políticas de desconto, fidelização com o consumidor. E a gente também achou que iso seria razoável, mas como a gente partiu pra identificar aqueles que estão bem acima disso, quando começa a cair de $40 \%$ pra cima, já a gente não entende que isso seja só uma política de desconto de comercialização,na verdade existe sim essa margem que acaba sendo prejudicial ao consumidor, porque é dentro dela que se pratica os verdadeiros reajustes de preço que passa, que deixa de ser fiscalizado.

(E): Insistindo ainda nessa questão da regionalização em relação com a regulação, é praticamente impossível considerar o critério da distribuição em um índice de reajuste regional. Mas um índice de reajuste regional mais próximo da realidade da concorrência ou do tamanho da demanda, idealmente, será que isso seria melhor para a eficiência da poítica regulatória?

(I): Eu entendo que não, porque se criássemos uma política de um índice regional, nós estaríamos atribuindo ao fator da regionalização o fator determinante para reajustar preço de medicamento e não mais as condições, primeiro, a questão de demanda desse medicamento, que não responde a uma regra lógica, a questão de doenças não tem um comportamento lógico, então essa distribuição, esse enfoque, essa tendência de acesso tem que ser uniforme, a política tem que ser mais abrangente, ainda que você tenha que levar em consideração o preço regional pra que não tenha essa: lá é o teto, porque tem todos os fatores de distância pra se chegar e etc e aqui tem todo o acesso, ainda que você faça essa ponderação, ela deve ser refletida em uma política mais ampla, porque hoje nós temos, por exemplo, a questão do ICMS, que ele já é contemplado. O preço do medicamento, quando você consulta as tabelas, você tem lá o preço que é um só e você aplica ali o ICMS de cada Estado ou daquela região, enfim, vários estados têm o mesmo ICMS, você deve contemplar dessa mesma forma, esse fator regional, ele tem que ser amplo e essa regionalização ela tem que refletir opontualmente como hoje o ICMS tem o seu papel.

(E): Então, tem que ser amplo, nacional, mas poderia então ser incluído nesse índice esses critérios de, por exemplo, tamanho da população, tamanho da demanda ou a própria concorência, não sei se isso é possível de ser feito?

(I): De população, avaliar os municípios pelo tamanho da população, isso seria uma complexidade muito grande, mas se considerar, se você tem conhecimento do preço praticado ali, você tem condição de montar essas séries históericas e estabelecer qual é a tendência desse preço e a partir daí você fazer essa ponderação, olha, São Paulo costuma ficar longe do preço teto em torno de 50\%. Mas com todas as suas variáveis, levando em 
consideração concorrência, levando em consideração, a distribuição, enfim, a concorência do produto com os seus concorrentes aí no caso genéricos e similares e a concorrência entre o setor farmacêutico, que entre as farmácias aqui, uma delas vai querer ter o preço melhor que a outra pra que você compre o medicamento lá, então, você tem vários atores atuando, a concorrência se estabelece em vários níveis,e então quando a gente leva isso para uma região mais distante, essa concorrência tá indo junto, você vai ter o menor número de pontos de venda, mas parte dessa concorrência tá indo junto com essa história pra lá. O que você vai ter é um menor número de farmácias e esse preço que costuma ser praticado ali ele tende a ter a sua própria evolução, a sua tendência, então, a mesma coisa, traz isso, pega atendência aqui, a tendência lá e aí você estabelece fatores que vão fazer que esse preço toda vez que ele for, quer dizer esse indicador, vai ser contemplado, chegou nesse preço e costuma ficar nesse patamar. Lá tem o frete, sei lá o que mais pra chegar naquela região, sei lá mais quais outros fatores poderiam interferir.

(E): Com o ICMS eles contemplam essa diferença em cada Estado, mas mesmo assim o índice consegue ser amplo. Como que eles conseguem fazer isso? O PMC final aca sendo o mesmo para o país inteiro?

(I): Não, é assim: você tem o PMC que vem do laboratório, da indústria...

(E): O PF, preço fábrica, né?

(I): Isso. Quando você chega nesse preço pra informar o preço ao consumidor você vai incluir ali a alíquota, tanto que a ABCFARMA, acho que é, eu não sei se é a indústria ou se são os próprios distribuidores que imprimem, é como se fose uma lista telefônica que tem todos os preços, de todos os medicamentos, todas as farmácias têm essa publicação,e ali, o preço já vem indicando, você vai aplicar o preço dele, ó pra São Paulo, o preço é R\$12,00, para o Rio de Janeiro que o ICMS é diferente, o preço é de R\$12,50, e ;para Minas Gerais é R\$ 12,35, então, esse manual, inclusive aquela relação disponível na CMED já vem indicando o preço e a alíquota de cada Estado. E aí é só você aplicar ali. 


\section{Anexo C: transcrição da primeira entrevista realizada com dois membros da CMED (entrevista concedida sob a condição de manter o anonimato dos entrevistados):}

(E): A primeira pergunta que eu gostaria de fazer a vocês é: o controle de preços é a única forma de regulação econômica praticada pela CMED?

(E1): É

(E2): É

(E1): O que você entende, assim, por controle de preços, porque há a questão do reajuste anual e a questão da apuração dos preços iniciais dos medicamentos que estão entrando no mercado.

(E2): O monitoramento seria uma forma...

(E1): E há o monitoramento que a gente acompanha pelas publicações das revistas, a ABCFARMA é a mais conhecida.

(E): É isso mesmo o que eu entendo, a fixação do preço inicial e o reajuste.

(E1): E o monitoramento para ver se as empresas estão praticando realmente o teto de preços que foi preestabelecido.

(E2): É porque teve um marco com o início da regulação, e alguns produtos já vinham sendo comercializados antes, né, e a gente faz o monitoramento para que não haja nenhum reajuste extraordinário.

(E): Como é feito esse monitoramento pela CMED? E com que frequência que vocês fazem?

(E1): Há um acompanhamento das publicações, das revistas, dessa publicação mensal, e o relatório de comercialização que as empresas enviam anualmente à época do reajuste de preços que é no início de abril, na virada de março para abril, que acontece, e através, às vezes, até de denúncias que a gente recebe de prática de preços superiores, nesse caso das revistas também, medicamentos que entraram no mercado sem ter o preço submetido aqui, na CMED.

(E2): É essas são as principais formas. Nós tambem temos um banco de preços, nós temos um banco de dados, onde nós agregamos as informações que nós recebemos da empresa e as informações orinudas que nós cruzamos aqui com as bases de dados da ANVISA. Aí nós contruímos um banco de dados que é uma das nossas ferramentas principais de trabalho. 
(E): E essas informações que vocês recebem da indústria, não só sobre preços, elas versam sobre a produtividade, valor dos insumos...?

(E1): Não. A regulação é baseada, conforme Misani havia dito, foi feita uma fotografia do mercado, quando iniciou a regulação lá no início dos anos 2000, aqueles medicamentos que já estavam no mercado continuaram com aqueles preços, e atualmente, como é feita essa regulação a preços iniciais: preço internacional, né Misani, e custo do tratamento com medicamentos comparadores aqui no Brasil, medicamentos utilizados para o mesmo tratamento.

(E2): É, essa é a nossa legislação mais recente. Você já deve ter lido alguma coisa a respeito da CAMED, que foi a nossa primeira Câmara, a nossa legislação de fixação de preço de entrada ela foi evoluindo.

(E1): A gente bão cuida dessa questão de insumos e de custo de produção.

(E2): A lei não trata dessa questão de custo de produção, quando você determina o preço de um novo produto. Normalmente, o que a gente considera é o que existe no mercado, seja em termos de custo de tratamento com os concorrentes ou com os substitutos terapêuticos, ou com o mercado internacional do produto.

(E): E as informações que vocês recebem das indústrias são a respeito do quê?

(E2): Faturamento e unidades vendidas.

(E): E com que frequência vocês recebem?

(E1) e (E2): Anual.

(E2): Existe um período, normalmente a época de reajuste, e as empresas atualizam essas informações que vão alimentar o nosso banco de dados. Nós recebemos também informações do IMS, que é a base de dados que nós trabalhamos, que fornece, mensalmente, informações das vendas em varejo.

(E): Quais são as penalidades para os laboratórios que se recusam a vender para o governo observando o CAP?

(E1): Essas penalidades estão definidas na Lei 10.472 que criou a CMED, que por sua vez baseia a sanção no CDC. É a multa.

(E): Para o CAP é o mesmo critério do varejo?

(E1): Sim, utiliza o mesmo critério.

(E): E quem aplica essas penalidades?

(E1): Os processos administrativos são instaurados aqui na Secretaria-Executiva. A decisão em primeira instância é aqui da Secretaria-Executiva, cabendo recurso ao Comitê 
Técnico-Executivo que é o hierarquicamente superior à Secretaria-Executiva dentro da CMED.

(E): Sobre a estrutura organizacional da CMED. O órgão mais importante da CMED é o Conselho de Ministros. São os ministros de estado que tomam as decisões finais sobre o ajuste de preços dos medicamentos. Em que medida os técnicos da Secretaria-Executiva colaboram na formação das decisões dos ministros e já houve casos em que os ministros deliberaram de forma contrária às recomendações técnicas?

(E1): Que eu tenha conhecimento nunca houve. E as decisões dos ministros são realmente baseadas nas recomendações técnicas, principalmente, na parte técnica do Comitê Técnico-Executivo, você já deve ter estudado a legislação que tem o reajuste de preço com base no critério do fator de produtividade, etc., esses fatores são calculados pelo Comitê Ténico-Executivo, que faz aquele desconto do IPCA, aquela compensação do, a Secretaria-Executiva dá um a embasamento técnico, mas esses fatores são mesmo criados no âmbito do Comitê e levados para a deliberação do Conselho de Ministros.

(E): Fiscalização. Como a CMED realiza a fiscalização do cumprimento das regras regulatórias e quem é encarregado dessa atividade dentro da CMED?

(E1): A Secretaria-Executiva e essa fiscalização é dentro do monitoramento. O primeiro passo dessa fiscalização se dá na submissão do preço inicial pelas empresas. $\mathrm{Na}$ maioria das vezes elas peem um preço superior que os critérios daqui determinam. E depois vem esse acompanhamento, principalmente, dentro das revistas, que é feito mês a mês.

(E2): E denúncias de prática de preço superior. Existem canais de atendimento ao consumidor aqui dentro da ANVISA, serviço de atendimento ao consumidor a ANVISA tem, e a CMED pode receber também manifestações do consumidor.

(E): E sobre essas revistas tão importantes ao monitoramento, vocês têm conhecimento sobre como é feito o monitoramento pela revista? É no ponto de venda?

(E1): A revista é o seguinte: a indústria passa a lista de preços dela mês a mês e as revistas compilam os dados de todas as empresas e fazem a publicação. Elas têm uma responsabilidade, que há um comunicado nosso aqui da CMED que responsabiliza as revistas solidariamente, porque elas também têm acesso a nossa lista de preços. Então se algum laboratório encaminha um preço, de um medicamento, por menos importante que ele seja, que seja superior ao teto, a revista responde solidariamente se ela publicar aquele preço que é maior do que o permitido pela CMED. A gente recebe aqui, por acordo, com 
as revistas, a edição delas física e por meio eletrônico também, para facilitar esse cruzamento com o nosso banco de dados.

(E): A indústria regulada e os consumidores participam do processo regulatório? Há a procedimentalizção dessa participação?

(E2): Até o momento, a legislação da CMED implementada não vai para consulta pública tal como as outras normas da ANVISA. Agora, com a indústria esse contato ocorre.

(E1): Há uma certa interação com, vamos dizer assim, os órgãos de classe da indústria, o Interfarma, o Sindusfarma, e quando há uma proposta de nova regulamentação, há mesmo que informalmente, uma discussão com eles, eles trazem as suas reivindicações aqui, que a gente também analisa.

(E2): Mas não existe um fluxo obrigatório nesse processo e nem na questão da consulta pública.

(E): Você quer dizer que não é institucionalizado?

(E2): É. Dentro da CMED ainda não. Com relação aos consumidores, nós já tivemos um contato muito grande com os Procons estaduais.

(E1): Há um tempo atrás a gente ia até as localidades fazer a divulgação do medicamento genérico e teto de preços direto com a população mesmo.

(E): Quando há uma mudança da norma regulatória normalmente se entra em contato com os órgãos que representam os consumidores? Mas com indústria sim, vocês me disseram que ela se posiciona.

(E1): Sim, e mesmo quando nã há uma regulamnetação, ela traz as suas reivindicações e pode ser que gere alguma regulamentação ali dentro do que elas estão requerendo.

(E): Existe alguma previsão de instrumento que garanta o accountability? Prestação de contas por parte da CMED, uma forma de controle da atuação da CMED?

(E1): Olha, isso agora com a lei de acesso a informação está começando a ser discutido no Comitê. Na última reuniã do Comitê que foi no final de maio foi tratado desse assunto para um início de regulamentação de informação, de acesso, dentro da CMED. Mas está muito no início.

(E): Para vocês, quais são as maiores dificuldades, gargalos e desafios para a regulação do mercado de medicamentos? 
(E2): Acho que o principal desafio é definir o modelo, que é muito importante, e atualizar em tempo a legislação, porque o mercado está a todo tempo mudando. Como nós trabalhamos com novas tecnologias, a legislação deve acompanhar esses avanços e isso é um grande desafio. A legislação conseguir contemplar todos os aspectos relacionados à inovação. Isso é muito complicado, você precificar a inovação. Acho que esse é um dos principais desafios hoje.

(E1): Você chegou a tomar conhecimento da Resolução n. 2, que cuida dos critérios de preço?

(E): Sim.

(E1): Ali a gente fez uma categorização por tipo de produto, só que com o avanço da tecnologia vão surgindo novas formas farmacêuticas, novos tipos de medicamentos, né E2, que muitas vezes não se encaixa perfeitamente naquilo que está descrito ali. Isso é um desafio. A gente tem que pensar em aprimorar esses critérios, para manter a atualização e até mesmo para a seguraná jurídica da própria empresa que é regulada, para que ela possa ter uma previsibilidade do preço dela que vai ser estabelecido.

(E): A indústria farmacêutica já ajuizou ações contra a CMED, as mais conhecidas foram aquelas que questionaram a constitucionalidade do controle de preços. A atuação da CMED já sofreu restrições ou intererência do Poder Judiciário?

(E1): Dentro dessa questão da constitucionalidade ainda não.Tem alguma coisa referente a processos administrativos que foi imposta uma multa e a empresa conseguiu uma suspensão. A maioria desses processos ainda não teve uma decisão final, entendeu? Mas alguns deles estão com a exigibilidade da multa suspensa.

(E2): Já teve um caso ta,bém de modificação de preços. O juiz modificou a decisão de um critério que a CMED usa para o estabelecimento de preço. A gente usa um critério para calcular preço e obviamente não atendeu ao que foi pretendido pela empresa e ao que foi pleiteado e o juiz determinou que a gente usasse uma outra metodologia de cálculo.

(E): Você tem maior conhecimento sobre esse caso. Houve recurso da CMED, já houve decisão final?

(E2): Olha, nesse caso específico eu não sei te informar se chegou na instância final.

(E1): É eu também não sei.

(E): O CAP é aplicado à venda de medicamentos para hospitais particulares queatendem o SUS? 
(E1): Não. Ele só vale para hospitais públicos, para compra pública mesmo.

(E): Agora eu gostaria de falar sobre o estudo do IDEC. Vocês têm conhecimento desse estudo?

(E1): Sim. Eles fazem de forma recorrente. Aí sai na mídia, eles mandam alguns questionamentos para a gente.

(E): O IDEC apurou que os preços encontrados nas farmácias são inferiores ao PMC. Eles acham que isso ocorre, resumidamente, em razão do monitoramento dos preços. Eles alegam que a CMED não monitora os preços no ponto de venda. Segundo o IDEC isso é importante, para saber qual é a prática de preços e depois incluí-la na formação do índice de reajuste. O que vocês acham disso?

(E1): Vou te responder tecnicamente. Ocorre isso realmente. Não há como negar. Aqui a gente pensa que a gente trabalha com o price cap, teto de preços, e que desse preço para baixo, eles podem praticar qualquer preço. Com a proliferação dessas grandes redes de drogarias, eles conseguem comprar a preços bem menores, praticando descontos consideráveis. Quanrto ao monitoramento e a gente utilizar, de certa forma, essa variação do preço em relação ao que é o PMC e ao que é realmente praticado, a gente fica um pouco atrelado à legislação. Na questão do reajuste, está muito bem definido como é formado o índice de reajuste, que é o IPCA, fator produtividade, índice intra e entre setores, preços relativos. É... a gente não teria como fazer isso a não ser que houvesse uma mudança na legislação que passasse a considerar isso.

(E2): O que já ocorreu, quando nós tínhamos convênios com esses Procons estaduais, havia pesquisas nos pontos de venda. Mas era uma coisa que estava atrelada a este convênio com o Procon, não era um procedimento que a CMED tinha que fazer obrigatoriamente, mas ...

(E1): Sim, era mais uma forma que a gente utilizava para monitorar os preços. Nesse caso do Procon, os preços eram monitorados mais para acompanhamento do mercado mesmo, da dinâmica desse mercado. Depois disso, a gente ainda teve um contrato com uma empresa, foi feita uma licitação com uma empresa particular de pesquisa que também realizou por um tempo essa pesquisa na farmácia. Não me mlembro quantas capitais, mas abrangia asa cinco regiões do país. Mas também apenas com o objetivo de acompanhar o mercado, de conhecimento, de ver, por exemplo, como o preço no Norte no país não têm tanto desconto quanto tem no Sudeste. 
(E): Uma pergunta mais técnica: o índice é fixado, como você disse, pelo fator produtividade, pelo fator intra setor e extra. O intra seria por exemplo a apuração da concorrência entre medicamentos genéricos, similares e de referência? Seria isso?

(E1): É o Z da fórmula?

(E): Isso.

(E1): Isso é difícil até pra mim. Isso foi uma questão colocada na época pelo Ministério da Fazenda que usou o genérico como um critério de mercado mais concorrencial. Então, assim, por o medicamento estar num mercado mais concorrencial ele ganharia, vamos dizer assim, um prêmio por isso, então o desconto do fator produtividade seria menor para eles. Foi estabelecido até $15 \%$, se eu não me engano, de 10 a $15 \%$, de 15 a $20 \%$, se eu não me engano, alguma coisa assim, de participação de genéricos naquele mercado por calsse terapêutica. Tem-se pensado em melhor esse critério de definição de mercado concorrencial.

(E): Em resumo, esse fator intra setor significa que quando tiver maior concorrência no setor econômico daquela classe terapêutica, o reajuste será menor?

(E1): Não. Com maior concorrência é justamente o contrário. Por exemplo, aqui [olha a resolução], nível 1: classe terapêutica, com participação de renda ou faturamento superior a $20 \%$, ou seja, muito concorrencial, onde o valor $\mathrm{Z}$ é sobre o valor de 2,47 , esse vai ganhar um prêmio, ele vai ter um reajuste maior, no mercado mais concorencial, por quê? $\mathrm{O} X$ é o fator produtividade que é descontado do IPCA. E aí, no mercado muito concorrencial, o $\mathrm{Z}$ fica com um valor igual ao do $\mathrm{X}$ que é a produtividade, então um anula o outro, e há o repasse quase todo do IPCA. Onde a produtividade foi maior, eles ganham um reajuste menor, porque ele já ganhou com a melhoria da produtividade dele, aquelas classes terapêuticas.

(E): E as informações sobre a concorrência entre cada classe terapêutica? Como eslas são apuradas?

(E1): Isso é feito aqui na CMED, por meio do nosso banco de dados. Por classe terapêutica, a gente consegue ver a participação de medicamentos genéricos.

(E): E em relação aos insumos? Informações referentes ao fator extra-setor?

(E1): Aí esses cálculos são... Tem no banco de dados da CMED, mas sei que há a captação de outros dados também. Aí eu não vou saber te dizer direitinho, porque essa parte é feita lá no Ministério da Fazenda, com o pessoal da SEAE.

(E): Bom... era isso. Muito obrigada. 


\section{Anexo D: segunda entrevista com dois membros da CMED (entrevista concedida sob a condição de manter o anonimato dos entrevistados)}

Observação: um dos membros entrevistado foi o mesmo da primeira entrevista.

(E): A CMED já exerceu a competência fixada nos incisos IX ("opinar sobre regulamentações que envolvam tributação de medicamentos") e XI ("sugerir a celebração de acordos e convênios internacionais relativos ao setor de medicamentos), do art. $6^{\circ}$, da Lei n. 10.742/03?

(E3): A competência do inciso IX já foi exercida pela CMED, por exemplo, com relação à exoneração da PIS/COFINS. A primeira vez foi realizada pela CAMED. Isso porque o PIS/COFINS tem um grande impacto sobre preços de medicamentos. Existe um decreto que fala sobre isso que deveria ser analisado todos os anos, mas isso não tem sido feito. Todos os projetos de lei acerca de tributação de medicamentos são enviados previamente à CMED para que essa câmara opine. Sobre a COFINS, existe uma lei sobre o assunto que estabelece o papel da CMED na isenção: Lei 10.147/03.

Quanto ao inciso XI, a CMED nunca exerceu essa competência.

(E): O IPCA considerado na elaboração do índice de reajuste de preços de medicamentos é o IPCA do setor de medicamentos ou o IPCA "genérico" calculado pelo IBGE?

(E1): É o IPCA geral.

(E):Como é composta a base de dados de preços de medicamentos que a CMED possui?

(E3): A base de dados na CMED nasceu no tempo da CAMED. Essa base foi alimentada pela primeira vez com os preços de medicamentos informados 1 ano e meio antes da criação...

Ela é composta pelos preços dos novos medicamentos, conforme a Resolução n.2, de 2004, e pelo preço médio dos medicamentos vendidos pelas empresas no ano anterior, conforme é repassado à CMED por meio de relatório anual.

(E): A ANVISA possui uma base de dados sobre preços de medicamentos diversa da base de dados da CMED?

(E1): A ANVISA e a CMED possuem base de cálculo comum.

(E): Qual é a diferença na regulação exercida pela antiga Câmara de Medicamentos (CAMED) e a atual Câmara de Regulação do Mercado de Medicamentos (CMED)? 
(E3): A CAMED surgiu na esteira da CPI dos medicamentos e tinha como objetivo principal frear o ajuste arbitrário de preços praticado pela indústria. $\mathrm{O}$ foco dessa regulação era a questão cambial. Ela se baseava numa fórmula paramétrica, que permitia o ajuste dos medicamentos com base na inflação até determinado teto. Qualquer preço abaixo do teto poderia ser praticado pela indústria. Assim, como a CMED, a CAMED utilizava o modelo de teto de preços, com a diferença de que não usava o price cap. Não se tratava, portanto, de congelamento ou tabelamento de preços. Além disso, no período da CAMED, eram reguladas apenas as produtoras e importadoras de medicamentos. Ficavam de fora as farmácias e drogarias. A CAMED foi um órgão criado para atuar pelo período de apenas 1 anos. Esse período foi prorrogado por mais um ano, até a criação da CMED.

Em contrapartida, a CMED foi criada sem limite de tempo de atuação. Com esse novo órgão, o escopo dos entes regulados aumentou, incluindo farmácias, drogarias e demais pessoas jurídicas, conforme previsto no art. $2^{\circ}$, da Lei. 10.742/03. O modelo regulatório ainda é o teto de preços, mas com a utilização do price cap. 
Anexo E: transcrição da entrevista com Basilia Aguirre, especialista em economia da saúde, pesquisadora da FIPE e coordenadora do monitoramento de preços realizado pela Câmara de Medicamentos (CAMED)

(E): A senhora já trabalhou com o monitoramento de preços de medicamentos. Em que consistia esse trabalho, em que época foi realizado e como era feito?

(B): A FIPE foi contratada pela CMED para fazer um levantamento de preços em 5 capitais do Brasil e, em outras 6 cidades, também era feito o levantamento pelo IPEAD, de Minas Gerais. Nós tínhamos uma metodologia, na verdade, era para calcular o índice de preços. A gente calculava o índice de preços, fazia o levantamento, com a mesma metodologia nestas 11 cidades, todas capitais. E nós fizemos isso acho que durante uns 4 anos. O levantamento era no nível das farmácias, os nossos pesquisadores iam nas farmácias e em cada farmácia eles coletavam em média 30 itens e eram coletados mais ou menos uns 600 itens todo mês, por mês, e a partir disso a gente calculava o índice e mandava os preços, máximo, mínimo e médio, e os índices de preços pra CMED.

(E): Vocês foram contratados pela CMED em que época a senhora lembra?

(B): Já faz tempo, viu. A pesquisa deve ter começado tipo 98, eu posso me certificar depois. Você me manda um email e eu te mando direitinho.

(E): Certo. Por que regular e monitorar os preços dos medicamentos no mercado farmacêutico?

(B): Bom, eu acho que isso ainda é um resquício da época do controle de preço da inflação, da década de 60, porque o controle de preço foi instituído no Brasil acho que em 66,67 , e ele era meio generalizado por conta da dificuldade do combate inflacionário e aí ele ficou, voltou sua necessidade na década de 80, mas aí não se conseguiu controlar nada, por causa da hiperinflação, veio o plano real, não tem por que controlar preço e eu sinceramente não entendo por que tem esse dito controle de preços de medicamentos. A justificativa oficial é que é um item essencial, que é uma coisa necessária e que precisa proteger o consumidor, mas eu tenho minhas dúvidas se faz esse serviço mesmo.

(E): Entendi. Quais foram as dificuldades encontradas na realização do monitoramento?

(B): Não tinha nenhuma dificuldade não. Os nossos pesquisadores eram bem recebidos, tinha uma farmácia ou outra que não queria, nós tivemos um problema em favela, mas aí por outras razões, não por causa das farmácias, mas causa do ambiente, 
coisa do pesquisador falar assim "nesse lugar eu não volto", de medo, mas nós não tivemos problemas não com os levantamentos.

(E): A qualidade do monitoramento dos preços pode comprometer a eficácia do controle de preços, da regulação?

(B): Pode. Você pode estar fazendo um trabalho de qualquer jeito, né [risadas]? Mas de qualquer forma, o monitoramento que era feito com a regulação que existe não acrescenta muito, sabe? A gente fazia o monitoramento, era um trabalho importante, mas eu acho que se não tivesse esse preço máximo ao consumidor eu acho que seria mais eficiente o monitoramento. É claro que a justificativa para o monitoramento é que existe o preço máximo ao consumidor, mas o que é que acontece, eu acho, acho que o pessoal do IDEC tem muita clareza nesse ponto: esse preço máximo ao consomidor ao invés dele servir como um preço máximo, acaba servindo como um preço mínimo quase. Aí eu acho que a justificativa principal da regulação se perde. A minha impressão é que se você não tivesse o PMC você teria muito mais concorrência, principalmente entre os genéricos. Os remédios de marca, eles têm tido uma questão de patente que precisa ser respeitada, porque senão não vai ter mais medicamento novo. Agora o genérico que já perdeu a patente, não consigo ver porque precisa ter esse controle. Tem vários laboratórios que produzem a mesmíssima coisa e o fato de você colocar o preço áximo faz com que eles fiquem tudo aqui em baixo [mostra como estivesse pouco abaixo do PMC], entendeu? Eu não preciso descer muito daqui, mas se você tirar isso daqui [o PMC] aí vai estabelecer uma briga entre eles, eu acho. E aí eu acho que você poderia ter uma redução de preço efetiva.

(E): Por que a senhora acha que a forma de monitoramento realizada na época em que existia a CAMED não foi adotada pela CMED? Houve aperfeiçoamento ou retrocesso na sua opinião?

(B): Eu não sei que monitoramento é realizado hoje em dia.

(E): Hoje em dia eles realizam monitoramento pelas revistas da ABCFARMA, eles não vão aos pontos de venda ...

(B): Isso nem pode ser chamado de monitoramento [risadas]. Então, acho que não existe monitoramento hoje. Pelo menos você tinha um levantamento dos preços efetivamente cobrados do consumidor, porque a gente perguntava... na verdade, a gente tava muito mais atrás do desconto do que do preço. $\mathrm{O}$ nosso pesquisador perguntava o preço, o desconto e o valor, e nós calculávamos a porcentagem do desconto. Ele não perguntava a porcentagem, mas o valor do desconto. Então a gente conseguiu o preço que 
era oferecido ao consumidor que pedia o desconto, porque tem muito consumidor que não pede o desconto e não leva o desconto. Se você não pode você paga o preço máximo. Geralmente você só tem o desconto quando você pede. A gente não perguntava os preços, assim, se você tem esse ou aquele plano de saúde ou se é de determinada professião tem certo desconto. Esses preços a gente não perguntava, a gente perguntava o preço para o consumidor normal, que não tem nenhum privilégio, nem de plano, nem de profissão, sindicato ou qualquer outra coisa. Enfim, a gente levantava o preço pelo qual o medicamento era comercializado com desconto. Geralmente não era grande mas era alguma coisa.

(E): Eles pararam de acompanhar os preços nos pontos de venda, né?

(B): É não sei eu sei que nós andamos participando de propostas. Eles pediram depois de vários anos que encerraram o contrato conosco, de vez em quando, eles mandam o pedido de proposta. Mas é uma coisa assim, no último contrato que nós tínhamos com eles, já estava num valor assim de 1 milhão e duzentos, pra 5 cidades, e do IPEAD, era um pouquinho mais baixo porque eram cidades menores. Aí, o teto da tomada de preços deles era de 300 mil reais. Brincadeira, né? Se há 14 anos artás o contrato era de 1 milhão e duzentos, 6 anos depois eles querem fazer o mesmo levantamento por 300 mil reais. A gente nem mandava porque a gente não ia validar um processo desse. Dizer que você vai fazer um levantamento desse em 11 cidades no Brasil, de 700 itens farmacêuticos por 300 mil reais é dizer que você não vai fazer nada, né. É impossível.

(E): Porque é um procedimento caro. Então custa caro monitorar o mercado.

(B): Levantamento de preço é caro. Todo o levantamento de preço. E se for querer fazer em várias cidades do Brasil, não tem como ficar barato. É por isso que as pessoas fazem pouco. O próprio IDEC faz, mas numa escala bem pequenininha. Porque é muito caro.

(E): Na sua opinião a regulação atual da CMED é eficiente do ponto de vista da performance reguladora ou poderia ser melhorada? Qual os aspectos positivos e negativos da atual regulação?

(B): Acho que eu já respondi, acho que esse preço máximo, a mim me parece, mais um des-serviço do que um serviço eu acho que avaliza um preço muito maior do que poderia ser cobrado, principalmente pros genéricos, porque o genérico não precisa pagar investimento. O investimento grosso feito é na pesquisa, produzir uma dipirona uma vez conhecida a fórmula não é um grande investimento, então, o genérico poderia certamente 
ser muito mais barato. Eu acho que a vantagem instrínseca do medicamento genérico, o que se aproveitaria dessa política, não é aproveitada na totalidade por causa dessa política de preço máximo.

(E): O IDEC chegou a perguntar ao Secretário Executivo da CMED por que o PMC era tão superior ao preço realmente praticado, porque o que acontece é que eles conseguem praticar um preço muito inferior do que o teto estipulado pela CMED.

(B): Sim.

(E): Ele disse que esse problema remete à criação da CMED em 2003, quando a indústria com medo de um congelamento de preços enviou preços com uma margem muito superior...

(B): Em 2003 congelamento?

(E): Em 2003 foi criada a CMED em substituição à CAMED, né? Antes existia a CAMED, com uma outra forma de regulação, com medo de uma alteração da forma de regulação para o congelamento, esses laboratórios enviaram à CMED informações sobre os preços dos medicamentos em patamares muito superiores do que realmente eram praticados.

(B): Ué, mas eles já não tinham os preços antes, da nossa pesquisa?

(E): Pois é, essa parte para mim não está muito clara. Essas informações não estão fechando.

(B): Pra começar, congelamento de preços em 2003 ninguém nunca pensaria nisso.

(E): A senhora acha então que não foi isso que aconteceu? O que ele disse ao IDEC foi o seguinte: a indústria com medo de uma mudança radical da forma regulatória jogou os preços para cima, a CMED, então se baseou nesses preços para a regulação.

(B): Mas a CMED não veio trabalhando a partir dos preços da CAMED? Eles já tinham essa referência. Por que resolveram pegar preços novos? Precisa perguntar para eles. [risadas]

(E): É verdade. É uma boa pergunta para eles. Em resumo, na sua opinião, uma forma de melhorar a regulação seria acabar com a forma do controle pelo price cap, acabar com esse PMC tão alto.

(B): Sim.

(E): Na sua opinião seria melhor liberar o mercado?

(B): Eu acho que sim, pelo menos experimentar durante um determinado período de tempo e ver o que acontece. 
(E): Entendi. Isso por conta da política dos genéricos. A senhora acha que isso seria mais eficiente?

(B): Sim. Principalmente por causa dos genéricos, porque os outros, não têm concorrência. O remédio que está sob patente não tem concorrente, aí não tem o que fazer, ou você compra aquele ou você compra aquele. Ou você não se trata. Talvez o mais correto fosse manter uma forma de preço máximo para remédio sob patente e liberar os demais e ver como o mercado se acomoda a isso. Eu acho que a indústria seria totalmente contra, porque eles iaam ficar desnorteados, eles não iam ter mais aquela referência e eu acho que seria capaz de se estabelecer uma guerra de preço e eu acho que eles tem muito medo disso. Eu acho que é muito conveniente pra indústria o preço máximo ao consumidor, principalmente para o genérico.

(E): Entendi. O Instituto de Defesa do Consumidor acredita que o principal problema da regulação atual dos preços consiste nessa diferença entre os preços praticados nos pontos de venda e os tetos estabelecidos pela CMED. Por que a senhora acha que existe essa diferença significativa? Isso sinaliza uma falha regulatória. Por que isso acontece. Por que a indústria, por exemplo, não joga o preço no teto ou mais próximo ao teto? Como eles conseguem praticar esses preços?

(B): Quem faz isso não é a indústria. Quem faz isso são as redes de farmácias e os distribuidores. Por que as farmácias pequenininhas de bairro essas compram dos distribuidores, elas não compram da indústria. Quem compra da indústria são os distribuidores e as redes. Eles compram em grande quantidade. Quem pode, portanto, dar os descontos são os distribuidores e as redes. A rede resolve o desconto que ela vai dar em função da concorrência que ela tem das outras redes. Em geral, os preços das redes é mais baixo do que o preço das farmácias independentes para o consumidor, porque as redes têm mais flexibilidade na política de preços delas do que as farmácias independentes que ficam dependendo do desconto a ser fornecido pelo distribuidor.

(E): Tá certo. Quais as principais diferenças entre a regulação exercida pela CMED e a regulação exercida pela CAMED?

(B): Não sei se é muito diferente. Não sei extamente como é feito hoje, mas o que se fazia quando a gente fazia o monitoramento era que anualmente, em março, juntava-se as indústrias, as empresas, que diziam qual era o preço de venda delas, o custo mais a margem de lucro. Em cima desse custo mais margem de lucro, a CAMED e posteriormente 
a CMED colocava os $30 \%$ para definir o preço máximo ao consumidor. Eu não sei se é feito diferente disso hoje é?

(E): Bom, eu sei que eles levam em consideração o fator produtividade, fator intra setor, extra setor pra definir os índices de reajuste. Para a fixação do preço inicial não, aí eles usam outro critério, dividem os medicamentos em categorias, se é genérico, ou seja, se a concorrência é maior, a interferêcia pra definição do preço inicial é uma e por aí vai. E uma coisa que eu até tava vendo no meu trabalho é que o Dr. Ivo Bucaresky e o antigo secretário o Dr. Luiz Milton utilizavam esse argumento de que havia uma dificuldade quanto aos medicamentos lançados antes de 2003, porque, a indústria teria jogado os preços desses medicamentos muito acima com medo de um congelamento, então os preços já estariam distorcidos e eles estariam trabalhando em cima dos preços distorcidos e a lei que estabelece as diretrizes da regulação não permite a redução de preços, só o rejuste pra cima. Então esse era o argumento deles. Aí eu pensei: bom, se esse é o argumento deles, vamos ver o que acontece com os medicamentos lançados depois de 2003, pra ver se para esses medicamentos a variação em relação ao PMC é grande como nos outros. Mas eu encontrei a seguinte dificuldade: como eu não tenho como ter acesso aos preços de todos os medicamentos, a não ser pelas pesquisas do IDEC e do PROCON, eu verifiquei que apenas 7 medicamentos foram lançados após 2003, dentre os medicamentos que eu tinha a relação de preços e desses 7 eu obtive dados que não me levaram a lugar nenhum, porque 3 deles tiveram uma variação de cerca de $10 \%$ do PMC, que é uma variação teoricamente pequena, e os outros 4 apresentaram variação de $50 \%$ outro apresentou variação de $99 \%$. Então, eu não consegui chegar a conclusão nenhuma sobre se quantos aos medicamentos lançados depois de 2003, a regulação tem sido eficiente, desse ponto de vista, eficiente no sentido de conseguir controlar a alta dos preços. Tecnicamente, não sei se isso apura mesmo eficiência, a senhora é quem pode me dizer melhor, a ideia que eu tenho de eficiência é que se o preço se aproxima do teto é porque a regulação está sendo razoavelmente eficiente porque tá contendo o preço de subir acima dela. Se a distância do teto é muito grande, quer dizer que ela está sendo inócua, não tá adiantando pra nada, porque eles estão prticando preços muito inferiores. E nesse resultado que eu cheguei quanto aos medicamentos lançados depois de 2003, houve praticamente um empate, tendo medicamentos que variaram pouco e medicamentos que variaram muito.

(B): Eu acho que essa sua ideia de eficiência no caso da regulação é correta, o objetivo da regulação é não deixar crescer, subir de mais o preço. Então, se está segurando 
o preço, de fato o preço no ponto de venda teria que estar coladinho ali no PMC. Se tem muito desconto é porque esse teto aí não tá servindo para nada, a não ser acobertar uma extração de excedente muito maior do consumidor, em alguns casos, do que seria necessário. O medicamento poderia ser vendido por um preço muito mais baixo. A gente não pegava discrepâncias tão grandes assim não, viu? Na média, o último levantamento que nós fizemos, o mais recente, para o Instituto ÉTICO. Eles contrataram a gente pra fazer esse levantamento, porque eles estavam com esse problema. E também meio influenciados pelo IDEC, e o objetivo era calcular o desconto médio. E o desconto médio, daquele conjunto, acho que foram um 600 itens também que nós fizemos o levantamento, foi em torno de $8 \%$, o que indicaria que não tá assim tão discrepante. Mas a questão é a seguinte: se um ou dois conseguem vender com o desconto de $30 \%$ e 100 vende com o desconto de $8 \%$, a média fica nos 8 . Então a média não quer dizer muita coisa, pois se 2 ou 3 conseguem vender por $30 \%$ de desconto significa que todos conseguiriam vender por $30 \%$ de desconto. E por que não vende? Porque tem essa couraça, esse PMC é uma couraça e protege esses interesses de vender mais caro, de extrair mais do consumidor. Esporadicamente, aparceia preço cima. A gente ia lá, voltava e a farmácia confirmava que o preço era acima. Era raro, mas tinha.

(E): Eu até peguei uns preços acima na pesquisa do PROCON. Essa pesquisa não compara com o PMC, no relatório. Então eu fui lá, peguei todos os itens que eles pesquisaram, entrei no site da CMED e busquei o PMC respectivo do período. E vi que aguns medicamentos pesquisados pelo PROCON estavam acima do PMC. Mas foi aminoria. A grande maioria apresentou o resultado da pesquisa do IDEC de descontos muito significativos.

(B): Não sabe da onde vem os decontos?

(E): Eu sei que os maiores descontos estão na capital, no interior os descontos foram bem menores, mas acho que por conta da concorrência. Foi o que eu imaginei. O PROCON verificou em cidades pequenas do interior e eu vi que a diferença do preço praticado no ponto de venda e o PMC é bem menor do que na capital.

(B): Eu acho que nós tivemos isso também. E acho que era menor também. É a concorrência deve ser menor no interior.Tem menos rede de farmácias também no interior, né, conforme a cidade. As redes estão mais concentradas nas cidades bem grandes e em São Paulo. As redes grandes também a concentração é quase total em São Paulo. 
(E):A Ione me disse, assim como o PROCON, que um das dificuldades dessas pesquisas foi que eles nao encontravam os mesmos medicamentos que existiam em São Paulo, no interior, por exemplo, os genéricos. Em São Paulo você tem muito mais opção de genérico do que no interior, que as vezes você tem só uma ou duas opções. Eu imaginei que isso deve influenciar também, né?

(B): É, deve.

(E): Certo, Professora. Era basicamente isso. Foi ótima a entrevista. Obrigada. 
Anexo F: Tabelas relativas ao cruzamento de dados obtidos nas pesquisas comparativas de preços do PROCON-SP ${ }^{422}$ e o PMC da CMED

- Medicamentos pesquisados pelo PROCON-SP, data da publicação do primeiro registro, conforme informações fornecidas pela ANVISA

Tabela 16 (Anexo F). Lista de medicamentos da pesquisa do Procon-SP

\begin{tabular}{|c|c|c|c|c|c|}
\hline Medicamento & Apresentação & Laboratório & $\begin{array}{l}\text { Processo de } \\
\text { registro }\end{array}$ & $\begin{array}{l}\text { Ano do } \\
\text { processo }\end{array}$ & $\begin{array}{c}\text { Data da primeira publicação do registro no } \\
\text { banco de dados da ANVISA }\end{array}$ \\
\hline Dexason & $\begin{array}{c}1 \mathrm{mg} / \mathrm{g} \text { creme } \\
\text { derm } 10 \mathrm{~g}\end{array}$ & Teuto & $\begin{array}{l}25000.014189- \\
88\end{array}$ & Não consta & $29 / 06 / 2001$ \\
\hline Carbolitium & $\begin{array}{l}300 \mathrm{mg} \\
50 \text { comp }\end{array}$ & Eurofarma & $\begin{array}{l}25992.012446- \\
70\end{array}$ & Não consta & $25 / 03 / 2002$ \\
\hline Rivotril & $\begin{array}{l}2 \mathrm{mg} \mathrm{cx} \\
20 \text { comp }\end{array}$ & Roche & $\begin{array}{l}25992.005875 / 7 \\
3\end{array}$ & Não consta & $21 / 01 / 2002$ \\
\hline Anafranil & $\begin{array}{l}25 \mathrm{mg} \\
20 \mathrm{drgs}\end{array}$ & Novartis & $\begin{array}{l}25992.017218- \\
67\end{array}$ & Não consta & $30 / 04 / 2001$ \\
\hline Plasil & $\begin{array}{c}10 \mathrm{mg} \\
20 \mathrm{comp}\end{array}$ & $\begin{array}{l}\text { Sanofi- } \\
\text { Aventis }\end{array}$ & $\begin{array}{l}25992.001021 / 6 \\
6\end{array}$ & Não consta & $04 / 11 / 2002$ \\
\hline Pamelor & $\begin{array}{c}25 \mathrm{mg} \\
30 \text { cápsulas }\end{array}$ & Novartis & $25000.01913 / 89$ & Não consta & $29 / 08 / 2002$ \\
\hline Fenergan & $\begin{array}{l}25 \mathrm{mg} \\
20 \text { comp }\end{array}$ & $\begin{array}{l}\text { Sanofi- } \\
\text { Aventis }\end{array}$ & $\begin{array}{l}25992.009259 / 4 \\
9\end{array}$ & Não consta & 04/06/2001 \\
\hline Voltaren & $\begin{array}{c}50 \mathrm{mg} \\
20 \mathrm{comp}\end{array}$ & Novartis & $\begin{array}{c}25992.016553 / 7 \\
4\end{array}$ & Não consta & $20 / 08 / 1998$ \\
\hline Mesigyna & $\begin{array}{l}50+5 \mathrm{mg} / \mathrm{ml} \text { inj } \\
\mathrm{c} / 1 \text { seringa } 1 \mathrm{ml}\end{array}$ & Bayer & $\begin{array}{c}25351.091837 / 2 \\
008-66\end{array}$ & 2008 & $13 / 04 / 2009$ \\
\hline Gardenal & $\begin{array}{l}100 \mathrm{mg} \\
20 \text { comp }\end{array}$ & $\begin{array}{l}\text { Sanofi- } \\
\text { Aventis }\end{array}$ & $\begin{array}{c}25992.001741 / 2 \\
0\end{array}$ & Não consta & 06/06/2001 \\
\hline Lasix & $\begin{array}{c}40 \mathrm{mg} \\
20 \text { comp }\end{array}$ & $\begin{array}{l}\text { Sanofi- } \\
\text { Aventis }\end{array}$ & $\begin{array}{c}25992.009665 / 6 \\
4\end{array}$ & Não consta & 20/12/1999 \\
\hline Clorana & $\begin{array}{c}25 \mathrm{mg} \\
30 \text { comp }\end{array}$ & $\begin{array}{l}\text { Sanofi- } \\
\text { Aventis }\end{array}$ & $\begin{array}{c}25992.011352 / 5 \\
8\end{array}$ & Não consta & 04/05/1984 \\
\hline Pantelmin & $\begin{array}{c}20 \mathrm{mg} / \mathrm{ml} \\
\text { suspensão } 30 \mathrm{ml}\end{array}$ & Janssen-Cilag & $\begin{array}{c}25992.019576 / 7 \\
1\end{array}$ & Não consta & 27/05/1998 \\
\hline Flagyl & $\begin{array}{l}250 \mathrm{mg} \\
20 \text { comp }\end{array}$ & $\begin{array}{l}\text { Sanofi- } \\
\text { Aventis }\end{array}$ & $\begin{array}{c}25351.003531 / 0 \\
1-96\end{array}$ & 2001 & $22 / 02 / 2001$ \\
\hline Aerolin & $\begin{array}{c}2 \mathrm{mg} / 5 \mathrm{ml} \\
\text { xpe } 120 \mathrm{ml}\end{array}$ & $\begin{array}{c}\text { Glaxosmithkli } \\
\text { ne }\end{array}$ & $\begin{array}{c}25992.000136 / 7 \\
0\end{array}$ & Não consta & $27 / 06 / 2001$ \\
\hline
\end{tabular}

${ }^{422}$ SÃO PAUlO (Estado). Fundação de Defesa do Consumidor do Estado de São Paulo. Pesquisas comparativas de preços de medicamentos. Disponível em:<http://www.procon.sp.gov.br/categoria.asp?id=903>. Acesso em 10 set. 2012. 
Tabela 17 (Anexo F). Pesquisa comparativa de preços (PROCON) - maio de 2010 São Paulo

\begin{tabular}{|c|c|c|c|c|c|}
\hline Medicamento & Apresentação & Laboratório & $\begin{array}{c}\text { Preço Médio em } \\
\text { Reais }\end{array}$ & $\begin{array}{l}\text { PMC em } \\
\text { Reais }\end{array}$ & $\begin{array}{c}\text { Variação } \\
(\%)\end{array}$ \\
\hline Dexason & $\begin{array}{c}1 \mathrm{mg} / \mathrm{g} \\
\text { creme dermatológico } \\
10 \mathrm{~g}\end{array}$ & Teuto & 6,17 & 8,59 & 39,22 \\
\hline Carbolitium & $300 \mathrm{mg} 50$ comprimidos & Eurofarma & 21,37 & 24,65 & 15,35 \\
\hline Rivotril & $\begin{array}{c}\text { 2mg caixa } \\
20 \text { comprimidos }\end{array}$ & Roche & 7,8 & 9,37 & 20,13 \\
\hline Anafranil & 25 mg 20 drágeas & Novartis & 21,8 & 24,62 & 12,94 \\
\hline Plasil & 10 mg 20 comprimidos & Sanofi-Aventis & 5,05 & 5,91 & 17,03 \\
\hline Pamelor & 25 mg 30 cápsulas & Novartis & 22,34 & 26,19 & 17,23 \\
\hline Fenergan & 25 mg 20 comprimidos & Sanofi-Aventis & 6,76 & 7,95 & 17,60 \\
\hline Voltaren & 50 mg 20 comprimidos & Novartis & 18,11 & 22,2 & 22,58 \\
\hline Mesigyna & $\begin{array}{c}50+5 \mathrm{mg} / \mathrm{ml} \text { injeção, } \\
1 \text { seringa/ } 1 \mathrm{ml}\end{array}$ & Bayer & 19,16 & 23,25 & 21,35 \\
\hline Gardenal & 100 mg 20 comprimidos & Sanofi-Aventis & 4,48 & 5,41 & 20,76 \\
\hline Lasix & 40mg 20 comprimidos & Sanofi-Aventis & 8,81 & 10,71 & 21,57 \\
\hline Clorana & 25 mg 30 comprimidos & Sanofi-Aventis & 5,31 & 6,25 & 17,70 \\
\hline Pantelmin & $\begin{array}{c}20 \mathrm{mg} / \mathrm{ml} \text { suspensão } \\
30 \mathrm{ml}\end{array}$ & Janssen-Cilag & 8,07 & 9,35 & 15,86 \\
\hline Flagyl & $250 \mathrm{mg} 20$ comprimidos & Sanofi-Aventis & 9,9 & 11,8 & 19,19 \\
\hline Aerolin & $2 \mathrm{mg} / 5 \mathrm{ml}$ xarope $120 \mathrm{ml}$ & Glaxosmithkline & 6,68 & 29,93 & 348,05 \\
\hline
\end{tabular}

PMC: preço máximo ao consumidor; PROCON: (Fundação) Proteção e Defesa do Consumidor.

Fonte: Elaboração própria 
Tabela 18 (Anexo F). Pesquisa comparativa de preços (PROCON) - maio de 2011 São Paulo

\begin{tabular}{|c|c|c|c|c|c|}
\hline \multirow[t]{2}{*}{ Medicamento } & \multirow[t]{2}{*}{ Apresentação } & \multirow[t]{2}{*}{ Laboratório } & \multirow{2}{*}{$\begin{array}{c}\text { Preço Médio em } \\
\text { Reais }\end{array}$} & \multirow{2}{*}{$\begin{array}{c}\text { PMC em } \\
\text { Reais }\end{array}$} & \multirow{2}{*}{$\begin{array}{c}\text { Variação } \\
(\%)\end{array}$} \\
\hline & & & & & \\
\hline Dexason & $1 \mathrm{mg} / \mathrm{g}$ creme dermatológico & Teuto & 6,09 & 9,12 & 49,75 \\
\hline & $10 \mathrm{~g}$ & & & & \\
\hline Carbolitium & 300 mg 50 comprimidos & Eurofarma & 20,72 & 26,13 & 26,11 \\
\hline Rivotril & $2 \mathrm{mg}$ caixa 20 comprimidos & Roche & 7,22 & 9,82 & 36,01 \\
\hline Anafranil & $25 \mathrm{mg} 20$ drágeas & Novartis & 20,75 & 26,1 & 25,78 \\
\hline Plasil & $10 \mathrm{mg} 20$ comprimidos & Sanofi-Aventis & 5,1 & 6,27 & 22,94 \\
\hline Pamelor & 25 mg 30 cápsulas & Novartis & 22,07 & 27,76 & 25,78 \\
\hline Fenergan & 25 mg 20 comprimidos & Sanofi-Aventis & 6,82 & 8,43 & 23,61 \\
\hline Voltaren & $50 \mathrm{mg} 20$ comprimidos & Novartis & 18,31 & 23,53 & 28,51 \\
\hline Mesigyna & $50+5 \mathrm{mg} / \mathrm{ml}$ injeção, & Bayer & 19,06 & 24,07 & 26,29 \\
\hline & 1 seringa/ $1 \mathrm{ml}$ & & & & \\
\hline Gardenal & $100 \mathrm{mg} 20$ comprimidos & Sanofi-Aventis & 4,53 & 5,66 & 24,94 \\
\hline Lasix & 40mg 20 comprimidos & Sanofi-Aventis & 8,99 & 11,36 & 26,36 \\
\hline Clorana & $25 \mathrm{mg} 30$ comprimidos & Sanofi-Aventis & 5,28 & 6,62 & 25,38 \\
\hline Pantelmin & $20 \mathrm{mg} / \mathrm{ml}$ suspensão $30 \mathrm{ml}$ & Janssen-Cilag & 7,86 & 9,91 & 26,08 \\
\hline Flagyl & 250 mg 20 comprimidos & Sanofi-Aventis & 9,89 & 12,5 & 26,39 \\
\hline Aerolin & $2 \mathrm{mg} / 5 \mathrm{ml}$ xarope $120 \mathrm{ml}$ & Glaxosmithkline & 6,43 & 8,07 & 25,51 \\
\hline
\end{tabular}

PMC: preço máximo ao consumidor; PROCON: (Fundação) Proteção e Defesa do Consumidor.

Fonte: Elaboração própria 
Tabela 19 (Anexo F). Pesquisa comparativa de preços - maio de 2012 - São Paulo

\begin{tabular}{|c|c|c|c|c|c|}
\hline Medicamento & Apresentação & Laboratório & Preço Médio em Reais & PMC em Reais & Diferença $(\%)$ \\
\hline Dexason & $1 \mathrm{mg} / \mathrm{g}$ creme dermatológico $10 \mathrm{~g}$ & Teuto & 5,6 & 9,65 & 72,32 \\
\hline Carbolitium & 300 mg 50 comprimidos & Eurofarma & 22,64 & 27,65 & 22,13 \\
\hline Rivotril & $2 \mathrm{mg}$ caixa 20 comprimidos & Roche & 8,86 & 10,39 & 17,27 \\
\hline Anafranil & 25 mg 20 drágeas & Novartis & 23,51 & 27,63 & 17,52 \\
\hline Plasil & $10 \mathrm{mg} 20$ comprimidos & Sanofi-Aventis & 5,68 & 6,64 & 16,90 \\
\hline Pamelor & 25 mg 30 cápsulas & Novartis & 24,27 & 29,38 & 21,05 \\
\hline Fenergan & $25 \mathrm{mg} 20$ comprimidos & Sanofi-Aventis & 7,66 & 8,93 & 16,58 \\
\hline Voltaren & $50 \mathrm{mg} 20$ comprimidos & Novartis & 20,45 & 24,92 & 21,86 \\
\hline Mesigyna & $50+5 \mathrm{mg} / \mathrm{ml}$ injeção, 1 seringa/ $1 \mathrm{ml}$ & Bayer & 20,36 & 24,02 & 17,98 \\
\hline Gardenal & $100 \mathrm{mg} 20$ comprimidos & Sanofi-Aventis & 5,07 & 6 & 18,34 \\
\hline Lasix & 40mg 20 comprimidos & Sanofi-Aventis & 10,13 & 12,03 & 18,76 \\
\hline Clorana & $25 \mathrm{mg} 30$ comprimidos & Sanofi-Aventis & 5,88 & 7,01 & 19,22 \\
\hline Pantelmin & $20 \mathrm{mg} / \mathrm{ml}$ suspensão $30 \mathrm{ml}$ & Janssen-Cilag & 9,05 & 10,49 & 15,91 \\
\hline Flagyl & $250 \mathrm{mg} 20$ comprimidos & Sanofi-Aventis & 11,26 & 13,23 & 17,50 \\
\hline Aerolin & $2 \mathrm{mg} / 5 \mathrm{ml}$ xarope $120 \mathrm{ml}$ & Glaxosmithkline & 6,6 & 8,05 & 21,97 \\
\hline Média & & & 12,468 & & 22,3538569 \\
\hline
\end{tabular}

PMC: preço máximo ao consumidor; PROCON: (Fundação) Proteção e Defesa do Consumidor.

Fonte: Elaboração própria 
Tabela 20(Anexo F). Pesquisa comparativa de preços - maio 2012 - Interior - Araçatuba

\begin{tabular}{|c|c|c|c|c|c|}
\hline Medicamento & Apresentação & Laboratório & Preço Médio em Reais & PMC em Reais & Diferença $(\%)$ \\
\hline Dexason & $1 \mathrm{mg} / \mathrm{g}$ creme dermatológico $10 \mathrm{~g}$ & Teuto & 5,75 & 9,65 & 67,83 \\
\hline Carbolitium & 300 mg 50 comprimidos & Eurofarma & 22,4 & 27,65 & 23,44 \\
\hline Rivotril & $2 \mathrm{mg}$ caixa 20 comprimidos & Roche & 8,13 & 10,39 & 27,80 \\
\hline Anafranil & 25 mg 20 drágeas & Novartis & 22,39 & 27,63 & 23,40 \\
\hline Plasil & $10 \mathrm{mg} 20$ comprimidos & Sanofi-Aventis & 5,44 & 6,64 & 22,06 \\
\hline Pamelor & 25 mg 30 cápsulas & Novartis & 23,49 & 29,38 & 25,07 \\
\hline Fenergan & $25 \mathrm{mg} 20$ comprimidos & Sanofi-Aventis & 7,3 & 8,93 & 22,33 \\
\hline Voltaren & $50 \mathrm{mg} 20$ comprimidos & Novartis & 20,04 & 24,92 & 24,35 \\
\hline Mesigyna & $50+5 \mathrm{mg} / \mathrm{ml}$ injeção, 1 seringa/ $1 \mathrm{ml}$ & Bayer & 19,33 & 24,02 & 24,26 \\
\hline Gardenal & $100 \mathrm{mg} 20$ comprimidos & Sanofi-Aventis & 4,84 & 6 & 23,97 \\
\hline Lasix & 40mg 20 comprimidos & Sanofi-Aventis & 9,53 & 12,03 & 26,23 \\
\hline Clorana & $25 \mathrm{mg} 30$ comprimidos & Sanofi-Aventis & 5,65 & 7,01 & 24,07 \\
\hline Pantelmin & $20 \mathrm{mg} / \mathrm{ml}$ suspensão $30 \mathrm{ml}$ & Janssen-Cilag & 8,69 & 10,49 & 20,71 \\
\hline Flagyl & $250 \mathrm{mg} 20$ comprimidos & Sanofi-Aventis & 10,79 & 13,23 & 22,61 \\
\hline Aerolin & $2 \mathrm{mg} / 5 \mathrm{ml}$ xarope $120 \mathrm{ml}$ & Glaxosmithkline & 6,71 & 8,05 & 19,97 \\
\hline Média & & & 12,03 & & 26,54 \\
\hline
\end{tabular}

PMC: preço máximo ao consumidor; PROCON: (Fundação) Proteção e Defesa do Consumidor Fonte: Elaboração própria 
Tabela 21 (Anexo F). Pesquisa comparativa de preços - maio 2012 - Interior - Bauru

\begin{tabular}{|c|c|c|c|c|c|}
\hline Medicamento & Apresentação & Laboratório & Preço Médio em Reais & PMC em Reais & Diferença $(\%)$ \\
\hline Dexason & $1 \mathrm{mg} / \mathrm{g}$ creme dermatológico $10 \mathrm{~g}$ & Teuto & 7,21 & 9,65 & 33,84 \\
\hline Carbolitium & $300 \mathrm{mg} 50$ comprimidos & Eurofarma & 24,33 & 27,65 & 13,65 \\
\hline Rivotril & $2 \mathrm{mg}$ caixa 20 comprimidos & Roche & 9,28 & 10,39 & 11,96 \\
\hline Anafranil & $25 \mathrm{mg} 20$ drágeas & Novartis & 24,31 & 27,63 & 13,66 \\
\hline Plasil & 10 mg 20 comprimidos & Sanofi-Aventis & 5,89 & 6,64 & 12,73 \\
\hline Pamelor & 25 mg 30 cápsulas & Novartis & 25,85 & 29,38 & 13,66 \\
\hline Fenergan & $25 \mathrm{mg} 20$ comprimidos & Sanofi-Aventis & 7,9 & 8,93 & 13,04 \\
\hline Voltaren & $50 \mathrm{mg} 20$ comprimidos & Novartis & 21,55 & 24,92 & 15,64 \\
\hline Mesigyna & $50+5 \mathrm{mg} / \mathrm{ml}$ injeção, 1 seringa/ $1 \mathrm{ml}$ & Bayer & 21,32 & 24,02 & 12,66 \\
\hline Gardenal & $100 \mathrm{mg} 20$ comprimidos & Sanofi-Aventis & 5,36 & 6 & 11,94 \\
\hline Lasix & 40mg 20 comprimidos & Sanofi-Aventis & 10,66 & 12,03 & 12,85 \\
\hline Clorana & $25 \mathrm{mg} 30$ comprimidos & Sanofi-Aventis & 6,33 & 7,01 & 10,74 \\
\hline Pantelmin & $20 \mathrm{mg} / \mathrm{ml}$ suspensão $30 \mathrm{ml}$ & Janssen-Cilag & 9,34 & 10,49 & 12,31 \\
\hline Flagyl & $250 \mathrm{mg} 20$ comprimidos & Sanofi-Aventis & 11,62 & 13,23 & 13,86 \\
\hline Aerolin & $2 \mathrm{mg} / 5 \mathrm{ml}$ xarope $120 \mathrm{ml}$ & Glaxosmithkline & 7,21 & 8,05 & 11,65 \\
\hline Média & & & 13,21 & & 14,28 \\
\hline
\end{tabular}

PMC: preço máximo ao consumidor; PROCON: (Fundação) Proteção e Defesa do Consumidor.

Fonte: Elaboração própria 
Tabela 22(Anexo F). Pesquisa comparativa de preços - maio 2012 - Interior - Caçapava

\begin{tabular}{|c|c|c|c|c|c|}
\hline Medicamento & Apresentação & Laboratório & Preço Médio em Reais & PMC em Reais & Diferença $(\%)$ \\
\hline Dexason & $1 \mathrm{mg} / \mathrm{g}$ creme dermatológico $10 \mathrm{~g}$ & Teuto & 7,05 & 9,65 & 36,88 \\
\hline Carbolitium & 300 mg 50 comprimidos & Eurofarma & 24,5 & 27,65 & 12,86 \\
\hline Rivotril & $2 \mathrm{mg}$ caixa 20 comprimidos & Roche & 9,3 & 10,39 & 11,72 \\
\hline Anafranil & 25 mg 20 drágeas & Novartis & 25,19 & 27,63 & 9,69 \\
\hline Plasil & 10 mg 20 comprimidos & Sanofi-Aventis & 5,96 & 6,64 & 11,41 \\
\hline Pamelor & 25 mg 30 cápsulas & Novartis & 24,48 & 29,38 & 20,02 \\
\hline Fenergan & $25 \mathrm{mg} 20$ comprimidos & Sanofi-Aventis & 8,03 & 8,93 & 11,21 \\
\hline Voltaren & $50 \mathrm{mg} 20$ comprimidos & Novartis & 22,17 & 24,92 & 12,40 \\
\hline Mesigyna & $50+5 \mathrm{mg} / \mathrm{ml}$ injeção, 1 seringa/ $1 \mathrm{ml}$ & Bayer & 21,63 & 24,02 & 11,05 \\
\hline Gardenal & 100 mg 20 comprimidos & Sanofi-Aventis & 5,31 & 6 & 12,99 \\
\hline Lasix & 40mg 20 comprimidos & Sanofi-Aventis & 10,42 & 12,03 & 15,45 \\
\hline Clorana & $25 \mathrm{mg} 30$ comprimidos & Sanofi-Aventis & 6,11 & 7,01 & 14,73 \\
\hline Pantelmin & $20 \mathrm{mg} / \mathrm{ml}$ suspensão $30 \mathrm{ml}$ & Janssen-Cilag & 9,47 & 10,49 & 10,77 \\
\hline Flagyl & $250 \mathrm{mg} 20$ comprimidos & Sanofi-Aventis & 11,6 & 13,23 & 14,05 \\
\hline Aerolin & $2 \mathrm{mg} / 5 \mathrm{ml}$ xarope $120 \mathrm{ml}$ & Glaxosmithkline & 6,69 & 8,05 & 20,33 \\
\hline Média & & & 13,19 & & 15,03 \\
\hline
\end{tabular}

PMC: preço máximo ao consumidor; PROCON: (Fundação) Proteção e Defesa do Consumidor.

Fonte: Elaboração própria 
Tabela 23 (Anexo F). Pesquisa comparativa de preços - maio 2012 - Interior - Campinas

\begin{tabular}{|c|c|c|c|c|c|}
\hline Medicamento & Apresentação & Laboratório & Preço Médio em Reais & PMC em Reais & Diferença $(\%)$ \\
\hline Dexason & $1 \mathrm{mg} / \mathrm{g}$ creme dermatológico $10 \mathrm{~g}$ & Teuto & 7,09 & 9,65 & 36,11 \\
\hline Carbolitium & 300 mg 50 comprimidos & Eurofarma & 25,02 & 27,65 & 10,51 \\
\hline Rivotril & $2 \mathrm{mg}$ caixa 20 comprimidos & Roche & 9,4 & 10,39 & 10,53 \\
\hline Anafranil & 25 mg 20 drágeas & Novartis & 24,83 & 27,63 & 11,28 \\
\hline Plasil & $10 \mathrm{mg} 20$ comprimidos & Sanofi-Aventis & 6,08 & 6,64 & 9,21 \\
\hline Pamelor & 25 mg 30 cápsulas & Novartis & 26,03 & 29,38 & 12,87 \\
\hline Fenergan & $25 \mathrm{mg} 20$ comprimidos & Sanofi-Aventis & 8,14 & 8,93 & 9,71 \\
\hline Voltaren & $50 \mathrm{mg} 20$ comprimidos & Novartis & 22,18 & 24,92 & 12,35 \\
\hline Mesigyna & $50+5 \mathrm{mg} / \mathrm{ml}$ injeção, 1 seringa/ $1 \mathrm{ml}$ & Bayer & 20,67 & 24,02 & 16,21 \\
\hline Gardenal & 100 mg 20 comprimidos & Sanofi-Aventis & 5,49 & 6 & 9,29 \\
\hline Lasix & 40mg 20 comprimidos & Sanofi-Aventis & 10,14 & 12,03 & 18,64 \\
\hline Clorana & $25 \mathrm{mg} 30$ comprimidos & Sanofi-Aventis & 6,3 & 7,01 & 11,27 \\
\hline Pantelmin & $20 \mathrm{mg} / \mathrm{ml}$ suspensão $30 \mathrm{ml}$ & Janssen-Cilag & 9,18 & 10,49 & 14,27 \\
\hline Flagyl & $250 \mathrm{mg} 20$ comprimidos & Sanofi-Aventis & 11,86 & 13,23 & 11,55 \\
\hline Aerolin & $2 \mathrm{mg} / 5 \mathrm{ml}$ xarope $120 \mathrm{ml}$ & Glaxosmithkline & 6,54 & 8,05 & 23,09 \\
\hline Média & & & 13,26 & & 14,45 \\
\hline
\end{tabular}

PMC: preço máximo ao consumidor; PROCON: (Fundação) Proteção e Defesa do Consumidor.

Fonte: Elaboração própria 
Tabela 24 (Anexo F). Pesquisa comparativa de preços - maio 2012 - Interior -Jundiaí

\begin{tabular}{|c|c|c|c|c|c|}
\hline Medicamento & Apresentação & Laboratório & Preço Médio em Reais & PMC em Reais & Diferença (\%) \\
\hline Dexason & $1 \mathrm{mg} / \mathrm{g}$ creme dermatológico $10 \mathrm{~g}$ & Teuto & 8,68 & 9,65 & 11,18 \\
\hline Carbolitium & $300 \mathrm{mg} 50$ comprimidos & Eurofarma & 24,77 & 27,65 & 11,63 \\
\hline Rivotril & $2 \mathrm{mg}$ caixa 20 comprimidos & Roche & 9,64 & 10,39 & 7,78 \\
\hline Anafranil & $25 \mathrm{mg} 20$ drágeas & Novartis & 25,45 & 27,63 & 8,57 \\
\hline Plasil & $10 \mathrm{mg} 20$ comprimidos & Sanofi-Aventis & 6,19 & 6,64 & 7,27 \\
\hline Pamelor & 25 mg 30 cápsulas & Novartis & 27,06 & 29,38 & 8,57 \\
\hline Fenergan & $25 \mathrm{mg} 20$ comprimidos & Sanofi-Aventis & 8,28 & 8,93 & 7,85 \\
\hline Voltaren & $50 \mathrm{mg} 20$ comprimidos & Novartis & 23,06 & 24,92 & 8,07 \\
\hline Mesigyna & $50+5 \mathrm{mg} / \mathrm{ml}$ injeção, 1 seringa/ $1 \mathrm{ml}$ & Bayer & 22,02 & 24,02 & 9,08 \\
\hline Gardenal & $100 \mathrm{mg} 20$ comprimidos & Sanofi-Aventis & 5,59 & 6 & 7,33 \\
\hline Lasix & 40mg 20 comprimidos & Sanofi-Aventis & 11,06 & 12,03 & 8,77 \\
\hline Clorana & $25 \mathrm{mg} 30$ comprimidos & Sanofi-Aventis & 6,49 & 7,01 & 8,01 \\
\hline Pantelmin & $20 \mathrm{mg} / \mathrm{ml}$ suspensão $30 \mathrm{ml}$ & Janssen-Cilag & 9,7 & 10,49 & 8,14 \\
\hline Flagyl & $250 \mathrm{mg} 20$ comprimidos & Sanofi-Aventis & 12,24 & 13,23 & 8,09 \\
\hline Aerolin & $2 \mathrm{mg} / 5 \mathrm{ml}$ xarope $120 \mathrm{ml}$ & Glaxosmithkline & 7,53 & 8,05 & 6,91 \\
\hline Média & & & 13,85 & & 8,48 \\
\hline
\end{tabular}

PMC: preço máximo ao consumidor; PROCON: (Fundação) Proteção e Defesa do Consumidor Fonte: Elaboração própria 
Tabela 25 (Anexo F). Pesquisa comparativa de preços - maio 2012 - Interior - Marília

\begin{tabular}{|c|c|c|c|c|c|}
\hline Medicamento & Apresentação & Laboratório & Preço Médio em Reais & PMC em Reais & Diferença (\%) \\
\hline Dexason & $1 \mathrm{mg} / \mathrm{g}$ creme dermatológico $10 \mathrm{~g}$ & Teuto & 7,04 & 9,65 & 37,07 \\
\hline Carbolitiu & $300 \mathrm{mg} 50$ comprimidos & Eurofarma & 23,64 & 27,65 & 16,96 \\
\hline Rivotril & $2 \mathrm{mg}$ caixa 20 comprimidos & Roche & 9,08 & 10,39 & 14,43 \\
\hline Anafranil & 25 mg 20 drágeas & Novartis & 23,01 & 27,63 & 20,08 \\
\hline Plasil & $10 \mathrm{mg} 20$ comprimidos & Sanofi-Aventis & 5,83 & 6,64 & 13,89 \\
\hline Pamelor & 25 mg 30 cápsulas & Novartis & 25,61 & 29,38 & 14,72 \\
\hline Fenergan & $25 \mathrm{mg} 20$ comprimidos & Sanofi-Aventis & 7,79 & 8,93 & 14,63 \\
\hline Voltaren & $50 \mathrm{mg} 20$ comprimidos & Novartis & 21,54 & 24,92 & 15,69 \\
\hline Mesigyna & $50+5 \mathrm{mg} / \mathrm{ml}$ injeção, 1 seringa/ $1 \mathrm{ml}$ & Bayer & 20,87 & 24,02 & 15,09 \\
\hline Gardenal & 100 mg 20 comprimidos & Sanofi-Aventis & 5,3 & 6 & 13,21 \\
\hline Lasix & 40mg 20 comprimidos & Sanofi-Aventis & 10,39 & 12,03 & 15,78 \\
\hline Clorana & $25 \mathrm{mg} 30$ comprimidos & Sanofi-Aventis & 6,13 & 7,01 & 14,36 \\
\hline Pantelmin & $20 \mathrm{mg} / \mathrm{ml}$ suspensão $30 \mathrm{ml}$ & Janssen-Cilag & 9,04 & 10,49 & 16,04 \\
\hline Flagyl & 250 mg 20 comprimidos & Sanofi-Aventis & 11,56 & 13,23 & 14,45 \\
\hline Aerolin & $2 \mathrm{mg} / 5 \mathrm{ml}$ xarope $120 \mathrm{ml}$ & Glaxosmithkline & 7,04 & 8,05 & 14,35 \\
\hline Média & & & 12,92 & & 16,71 \\
\hline
\end{tabular}

PMC: preço máximo ao consumidor; PROCON: (Fundação) Proteção e Defesa do Consumidor.

Fonte: Elaboração própria 
Tabela 26 (Anexo F). Pesquisa comparativa de preços - maio 2012 - Interior - Presidente Prudente

\begin{tabular}{|c|c|c|c|c|c|}
\hline Medicamento & Apresentação & Laboratório & Preço Médio em Reais & PMC em Reais & Diferença $(\%)$ \\
\hline Dexason & $1 \mathrm{mg} / \mathrm{g}$ creme dermatológico $10 \mathrm{~g}$ & Teuto & 8,76 & 9,65 & 10,16 \\
\hline Carboltium & 300 mg 50 comprimidos & Eurofarma & 24,81 & 27,65 & 11,45 \\
\hline Rivotril & $2 \mathrm{mg}$ caixa 20 comprimidos & Roche & 9,29 & 10,39 & 11,84 \\
\hline Anafranil & $25 \mathrm{mg} 20$ drágeas & Novartis & 24,77 & 27,63 & 11,55 \\
\hline Plasil & $10 \mathrm{mg} 20$ comprimidos & Sanofi-Aventis & 5,97 & 6,64 & 11,22 \\
\hline Pamelor & 25 mg 30 cápsulas & Novartis & 26,24 & 29,38 & 11,97 \\
\hline Fenergan & $25 \mathrm{mg} 20$ comprimidos & Sanofi-Aventis & 7,99 & 8,93 & 11,76 \\
\hline Voltaren & $50 \mathrm{mg} 20$ comprimidos & Novartis & 22,29 & 24,92 & 11,80 \\
\hline Mesigyna & $50+5 \mathrm{mg} / \mathrm{ml}$ injeção, 1 seringa/ $1 \mathrm{ml}$ & Bayer & 22,04 & 24,02 & 8,98 \\
\hline Gardenal & $100 \mathrm{mg} 20$ comprimidos & Sanofi-Aventis & 5,38 & 6 & 11,52 \\
\hline Lasix & 40mg 20 comprimidos & Sanofi-Aventis & 10,79 & 12,03 & 11,49 \\
\hline Clorana & $25 \mathrm{mg} 30$ comprimidos & Sanofi-Aventis & 6,28 & 7,01 & 11,62 \\
\hline Pantelmin & $20 \mathrm{mg} / \mathrm{ml}$ suspensão $30 \mathrm{ml}$ & Janssen-Cilag & 9,24 & 10,49 & 13,53 \\
\hline Flagyl & $250 \mathrm{mg} 20$ comprimidos & Sanofi-Aventis & 11,84 & 13,23 & 11,74 \\
\hline Aerolin & $2 \mathrm{mg} / 5 \mathrm{ml}$ xarope $120 \mathrm{ml}$ & Glaxosmithkline & 7,36 & 8,05 & 9,38 \\
\hline Média & & & 13,53 & & 11,33 \\
\hline
\end{tabular}

PMC: preço máximo ao consumidor; PROCON: (Fundação) Proteção e Defesa do Consumidor Fonte: Elaboração própria 
Tabela 27 (Anexo F). Pesquisa comparativa de preços - maio 2012 - Interior - Santos

\begin{tabular}{|c|c|c|c|c|c|}
\hline Medicamento & Apresentação & Laboratório & Preço Médio em Reais & PMC em Reais & Diferença $(\%)$ \\
\hline Dexason & $1 \mathrm{mg} / \mathrm{g}$ creme dermatológico $10 \mathrm{~g}$ & Teuto & 7,44 & 9,65 & 29,70 \\
\hline Carbolitium & $300 \mathrm{mg} 50$ comprimidos & Eurofarma & 24,22 & 27,65 & 14,16 \\
\hline Rivotril & $2 \mathrm{mg}$ caixa 20 comprimidos & Roche & 9,39 & 10,39 & 10,65 \\
\hline Anafranil & $25 \mathrm{mg} 20$ drágeas & Novartis & 24,33 & 27,63 & 13,56 \\
\hline Plasil & $10 \mathrm{mg} 20$ comprimidos & Sanofi-Aventis & 5,99 & 6,64 & 10,85 \\
\hline Pamelor & 25 mg 30 cápsulas & Novartis & 26,04 & 29,38 & 12,83 \\
\hline Fenergan & $25 \mathrm{mg} 20$ comprimidos & Sanofi-Aventis & 8,1 & 8,93 & 10,25 \\
\hline Voltaren & $50 \mathrm{mg} 20$ comprimidos & Novartis & 21,81 & 24,92 & 14,26 \\
\hline Mesigyna & $50+5 \mathrm{mg} / \mathrm{ml}$ injeção, 1 seringa $/ 1 \mathrm{ml}$ & Bayer & 20,24 & 24,02 & 18,68 \\
\hline Gardenal & $100 \mathrm{mg} 20$ comprimidos & Sanofi-Aventis & 5,45 & 6 & 10,09 \\
\hline Lasix & 40mg 20 comprimidos & Sanofi-Aventis & 10,35 & 12,03 & 16,23 \\
\hline Clorana & $25 \mathrm{mg} 30$ comprimidos & Sanofi-Aventis & 6,2 & 7,01 & 13,06 \\
\hline Pantelmin & $20 \mathrm{mg} / \mathrm{ml}$ suspensão $30 \mathrm{ml}$ & Janssen-Cilag & 9,24 & 10,49 & 13,53 \\
\hline Flagyl & $250 \mathrm{mg} 20$ comprimidos & Sanofi-Aventis & 11,79 & 13,23 & 12,21 \\
\hline Aerolin & $2 \mathrm{mg} / 5 \mathrm{ml}$ xarope $120 \mathrm{ml}$ & Glaxosmithklie & 7,3 & 8,05 & 10,27 \\
\hline Média & & & 13,19 & & 14,02 \\
\hline
\end{tabular}

PMC: preço máximo ao consumidor; PROCON: (Fundação) Proteção e Defesa do Consumidor Fonte: Elaboração própria 
Tabela 28 (Anexo F). Pesquisa comparativa de preços - maio 2012 - Interior - São José dos Campos

\begin{tabular}{|c|c|c|c|c|c|}
\hline Medicamento & Apresentação & Laboratório & Preço Médio em Reais & PMC em Reais & Diferença $(\%)$ \\
\hline Dexason & $1 \mathrm{mg} / \mathrm{g}$ creme dermatológico $10 \mathrm{~g}$ & Teuto & 5,31 & 9,65 & 81,73 \\
\hline Carbolitium & $300 \mathrm{mg} 50$ comprimidos & Eurofarma & 22,55 & 27,65 & 22,62 \\
\hline Rivotril & $2 \mathrm{mg}$ caixa 20 comprimidos & Roche & 8,62 & 10,39 & 20,53 \\
\hline Anafranil & 25 mg 20 drágeas & Novartis & 22,63 & 27,63 & 22,09 \\
\hline Plasil & $10 \mathrm{mg} 20$ comprimidos & Sanofi-Aventis & 5,61 & 6,64 & 18,36 \\
\hline Pamelor & 25 mg 30 cápsulas & Novartis & 23,97 & 29,38 & 22,57 \\
\hline Fenergan & $25 \mathrm{mg} 20$ comprimidos & Sanofi-Aventis & 7,59 & 8,93 & 17,65 \\
\hline Voltaren & $50 \mathrm{mg} 20$ comprimidos & Novartis & 20,59 & 24,92 & 21,03 \\
\hline Mesigyna & $50+5 \mathrm{mg} / \mathrm{ml}$ injeção, 1 seringa/ $1 \mathrm{ml}$ & Bayer & 19,61 & 24,02 & 22,49 \\
\hline Gardenal & $100 \mathrm{mg} 20$ comprimidos & Sanofi-Aventis & 5,02 & 6 & 19,52 \\
\hline Lasix & 40mg 20 comprimidos & Sanofi-Aventis & 9,7 & 12,03 & 24,02 \\
\hline Clorana & $25 \mathrm{mg} 30$ comprimidos & Sanofi-Aventis & 5,71 & 7,01 & 22,77 \\
\hline Pantelmin & $20 \mathrm{mg} / \mathrm{ml}$ suspensão $30 \mathrm{ml}$ & Janssen-Cilag & 8,62 & 10,49 & 21,69 \\
\hline Flagyl & $250 \mathrm{mg} 20$ comprimidos & Sanofi-Aventis & 10,87 & 13,23 & 21,71 \\
\hline Aerolin & $2 \mathrm{mg} / 5 \mathrm{ml}$ xarope $120 \mathrm{ml}$ & Glaxosmithkline & 6,77 & 8,05 & 18,91 \\
\hline Média & & & 12,21 & & 25,18 \\
\hline
\end{tabular}

PMC: preço máximo ao consumidor; PROCON: (Fundação) Proteção e Defesa do Consumidor Fonte: Elaboração própria 
Tabela 29 (Anexo F). Pesquisa comparativa de preços - maio 2012 - Interior - Sorocaba

\begin{tabular}{|c|c|c|c|c|c|}
\hline Medicamento & Apresentação & Laboratório & Preço Médio em Reais & PMC em Reais & Diferença $(\%)$ \\
\hline Dexason & $1 \mathrm{mg} / \mathrm{g}$ creme dermatológico $10 \mathrm{~g}$ & Teuto & 8,84 & 9,65 & 9,16 \\
\hline Carbolitium & 300 mg 50 comprimidos & Eurofarma & 24,54 & 27,65 & 12,67 \\
\hline Rivotril & $2 \mathrm{mg}$ caixa 20 comprimidos & Roche & 8,96 & 10,39 & 15,96 \\
\hline Anafranil & 25 mg 20 drágeas & Novartis & 24,51 & 27,63 & 12,73 \\
\hline Plasil & $10 \mathrm{mg} 20$ comprimidos & Sanofi-Aventis & 5,89 & 6,64 & 12,73 \\
\hline Pamelor & 25 mg 30 cápsulas & Novartis & 25,38 & 29,38 & 15,76 \\
\hline Fenergan & $25 \mathrm{mg} 20$ comprimidos & Sanofi-Aventis & 7,89 & 8,93 & 13,18 \\
\hline Voltaren & $50 \mathrm{mg} 20$ comprimidos & Novartis & 20,86 & 24,92 & 19,46 \\
\hline Mesigyna & $50+5 \mathrm{mg} / \mathrm{ml}$ injeção, 1 seringa/ $1 \mathrm{ml}$ & Bayer & 19,35 & 24,02 & 24,13 \\
\hline Gardenal & 100 mg 20 comprimidos & Sanofi-Aventis & 5,07 & 6 & 18,34 \\
\hline Lasix & 40mg 20 comprimidos & Sanofi-Aventis & 9,69 & 12,03 & 24,15 \\
\hline Clorana & $25 \mathrm{mg} 30$ comprimidos & Sanofi-Aventis & 5,85 & 7,01 & 19,83 \\
\hline Pantelmin & $20 \mathrm{mg} / \mathrm{ml}$ suspensão $30 \mathrm{ml}$ & Janssen-Cilag & 8,62 & 10,49 & 21,69 \\
\hline Flagyl & $250 \mathrm{mg} 20$ comprimidos & Sanofi-Aventis & 11,18 & 13,23 & 18,34 \\
\hline Aerolin & $2 \mathrm{mg} / 5 \mathrm{ml}$ xarope $120 \mathrm{ml}$ & Glaxosmithkline & 6,88 & 8,05 & 17,01 \\
\hline Média & & & 12,9 & & 17,01 \\
\hline
\end{tabular}

PMC: preço máximo ao consumidor; PROCON: (Fundação) Proteção e Defesa do Consumidor Fonte: Elaboração própria 
Tabela 30 (Anexo F). Pesquisa comparativa de preços - maio 2012 - Interior - Taubaté

\begin{tabular}{|c|c|c|c|c|c|}
\hline Medicamento & Apresentação & Laboratório & Preço Médio em Reais & PMC em Reais & Diferença $(\%)$ \\
\hline Dexason & $1 \mathrm{mg} / \mathrm{g}$ creme dermatológico $10 \mathrm{~g}$ & Teuto & 6,85 & 9,65 & 40,88 \\
\hline Carbolitium & $300 \mathrm{mg} 50$ comprimidos & Eurofarma & 20,37 & 27,65 & 35,74 \\
\hline Rivotril & $2 \mathrm{mg}$ caixa 20 comprimidos & Roche & 9,55 & 10,39 & 8,80 \\
\hline Anafranil & 25 mg 20 drágeas & Novartis & 23,29 & 27,63 & 18,63 \\
\hline Plasil & $10 \mathrm{mg} 20$ comprimidos & Sanofi-Aventis & 5,74 & 6,64 & 15,68 \\
\hline Pamelor & 25 mg 30 cápsulas & Novartis & 24,63 & 29,38 & 19,29 \\
\hline Fenergan & $25 \mathrm{mg} 20$ comprimidos & Sanofi-Aventis & 7,73 & 8,93 & 15,52 \\
\hline Voltaren & $50 \mathrm{mg} 20$ comprimidos & Novartis & 21,21 & 24,92 & 17,49 \\
\hline Mesigyna & $50+5 \mathrm{mg} / \mathrm{ml}$ injeção, 1 seringa/ $1 \mathrm{ml}$ & Bayer & 20,33 & 24,02 & 18,15 \\
\hline Gardenal & $100 \mathrm{mg} 20$ comprimidos & Sanofi-Aventis & 5,07 & 6 & 18,34 \\
\hline Lasix & 40mg 20 comprimidos & Sanofi-Aventis & 10,21 & 12,03 & 17,83 \\
\hline Clorana & $25 \mathrm{mg} 30$ comprimidos & Sanofi-Aventis & 5,88 & 7,01 & 19,22 \\
\hline Pantelmin & $20 \mathrm{mg} / \mathrm{ml}$ suspensão $30 \mathrm{ml}$ & Janssen-Cilag & 8,63 & 10,49 & 21,55 \\
\hline Flagyl & $250 \mathrm{mg} 20$ comprimidos & Sanofi-Aventis & 11,75 & 13,23 & 12,60 \\
\hline Aerolin & $2 \mathrm{mg} / 5 \mathrm{ml}$ xarope $120 \mathrm{ml}$ & Glaxosmithkline & 6,95 & 8,05 & 15,83 \\
\hline Média & & & 12,54 & & 19,7 \\
\hline
\end{tabular}

PMC: preço máximo ao consumidor; PROCON: (Fundação) Proteção e Defesa do Consumidor Fonte: Elaboração própria 


\section{Anexo G: Banco de dados elaborado, com base em levantamento de preços do IDEC $^{423}$}

Tabela 31 (Anexo G). Referência único no mercado - Pesquisa IDEC 2009

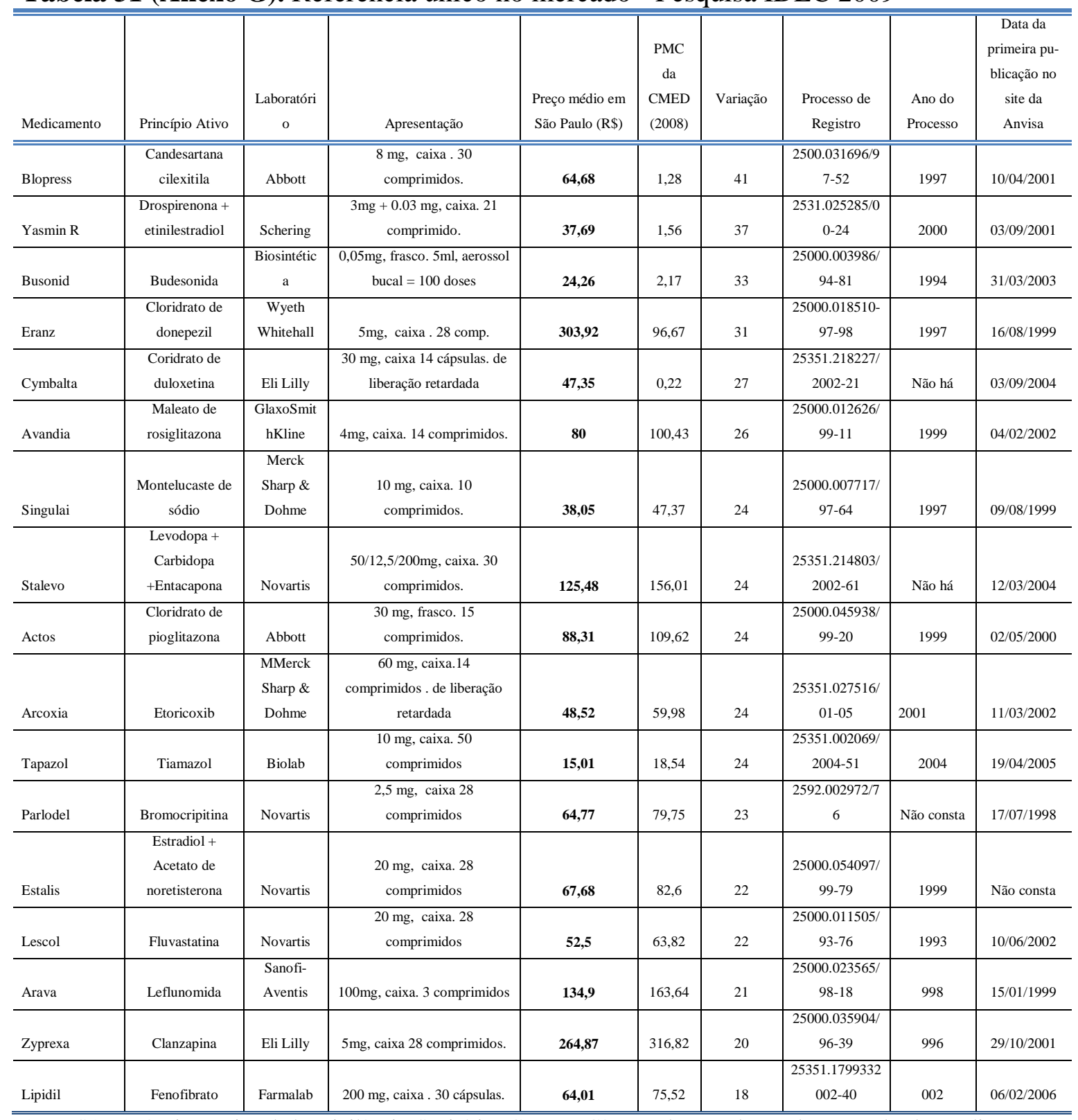

ANVISA: Agência Nacional de Vigilância Sanitária; CMED: Câmara de Regulação do Mercado de Medicamentos; IDEC: Instituto Brasileiro de Defesa do Consumidor; mg: miligrama; ml: mililitro; PMC: preço máximo ao consumidor.

${ }^{4 \angle\lrcorner}$ REMEDIO pro bolso. Revista do IDEC. São Paulo, n. 130, p.16-20, mar. 2009; MEIO cheio ou meio vazio? Revista do IDEC. São Paulo, n.142, p. 22-25, abr. 2010; e DIFERENÇA além da conta. Revista do IDEC. São Paulo, n.162, p.16-19, fev. 2012. p. 18-19.

Vale registrar que no que diz respeito ao levantamento de preços de 2009 realizado pelo IDEC não foi elaborada tabela com o cruzamento dos preços dos genéricos e o PMC, vez que não foi possível identificar o processo e a data de publicação do registro no sítio eletrônico da ANVISA, porquanto não consta da pesquisa do IDEC os laboratórios produtores de medicamentos genéricos. 
Tabela 32 (Anexo G). Referência com similar - Pesquisa IDEC 2009

\begin{tabular}{|c|c|c|c|c|c|c|c|c|c|}
\hline Medicamentos & Princípio Ativo & Laboratório & Apresentação & $\begin{array}{l}\text { Preço médio em } \\
\text { São Paulo }(\mathrm{R} \$) \\
\end{array}$ & $\begin{array}{c}\text { PMC } \\
\text { da } \\
\text { CMED } \\
(2008) \\
\end{array}$ & $\begin{array}{l}\text { Vari } \\
\text { ação } \\
(\%)\end{array}$ & Processo de Registro & $\begin{array}{c}\text { Ano do } \\
\text { Processo } \\
\end{array}$ & $\begin{array}{c}\text { Data da } \\
\text { primeira } \\
\text { publicação no } \\
\text { site da Anvisa } \\
\end{array}$ \\
\hline Imuran & Azatioprina & $\begin{array}{c}\text { GlaxoSmit } \\
\text { hKline }\end{array}$ & $\begin{array}{l}50 \text { mg, caixa. } 50 \\
\text { comprimidos. }\end{array}$ & 108,53 & 133,69 & 23 & $25992.001302 / 65$ & $\begin{array}{l}\text { Não } \\
\text { consta }\end{array}$ & 02/02/1996 \\
\hline Citalor & Atorvastatina & Pfizer & $\begin{array}{l}10 \text { mg, caixa.. } 30 \\
\text { comprimidos. }\end{array}$ & 92,22 & 112,68 & 22 & $25000.004841 / 97-87$ & 1997 & $03 / 10 / 2001$ \\
\hline Postinor & Levonorgestrel & Aché & $\begin{array}{l}1,5 \mathrm{mg} \text {, caixa.. } 1 \\
\text { comprimidos. }\end{array}$ & 18,89 & 22,86 & 21 & $25000.001797 / 99-42$ & 1999 & $07 / 06 / 2010$ \\
\hline Diane 35 & $\begin{array}{c}\text { Acetato de } \\
\text { ciproterona } \\
+ \text { Etinilestradiol }\end{array}$ & Schering & $\begin{array}{c}2 \mathrm{mg}+0,035 \mathrm{mg} \text {, caixa. } 21 \\
\text { drágeas }\end{array}$ & 14,78 & 17,75 & 20 & $25991.008629 / 79$ & $\begin{array}{l}\text { Não } \\
\text { consta }\end{array}$ & $23 / 10 / 2002$ \\
\hline Excelon & Rivastigmina & Novartis & $\begin{array}{c}1,5 \mathrm{mg} \text {, caixa. } 28 \text { cápsulas. de } \\
\text { gel duras }\end{array}$ & 130,35 & 156,52 & 20 & $25000.013606 / 97-98$ & 1997 & $10 / 01 / 2003$ \\
\hline Adalat Retard & Nifedipino & Bayer & $\begin{array}{c}10 \text { mg, frasco. } 30 \\
\text { comprimidos. de liberação } \\
\text { retardada }\end{array}$ & 13,05 & 15,47 & 19 & $25992.006708 / 74$ & $\begin{array}{l}\text { Não } \\
\text { consta }\end{array}$ & $07 / 11 / 2001$ \\
\hline Puran T4 & Levotiroxina Sódica & $\begin{array}{c}\text { SanofiAve } \\
\text { ntis }\end{array}$ & $\begin{array}{c}100 \mathrm{mg} \text {, caixa. } 30 \\
\text { comprimidos. }\end{array}$ & 7,06 & 8,31 & 18 & $25992.025091 / 76$ & $\begin{array}{l}\text { Não } \\
\text { consta }\end{array}$ & 04/09/1992 \\
\hline Megestat & Acetato de megestrol & $\begin{array}{l}\text { Bristol } \\
\text { Myers } \\
\text { Squibb }\end{array}$ & $\begin{array}{l}160 \mathrm{mg} \text {, frasco. } 30 \\
\text { comprimidos. }\end{array}$ & 176,54 & 206,19 & 17 & $25991.03172 / 79$ & $\begin{array}{l}\text { Não } \\
\text { consta }\end{array}$ & 20/11/1991 \\
\hline Micronor & Noretindrona & $\begin{array}{c}\text { Janssen- } \\
\text { Cilag }\end{array}$ & 0,35mg, cx. 35 comprimidos. & 7,14 & 8,32 & 16 & $25000.009075 / 79$ & $\begin{array}{l}\text { Não } \\
\text { consta }\end{array}$ & 26/08/1999 \\
\hline Propil & Propiltiouracila & Pizer & $\begin{array}{l}100 \mathrm{mg} \text {, caixa. } 30 \\
\text { comprimidos. }\end{array}$ & 16,15 & 18,70 & 16 & $25992.012072 / 47$ & $\begin{array}{l}\text { Não } \\
\text { consta }\end{array}$ & 08/03/1992 \\
\hline Provera & $\begin{array}{c}\text { Acetato de } \\
\text { medroxiprogesterona }\end{array}$ & Pfizer & $\begin{array}{l}10 \mathrm{mg} \text {, caixa. } 14 \\
\text { comprimidos. }\end{array}$ & 18,81 & 21,72 & 15 & $25991.003379 / 81$ & $\begin{array}{l}\text { Não } \\
\text { consta }\end{array}$ & 09/02/2001 \\
\hline
\end{tabular}

ANVISA: Agência Nacional de Vigilância Sanitária; CMED: Câmara de Regulação do Mercado de Medicamentos; IDEC: Instituto Brasileiro de Defesa do Consumidor; mg: miligrama; ml: mililitro; PMC: preço máximo ao consumidor. 
Tabela 33 (Anexo G). Referência com similar e genérico no mercado - Pesquisa IDEC 2009

\begin{tabular}{|c|c|c|c|c|c|c|c|c|c|}
\hline Medicamento & Princípio Ativo & Laboratório & Apresentação & $\begin{array}{l}\text { Preço médio em } \\
\text { São Paulo }(\mathrm{R} \$)\end{array}$ & $\begin{array}{l}\text { PMC da } \\
\text { CMED } \\
(2008)\end{array}$ & $\begin{array}{l}\text { Varĩ } \\
\text { acão } \\
(\%)\end{array}$ & Processo de Registro & $\begin{array}{l}\text { Ano do } \\
\text { Processo }\end{array}$ & $\begin{array}{c}\text { Data da primeira } \\
\text { publicação no } \\
\text { site da Anvisa }\end{array}$ \\
\hline Prepazol & Omeprazol & Libbs & $20 \mathrm{mg}$ caixa 28 cápsulas. & 63,33 & 96,74 & 53 & $25351.0042471 / 01-28$ & 2001 & $24 / 07 / 2001$ \\
\hline Ebix & Cloridrato de memantina & Lundbeck & $10 \mathrm{mg}$, caixa 28 comprimidos. & 145,15 & 195,22 & 34 & $25351.215852 / 2002-11$ & 2002 & $28 / 08 / 2003$ \\
\hline Stilnox & $\begin{array}{l}\text { Hemitartarato de } \\
\text { zolpidem }\end{array}$ & $\begin{array}{l}\text { Sanofi } \\
\text { Aventis }\end{array}$ & $10 \mathrm{mg}$, caixa 10 comprimidos. & 23,45 & 30,75 & 31 & 25000/018049/92-96 & 1992 & $21 / 12 / 2001$ \\
\hline Tagamet & cimetidina & $\begin{array}{l}\text { GlaxoSmith } \\
\text { Kline }\end{array}$ & $\begin{array}{l}200 \mathrm{mg}, \text { cx. } 40 \text { comprimidos } \\
\text {.revestidos }\end{array}$ & 32,46 & 41,1 & 27 & $25351.000629 / 02-63$ & 2002 & $02 / 09 / 2002$ \\
\hline Zoloft & Cloridrato de sertralina & Pfizer & $50 \mathrm{mg}$, caixa 28 comprimidos.. & 93,05 & 115,21 & 24 & $25000.007911 / 90$ & 2000 & $19 / 12 / 2000$ \\
\hline Reuctil & $\begin{array}{c}\text { Cloridrato de } \\
\text { sibutramina }\end{array}$ & Abbott & $10 \mathrm{mg}, \mathrm{cx} .30$ cápsulas. & 163,38 & 201,32 & 23 & $25000.028863 / 96-33$ & 1996 & $15 / 04 / 2002$ \\
\hline Zocor R & Sinvastatina & $\begin{array}{l}\text { Merck Sharp } \\
\text { \& Dohme }\end{array}$ & $20 \mathrm{mg}$, caixa 30 comprimidos. & 94,91 & 116,44 & 23 & $25000.007082 / 88$ & $\begin{array}{c}\text { Não } \\
\text { consta }\end{array}$ & $16 / 01 / 2003$ \\
\hline Antak & Cloridrato de ranitidina & $\begin{array}{l}\text { GlaxoSmith } \\
\text { Kline } \\
\end{array}$ & $150 \mathrm{mg}$, caixa 20 comprimidos.. & 32,57 & 39,83 & 22 & $25000.000147 / 81$ & $\begin{array}{c}\text { Não } \\
\text { consta }\end{array}$ & $14 / 11 / 2002$ \\
\hline Klaricid R & Caritromicina & Abbott & $\begin{array}{l}125 \mathrm{mg} / \mathrm{ml} \text {, suspensão oral, frasco } \\
60 \mathrm{ml}\end{array}$ & 37,29 & 45,4 & 22 & $25370.000293 / 89$ & $\begin{array}{c}\text { Não } \\
\text { consta }\end{array}$ & $05 / 02 / 1998$ \\
\hline Amoxil & Amoxicilina & $\begin{array}{l}\text { GlaxoSmith } \\
\text { Kline }\end{array}$ & $500 \mathrm{mg}$, caixa 30 cápsulas. & 47,82 & 57,98 & 21 & $25992.022149 / 72$ & $\begin{array}{c}\text { Não } \\
\text { consta }\end{array}$ & $15 / 02 / 1991$ \\
\hline Keflex & Cefalexina & Eli Lilly & $500 \mathrm{mg}$, caixa. 8 cápsulas & 25,14 & 30,47 & 21 & $25992.012890 / 69$ & $\begin{array}{c}\text { Não } \\
\text { consta }\end{array}$ & $04 / 10 / 2002$ \\
\hline Voltaren & Diclofenaco sódico & Novartis & $50 \mathrm{mg}$, caixa. 20 comprimidos. & 16,55 & 20 & 21 & $25992.016553 / 74$ & $\begin{array}{c}\text { Não } \\
\text { consta }\end{array}$ & $20 / 08 / 1998$ \\
\hline Prozac & Cloridrato de fluoxetina & Eli Lilly & 20 microgotas, caixa. 20 cápsulas. & 109,54 & 131,46 & 20 & $25001.000507 / 87$ & $\begin{array}{l}\begin{array}{l}\text { Não } \\
\text { consta }\end{array} \\
\end{array}$ & $20 / 01 / 2000$ \\
\hline Nolvadex & Citrato de tamoxifeno & $\begin{array}{l}\text { Astra } \\
\text { Zeneca }\end{array}$ & $10 \mathrm{mg}$, caixa. 30 comprimidos. & 71,38 & 85,5 & 20 & $25992.020032 / 75$ & $\begin{array}{c}\text { Não } \\
\text { consta }\end{array}$ & $07 / 06 / 2001$ \\
\hline Renitec & Maleato de enalapril & $\begin{array}{l}\text { Merck Sharp } \\
\& \text { Dohme }\end{array}$ & $20 \mathrm{mg}$, caixa. 230 comprimidos. & 24,81 & 29,71 & 20 & $25000.014729 / 83$ & $\begin{array}{c}\text { Não } \\
\text { consta }\end{array}$ & $01 / 11 / 1999$ \\
\hline Atenol & Atenolol & $\begin{array}{c}\text { Astra } \\
\text { Zeneca } \\
\end{array}$ & $50 \mathrm{mg}$, caixa 28 comprimidos. & 24,47 & 29,25 & 20 & $25992.033243 / 76$ & $\begin{array}{l}\text { Não } \\
\text { consta }\end{array}$ & $02 / 04 / 1998$ \\
\hline Zaditen & Cetotileno & Novartis & $0,2 \mathrm{mg}$ xarope, frasco. $120 \mathrm{ml}$ & 36,04 & 43,06 & 19 & $25991.006741 / 78$ & $\begin{array}{c}\text { Não } \\
\text { consta }\end{array}$ & $06 / 11 / 2002$ \\
\hline Bactrim & $\begin{array}{c}\text { Sulfametoxazol } \\
\text { +Trimetopina }\end{array}$ & Roche & $\begin{array}{l}400 \mathrm{mg}+80 \mathrm{mg} \text {, caixa. } \\
20 \text { comprimidos.. }\end{array}$ & 13,35 & 15,88 & 19 & $25992.013512 / 69$ & $\begin{array}{c}\text { Não } \\
\text { consta }\end{array}$ & $01 / 08 / 2002$ \\
\hline Zyban R & $\begin{array}{l}\text { Cloridrato de } \\
\text { bupropiona }\end{array}$ & $\begin{array}{l}\text { GlaxoSmith } \\
\text { Kline }\end{array}$ & $150 \mathrm{mg}$, caixa. 30 comprimidos. & 76,12 & 90,54 & 19 & 25351.177929/2009-56 & 2009 & $10 / 08 / 2009$ \\
\hline Norvase & Benzilato de anlodipino & Pfizer & $10 \mathrm{mg}$, caixa. 20 comprimidos. & 80,81 & 96 & 19 & $25000.007008 / 89$ & $\begin{array}{c}\text { Não } \\
\text { consta }\end{array}$ & $15 / 08 / 2001$ \\
\hline Cataflam & Diclofenaco potássico & Novartis & $50 \mathrm{mg}$, caixa. 20 drágeas & 16,73 & 19,81 & 18 & $25001.001884 / 84$ & $\begin{array}{c}\text { Não } \\
\text { consta }\end{array}$ & $17 / 01 / 2003$ \\
\hline Vibramicina & Cloridrato de doxiciclina & Pfizer & $100 \mathrm{mg}$, caixa. 15 comprimidos. & 34,65 & 409,86 & 18 & $25992.016997 / 66$ & $\begin{array}{c}\text { Não } \\
\text { consta }\end{array}$ & $12 / 09 / 2001$ \\
\hline Femara & Letrozol & Novartis & $2,5 \mathrm{mg}$, caixa.. 28 comprimidos. & 511,53 & 601,41 & 18 & $25000.037180 / 96-21$ & 1996 & $28 / 12 / 2001$ \\
\hline Akineton & Cloridrato de biperideno & Abbott & $2 \mathrm{mg}$, caixa. 80 comprimidos. & 20,74 & 24,34 & 17 & $25992.001198 / 56$ & $\begin{array}{c}\text { Não } \\
\text { consta }\end{array}$ & $10 / 03 / 2003$ \\
\hline Cipro & $\begin{array}{c}\text { Cloridrato de } \\
\text { ciprofloxacina }\end{array}$ & Bayer & $500 \mathrm{mg}$, caixa. 14 comprimidos. & 151,12 & 177,25 & 17 & $25001.005028 / 87$ & $\begin{array}{c}\text { Não } \\
\text { consta }\end{array}$ & $06 / 12 / 1995$ \\
\hline Frontal & Alprazolam & Pfizer & $0,5 \mathrm{mg}$, caixa.. 20 comprimidos. & 14,85 & 17,42 & 17 & $25991.001350 / 80$ & $\begin{array}{c}\text { Não } \\
\text { consta }\end{array}$ & $19 / 04 / 2000$ \\
\hline $\begin{array}{ll}\text { Glifage } \\
\end{array}$ & Metiformina & Merck & $500 \mathrm{mg}$, caixa. 30 comprimidos & 10,78 & 12,63 & 17 & $25000.012159 / 93-52$ & 1993 & $25 / 07 / 2003$ \\
\hline Valium & Diazepam & Roche & $5 \mathrm{mg}$ caixa. 20 comprimidos & $\mathbf{5 , 4 7}$ & 6,4 & 17 & $25992.017929 / 62$ & $\begin{array}{l}\text { Não } \\
\text { consta }\end{array}$ & $04 / 12 / 1997$ \\
\hline Zitromax & Azitromicina & Pfizer & $500 \mathrm{mg}$, caixa.. 2 comprimidos & 34,84 & 40,74 & 17 & $25000.015063 / 90$ & $\begin{array}{c}\text { Não } \\
\text { consta }\end{array}$ & $29 / 12 / 2000$ \\
\hline Decadron & Dexametasona & Aché & $4 \mathrm{mg}, \mathrm{cx} .10$ comprimidos & 8,56 & 9,99 & 17 & $25351.023792 / 2003-92$ & 2003 & $16 / 04 / 2004$ \\
\hline Pantelmin & Mebendazol & $\begin{array}{c}\text { Janssen } \\
\text { Cilag }\end{array}$ & $\begin{array}{l}20 \mathrm{mg} / \mathrm{ml}, \text { suspensão oral, } \\
\text { frasco } 30 \mathrm{ml} .\end{array}$ & 7,22 & 8,43 & 17 & $25992.019576 / 71$ & $\begin{array}{l}\text { Não } \\
\text { consta }\end{array}$ & $27 / 05 / 1998$ \\
\hline Lopid & Genfibrozila & Pfizer & $600 \mathrm{mg}$, caixa. 24 comprimidos. & 70,16 & 81,9 & 17 & $25351.168525 / 2002-62$ & 2002 & $02 / 10 / 2002$ \\
\hline Vibral & Dropopizina & Solvay & $\begin{array}{l}3 \mathrm{mg} / \mathrm{ml} \text {, xarope, frasco } 120 \mathrm{ml} \\
\text { (adulto) }\end{array}$ & 10,8 & 12,57 & 16 & $25991.001350 / 80$ & $\begin{array}{l}\text { Não } \\
\text { consta } \\
\end{array}$ & $22 / 06 / 2001$ \\
\hline $\begin{array}{l}\text { Aminofilina } \\
\text { Sandoz }\end{array}$ & Aminofilina & Novartis & $100 \mathrm{mg}$, caixa.. 20 comprimidos. & 4,45 & 5,18 & 16 & $25992.000310 / 44$ & $\begin{array}{c}\text { Não } \\
\text { consta }\end{array}$ & $09 / 05 / 2002$ \\
\hline Tryptanol & $\begin{array}{l}\text { Cloridrato de } \\
\text { amitriptilina }\end{array}$ & $\begin{array}{l}\text { Merck Sharp } \\
\text { \& Dohme }\end{array}$ & $25 \mathrm{mg}$, caixa. 20 comprimidos. & 12,35 & 14,31 & 16 & $25992.000255 / 61$ & $\begin{array}{c}\text { Não } \\
\text { consta }\end{array}$ & \\
\hline Zentel & albendazol & $\begin{array}{l}\text { GlaxoSmith } \\
\text { Kline }\end{array}$ & $\begin{array}{c}400 \mathrm{mg} \text {, caixa.. } 1 \\
\text { comprimido.mastigável }\end{array}$ & 6,1 & 7,06 & 16 & $25001.012956 / 84$ & $\begin{array}{l}\begin{array}{c}\text { Não } \\
\text { consta }\end{array} \\
\end{array}$ & $26 / 03 / 2001$ \\
\hline Dilacoron & Cloridrato de verapamil & Abbott & $80 \mathrm{mg}$, caixa.. 30 comprimidos. & 21,2 & 24,54 & 16 & $25992.002032 / 64$ & $\begin{array}{c}\text { Não } \\
\text { consta }\end{array}$ & $05 / 07 / 2002$ \\
\hline Zovirax & Aciclovir & $\begin{array}{c}\text { GlaxoSmith } \\
\text { Kline }\end{array}$ & $200 \mathrm{mg}$, cx. 25 comprimidos. & 135,16 & 155,78 & 15 & $25001.002625 / 82$ & $\begin{array}{c}\text { Não } \\
\text { consta }\end{array}$ & $02 / 02 / 1996$ \\
\hline Fenergan & $\begin{array}{l}\text { Cloridrato de } \\
\text { prometazina }\end{array}$ & $\begin{array}{l}\text { Sanofi- } \\
\text { Aventis }\end{array}$ & $25 \mathrm{mg}$, caixa. 20 comprimidos. & 6,23 & 7,17 & 15 & $25992.009259 / 49$ & $\begin{array}{l}\text { Não } \\
\text { consta }\end{array}$ & $04 / 06 / 2001$ \\
\hline $\begin{array}{l}\text { Flagyl } \\
\text { ginecológico }\end{array}$ & Metronidazol & $\begin{array}{l}\text { Sanofi- } \\
\text { Aventis }\end{array}$ & $\begin{array}{c}100 \mathrm{mg} / \mathrm{g}, \text { geleia } \\
\text { ginecológica,bisnaga } 50 \mathrm{~g}, 10 \\
\text { aplicadores }\end{array}$ & 21,41 & 24,65 & 15 & $25000.028099 / 97-03$ & 1997 & $22 / 02 / 2001$ \\
\hline Meticorten & Preinisona & $\begin{array}{l}\text { Schering- } \\
\text { Plough }\end{array}$ & $20 \mathrm{mg}$, caixa. 10 comprimidos & 15,87 & 18,25 & 15 & $25992.003137 / 55$ & $\begin{array}{l}\text { Não } \\
\text { consta }\end{array}$ & $12 / 05 / 1976$ \\
\hline Clavulin & $\begin{array}{c}\text { Amoxicilina }+ \\
\text { Clavulanato potássico } \\
\end{array}$ & $\begin{array}{l}\text { GlaxoSmith } \\
\text { Kline }\end{array}$ & $\begin{array}{l}500 \mathrm{mg}+125 \mathrm{mg} \text {, caixa.. } 18 \\
\text { comprimidos }\end{array}$ & 83,78 & 96,2 & 15 & $25991.002612 / 81$ & $\begin{array}{c}\text { Não } \\
\text { consta }\end{array}$ & $27 / 03 / 2002$ \\
\hline Mucosolvan & Cloridrato de ambroxol & $\begin{array}{l}\text { Boehringer } \\
\text { Ingelheim } \\
\end{array}$ & $6 \mathrm{mg} / \mathrm{ml}$, xarope, frasco. $120 \mathrm{ml}$ & 19,89 & 22,74 & 14 & $25991.011555 / 78$ & $\begin{array}{c}\text { Não } \\
\text { consta }\end{array}$ & $01 / 02 / 2001$ \\
\hline Rivotril & Clonazepam & Roche & $2 \mathrm{mg}$, caixa.. 20 comprimidos & 7,49 & 8,46 & 13 & $25992.005875 / 73$ & $\begin{array}{l}\text { Não } \\
\text { consta }\end{array}$ & $21 / 02 / 2002$ \\
\hline Polaramine & $\begin{array}{c}\text { Maleato de } \\
\text { dexclorfeniramina }\end{array}$ & Mantecorp & $\begin{array}{c}0,4 \mathrm{mg} / \mathrm{ml}, \text { solução oral, frasco. } \\
120 \mathrm{ml}\end{array}$ & 11,2 & 12,62 & 13 & $25000.002183 / 79$ & $\begin{array}{c}\text { Não } \\
\text { consta }\end{array}$ & $11 / 11 / 1991$ \\
\hline Claritin & Loratadina & $\begin{array}{c}\begin{array}{c}\text { Schering- } \\
\text { Plough }\end{array} \\
\end{array}$ & $10 \mathrm{mg}$, caixa.. 12 comprimidos. & 28,66 & 32,19 & 12 & $25000.005239 / 86$ & $\begin{array}{c}\text { Não } \\
\text { consta }\end{array}$ & $01 / 09 / 2000$ \\
\hline Fluimucil & Acetilcisteína & Zambon & $40 \mathrm{mg}$, xarope, frasco. $120 \mathrm{ml}$ & 28,09 & 31,37 & 12 & $25992.011319 / 64$ & $\begin{array}{c}\text { Não } \\
\text { consta }\end{array}$ & $16 / 11 / 2010$ \\
\hline Fluimucil & Acetilcisteína & Zambon & $20 \mathrm{mg}$, xarope, frasco. $120 \mathrm{ml}$ & 21,66 & 23,96 & 11 & $25992.011319 / 64$ & $\begin{array}{c}\text { Não } \\
\text { consta }\end{array}$ & $16 / 11 / 2010$ \\
\hline
\end{tabular}

ANVISA: Agência Nacional de Vigilância Sanitária; CMED: Câmara de Regulação do Mercado de Medicamentos; IDEC: Instituto Brasileiro de Defesa do Consumidor; g: gramas; mg: miligrama; ml: mililitro; PMC: preço máximo ao consumidor. 
Tabela 34 (Anexo G). Similares - Pesquisa IDEC 2009

\begin{tabular}{|c|c|c|c|c|c|c|c|c|c|}
\hline Medicamento & Princípio Ativo & Laboratório & Apresentação & $\begin{array}{l}\text { Preço médio em } \\
\text { São Paulo (R\$) }\end{array}$ & $\begin{array}{l}\text { PMC da } \\
\text { CMED } \\
(2008)\end{array}$ & $\begin{array}{l}\text { Vari } \\
\text { ação } \\
(\%)\end{array}$ & Processo de Registro & $\begin{array}{l}\text { Ano do } \\
\text { Processo }\end{array}$ & $\begin{array}{c}\text { Data da primeira } \\
\text { publicação no } \\
\text { site da ANVISA }\end{array}$ \\
\hline Angipress & Atenolol & Biossintética & 50mg, caixa. 28 comprimidos & 10,35 & 26,26 & 154 & $25001.025606 / 84$ & $\begin{array}{l}\text { Não } \\
\text { consta }\end{array}$ & $02 / 03 / 2000$ \\
\hline Biomag & $\begin{array}{l}\text { Cloridrato de } \\
\text { sibutramina }\end{array}$ & Aché & $10 \mathrm{mg}$, caixa 30 cápsulas & 21,16 & 42,12 & 99 & 25351.462625/2006-14 & 2006 & 03/09/2007 \\
\hline Angipril & Maleato de enalapril & $\begin{array}{c}\text { DiflucapChe } \\
\text { mobrás }\end{array}$ & 20mg, caixa 30 comprimidos & 16,84 & 32,31 & 92 & $25000.008021 / 98-36$ & 1998 & 24/08/1998 \\
\hline Clav-Air & $\begin{array}{c}\text { Amoxicilina + } \\
\text { clavulanatopotássico }\end{array}$ & Biofarma & $\begin{array}{c}500 \mathrm{mg}+125 \mathrm{mg}, \text { caixa } \\
18 \text { comprimidos }\end{array}$ & 36,95 & 67,45 & 83 & $25351.164018 / 2002-50$ & 2002 & $02 / 10 / 2002$ \\
\hline Cimetetax & Cimetidina & Biofarma & $\begin{array}{c}\text { 200mg, caixa } 40 \\
\text { comprimidosrevestidos }\end{array}$ & 8,62 & 15,23 & 77 & 25000.001338//93-18 & 1993 & $21 / 01 / 2001$ \\
\hline Astro & Azitromicina & Eurofarma & $500 \mathrm{mg}$, caixa 2 comprimidos & 8,21 & 13,96 & 70 & $25351.165264 / 2002-29$ & 2002 & $21 / 10 / 2002$ \\
\hline Elprazol & Omeprazol & Pharlab & 20mg, caixa 28 cápsulas & 31,91 & 53,66 & 68 & $25000.032721 / 99-03$ & 1999 & $12 / 09 / 2001$ \\
\hline Flucistein & Acetilcisteína & $\begin{array}{c}\text { União } \\
\text { Química }\end{array}$ & Xarope $20 \mathrm{mg} / \mathrm{ml}$, frasco $100 \mathrm{ml}$ & 8,57 & 14,35 & 68 & $25000.026053 / 97-23$ & 1997 & $17 / 10 / 2011$ \\
\hline Aciclor & Aciclovir & Hertz & 200mg, caixa 25 comprimidos & 32,32 & 52,81 & 63 & $25000.036245 / 98$ & $\begin{array}{c}\text { Não } \\
\text { consta }\end{array}$ & 21/10/1999 \\
\hline Hystin & $\begin{array}{c}\text { Maleato } \\
\text { dedexclorfeniramina }\end{array}$ & Geolab & $\begin{array}{c}\text { Solução oral, } 0,4 \mathrm{mg} / \mathrm{ml} \text {, frasco } \\
100 \mathrm{ml}\end{array}$ & 7,21 & 11,46 & 59 & 25351.008507/2003-11 & 2003 & 20/03/2003 \\
\hline Alergaliv & Loratadina & Legrand & 10mg, caixa 15 comprimidos & 11,89 & 18,61 & 57 & $25000.012394 / 95-12$ & 1995 & $06 / 12 / 1995$ \\
\hline Cefaben & Cefalexina & $\begin{array}{c}\text { Cazi } \\
\text { Química }\end{array}$ & 500mg, caixa 8 cápsulas & 16,11 & 24,95 & 55 & $25000.010960 / 96-70$ & 1996 & 05/02/1998 \\
\hline Depress & Cloridrato de fluoxetina & $\begin{array}{c}\text { União } \\
\text { Química }\end{array}$ & $20 \mathrm{mg}$, caixa 28 cápsulas & 38,87 & 59,11 & 52 & $25000.022899 / 94-04$ & 1994 & 19/04/1996 \\
\hline Profergan & $\begin{array}{c}\text { Cloridrato } \\
\text { deprometazina }\end{array}$ & Teuto & $25 \mathrm{mg}$, caixa 20 comprimidos & 3,71 & 5,44 & 47 & $25000.033449 / 98-35$ & 1998 & 04/06/2001 \\
\hline Assert & Cloridrato de setralina & Eurofarma & 50mg, caixa 28 comprimidos & 43,6 & 63,05 & 45 & $25351.164064 / 2002-59$ & 2002 & $06 / 02 / 2003$ \\
\hline Asmapen & Aminofilina & $\begin{array}{c}\text { Neo } \\
\text { Química }\end{array}$ & 100mg, caixa 20 comprimidos & 2,92 & 4,19 & 43 & 25000.006791/96-09 & 1996 & $10 / 10 / 2001$ \\
\hline Albel & Albendazol & Geolab & $\begin{array}{c}\text { 400mg, caixa } 1 \\
\text { comprimidomastigável }\end{array}$ & 4,3 & 5,45 & 27 & $25351.01783 / 2003-18$ & 2003 & $10 / 08 / 2004$ \\
\hline Dimefor & Metformina & $\begin{array}{c}\text { Farmoquími } \\
\text { adropopizin } \\
\text { a }\end{array}$ & 500mg, caixa 30 comprimidos & 8,25 & 10,42 & 26 & $25351.204270 / 2002-17$ & 2002 & $13 / 01 / 2003$ \\
\hline Atossion & Dropopizina & Elofar & Xarope adulto, frasco $100 \mathrm{ml}$ & 6,98 & 8,78 & 26 & $25992.009994 / 40$ & $\begin{array}{c}\text { Não } \\
\text { consta }\end{array}$ & $08 / 03 / 2002$ \\
\hline Infectrin & $\begin{array}{c}\text { Sulfametoxazol } \\
+ \text { Trimetopina }\end{array}$ & $\begin{array}{c}\text { BoehringerI } \\
\text { ngelheim }\end{array}$ & $\begin{array}{l}\text { 400mg+80mg, caixa } \\
20 \text { comprimidos }\end{array}$ & 9,27 & 11,54 & 25 & $25992.010825 / 70$ & $\begin{array}{c}\text { Não } \\
\text { consta }\end{array}$ & $30 / 09 / 2005$ \\
\hline Clonotril & Clonazepam & Torent & $2 \mathrm{mg}$, caixa 20 comprimidos & 4,71 & 5,74 & 22 & $25351.039525 / 01-95$ & 2001 & $01 / 07 / 2002$ \\
\hline Alois & $\begin{array}{c}\text { Cloridrato } \\
\text { demameantina }\end{array}$ & Apsen & $10 \mathrm{mg}$, caixa 30 comprimidos & 51,02 & 62 & 22 & $25351.016175 / 2003-31$ & 2003 & $26 / 10 / 2004$ \\
\hline Altrox & Alprazolam & Torrent & $0,5 \mathrm{mg}$, caixa 20 comprimidos & 7,12 & 8,54 & 22 & $25351.016475 / 01-50$ & 2001 & $03 / 05 / 2002$ \\
\hline Lipotex & Sinavastatina & Medley & $20 \mathrm{mg}$, caixa 30 comprimidos & 42,6 & 50,76 & 20 & $25351.014888 / 2003-60$ & 2003 & $15 / 01 / 2003$ \\
\hline Amytril & $\begin{array}{l}\text { Cloridrato de } \\
\text { Amitriptilina }\end{array}$ & Cristália & $25 \mathrm{mg}$, caixa 20 comprimidos & 10,07 & 11,97 & 19 & $25001.004909 / 86$ & $\begin{array}{c}\text { Não } \\
\text { consta }\end{array}$ & 12/03/1999 \\
\hline Inibex & $\begin{array}{c}\text { Cloridrato } \\
\text { deAnfepramona }\end{array}$ & Medley & $25 \mathrm{mg}$, caixa 20 comprimidos & 22,12 & 26,27 & 19 & $25992.006964 / 71$ & $\begin{array}{c}\text { Não } \\
\text { consta }\end{array}$ & 03/10/2011 \\
\hline Ductelmin & Mebendazon & Ducto & $\begin{array}{l}\text { Suspensão oral } 20 \mathrm{mg} / \mathrm{ml}, \\
\text { frasco30ml }\end{array}$ & 3,62 & 4,29 & 19 & $25000.008045 / 98-02$ & $\begin{array}{c}\text { Não } \\
\text { consta }\end{array}$ & $04 / 02 / 2000$ \\
\hline Asmalergin & Cetotileno & Merck & Xarope $0,2 \mathrm{mg}$,frasco100ml & 23,12 & 27,37 & 18 & $25001.009776 / 83$ & $\begin{array}{l}\text { Não } \\
\text { consta }\end{array}$ & $11 / 07 / 2000$ \\
\hline Cinetol & $\begin{array}{l}\text { Cloridrato de } \\
\text { biperideno }\end{array}$ & Cristália & $2 \mathrm{mg}$, caixa 80 comprimidos & 15,9 & 18,81 & 18 & $25000.016037 / 88$ & $\begin{array}{c}\text { Não } \\
\text { consta }\end{array}$ & $11 / 12 / 2003$ \\
\hline Bup & $\begin{array}{l}\text { Cloridrato de } \\
\text { bupropiona }\end{array}$ & Eurofarma & $150 \mathrm{mg}$, caixa 30 comprimidos & 49,46 & 57,3 & 16 & 25351.194979/2005-31 & 2005 & $15 / 05 / 2006$ \\
\hline Ansiliv & Diazepam & Libbs & $5 \mathrm{mg}$, caixa 20 comprimidos & 6,61 & 7,4 & 12 & $25001.004213 / 80$ & $\begin{array}{c}\text { Não } \\
\text { consta }\end{array}$ & $29 / 05 / 1980$ \\
\hline Nac & Acetilcisteína & $\begin{array}{l}\text { Sigma } \\
\text { Pharma }\end{array}$ & Xarope $40 \mathrm{mg}$, frasco $120 \mathrm{ml}$ & 13,35 & 14,83 & 11 & $25351.004861 / 2004-40$ & 2004 & 23/02/2005 \\
\hline Alergcortem & Prednisona & $\begin{array}{c}\text { Pharmascien } \\
\text { ce }\end{array}$ & $20 \mathrm{mg}$, caixa 20 comprimidos & 11,96 & 13,17 & 10 & $25351.024470 / 2003-61$ & 2003 & $18 / 09 / 2003$ \\
\hline Besflox & $\begin{array}{c}\text { Cloridrato } \\
\text { deciprofloxacina }\end{array}$ & Laboris & 500mg, caixa 14 comprimidos & 28,09 & 28,19 & 0 & 25351.015655/01-04 & 2001 & $12 / 02 / 2003$ \\
\hline
\end{tabular}

ANVISA: Agência Nacional de Vigilância Sanitária; CMED: Câmara de Regulação do Mercado de Medicamentos; IDEC: Instituto Brasileiro de Defesa do Consumidor; g: gramas; mg: miligrama; ml: mililitro; PMC: preço máximo de mercado. 
Tabela 35 (Anexo G). Medicamentos de Referência - Pesquisa IDEC 2010

\begin{tabular}{|c|c|c|c|c|c|c|c|c|c|}
\hline Medicamentos & Princípio Ativo & Laboratório & Apresentação & $\begin{array}{c}\text { Preço médio em } \\
\text { São Paulo (R\$) }\end{array}$ & $\begin{array}{c}\text { PMC } \\
\text { da } \\
\text { CMED } \\
(2009) \\
\end{array}$ & $\begin{array}{l}\text { Varị } \\
\text { ação } \\
(\%)\end{array}$ & Processo de Registro & $\begin{array}{c}\text { Ano do } \\
\text { Processo }\end{array}$ & $\begin{array}{c}\text { Data da } \\
\text { primeira } \\
\text { publicação no } \\
\text { site da Anvisa } \\
\end{array}$ \\
\hline Adalat Retard & Nifedipino & Bayer & $\begin{array}{c}10 \mathrm{mg} \text {, frasco. } \\
\text { 30comprimidos. de } \\
\text { liberação reardada }\end{array}$ & 13,76 & 16,38 & 19,04 & 14.372.981/0001-02 & $\begin{array}{l}\text { Não } \\
\text { consta }\end{array}$ & $07 / 11 / 2001$ \\
\hline Avandia R & Avandia & $\begin{array}{c}\text { GlaxoSmithKlin } \\
\text { e }\end{array}$ & $\begin{array}{l}4 \mathrm{mg} \text {, caixa. } \\
14 \text { comprimidos. }\end{array}$ & 91,46 & 106,35 & 16,28 & $25000.012626 / 99-11$ & 1999 & $04 / 02 / 2002$ \\
\hline Blopress & $\begin{array}{c}\text { Candesartanacilexi } \\
\text { tila }\end{array}$ & Abbott & $\begin{array}{c}8 \mathrm{mg} \text {, caixa. } \\
\text { 30comprimidos. }\end{array}$ & 74,98 & 85,9 & 14,56 & $2500.031696 / 97-52$ & 1997 & $10 / 04 / 2001$ \\
\hline Cataflam & $\begin{array}{c}\text { Diclofenacopotássi } \\
\text { co }\end{array}$ & Novartis & $\begin{array}{l}500 \text { mg, caixa. } 20 \\
\text { cápsulas. }\end{array}$ & 19,09 & 20,98 & 9,9 & $25001.001884 / 84$ & $\begin{array}{l}\text { Não } \\
\text { consta }\end{array}$ & $17 / 01 / 2003$ \\
\hline Ebix & $\begin{array}{c}\text { Cloridrato } \\
\text { dememantina }\end{array}$ & Lundbeck & $\begin{array}{l}10 \mathrm{mg} \text {, caixa. } \\
28 \text { comprimidos }\end{array}$ & 192,25 & 206,72 & 7,52 & $\begin{array}{c}25351.215852 / 2002- \\
11\end{array}$ & 2002 & $28 / 08 / 2003$ \\
\hline Imuran & Azatioprina & $\begin{array}{c}\text { GlaxoSmithKlin } \\
\text { e }\end{array}$ & $\begin{array}{c}50 \mathrm{mg} \text {, caixa } \\
50 \text { comprimidos. }\end{array}$ & 122,25 & 141,58 & 15,81 & $\begin{array}{c}25351.050437 / 2003- \\
96\end{array}$ & 2003 & $02 / 02 / 1996$ \\
\hline Meticorten & Preinisona & Schering Plough & $\begin{array}{l}20 \text { mg, caixa. } \\
10 \text { comprimidos. }\end{array}$ & 17,69 & 19,32 & 9,21 & $25992.003137 / 55$ & $\begin{array}{l}\text { Não } \\
\text { consta }\end{array}$ & $12 / 05 / 1976$ \\
\hline Prepazol & Omeprazol & Libbs & $\begin{array}{c}20 \mathrm{mg} \text {,caixa. } 28 \\
\text {.cápsulas }\end{array}$ & 43,41 & 54,89 & 26,44 & $\begin{array}{c}25351.0042471 / 01- \\
28\end{array}$ & 2001 & $24 / 07 / 2001$ \\
\hline Zitromax & Azitromicina & Pfizer & $\begin{array}{l}500 \mathrm{mg} \text {, caixa } \\
\text { 2comprimidos. }\end{array}$ & 39,23 & 43,14 & 9,96 & $25000.015063 / 90$ & $\begin{array}{l}\text { Não } \\
\text { consta }\end{array}$ & $29 / 12 / 2000$ \\
\hline Zocor & Sinvastatina & $\begin{array}{c}\text { Merck } \\
\text { Sharp\&Dohme }\end{array}$ & $\begin{array}{l}20 \text { mg, caixa. } \\
\text { 30comprimidos. }\end{array}$ & 105,18 & 123,31 & 17,23 & $25000.007082 / 88$ & $\begin{array}{l}\text { Não } \\
\text { consta }\end{array}$ & $16 / 01 / 2003$ \\
\hline Zoloft & $\begin{array}{l}\text { Cloridrato } \\
\text { desertralina }\end{array}$ & Pfizer & $\begin{array}{l}50 \mathrm{mg} \text {, caixa. } 28 \\
\text { comprimidos. }\end{array}$ & 109,35 & 122 & 11,56 & $25000.007911 / 90$ & $\begin{array}{l}\text { Não } \\
\text { consta }\end{array}$ & $19 / 12 / 2000$ \\
\hline
\end{tabular}

ANVISA: Agência Nacional de Vigilância Sanitária; CMED: Câmara de Regulação do Mercado de Medicamentos; IDEC: Instituto Brasileiro de Defesa do Consumidor; g: gramas; mg: miligrama; ml: mililitro; PMC: preço máximo ao consumidor. 
Tabela 36 (Anexo G). Medicamentos de Referência - Pesquisa do IDEC de 2012

\begin{tabular}{|c|c|c|c|c|c|c|c|c|c|}
\hline Medicamentos & Princípio Ativo & Laboratório & Apresentação & $\begin{array}{l}\text { Preço médio em } \\
\text { São Paulo (R\$) }\end{array}$ & $\begin{array}{c}\text { PMC } \\
\text { da } \\
\text { CMED } \\
(2011) \\
\end{array}$ & $\begin{array}{l}\text { Varị } \\
\text { ação } \\
(\%)\end{array}$ & $\begin{array}{l}\text { Processo de } \\
\text { Registro }\end{array}$ & $\begin{array}{l}\text { Ano do } \\
\text { Processo }\end{array}$ & $\begin{array}{c}\text { Data da primeira } \\
\text { publicação no site } \\
\text { da Anvisa }\end{array}$ \\
\hline Adalat Retard & Nifedipino & Bayer & $\begin{array}{l}10 \text { mg, frasco. } 30 \\
\text { comprimidos. de } \\
\text { liberação retardada }\end{array}$ & 14,4 & 18,2 & $\begin{array}{c}26,3 \\
8\end{array}$ & $\begin{array}{c}14.372 .981 / 0001 \\
02\end{array}$ & $\begin{array}{l}\text { Prejudica- } \\
\text { do }\end{array}$ & $07 / 11 / 01$ \\
\hline Amaryl & Glimepirida & $\begin{array}{c}\text { GlaxoSmithklin } \\
\text { e }\end{array}$ & $\begin{array}{c}\text { Não há dados sobre a } \\
\text { apresentação }\end{array}$ & 15,82 & 27,61 & $\begin{array}{c}74,5 \\
2\end{array}$ & $\begin{array}{c}5000.008057 / 95- \\
31\end{array}$ & 1995 & $\begin{array}{c}\text { Prejudic } \\
\text { ado }\end{array}$ \\
\hline Aspirina Prevent & $\begin{array}{l}\text { Antiagregante } \\
\text { plaquetário }\end{array}$ & Bayer & $\begin{array}{c}\text { Não há dados sobre a } \\
\text { apresentação }\end{array}$ & & & - & $\begin{array}{c}25000.017749 / 95 \\
-51\end{array}$ & 1995 & $\begin{array}{l}\text { Prejudic } \\
\text { ado }\end{array}$ \\
\hline Blopress & $\begin{array}{c}\text { Candesartana } \\
\text { cilexitila }\end{array}$ & Abbott & $\begin{array}{c}8 \mathrm{mg} \text {, caixa } .30 \\
\text { comprimidos }\end{array}$ & 75,21 & 95,45 & $\begin{array}{c}26,9 \\
1\end{array}$ & $25001.001884 / 84$ & Não consta & $\begin{array}{c}17 / 01 / 20 \\
3\end{array}$ \\
\hline Cataflam & $\begin{array}{c}\text { Diclofenaco } \\
\text { potássico }\end{array}$ & Novartis & $\begin{array}{l}500 \mathrm{mg} \text {, caixa. } 20 \\
\text { cápsulas. }\end{array}$ & 17,72 & 23,31 & $\begin{array}{c}31,5 \\
4\end{array}$ & $25001.001884 / 84$ & Não consta & $17 / 01 / 2003$ \\
\hline Cymbalta & $\begin{array}{c}\text { Coridrato } \\
\text { deduloxetina }\end{array}$ & Elli Lilly & $\begin{array}{l}30 \text { mg, caixa } 14 \text { cápsulas. } \\
\text { de liberação retardada }\end{array}$ & 240,97 & 283,5 & $\begin{array}{c}17,6 \\
4\end{array}$ & $\begin{array}{c}25351.218227 / 20 \\
02-21\end{array}$ & 2002 & 03/09/2004 \\
\hline Ebix & $\begin{array}{c}\text { Cloridrato } \\
\text { dememantina }\end{array}$ & Lundbeck & $\begin{array}{c}10 \mathrm{mg} \text {, caixa. } 28 \\
\text { comprimidos }\end{array}$ & 187,77 & 223,54 & $\begin{array}{c}19,0 \\
4\end{array}$ & $\begin{array}{c}25351.215852 / 20 \\
02-11\end{array}$ & 2002 & $28 / 08 / 2003$ \\
\hline Fosamax & $\begin{array}{l}\text { Aledronato } \\
\text { desódio }\end{array}$ & Pfizer & $\begin{array}{c}\text { Não há dados sobre a } \\
\text { apresentação }\end{array}$ & 127,46 & 161,75 & $\begin{array}{c}26,9 \\
0\end{array}$ & $25000.08584 / 94$ & Não consta & Prejudicado \\
\hline Frontal & Alprazolam & Pfizer & $\begin{array}{c}\text { Não há dados sobre a } \\
\text { apresentação }\end{array}$ & 25,84 & 30,77 & $\begin{array}{c}19,0 \\
7\end{array}$ & $25991.001350 / 80$ & Não consta & Prejudicado \\
\hline Imuran & Azatioprina & $\begin{array}{c}\text { GlaxoSmithKlin } \\
\text { e }\end{array}$ & $\begin{array}{l}\text { IDEC não calculou o } \\
\text { preço médio deste } \\
\text { medicamento }\end{array}$ & & & - & $\begin{array}{c}25351.050437 / 20 \\
03-96\end{array}$ & 2003 & 02/02/1996 \\
\hline Meticorten & Preinisona & Schering Plough & $\begin{array}{l}20 \mathrm{mg} \text {, caixa. } 10 \\
\text { comprimidos. }\end{array}$ & 19,81 & 21,48 & 8,43 & $25992.003137 / 55$ & Não consta & $20 / 02 / 2006$ \\
\hline Prepazol & Omeprazol & Libbs & $\begin{array}{c}20 \mathrm{mg} \text {, caixa. } 28 \\
\text {.cápsulas }\end{array}$ & 33,55 & 61 & $\begin{array}{c}81,8 \\
1\end{array}$ & $\begin{array}{c}25351.0042471 / 0 \\
1-28\end{array}$ & 2001 & $24 / 07 / 2001$ \\
\hline Profenid & Cetoprofeno & Sanofi-Aventis & $\begin{array}{c}\text { Não há dados sobre a } \\
\text { apresentação }\end{array}$ & 22,85 & 29 & $\begin{array}{c}26,9 \\
1\end{array}$ & $25992.002531 / 74$ & Não consta & Prejudicado \\
\hline Singulair & Montelucaste & $\begin{array}{c}\text { Merck Sharp \& } \\
\text { Dohme }\end{array}$ & $\begin{array}{c}\text { Não há dados sobre a } \\
\text { apresentação }\end{array}$ & & & - & $\begin{array}{c}205000.007717 / 9 \\
7-64\end{array}$ & 1997 & Prejudicado \\
\hline Zitromax & Azitromicina & Pfizer & $\begin{array}{l}500 \mathrm{mg} \text {, caixa } 2 \\
\text { comprimidos. }\end{array}$ & 16,46 & 19,18 & $\begin{array}{c}16,5 \\
2\end{array}$ & $25000.015063 / 90$ & Não consta & $29 / 12 / 2000$ \\
\hline Zocor & Sinvastatina & $\begin{array}{l}\text { Merck Sharp } \\
\text { \&Dohme }\end{array}$ & $\begin{array}{l}20 \text { mg, caixa. } 30 \\
\text { comprimidos. }\end{array}$ & 47,1 & 64,63 & $\begin{array}{c}37,2 \\
1\end{array}$ & $25000.007082 / 88$ & Não consta & $16 / 01 / 2003$ \\
\hline Zoloft & $\begin{array}{l}\text { Cloridrato } \\
\text { desertralina }\end{array}$ & Pfizer & $\begin{array}{l}50 \mathrm{mg} \text {, caixa. } 28 \\
\text { comprimidos. }\end{array}$ & 51,25 & 61,01 & $\begin{array}{c}19,0 \\
4\end{array}$ & $25000.007911 / 90$ & Não consta & $19 / 12 / 2000$ \\
\hline
\end{tabular}

ANVISA: Agência Nacional de Vigilância Sanitária; CMED: Câmara de Regulação do Mercado de Medicamentos; IDEC: InstitutoBrasileiro de Defesa do Consumidor; g: gramas; mg: miligrama; ml: mililitro; PMC: preço máximo ao consumidor. 
Anexo H: E-mail enviado por Rejane Gomes Silva, membro da Coordenação de Registro de Medicamentos da ANVISA (CRMED) esclaracendo como analisar os números de processos de registro de medicamentos

Prezada Nathália,

Conforme detalhado por você mesma no email abaixo, este é o método mais simples para identificarmos o ano em que o processo foi protocolado na ANVISA.

Como exemplo, no caso do processo de registro (Cymbalta) 25351.218227/200221, a sua data de entrada na ANVISA foi em 2002, pois após a barra (/) consta "2002".

Isso ocorre porque a padronização na criação de números para processos foi consolidada somente após a criação da ANVISA, no ano de 1999, em que todos os números de processos passaram a seguir uma sequência lógica e mais organizada. Portanto todos os números de processo administrativo da Anvisa tem o ano de entrada do protocolo na sua numeração, facilitando assim buscas por outros detalhes.

Por isso, podemos afirmar que todos os processos protocolados na ANVISA após a data da criação da Agência (1999) seguem a ordem mencionada, qual seja, o ano de protocolo após o sinal de barra (/).

Até o momento, esse é o método que identifica apenas o ano de entrada, não fazendo referência nenhuma ao mês ou dia do protocolo. A data exata de pedido de solicitação de registro somente pode ser visualizada no site da Anvisa e ainda assim para aqueles que já estão atualizados no novo eletrônico, pelo atual sistema chamado Datavisa.

O mesmo não ocorre com o processo 25992.022149/72 (Amoxil), o qual entrou no sistema da Anvisa no ano de 1955. Os processos antigos eram da extinta Secretaria Nacional de Vigilância Sanitária, SNVS, e tinham uma lógica de entrada de numeração de processo da qual desconheço. Por serem muito antigos, somente é possível obter a cópia da publicação em DOU do registro pelo meio físico, isto é acessando a biblioteca da Imprensa Nacional para se obter a data de publicação destes registros. Por pelo meio eletrônico ainda é impossível obtê-los. 
Talvez a Imprensa Nacional tenha uma forma mais fácil de conseguir o documento, veja pelo site se tem como entrar em contato com eles para obtê-los.

Uma bibliografia que vale a leitura pelo conteúdo relacionado ao registro de medicamentos no Brasil é a tese de doutorado do Prof. Geraldo Luchesi. Como li a muito tempo atrás, não sei se ele fala alguma coisa relacionado a numeração de processos administrativos de registro na SNVS. Dessa época temos pouco material. A biblioteca da Anvisa também pode auxiliar no sentido de dar algum norte a fim de localizar as referidas publicações do século passado.

Espero ter esclarecido as dúvidas.

Atenciosamente,

Rejane Gomes Silva

Coordenadora de Registro de Medicamentos Genéricos e Similares CRMED/GTFAR/GGMED/ANVISA 